\title{
MODELLING THE IMPACTS OF CLIMATE CHANGE ON BUILDING HEATING AND COOLING ENERGY USE IN TORONTO
}

by

\section{Pouriya Jafarpur}

\author{
Bachelor of Science \\ Dalhousie University, May 2014
}

\begin{abstract}
A thesis
presented to Ryerson University
\end{abstract}

in partial fulfillment of the

requirements for the degree of

Master of Applied Science

in the program of

Environmental Applied Science and Management

Toronto, Ontario, Canada, 2019

(C) Pouriya Jafarpur 2019 


\section{AUTHOR'S DECLARATION}

I hereby declare that I am the sole author of this thesis. This is a true copy of the thesis, including any required final revisions, as accepted by my examiners.

I authorize Ryerson University to lend this thesis to other institutions or individuals for the purpose of scholarly research.

I further authorize Ryerson University to reproduce this thesis by photocopying or by other means, in total or in part, at the request of other institutions or individuals for the purpose of scholarly research.

I understand that my thesis may be made electronically available to the public. 


\title{
MODELLING THE IMPACTS OF CLIMATE CHANGE ON BUILDING HEATING AND COOLING ENERGY USE IN TORONTO
}

\author{
Pouriya Jafarpur \\ Master of Applied Science, 2019 \\ Environmental Applied Science and Management \\ Ryerson University
}

\begin{abstract}
This study describes the results of climate change impact assessment on building energy use in Toronto, Canada. Accordingly, three future weather data sets are generated and applied to the energy simulation of 16 building prototypes. Both statistical and dynamical downscaling techniques are used to generate the future weather files. The results indicate an average decrease for the future in the range of $18-33 \%$ in heating EUI, and an average increase of $16-126 \%$ in cooling EUI, depending on the baseline climate and building type. In addition, the GHG emissions for each building model are presented. It is concluded that the application of future weather files for building performance simulation leads to a better quantification of building energy demand in the future than a historical weather file. Furthermore, the results demonstrate the need to modify and adapt existing building modelling regulations and to plan future buildings according to the future climate.
\end{abstract}




\section{Acknowledgments}

I would like to take this opportunity to express my gratitude to those who helped me with this thesis. First and foremost, this thesis could not have been realised without the support, guidance, and generosity of my supervisor Dr. Umberto Berardi. You pushed me to be a better researcher and believed in me and my ideas. I am also deeply appreciative of the valuable guidance I have received from Drs Michal Bardecki and Mark Gorgolewski.

None of this would have been possible without the continued love and support of my family and

friends. I am thankful for all the sacrifices that my father, mother and sister have made, and I could have never done it without you. You are the foundation on which all of this is built. Thank you for teaching me how to set meaningful goals. A reason to focus. A reason to get out of bed everyday and use everything that I've ever learned.

Finally, many thanks to my lifelong friends in the Environmental Applied Science and Management as well as the Building Science programs who provided me with much needed motivation through the hard times. 
Table of Contents

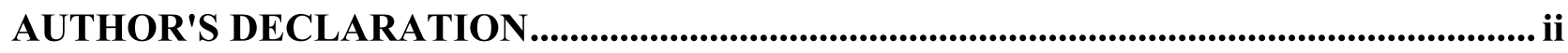

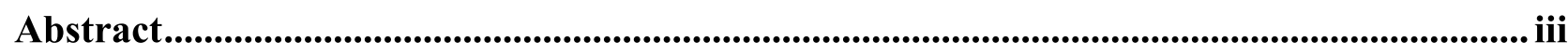

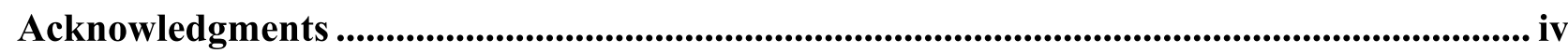

List of Tables ....................................................................................................................................... vii

List of Figures.............................................................................................................................. vii

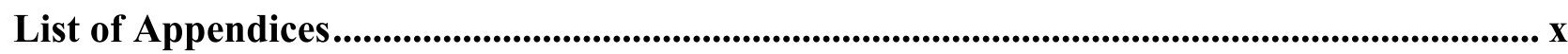

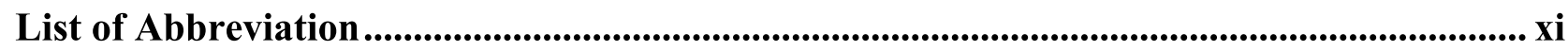

Chapter 1: Introduction ........................................................................................................................ 1

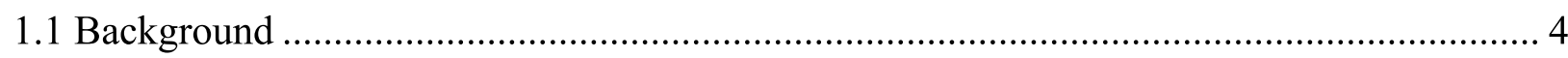

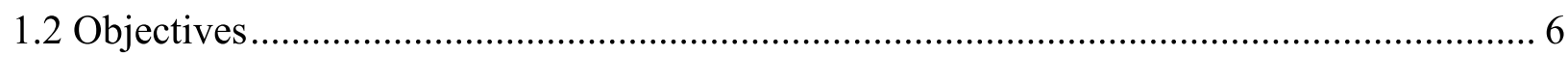

1.3 Thesis Structure

Chapter 2: Literature Review........................................................................................................ 9

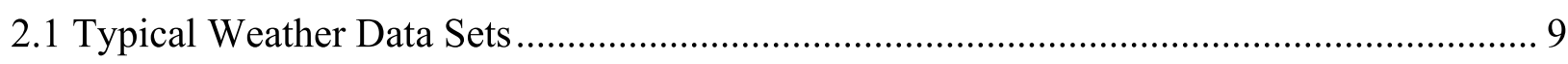

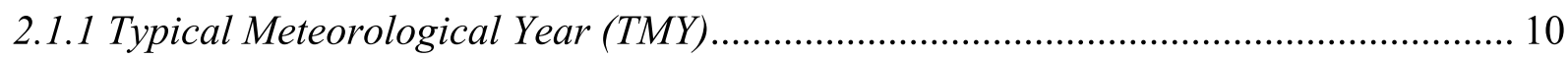

2.1.2 Canadian Weather Year for Energy Calculation (CWEC) Weather File ..................... 11

2.1.3 Weather File Baseline Climate ................................................................................ 12

2.2 Climate Change and Building Energy Use ................................................................... 13

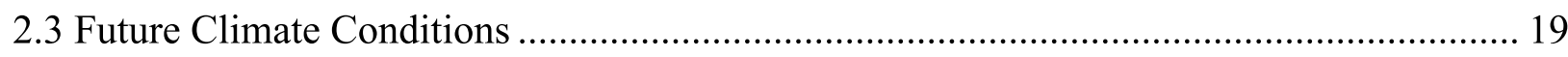

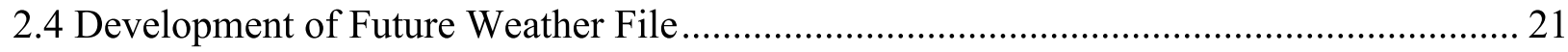

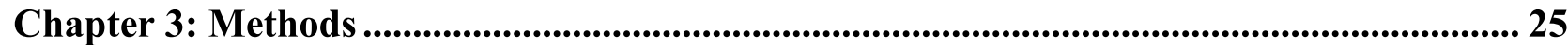

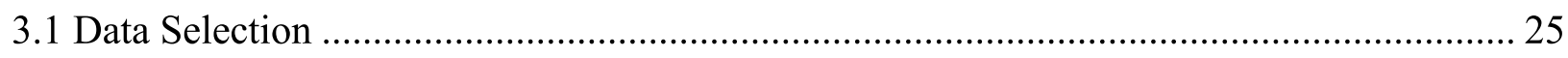

3.2 Preparing Future Weather Data for Building Performance Simulation ............................. 26

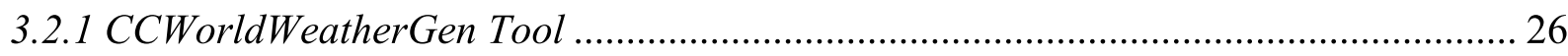

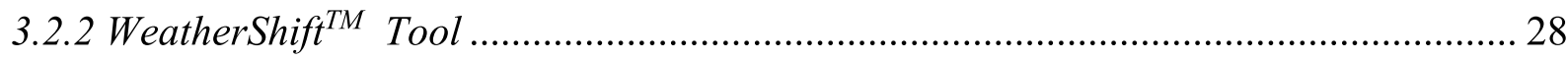

3.2.3 Weather File Generation from Hadley Regional Model 3 ...................................... 29

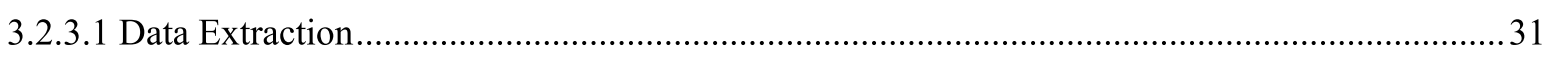

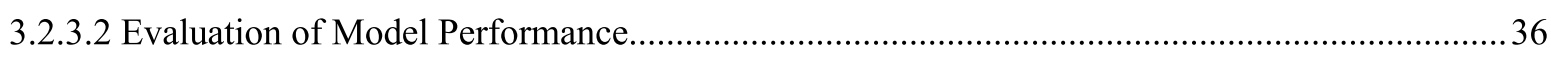

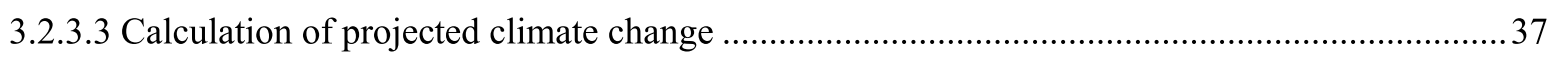

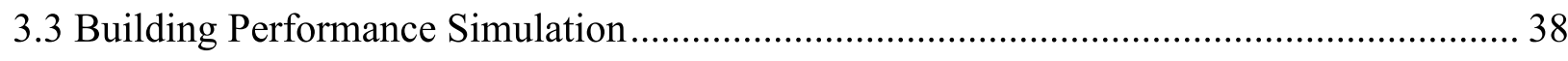

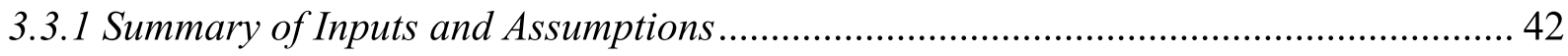

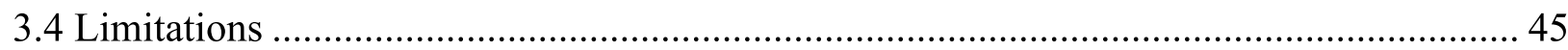


Chapter 4: Results and Discussion ................................................................................................. 47

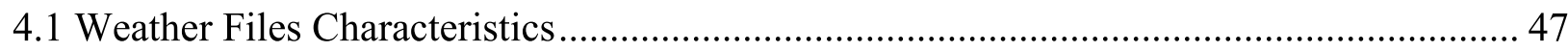

4.1.1 CCWorldWeatherGen Tool's Future Weather Files .................................................. 50

4.1.2 WeatherShift Tool's Future Weather Files .......................................................... 50

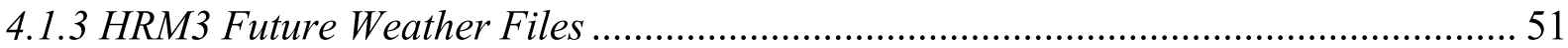

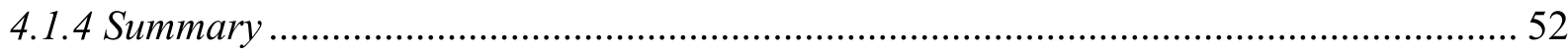

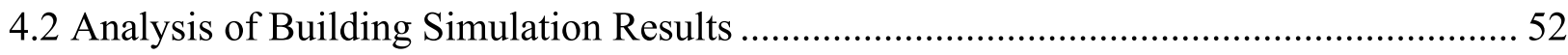

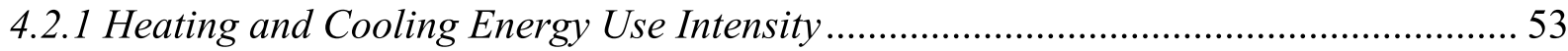

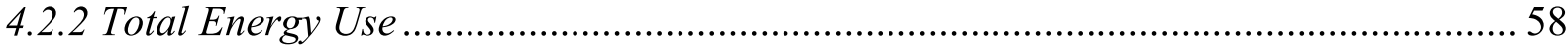

4.2.3 Climate Change Implications on Greenhouse Gas Emissions .................................. 59

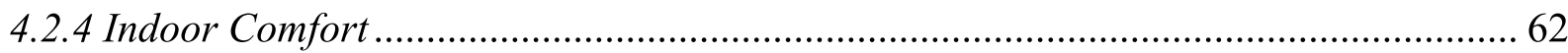

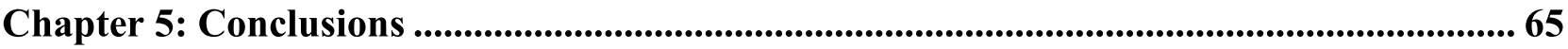

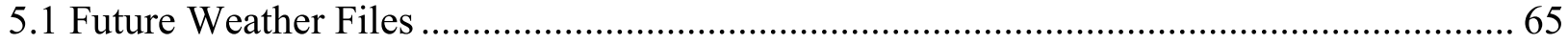

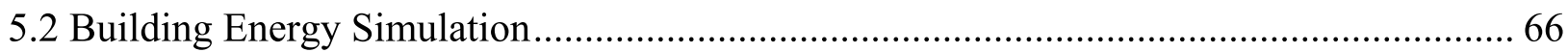

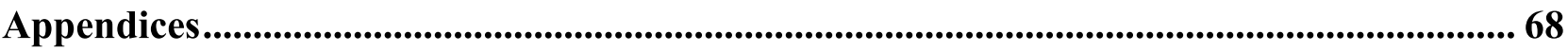

References ................................................................................................................................... 148 


\section{List of Tables}

Table 1. The Canadian Weather Year for Energy Calculation weather file breakdown for the period of 1959-1989 (CWEC file) as well as 1998-2014 (CWEC2016 file).

Table 2. A summary of literature review on the impacts of climate change on building energy use.

Table 3. Difference between WeatherShift ${ }^{\mathrm{TM}}$ and CCWorldWeatherGen tools in simulating future weather files (Moazami et al., 2017).

Table 4. GCM-RCM combination simulated in NARCCAP (NARCCAP, 2010)........................ 30

Table 5. Building envelope components of pre-designed reference building models.

Table 6. The design day climate data for building simulation performance.

Table 7. Heating degree day (HDD), base $18.3^{\circ} \mathrm{C}$, for Toronto weather files. 48

Table 8. The calculated annual hours that the dry bulb temperatures were above $30^{\circ} \mathrm{C}$ and below $-10^{\circ} \mathrm{C}$ for the weather files. 51

Table 9. The average percentage decrease and increase in heating and cooling EUI for different building types in the future compared to the two-baseline climate. 56

Table 10. The total energy use of the 16 prototype building models, 1959-1989 baseline climate.

Table 11. Electricity and natural gas emission factors for the city of Toronto, 2017 (The city of Toronto, 2018).

Table 12. The average cost of $\mathrm{CO}_{2}$ emissions for the heating and cooling energy use in various building types under the Canadian carbon pricing system.

Table 13. Unmet load hours for 16 prototype building models during occupied cooling and heating hours. 


\section{List of Figures}

Figure 1. Global share of buildings and construction final energy and emissions in 2017 (IEA, 2018)

Figure 2. Global share of building energy use by fuel type and change, 2010-2017 (IEA, 2018). 2

Figure 3. Global buildings energy use and change in intensity by end use, 2010-2017 (IEA, 2018)

Figure 4. Classification of energy consumption by end-use (PJ) for both residential and commercial buildings in Ontario (NRCan, 2015).

Figure 5. DOE climate zone classification including Canada and the warming trends seen in Toronto in terms of heating degree days (base $18^{\circ} \mathrm{C}$ )

Figure 6. The global circulation model structure (Trzaska and Schnarr, 2014).

Figure 7. Flow chart illustrating the two downscaling techniques used to prepare high-resolution weather data suitable for generating future weather file for building performance simulation (Trzaska and Schnarr, 2014).

Figure 8. The relationship between different methods used to project and generate future weather data (Guan, 2009). 23

Figure 9. Flowchart of various methods used in the present research for preparing high-resolution weather data suitable for generating future weather file for building performance simulation.... 26

Figure 10. The surface air temperature projection for the 2041-2070 period extracted from the HRM3 (NARCCAP, 2010)

Figure 11. Prototype building models from the ASHRAE 90.1-2013 standards.....

Figure 12. Configuration of simulation runs of 16 building prototype models used in this study under the historical and future weather files.

Figure 13. The hourly dry-bulb temperature for CWEC (blue) and CWEC2016 (red) historical weather files. The values are from 1959-1989 and 1998-2014 baseline climate....

Figure 14. Climate change projections for HRM3 show an additional shift toward Climate Zone

4 in the future, in terms of HDDs (Base $18^{\circ} \mathrm{C}$ ).

Figure 15. The boxplots present the outdoor dry-bulb temperature values for the historical weather file of CWEC (solid color) and CWEC2016 (hollow color), in addition to the three future weather files generated. 
Figure 16. The scatterplots showing the distribution of values for the annual heating energy (positive values) and cooling energy (negative values) under historical and future weather data sets for all 16 prototype buildings. Values for the 1959-1989 baseline climate are presented in solid color markers and the 1998-2014 baseline climate in hollow color markers. 54

Figure 17. The fast food restaurant's kitchen HVAC system. 55

Figure 18. The total energy use emissions for the 16 prototype building models, 1959-1989 baseline climate. 60

Figure 19. Heating and cooling energy use emissions for the 16 prototype building models, 19591989 baseline climate 


\section{List of Appendices}

Appendix A. Python code for extracting variables based on geographic location from the NetCDF file..

Appendix B. Python code for applying linear interpolation to the to 3-hourly data to generate hourly weather data.

Appendix C. A comparison of three different interpolation method for estimating the Missing Hourly Values for 24 Hours, and 1 Week...... 71

Appendix D. Model performance evaluation...................................................... 72

Appendix E. Detailed building information including number of floors, total area, floor height, and HVAC system. 73

Appendix F. Information on buildings envelope material, internal loads and schedules. ....... 76

Appendix G. Detailed weather data summary for the eight weather files.

Appendix H.The results for each individual building model simulated using 1959-1989 and 1998-2014 baseline and its future weather files 


\section{List of Abbreviation}

\begin{tabular}{ll} 
AOGCM & Atmosphere-Ocean General Circulation Model \\
ASHRAE & The American Society of Heating, Refrigerating and Air-Conditioning Engineers \\
CAV & Constant Air Volume \\
CDD & Cooling Degree Days \\
CWEC & Canadian Weather Year for Energy Calculation \\
CWEEDS & Canadian Weather Energy and Engineering Datasets \\
DOE & Department of Energy \\
DSY & Design Summer Year \\
EPW & EnergyPlus Weather \\
EUI & Energy Use Intensity \\
GCM & General Circulation Model - Global Climate Model \\
GEBA & Global Energy Balance Archive \\
GHG & Greenhouse Gas \\
GTA & Greater Toronto Area \\
HadCM3 & Hadley Climate Model 3 \\
HDD & Heating Degree Days \\
HRM3 & Hadley Regional Model 3 \\
HVAC & Heating, ventilation, and air conditioning \\
IEAD & Insulation Entirely Above Deck \\
IPCC & Intergovernmental Panel on Climate Change \\
NARCCAP & North American Regional Climate Change Assessment Program \\
NZEB & Net-Zero Energy Building \\
OBC & Ontario Building Code \\
RCM & Regional Climate Model \\
SHGC & Solar Heat Gain Coefficient \\
SRES & Special Report on Emission Scenarios \\
\hline
\end{tabular}


TGS

Toronto Green Standard

TMY

Typical Meteorological Year

TRY

Test Reference Year

VAV

Variable Air Volume

WRF

Weather Research Forecast 


\section{Chapter 1: Introduction}

As the world continues to urbanize, the urban population forces cities to become larger and more complex than before, leading to an increasing demand in housing, transportation, energy systems and other infrastructure. While rapid urbanization, due to population growth as well as improvements in the quality of life, has prompted economic and social development, it has also led to significantly increased energy demands and greenhouse gas (GHG) emissions. GHG emissions are one of the leading causes of climate change, producing adverse environmental effects such as global warming, changing weather patterns and extreme weather events.

In recent years, the building sector, a large energy-consuming system, has received increasing attention for sustainable development and decarbonization policies (Berardi, 2017). According to the International Energy Agency (2018), in 2017, building construction and operations accounted for 36\% of global final energy use and 39\% of energy-related emissions (Figure 1). In fact, the buildings and construction sector had the largest share of energy use and emission compared to other sectors.
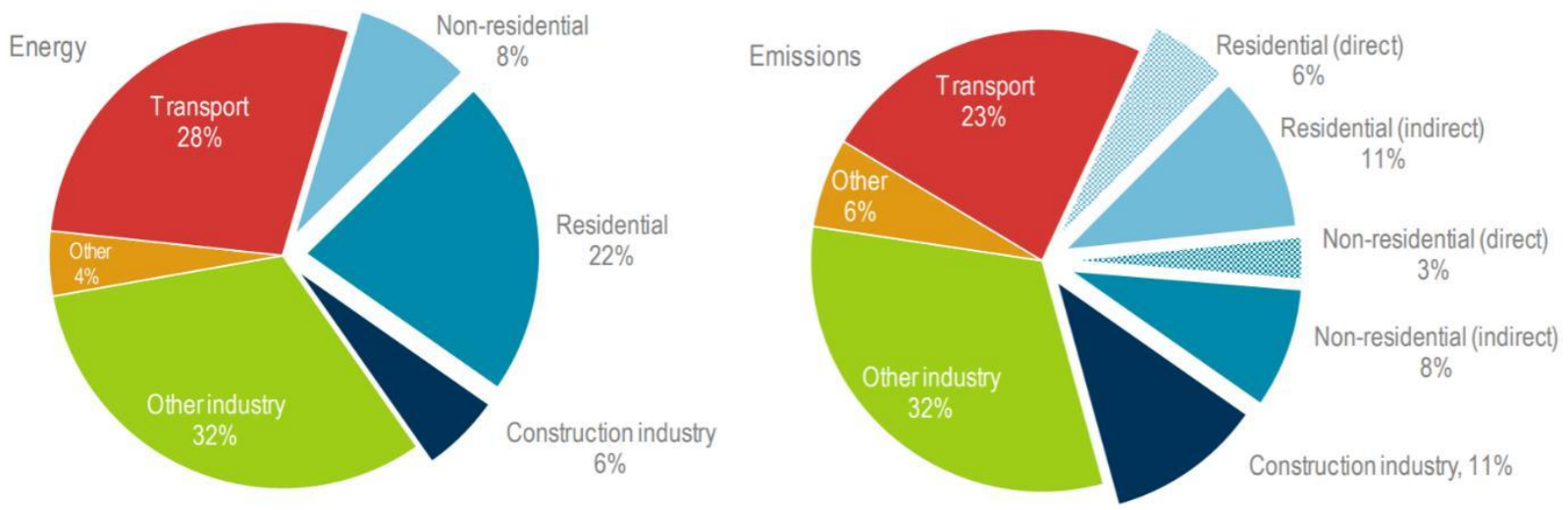

Figure 1. Global share of buildings and construction final energy and emissions in 2017 (IEA, 2018).

The global energy consumption from 2010 to 2017 saw an increase of approximately $5 \%$ due to increase in floor area, growth in building sector activity, as well as an increase in energy service demand, outpacing the reduction in energy intensity that was largely due to higher energy 
efficiency standards (IEA, 2018). During the same period, electricity use in buildings has had the largest growth globally compared to other fuel types. Natural gas use has also seen a large increase, with nearly 5\% growth since 2010 (IEA, 2018). Nevertheless, the $15 \%$ increase seen in the building electricity use has not been the result of a clean transition, given the large share of fossil fuel used for global electricity production. Figure 2 shows the global building energy use by fuel type and change for the period of 2010-2017.
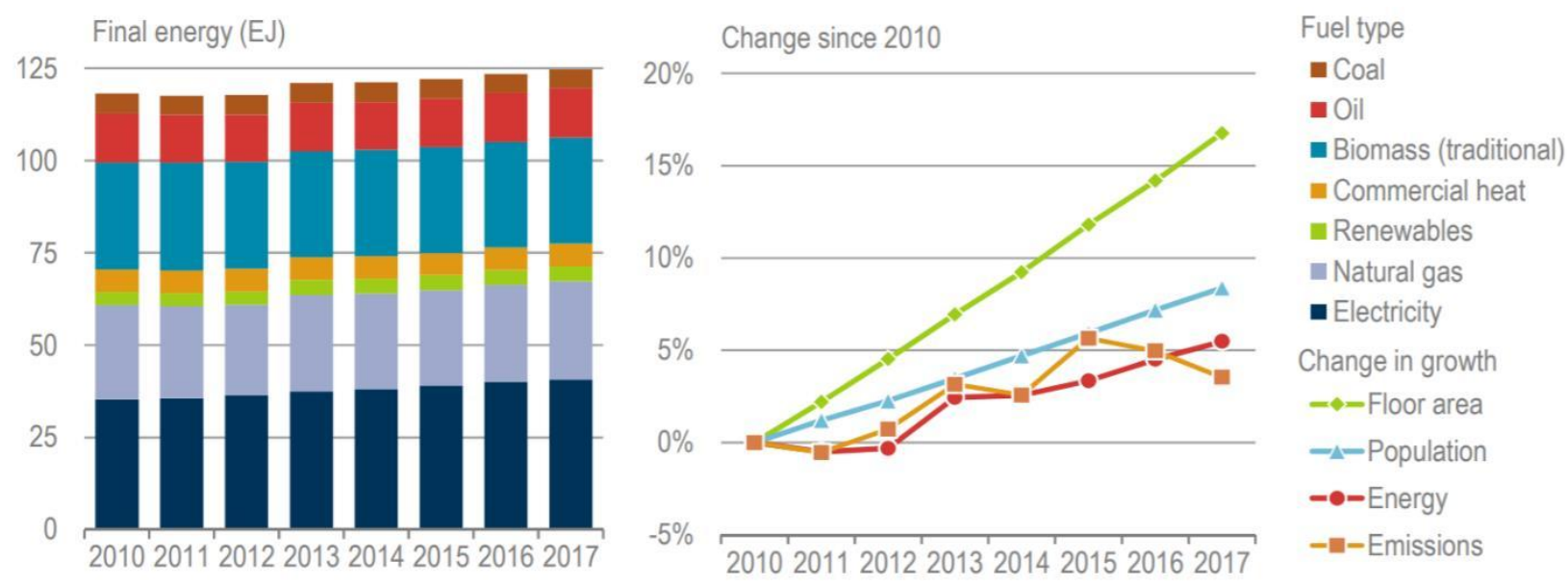

Figure 2. Global share of building energy use by fuel type and change, 2010-2017 (IEA, 2018).

According to the IEA (2018), building energy use has been dominated by the growth in space cooling and electrical appliance energy demand since 2010. Space cooling energy use has increased globally by more than $20 \%$, whereas the energy use for space heating has decreased by approximately 4\% (Figure 3). In fact, the reduction in space heating, which primarily uses fossil fuels, is putting increasing pressure on the use of electricity in buildings for space conditioning. Figure 3 displays the global building energy end-use and changes in energy use intensity for 20102017. 


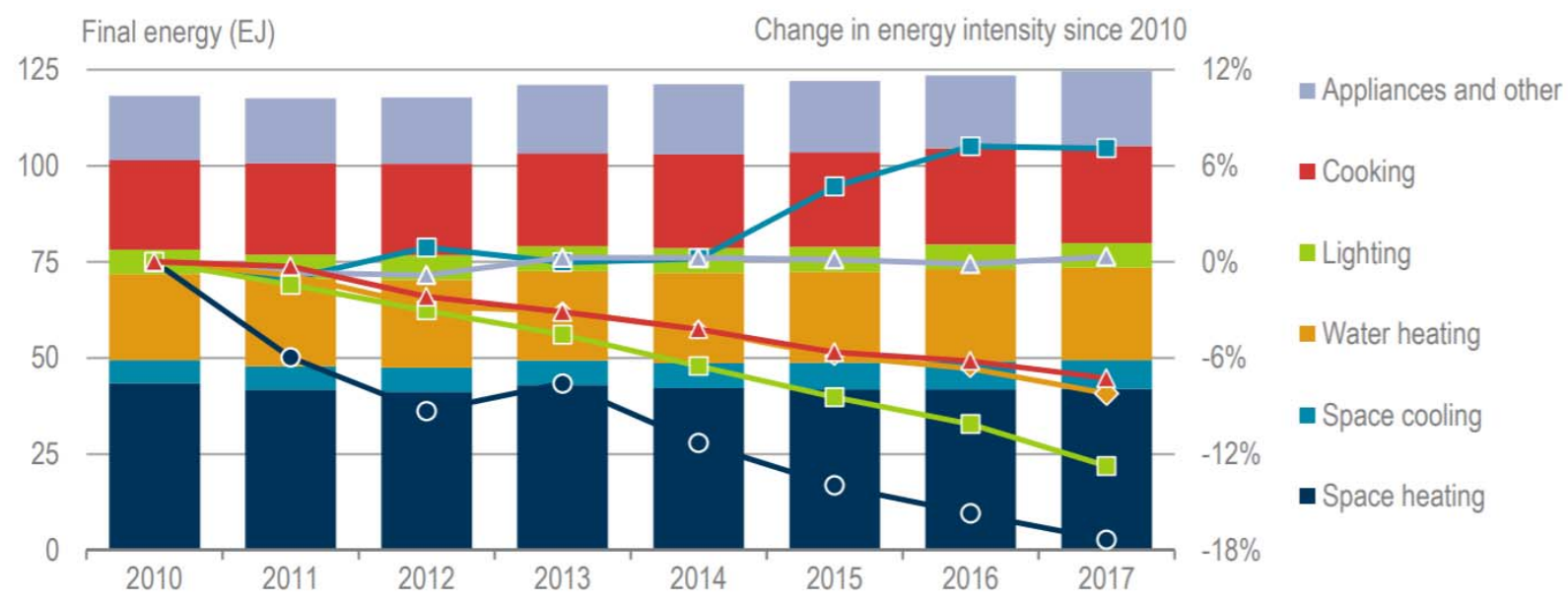

Figure 3. Global building energy use and change in intensity by end use, 2010-2017 (IEA, 2018).

The current trends of energy consumption, that primarily depend on the use of fossil fuels, have also raised concerns regarding the high levels of GHG emissions. Building sector emission is responsible for $28 \%$ of the global energy related $\mathrm{CO}_{2}$ emissions. Besides, if the energy related emissions from building construction are included, the total building related emissions accounts for $39 \%$ of the total global energy emissions (IEA, 2018). The global energy-related $\mathrm{CO}_{2}$ emissions from the building sector more than doubled between 1970 and 2010 and are also projected to increase by another twofold by 2050 (Berardi, 2017). According to IEA (2018), the emissions associated with the power generating for the consumption of electricity in buildings account for the largest share of global energy related emissions for the building sector.

In Canada, the residential building was responsible for $17.1 \%$, whereas the commercial and institutional building accounted for $11.2 \%$ of all energy used in 2015. The GHG emissions for residential, commercial and institutional buildings accounted for $22.6 \%$ of all secondary energy use-related GHGs emitted in Canada (NRCan, 2019).

In Ontario, the building sector is ranked third after the transportation and industry sectors for the total energy consumption and is accountable for $22 \%$ of the total GHG emissionsequivalent to $37 \mathrm{Mt} \mathrm{CO}_{2}$ (The Government of Ontario, 2016). Figure 4 illustrates a categorical classification of energy consumption by end-use for both residential, commercial and institutional buildings in Ontario. In residential buildings, space and water heating in addition to space cooling 
account for $85 \%$ of energy consumption. Moreover, in commercial and institutional buildings, space and water heating alone are responsible for more than $60 \%$ of energy end use. Other energy end uses, such as lighting, consumer electronics, appliances, make up the remainder. It is evident that the majority of energy use in Ontario building sector is for heating and cooling purposes. A significant portion (90\%) of GHG emissions from the Ontario building sector are from energy use, mainly associated with natural gas used for space heating (The Government of Ontario, 2018).
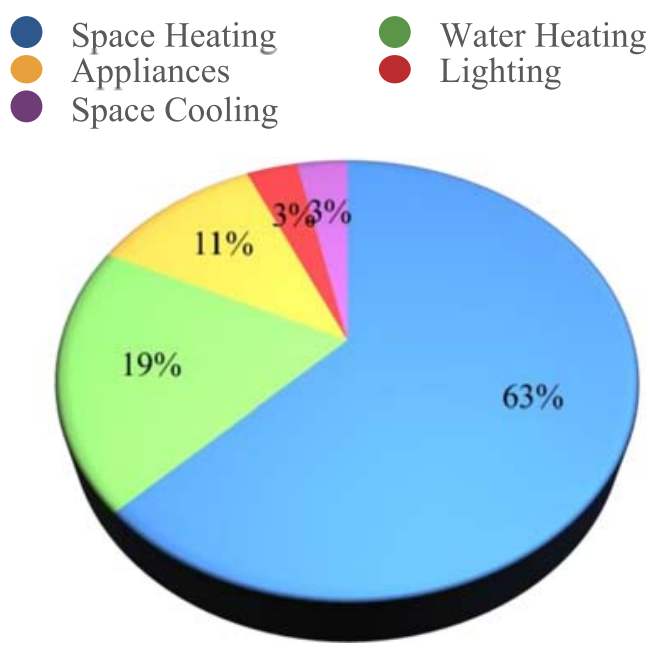

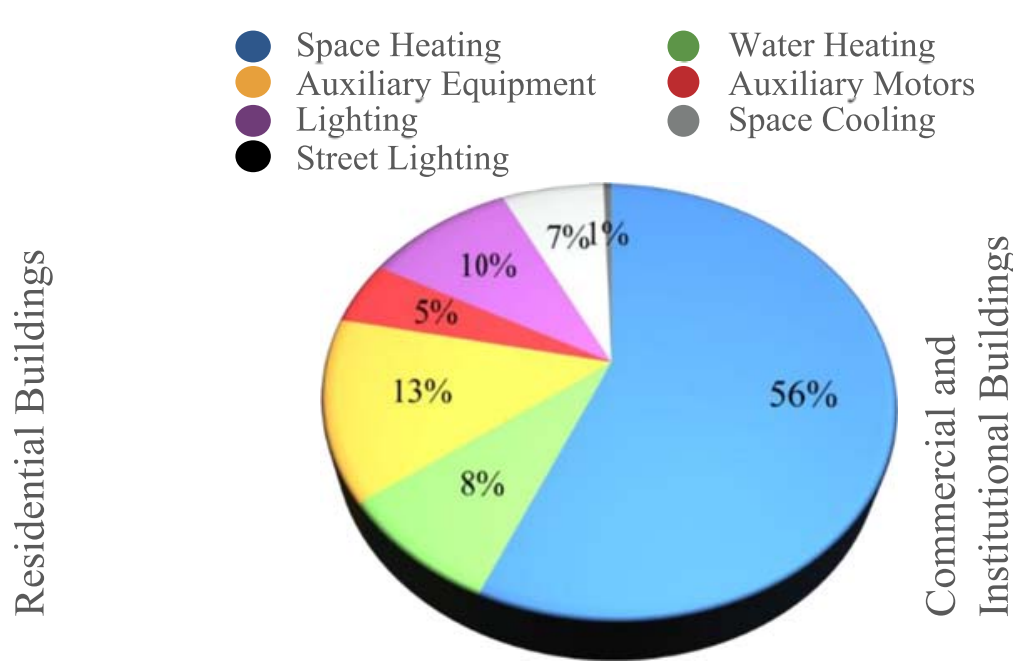

Figure 4. Classification of energy consumption by end-use (PJ) for both residential and commercial buildings in Ontario (NRCan, 2015).

\subsection{Background}

Apart from being a major factor in affecting the climate, it is expected that climate change will have significant impact on buildings performance as well as the occupants' comfort and productivity inside the building. In its most recent report, the Intergovernmental Panel on Climate Change (IPCC) has predicted that the global mean surface temperature will increase, in relation to the 1986-2005 period, by a range of $2.6^{\circ} \mathrm{C}$ to $4.6^{\circ} \mathrm{C}$ by the end of the $21^{\text {st }}$ century (IPCC, 2014). This temperature increase affect the buildings' indoor environment, leading to increase in heating, ventilation, and air conditioning (HVAC) system energy demand, which are the primary controls for the indoor thermal comfort and air quality. 
In general, decarbonizing the building sector requires the reduction in energy demand or transition to low carbon fuels; and improvement in building envelope as well as operating systems to reduce heating and cooling energy demands. Significant progress has been made in Ontario with the phase-out of coal for electricity generation as well as implementation of appliance standards, but improvements to the building envelope and operating systems represents the largest opportunity to reduce buildings energy consumption in the future. The building envelope provides a barrier that protects the indoor environment from the external climate conditions and can have substantial impact on building heating and cooling energy demands and indoor comfort. For example, building envelope influences the heating, cooling, and lighting energy consumption in buildings through conduction, solar energy transmittance via windows, and material shading. Glazing systems allow for the use of daylight in addition to the direct solar energy gain. Moreover, the geometrical configurations of a building such as its shape, window-to-floor ratio, and windowto-wall ratio can impact building energy loads. As a result, HVAC systems and lighting loads are directly influenced by the building envelope. In the literature, several studies have assessed the benefits of thermal insulation and envelope improvements on reducing energy consumption in buildings (Omrany et al, 2016; Wang et al., 2017). Globally, building envelope measures such as improved windows and insulation have helped to offset some of the increases in building energy consumption due to population and floor area increases (IEA, 2018).

Building energy models provide useful tools in simulating building energy demand. Models can assess different scenarios with various design and operation systems to determine the most appropriate design with the greatest overall performance for energy and emission mitigation. Furthermore, in building energy retrofits, energy simulations can also evaluate which refurbishment strategy is best for a particular building and climate. Current building simulation practices use weather files that have been based on historical records. However, given the scale of climate change and its impact on building heating and cooling demands, simulations using historical weather files fail to forecast the trends of building energy demand. In Canada, the same issues arise from the use of the Canadian Weather Year for Energy Calculation (CWEC) weather file, which is derived from historical weather data sets. For instance, the Ontario Building Code $(\mathrm{OBC})$ modelling guidelines do not mention a requirement for weather file. Moreover, the Toronto Green Standard (TGS) Version 3 modelling guidelines state "projects shall use a Toronto CWEC weather file" (The City of Toronto, 2019). In fact, the absolute performance targets under the TGS 
are based on Toronto's CWEC weather file representing 1958-1989 climate which does not reflect future climate change. Aside from building code compliance, engineers use weather data for equipment sizing and selecting HVAC systems which is a major source of energy consumption and emission in the building sector.

For a Canadian climate, global climate change warming may result in increases in building heat gain, impacting the occupants' indoor comfort. As policy direction for the building sector moves toward GHG emission reduction, building regulations such as highly insulated and airtight building envelopes may cause indoor overheating if not designed properly and according to the future climate (Government of Canada, 2016). Therefore, this not only lessens the occupant's wellbeing and comfort but also can lead to significant increases in building energy consumption due to the increase use of cooling systems. Therefore, without a comprehensive and insightful understanding of building energy heating and cooling energy demand in the future, it would be rather arbitrary for the local governments to regulate building codes. Besides, because of climate change, building equipment and HVAC systems must be designed and selected to perform efficiently in both the current and future climate, to prevent building energy use increase and reduce GHG emissions.

\subsection{Objectives}

As a response to the issues outlined above, this research proposes the use of future weather files in building energy simulation. The objective of this thesis is to

1. Develop future weather files that can be used to understand the impact of climate change on building performance in the future, as well as to allow for designers to consider future performance during the design process; and

2. Use the generated future weather files to examine the future performance of 16 building prototypes that are in compliance with the ASHRAE (American Society of Heating, Refrigerating and Air-Conditioning Engineers) 90.1-2013 standards, allowing for the better understanding of the effects of climate change on various building typology.

This is achieved by using climate forecasting models that assess how the climate conditions may change in the future. The aim is to add projected changes in climate models to the existing weather 
files, providing a tool for the assessment of building energy demand within a climate change perspective. The future weather files are generated using statistical downscaling to project climate change information produced by General Circulation Models (GCMs), and dynamical downscaling for higher resolution Regional Climate Model (RCM) coupled with Global Climate Models (GCMs).

The building simulation of the 16 building prototypes provides information on the longterm impacts of climate change on approximately two-thirds of the commercial building stock energy performance. In addition, the GHG emissions associated with heating and cooling for each building models as well as occupant's indoor thermal comfort for the future climate are presented and discussed. Ultimately, the forecasted changes in building heating and cooling energy use due to climate change can be used to develop appropriate policy measures by local governments and stakeholders to response to concerns regarding future energy production and consumption in the building sector. The results will offer a reference point for various building types in Toronto. 


\subsection{Thesis Structure}

To accurately estimate the annual energy demand of a proposed building design, the use of a building simulation technique along with weather data is often necessary. Using weather data as input to building simulation is the central theme of this thesis. In this regard,

Chapter 2 begins with an overview of typical weather data sets and weather variables used for building energy simulation. After that, previous studies on the impacts of climate change on building energy use are presented, showing the limited research on future building energy demand in Canada. In the end, a summary of the existing literature on future weather file generation for use in building simulation is provided that includes the techniques upon which the work is built.

Chapter 3 presents the methodology used in this research. Initially, this chapter focuses on the generation of future weather file by statistical downscaling technique using two future weather generator tools, CCWorldWeatherGen and WeatherShift ${ }^{\mathrm{TM}}$ tools. Furthermore, to improve the resolution of the climate simulation outputs, the dynamical downscaling technique is used to generated future weather files based on a regional climate model (RCM). Following the weather file generation, building simulation is performed using the ASHRAE building prototypes to assess the impacts of climate change on future building energy use.

Chapter 4 summarizes and discusses the characteristics of the future weather files as well as the results of heating and cooling energy use in different building types. Subsequently, occupants' indoor thermal comfort is assessed according to the future climate and the GHG emissions associated with each building model for the future climate is presented.

Chapter 5 outlines the conclusion of the study linking the results and the research objectives. This chapter demonstrates the contributions of this thesis and the suggestions for future work. The appendices include additional results related to generated future weather files and the building simulations. 


\section{Chapter 2: Literature Review}

The application of building performance simulation presents the opportunity to quantitatively predict the impacts of climate change on building energy demand in the future. To that end, initially, an introductory overview of typical weather data sets, weather variables, and baseline years used for generating a weather file in building energy simulation is presented. This literature review then examines and discusses previous research about the impacts of climate change on building energy use, allowing for the understanding of the gap in research. Furthermore, by reviewing previous methods, through progressive simplification of downscaling methods, this study investigates the generation of a typical future weather data set. The goal is to produce hourly time scale climate projections at higher spatial resolution with respect to limited resources while maintaining a high accuracy.

\subsection{Typical Weather Data Sets}

Building energy simulations involve hourly step calculations. Files for typical weather conditions consist of 8760 hourly values of various selected meteorological parameters such as ambient temperature, solar radiation, relative humidity and wind velocity that are used to determine the average building energy use and emissions. A typical weather file used for building simulation is created from historical data that usually consists of a 10-plus year weather data. Several methods for averaging or creating weather data have been used in the past in order to determine environmental conditions for engineering applications. As an output of those methods, different types of weather years were defined, such as Test Reference Year (TRY), Typical Meteorological Year (TMY), and Design Summer Year (DSY). Multiple studies have presented extensive literature reviews on the creation of weather file for a given location. Bilbao et al. (2004) used several different methods for generation of TRY from long-term hourly meteorological data and evaluated them by comparing the performance of different solar systems. According to their findings, Bilbao et al. suggested a methodology for TRY generation in the Mediterranean area. In Estonian, Kalamees and Kurnitsky (2006) created TRY for heating and cooling energy calculations. In South Korea, Lee et al. (2010) generated TRY from 20 years of meteorological data according to ISO15927 standards for seven major cities. Zang et al. (2012) proposed a 
modified method for generation of TMY for 35 cities in China from recorded weather data. Furthermore, Chan et al. (2006) reviewed different approaches for deriving a TMY, and generated TMY for Hong Kong using 25 years of recorded weather data. Liu and Coley (2015) created and analyzed the application of DSY for UK dwellings to assess indoor thermal comfort.

\subsubsection{Typical Meteorological Year (TMY)}

The most common sets of weather data used for assessing building energy use and carbon emission for buildings in North America is the typical meteorological year (TMY). TMY is a composite year that is generated by assigning ranking criteria to individual months of every year for a 30-year weather data, which are then compiled to create a 12-month typical weather year (Herrera et al., 2017). In the literature, TMY has been developed using various weightings applied to different meteorological parameters, prioritizing the selection of the most "typical" single months from a historical 30-year weather data to form a complete typical year (Hall et al., 1978; Bahadori et al., 1986; Pissimanis et al., 1988; Festa et al., 1993; Marion et al., 1995; Lam et al., 1996; Petrakis et al., 1998; Janjai et al., 2009). The most agreed upon method in creating TMY data is the Sandia method developed using the Filkenstein-Schafer (FS) statistic (Pusat et al., 2015). The Sandia method generates TMY by selecting a set of meteorological and solar radiation data for one year. The TMY data, however, do not relate to any actual year of recorded weather data, but rather represent a multi-year comparison of month-by-month, selecting the twelve most typical months to generate a composite year. The meteorological parameters used for TMY consisted of dry-bulb temperature (mean, maximum and minimum), global solar radiation, relative humidity, and wind speed (mean and maximum) (Hall et al., 1978). Later updates, in the early 1990s, introduced a newer TMY, the TMY2 data. The TMY2 derived from measurements during 1961-1990 (Marion and Urban, 1995) that had more complex solar models as well as adjustment in weighting criteria. Meanwhile, the most recent TMY, the TMY3 data, covers 1,020 sites across the US using data from 1976-2005 or 1991-2005 (Wilcox and Marion, 2008). TMY3 is created using procedures similar to those of TMY with few changes in the weighting criteria. Minor changes were made to the algorithm from TMY2 to TMY3, but according to Wilcox and Marion (2008), the overall effects on produced data sets were small. 


\subsubsection{Canadian Weather Year for Energy Calculation (CWEC) Weather File}

In a Canadian context, two sets of typical weather files are available for use. The first is the Canadian Weather Year for Energy Calculation (CWEC) weather files which is developed using statistical criteria from the Canadian Weather Energy and Engineering Datasets (CWEEDS) (Government of Canada, 2018). The CWEC files include data from 1959 through 1989 and are available for 75 locations in Canada. The CWEC files are created by selecting the twelve most typical months from CWEEDS data to generate a composite year, similar to the method used by Sandia Laboratories for the development of TMY (Government of Canada, 2018). According to the Meteorological Service of Canada (2008), the 'typical' months are selected by statistically comparing individual monthly with long-term monthly means for daily total global radiation, dry bulb temperature (mean, minimum and maximum), dew point temperature (mean, minimum and maximum), and wind speed (mean and maximum). Daily mean dry bulb temperature and daily total radiation are given higher prioritization in the selection process for typical months compared to other meteorological parameters. Siurna et al. (1984) provide a complete description of the procedure and weighting criteria used for the creation of CWEC files. The CWEC files have been most commonly used for building energy simulation in Canada and are available for download from EnergyPlus's weather sources ${ }^{1}$. In 2016, an updated version of CWEEDS including 492 Canadian locations for the period between 1998 and 2014 (CWEC2016) was released by the Government of Canada ${ }^{2}$ (2018). These CWEC files are not an actual year of recorded weather data, but rather a selection of the twelve most typical months from that 30-or 15-year timeframe (Table 1).

Table 1. The Canadian Weather Year for Energy Calculation weather file breakdown for the period of 1959-1989 (CWEC file) as well as 1998-2014 (CWEC2016 file).

\begin{tabular}{lllllllllllll}
\hline & Jan & Feb & Mar & Apr & May & Jun & Jul & Aug & Sep & Oct & Nov & Dec \\
\hline CWEC & 1969 & 1965 & 1964 & 1964 & 1963 & 1970 & 1981 & 1989 & 1978 & 1969 & 1983 & 1961 \\
CWEC2016 & 1999 & 2004 & 2006 & 2009 & 2006 & 2001 & 2013 & 2011 & 2003 & 2010 & 2000 & 2003 \\
\hline
\end{tabular}

\footnotetext{
${ }^{1}$ Available to download from EnergyPlus: https://energyplus.net/weather

${ }^{2}$ Available for download from Government of Canada Website. Engineering Climate Datasets: http://climate.weather.gc.ca/prods servs/engineering_e.html
} 
The second type of weather files available for Canada is the CN2014 files that have been developed by White Box Technologies for 224 Canadian cities. CN2014 files are based on more recent recorded weather data from 2000 to 2014 and use similar procedure as TMY files. The Integrated Surface Data datasets from the National Centers for Environmental Information is used to create these typical weather files (White Box Technologies, 2015). The CN2014 files have not yet achieved widespread use among the building industry and require meticulous assessment.

\subsubsection{Weather File Baseline Climate}

For building performance simulation, it is important to be aware of the weather file's baseline climate. A baseline period for TMY defines the recorded climate for which climate change information is combined to create a climate scenario used to generate the historical weather file. For instance, as previously stated, CWEC files are assembled by combining parts of historical data that usually span over 30-year intervals. However, the most recent baseline TMY data for Canada has potential to be from recent measurements (e.g., CWEEDS2016 or CN2014) which only spans for a 15-year period.

Briggs et al. (2003) developed a climate zone classification system for use by the Department of Energy (DOE) and the ASHRAE. Climate zones are defined by temperature, moisture, wind and sun which are combined to create the climate zone maps. There are eight major temperature-oriented climate zones in North America and the classifications are determined by degree days (Figure 5). The degree-day measurement is the difference in temperature between the average outdoor temperature over a 24-hour period and a given base temperature for a building space (Briggs et al., 2003). A case study by RWDI for the city of Toronto illustrated that warming trends seen over the period of 1959-89 compared to the 2000-14 are lower, and thus the heating degree days (HDDs) for the period of 2000-14 are considerably lower when compared with 19591989 (Williams and Harmer, 2017). This suggests for the use of most recent TMY (CWEEDS2016 or CN2014) for building energy simulation studies as it is irrelevant to assess building's energy performance relative to historical weather data that show cooler climate. On the other hand, it is argued that a longer range, a 30-year period, of historical weather data provides a better basis for selection of statistically typical months (Williams and Harmer, 2017). As a result, selecting a longer baseline period that spans 30 years compared to a 15 -year period can potentially give a more reliable climate scenario and ensure a statistically significant result. 


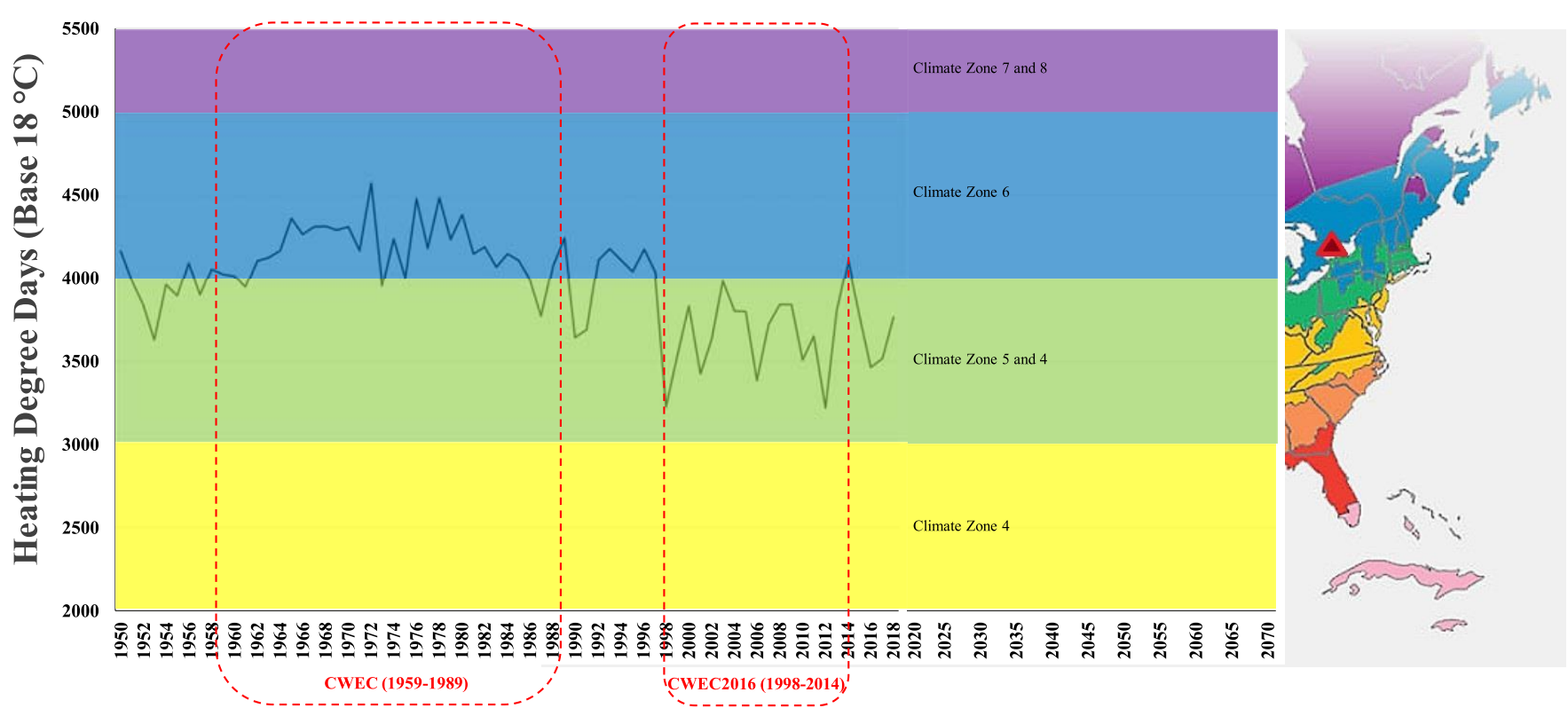

Figure 5. DOE climate zone classification including Canada and the warming trends seen in Toronto in terms of heating degree days (base $18^{\circ} \mathrm{C}$ ).

The CWEC file that spans a 30-year period of historical weather data provides a better representation of the historical climate, whereas, the more recent CWEC file (e.g. CWEC2016) characterizes the more current warming trends. Furthermore, not only the baseline climate is important in representing the climate conditions of the historical period, but it also have significant impact on future weather file generation as they are used as a benchmark for superimposing the changes in the future climate conditions.

\subsection{Climate Change and Building Energy Use}

A large number of studies have presented extensive literature reviews on the impact of climate change on building energy use. In this section, the broader trends projected in the literature have been incorporated. In the United States, Xu et al. (2012) examined the impacts of climate change on building heating and cooling energy patterns in California. The results showed that cooling electricity usage will increase by approximately $25 \%$; but the aggregated energy demand of all buildings including both heating and cooling will only increase slightly. Wang and Chen (2014) also predicted a net increase in source energy use in heating and cooling by the 2080 for hot humid, warm humid, and mixed humid climate zones and net decrease in cold and very cold 
climate zones in the U.S. based on the HadCM3 (Hadley Climate Model 3) weather projection. Shen (2017) showed that climate change has great impacts on residential and office building energy use during the year 2040-2069 for four U.S. cities. In addition, Huang and Gurney (2016) examined the impact of climate change on building energy consumption for 2 residential and 15 commercial building types at 925 U.S. locations. Overall, Huang and Gurney (2016) determined that national annual energy consumption will increase slightly for residential buildings, but for commercial buildings the increase will be larger (up to $8 \%$ ) by the 2090s. It was also concluded that large variations are found within and between building types at different climate zones. In UK, Jenkins et al. (2008) determined that warmer 2030 climate will increase the annual cooling energy uses by $2-4 \mathrm{kWh} / \mathrm{m}^{2}$ for office environments. In addition, the southern offices, in particular, were found more susceptible to temperature increase and thus had higher cooling energy demands. In Australia, Wang et al. (2011) analyzed the heating and cooling energy requirements and the corresponding emissions of residential houses under different future climatic conditions. Wang et al. (2011) determined that the carbon emission of residential houses was projected to be higher on average. In United Arab Emirates, Radhi (2009) evaluated the potential impact of climate change on residential buildings. This research concluded that the global warming is likely to increase the energy used for cooling buildings by $23.5 \%$, based on a $5.9^{\circ} \mathrm{C}$ warming. Furthermore, the $\mathrm{CO}_{2}$ emissions were estimated to increase at around 5.4\% over the next few decades (Radhi, 2009). Chan (2011) developed future hourly weather files for studying the impact of climate change on building energy performance in Hong Kong. This research found substantial increase in air conditioning energy use in the future, ranging $2.6-14.3 \%$ for office buildings and $3.7-24 \%$ for residential building (Chan, 2011). Table 2 outlines and summarizes the global climate change impact studies on building energy performance. It is mostly agreed upon that the cold climates will see a decrease, with various magnitude, in heating needs, and warm climates will see an increase in cooling loads. 


\begin{tabular}{|c|c|c|c|}
\hline 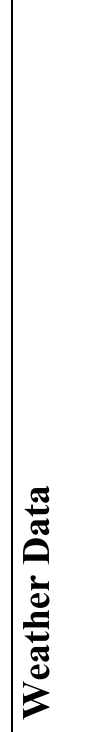 & 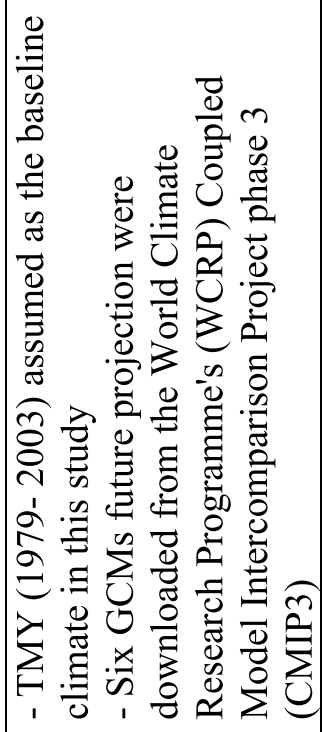 & 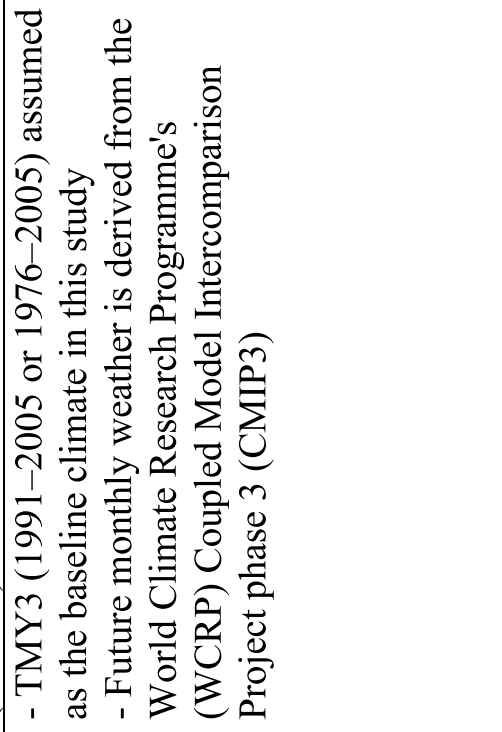 & 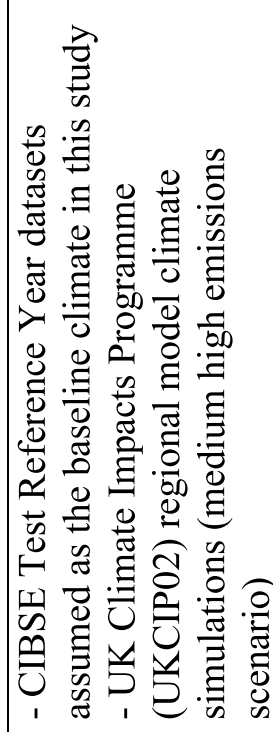 \\
\hline 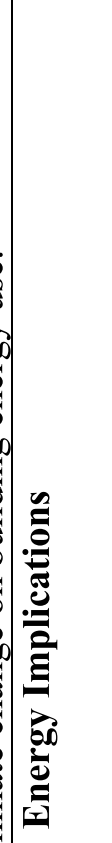 & 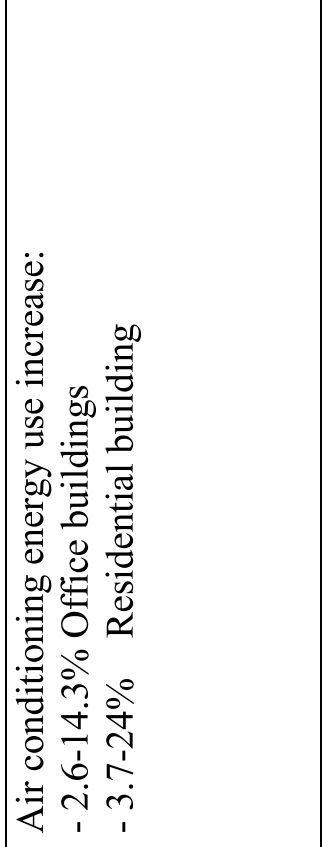 & 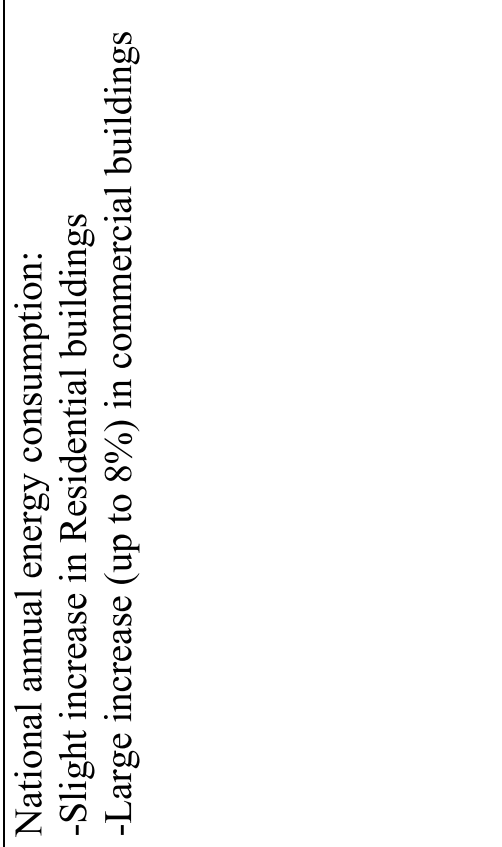 & 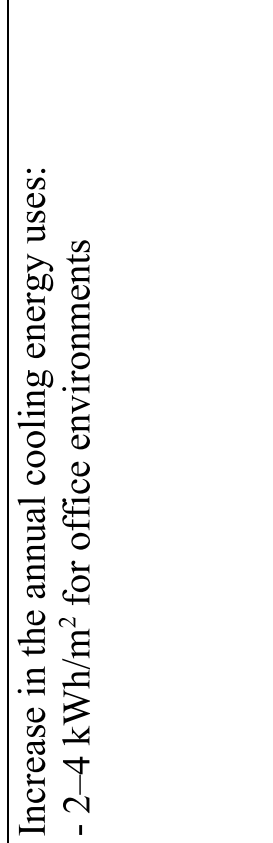 \\
\hline 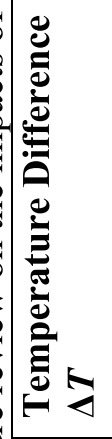 & 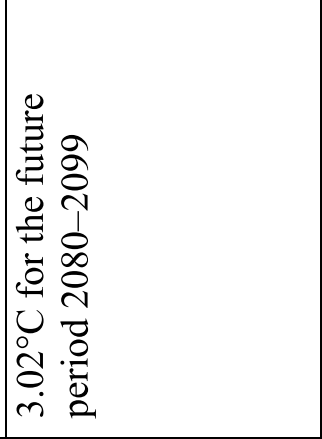 & 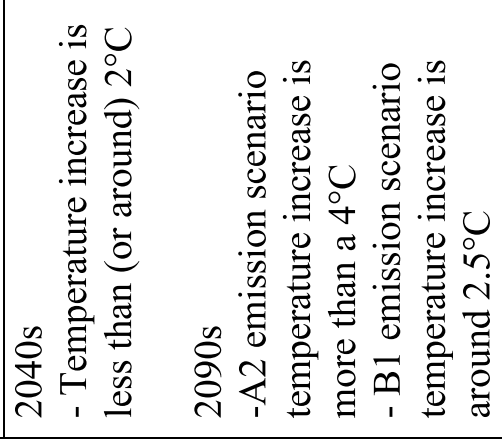 & 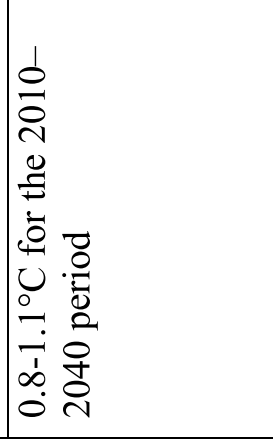 \\
\hline 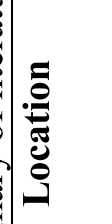 & $\mid \begin{array}{l}00 \\
0 \\
0 \\
1 \\
00 \\
0 \\
0 \\
0 \\
1\end{array}$ & 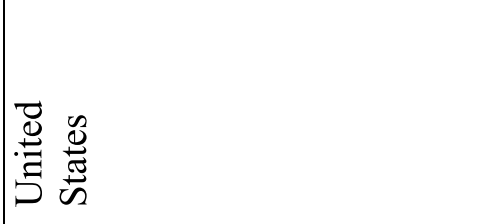 & 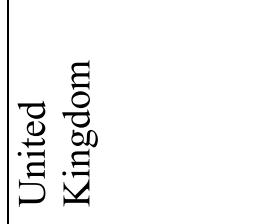 \\
\hline $\bar{E}$ & 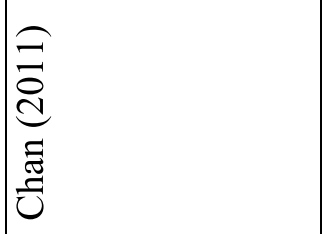 & 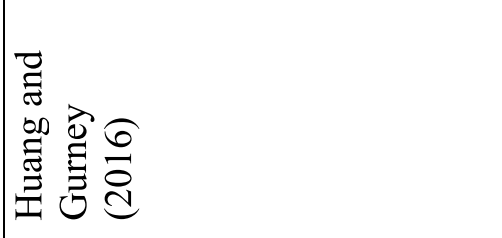 & 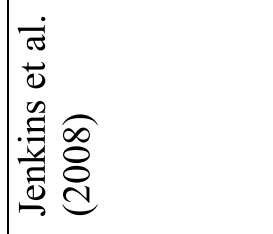 \\
\hline
\end{tabular}




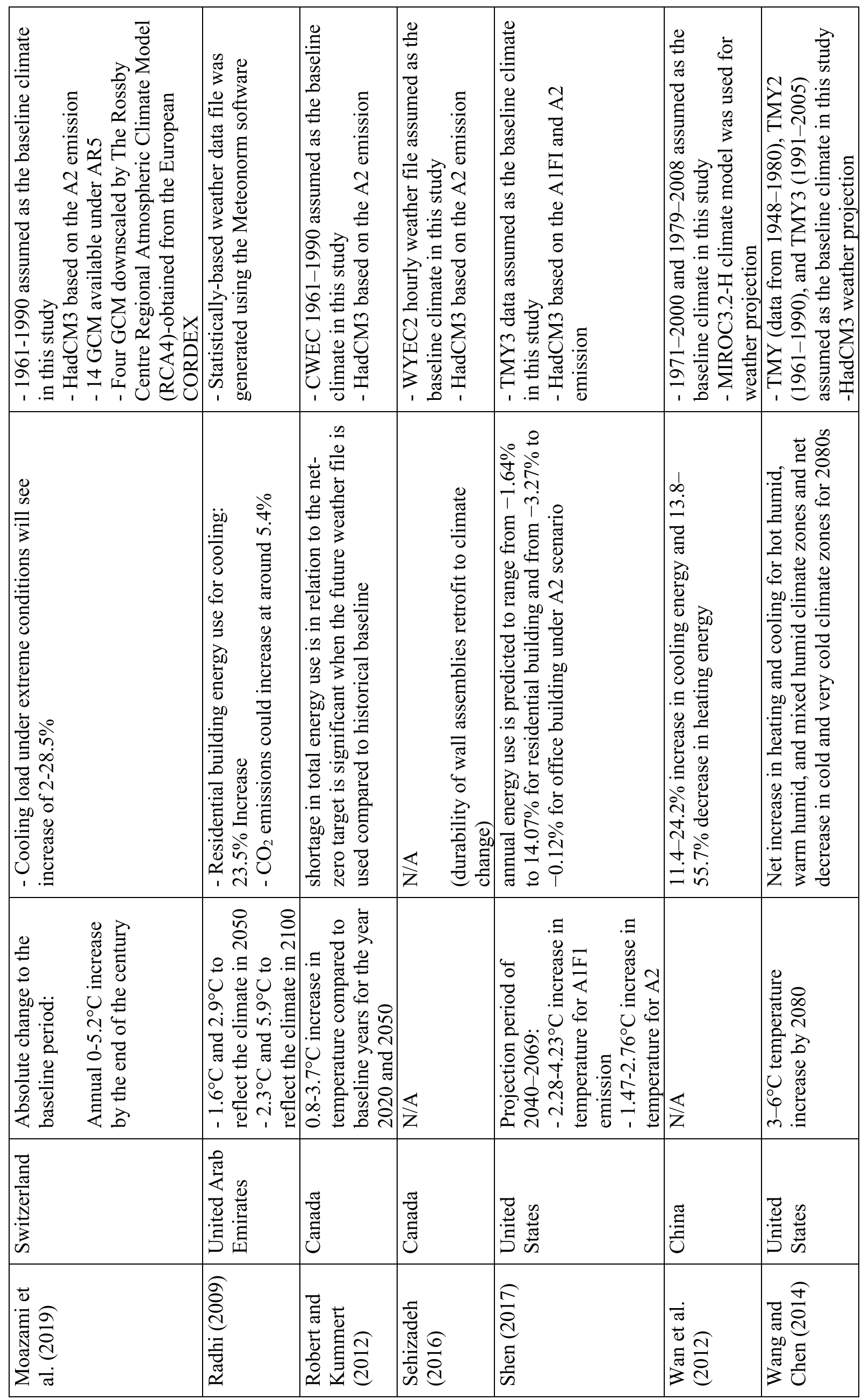




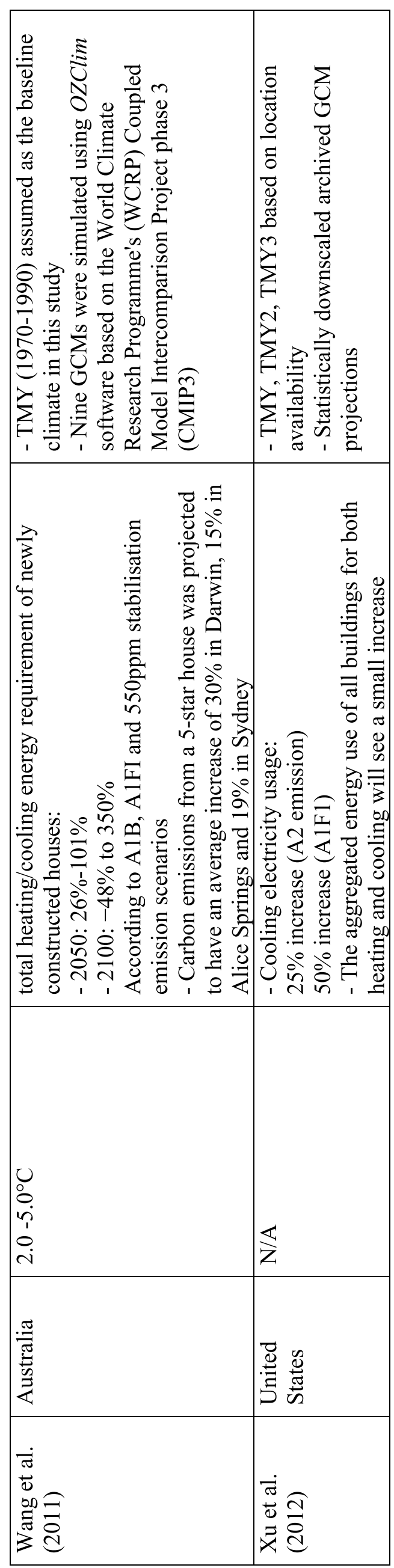


In recent years, there has been several researches conducted on evaluating impacts of climate change on buildings in Canada. For instance, Sehizadeh (2016) examined the impact of future climate on the durability of wall assemblies retrofit to residential buildings in Eastern Canada, concluding that upgrading wall assemblies to residential building would increase the frost damage risk of bricks. However, according to Sehizadeh (2016), the frost damage risk of bricks decreases under 2080 climatic conditions. The future weather files used in that study were generated using GCM, HadCM3, with the IPCC's A2 emission scenario (Sehizadeh, 2016). Robert and Kummert (2012) developed hourly future climate data to evaluate the performance of a zeroenergy building under future climate conditions. They concluded that climate-sensitive buildings such as net zero energy buildings should always be designed using multi-year simulations based on weather data that take climate change into account. For the City of Toronto, the Toronto's Future Weather and Climate Driver Study (2012) commissioned by the Toronto Environment Office simulated potential future weather data to support the City's climate change policies. The study was undertaken by SENES Consultants, now ARCADIS, using a fine-resolution Weather Research Forecast (WRF) model to make projections of future climate in Toronto. The result of the study was a simulation of the hourly weather details on a 1x1 km output grid across the Greater Toronto Area (GTA) for the years 2041 to 2049.

Although there are several studies that assess the impacts of climate change on buildings, in Canada, there is lack of climate change impact studies regarding building heating and cooling energy use in the future. As a result, this study aims to provide not only future weather files based on a more reliable forecast of the local boundary conditions, then previously seen in other research studies in Canada; but also, for the first time, offer an insight on the impacts of climate change on building energy use for 16 ASHRAE prototype building models. This is important as it will provide a reference point for heating and cooling energy use for various building types in Toronto according to the future climate. The following sections discuss relevant literature on projecting future weather data from climate models necessary for development of future weather files used in building energy simulation. 


\subsection{Future Climate Conditions}

Forecasting future climate conditions is the basic principle for all climate change impact studies. General circulation models (GCMs) were presented to provide quantitative estimates of future changes in the climate based on different emission scenario possibilities as put forward by IPCC. GCMs are mathematical representation of some of the major climate system components, their interactions, and feedbacks. They take into account the energy transfer mechanisms between a three-dimensional turbulent and radiation-active atmosphere and spatially heterogeneous land, ocean, and cryosphere surfaces (Eames et al., 2016). GCMs are composed of horizontal and vertical areas that divide the Earth's surface into earth plus the ocean and the atmosphere to threedimensional grid of cells (Figure 6).

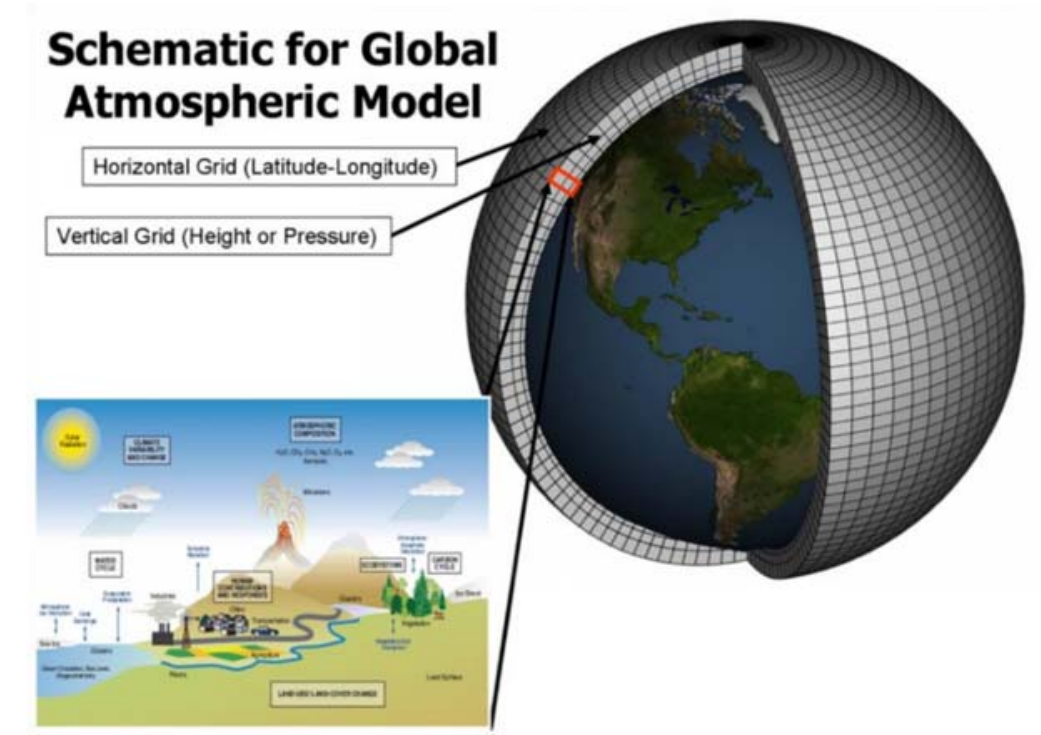

Figure 6. The global circulation model structure (Trzaska and Schnarr, 2014).

However, the outputs of GCMs have a relatively low level of spatial (100-500 km) and temporal resolution (daily or monthly) for direct use in building simulation (Trzaska and Schnarr, 2014). In fact, most building-related research is undertaken by means of building simulation tools that require hourly resolution weather data.

GCM adjustments are made possible by a process of "downscaling", which refers to the generation of climate change information at finer spatial and temporal resolutions than those provided by the GCMs (Trzaska and Schnarr, 2014). Spatial downscaling is a method used to derive high-resolution spatial information from coarse-resolution GCM output (e.g. $500 \mathrm{~km}$ to 
2.5-50 km). Temporal downscaling is used to drive fine-scale temporal information from coarsescale temporal GCM output (e.g. monthly weather data to hourly) (Trzaska and Schnarr, 2014). The downscaling process adds information to the coarse GCM output, so that the information is more realistic at a finer scale, capturing sub-grid scale contrasts.

As of now, two main forms of downscaling technique exist. Figure 7 shows the relationship between these two techniques and climate models in order to obtain a higher resolution information at spatial and temporal scales.

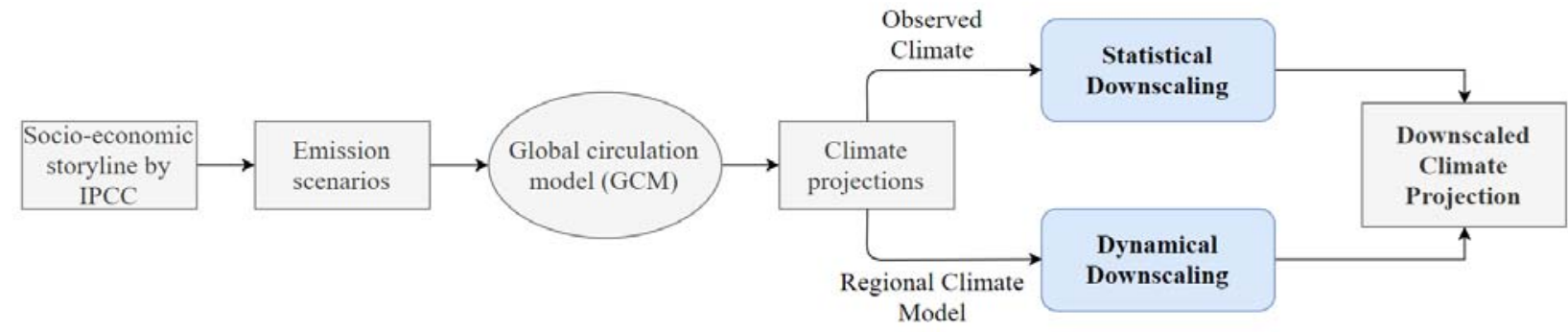

Figure 7. Flow chart illustrating the two downscaling techniques used to prepare high-resolution weather data suitable for generating future weather file for building performance simulation (Trzaska and Schnarr, 2014).

The first technique is the statistical downscaling which establishes an empirical relationship between large-scale circulation variables and local climate variables. Once a relationship has been determined, future atmospheric variables that GCMs project are used to predict future local climate variables (Guan, 2009). This approach relies on the critical assumption that the present relationship between large-scale circulation and local climate remains valid under different forcing conditions of possible future climates (Zorita and von Storch, 1999).

The second downscaling technique is the dynamical downscaling, where the output from a GCM is used to drive a regional model in higher spatial resolution. This method relies on the use of a regional climate model (RCM) which is fundamentally similar to a GCM but provides a finer resolution. RCMs take the large-scale atmospheric information supplied by GCM output at the lateral boundaries and incorporate more complex topography, the land-sea contrast, surface heterogeneities, and detailed descriptions of physical processes (Trzaska and Schnarr, 2014). This method generates realistic climate information at a spatial resolution of approximately 2.5-50 kilometers. It is worth mentioning that since the RCM is integrated in a GCM, the overall quality 
of dynamically downscaled RCM output is tied to the accuracy of the large scale forcing of the GCM and its biases. This technique is significant for use in building simulation as the assessment of building energy demand tends to focus on impacts of climate change at the local level. Thus, depending on the availability and accuracy of RCM, the weather files generated using dynamical downscaling, on top of weather files generated using statistical downscaling, provide a more reliable forecast of the local boundary conditions for building performance simulation.

At times, the combination of both downscaling techniques is used in order to obtain a more accurate finer-scale and hourly data from GCMs. For instance, dynamical-statistical downscaling involves the use of an RCM to downscale GCM output before statistical equations are used to further downscale RCM output to a finer resolution. Dynamical downscaling improves specific aspects of regional climate modelling and provides better predictors for further statistical downscaling to higher-resolution output (Guyennon et al., 2013). Statistical-dynamical downscaling is a somewhat more complex approach that statistically prefilters GCM outputs into a few characteristic states that are further used in RCM simulations (Fuentes amd Heimann, 2000).

\subsection{Development of Future Weather File}

Guan (2009) and Herrera et al. (2017) present a complete review of the method used to generate future weather data for the impact study of climate change on building energy performance. The first category relies on historical weather data which includes the extrapolating statistical method, imposed offset method, and the stochastic weather model.

The extrapolating statistical method generates future weather conditions based on the projection of the historical weather data trends into the future. This method predicts building energy consumption based on the degree-day method. The degree-day is a single-measure steady state method used to predict building energy consumption, according to the variation between the indoor and outdoor temperature (Christenson et al., 2006; Wang and Chen, 2014, Cox et al., 2015). This method provides simple and fast measurements but since solar radiation, humidity, or building thermal mass are not considered, degree-day analysis can lead to large deviations in building energy simulation, making its application limited. 
The imposed offset method predicts future climate information from complex climate models in addition to the recorded typical weather data sets. This method has been the most widely used in the literature for generating future weather files in buildings performance simulation. Imposed offset method includes the morphing technique described by Belcher et al. (2005) that requires one of three operations: "shifting" (addition), "stretching" (multiplication), or a combination of the two (shifting and stretching). The morphing technique is applied to the climate variables in the present-day recorded weather data, producing new weather data that illustrate the average projected climate change in the future (Belcher et al., 2005). Shifting is used for variables for which an absolute change of mean is provided. Stretching is applied for those variables which a fractional change of mean or variance is given. The combination of both shifting and stretching is used when both the mean and variance of a climate variable requires to be changed. Crawley (2008) applied this technique to create weather files that represent the future climate for about 25 locations worldwide, illustrating a range of predicted climate change and heat island scenarios for building simulation. Moreover, Chan (2011) examined the application of morphing for Hong Kong's subtropical climate. In Canada, Robert and Kummert (2011) reported on the use of morphing methodology on the creation of weather files for the city of Montréal, assessing energy performance of a zero-energy building. In the UK, Jentsch et al. (2013) described a method of morphing output from the Hadley Climate Model 3 (HadCM3) and created a tool by which future weather data for use in building simulation can be generated for any location worldwide. However, there are a few criticisms regarding the use of morphing technique for generating weather files. According to de Dear (2006), spatial and temporal inaccuracies can be created in climate projections when achieving finer local scale and hourly time step data sets by using the historical recoded climate variation for projecting a future weather change on top of the GCMs.

The stochastic weather model was developed by Van Paassen et al. (2002), and Adelard et al. (2000) to generate future weather data based on generating an artificial meteorological database. Some weather generators use algorithms that produce a long time-series of weather variables with statistical properties comparable to recorded historical records. For instance, the Meteonorm software can extrapolate hourly data from statistical data for any location in the world, using stochastic and physical processes (Remund et al., 2018). Meteonorm combines its climate database, spatial interpolation tool and stochastic weather generator, with global radiation data obtained from the Global Energy Balance Archive (GEBA) (Remund and Kunz, 1997). Thus, 
Meteonorm can be used to generate future weather data accounting for climate change if historical monthly averages that are normally used as inputs are replaced with results from a GCM. Meteonorm has been extensively used for generating TMYs (Ebrahimpour and Maerefat, 2010). An advantage of this method is that all the relationships between different weather variables are accounted for in the same way as for baseline data (de Dear, 2006). Despite that, Guan (2009) argues that the stochastic weather model is too complex and computationally intensive.

The second category relies on the use of numerical climate models as an alternative to the historical weather data approach. GCMs are used to generate local future weather files by means of dynamical downscaling or RCM. This has become a commonly used approach to improve the resolution of the climate simulation outputs. As research has shown, compared to the GCMs, the RCMs have the advantage of generating physically consistent data sets for different variables and have a better representation of the landscape and meso-scale processes, providing a more reliable forecast of the local boundary conditions of the future climate (Moazami et al., 2019). The different approaches most commonly used in the literature, to project and generate future weather data for the impact study of climate change on buildings, are illustrated in Figure 8.

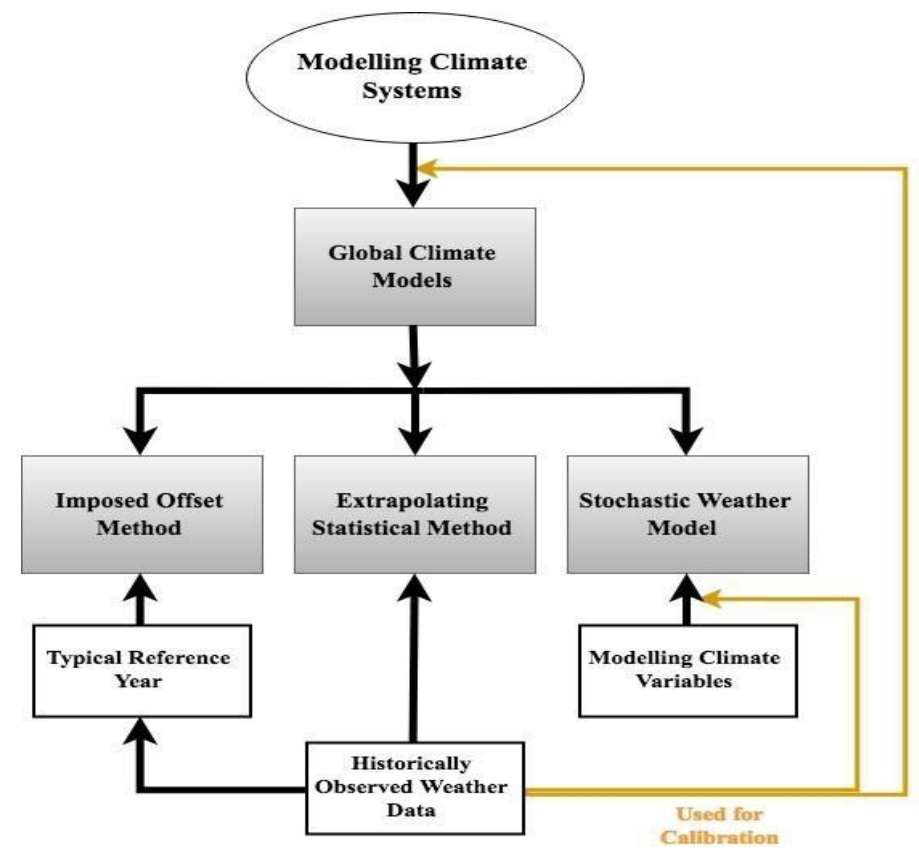

Figure 8 . The relationship between different methods used to project and generate future weather data (Guan, 2009). 
Based on the concerns raised above, of those considered from the first category, the imposed offset method is the most practical method for developing future weather as the extrapolating statistical method only considers degree-day measure and the stochastic weather model requires high computing power (Guan, 2009). Therefore, the future weather data sets developed in this research were generated by statistical downscaling technique using two future weather generator tools, CCWorldWeatherGen and WeatherShift ${ }^{\mathrm{TM}}$, which adhere to the imposed offset method for generating future weather files. And for the second category, the dynamical downscaling technique using the HRM3-the Hadley Regional Model 3 coupled with the HadCM3- the Hadley Climate Model 3 was used. 


\section{Chapter 3: Methods}

It is recognized that since climate conditions have significant influence on the thermal performance of buildings, the design of the building envelope and the HVAC system must incorporate climate projections. Following preliminary research, it was concluded that historical weather data regularly used for building simulation do not consider changes in the future climate. Therefore, in order to properly quantify the dynamic energy processes of a building, the use of future weather data in building energy simulation is essential. In addition, it was determined that in Canada, future weather file availability and accessibility is limited, leading to the absence of climate change impact studies in the building sector.

The methods for this thesis are divided into two streams: one focusing on the creation of future weather file, and one on the impact study of climate change on building energy performance. They are both required to achieve the overall objective of this thesis which is to quantify the future trends of building energy use for the city of Toronto. In order to generate future weather files, the methods proposed in the present research could be characterised as being both statistical and dynamical downscaling techniques. In the following, the methodology used for generating the future weather files as well as the building performance simulations are presented.

\subsection{Data Selection}

In order to generate future weather data sets, initially, typical weather data sets developed for Canada are required. Given the limitations of historically recorded weather data and the availability of long-term hourly time resolution for every location, two Canadian Weather Year for Energy Calculation (CWEC) files generated by Environment and Climate Change Canada were selected for this research (Government of Canada, 2018). The availability of the CWEC files is highly dependent on the weather stations. Thus, for weather station selection, this study assessed Billy Bishop Airport weather station located at $43.617^{\circ} \mathrm{N}, 79.383^{\circ} \mathrm{W}$, Toronto City Centre weather station located at $43.667^{\circ} \mathrm{N}, 79.400^{\circ} \mathrm{W}$ and Toronto Pearson International Airport weather station located at $43.677^{\circ} \mathrm{N}, 79.631^{\circ} \mathrm{W}$. Ultimately, the Toronto Pearson International Airport weather station was selected due to the recorded historical weather data availability and historical weather file compatibility with building performance simulation. On one hand, a CWEC 
file that spans a 30-year period of historical weather data (1959-1989) was available for this weather station, providing a better representation of the historical climate. Alternatively, a more recent CWEC file, which spans from 1998-2014 that was made recently available by Environment and Climate Change Canada was selected to characterize the most current warming trends. Billy Bishop Airport and the Toronto City Centre weather stations did not have a historical weather file for the years 1959 to 1989 .

\subsection{Preparing Future Weather Data for Building Performance Simulation}

The future weather data sets developed in this research were generated by statistical downscaling technique using two future weather generator tools, CCWorldWeatherGen and WeatherShift ${ }^{\mathrm{TM}}$, as well as a dynamical downscaling technique using one regional climate model, the HRM3-the Hadley Regional Model 3 (Figure 9).

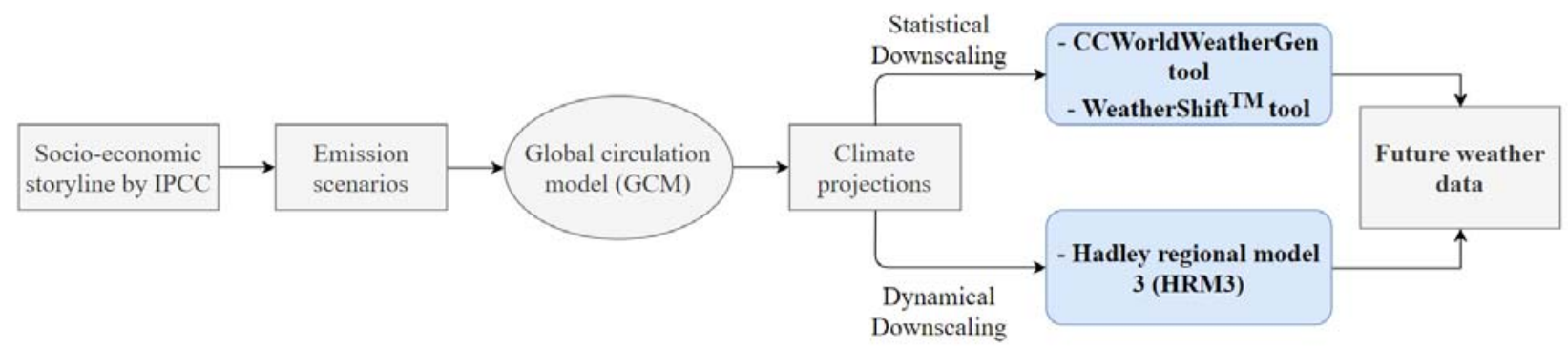

Figure 9. Flowchart of various methods used in the present research for preparing high-resolution weather data suitable for generating future weather file for building performance simulation.

\subsubsection{CCWorldWeatherGen Tool}

The Climate Change World Weather Generator tool (University of Southampton, 2009) allows for fast projection of future climate change to an existing weather file and is freely available for use (Wang and Chen, 2014; Ciscar and Dowling, 2014). With the application of statistical downscaling method as well as a time series adjustment technique (morphing), the CCWorldWeatherGen tool can generate a future weather file for each inputted Typical Meteorological Year (TMY) file. This Microsoft Excel based tool was developed by Jentsch et al. (2013), who applied the morphing method using HadCM3 forced with IPCC A2 emission scenario to generate EnergyPlus Weather (EPW) file. According to Moazami et al. (2017), after six GCMs 
under AR3 and 23 GCMs under AR4 were reviewed, it was concluded that the most suitable GCM for applying the morphing technique was the HadCM3 for A2 emission scenario. The A2 emissions scenario put forward by the IPCC represents a 'business as usual' case with continuously increasing global population and regionally oriented economic growth that is more fragmented and slower than in other storylines (Nakicenovic et al., 2000). This research considered the A2 as the most appropriate emission scenario for climate projection due to the ongoing climate change trends, $\mathrm{CO}_{2}$ emission scenario characterized by rapid economic growth and emphasis on fossil fuel. The HadCM3, A2 scenario, simulates changes in monthly values of climate condition relative to the 1961-1990 baseline years. The CCWorldWeatherGen tool superimpose these changes of the future climate on the meteorological parameters stored in the original TMY file.

This tool allows for the generation of future weather files within three timeframes of 20112040, 2041- 2070, and 2071-2100. In order to generate a future weather file, first, a TMY file was uploaded to the CCWorldWeatherGen. The HadCM3, A2 scenario, and a future projection timeframe were then selected, respectively. At the end, the morphing procedure was initiated to generate a future weather file. For instance, in this work, the original TMY files used were the CWEC files for Toronto, obtained from Toronto Pearson International Airport weather station. As a result, applying CCWorldWeatherGen tool to each of the CWEC files will superimpose the changes in 1961-1990 baseline on to the data from 1959-1989 and 1998-2014. In the case of CWEC file for the period of 1998-2014, as higher temperature values are observed compared to the 1961-1990 baseline climate, an overestimation of results in the morphed data set is expected. Table 3 demonstrates the differences between the two weather generator tools that apply statistical downscaling for future weather file development.

Table 3. Difference between WeatherShift ${ }^{\mathrm{TM}}$ and CCWorldWeatherGen tools in simulating future weather files (Moazami et al., 2017).

\begin{tabular}{lll}
\hline & CCWorldWeatherGen tool & WeatherShift $^{\text {TM }}$ \\
\hline Projected time period & $2011-2040,2041-2070$, & $2026-2045,2056-2075$, \\
& $2071-2100$ & $2081-2100$ \\
IPCC Report & AR3, AR4 & AR5 \\
GCMs & HadCM3 & 14 Models \\
IPCC emission scenario & A2 & RCP4.5, RCP8.5 \\
Downscaling period & Morphing & Morphing \\
Baseline climate & $1961-1990$ & $1976-2005$ \\
\hline
\end{tabular}


As buildings tend to exist for decades, the need for building maintenance and repairs varies depending on many factors. Some of these factors include the building design, quality of construction, environmental conditions as well as the level of care given by the owners or facility management. For this research, it was assumed that the useful life of a building is approximately 50 years, as they go through different stages of their life cycles. Therefore, the future weather files generated using CCWorldWeatherGen tool for the period of 2041- 2070 were chosen for the purpose of this study as it was the most appropriate timeframe.

\subsubsection{WeatherShift ${ }^{\text {TM }}$ Tool}

The second tool used for the projection of changes in the future climate to an existing weather file is WeatherShift ${ }^{\mathrm{TM}}$. This tool was acquired from Arup and Argos Analytics for the purpose of this research and uses $14 \mathrm{GCMs}$ (out of approximately 40 models) available under AR5 for its climate change projection (Dickinson and Brannon). With the application of statistical downscaling method as well as a time series adjustment technique, the WeatherShift ${ }^{\mathrm{TM}}$ tool can generate a future weather file for each inputted TMY files. This tool allows for the generation of

future weather files for three timeframes of 2026-2045, 2056-2075, 2081-2100 relative to the baseline climate 1976-2005 (Table 3).

Similar to the CCWorldWeatherGen tool, first, a TMY file was uploaded to the WeatherShift ${ }^{\mathrm{TM}}$ tool for generating a future weather file. Next, in WeatherShift ${ }^{\mathrm{TM}}$, the appropriate emission scenarios (RCP8.5 or RCP4.5 of the IPCC's AR5), as well as future projection timeframe were selected. Like A2 emission scenario the RCP8.5 illustrates high $\mathrm{CO}_{2}$ emission levels, characterized by rapid economic and population growth as well as the use of fossil fuels for energy production. The WeatherShift ${ }^{\mathrm{TM}}$ tool was then initiated to simulate and superimpose the changing climate of the future, creating a future weather file by applying the morphing technique to its 14 GCMs. Moreover, the WeatherShift ${ }^{\mathrm{TM}}$ offers a cumulative distribution function (CDF) for each of the variables, allowing the users to assign a likelihood to the projections (Dickinson and Brannon). CDF has been previously applied to the UKCP09 probabilistic projections (Jenkins et al. 2008). In this study, the $50^{\text {th }}$ (median) percentile along with the RCP 8.5 emission scenario were selected for generating future weather data sets based on the two CWEC files for Toronto. It is worth noting that an underestimation of values in the future weather data is expected when the original CWEC file for the period of 1959-1989 is used. This is predominantly because of the lower temperature 
values in this CWEC file compared to the 1976-2005 baseline climate used in WeatherShift ${ }^{\mathrm{TM}}$. On the other hand, an overestimation in the future weather data set is expected when the original CWEC file for the period of 1998-2014 is used. Finally, the future weather files generated by WeatherShift ${ }^{\mathrm{TM}}$ for the period of 2056- 2075 was selected as the useful life of a building was assumed to be approximately 50 years.

\subsubsection{Weather File Generation from Hadley Regional Model 3}

The present work used a dynamically downscaled RCM output developed under the North American Regional Climate Change Assessment Program (NARCCAP) to generate a future weather file by projecting climate change information based on the RCM (NARCCAP, 2010). NARCCAP is an international program focused on using RCMs driven by GCMs to generate highresolution climate change simulations (NARCCAP, 2010). The program includes two main phases. In phase 1, six RCMs use boundary conditions from the National Centers of Environmental Prediction-Department of Energy (NCEP-DOE) Reanalysis II (R2) for a 25-year period (19802004). In Phase 2, boundary conditions from four atmosphere-ocean general circulation models (AOGCMs) were used for 30 years of current climate (1971-2000) and future climate (2041-2070). The output data obtained from the AOGCMs simulated using the Special Report on Emission Scenarios (SRES) A2 emissions scenario were utilized for driving the RCMs. As a result, NARCCAP ran six regional climate models (RCMs) driven by four AOGCMs, resulting in 12 GCM-RCM pairings are summarized in Table 4. 
Table 4. GCM-RCM combination simulated in NARCCAP (NARCCAP, 2010).

\begin{tabular}{lll}
\hline $\begin{array}{l}\text { Atmosphere-ocean general } \\
\text { circulation models (AOGCMs) }\end{array}$ & $\begin{array}{l}\text { Regional climate models } \\
\text { (RCMs) }\end{array}$ & GCM-RCM pairing \\
\hline $\begin{array}{l}\text { Community Climate System } \\
\text { Model (CCSM) }\end{array}$ & $\begin{array}{l}\text { The Canadian Regional Climate } \\
\text { Model (CRCM) }\end{array}$ & $\begin{array}{l}\text { CCSM3-CRCM } \\
\text { CCSM3-MM5 } \\
\text { CCSM3-WRF }\end{array}$ \\
$\begin{array}{l}\text { Third Generation Coupled } \\
\text { Global Climate Model } \\
\text { (CGCM3) }\end{array}$ & $\begin{array}{l}\text { The NCAR Mesoscale Model } \\
\text { (MM5) }\end{array}$ & $\begin{array}{l}\text { CGCM3-CRCM } \\
\text { CGCM3-HRM3 }\end{array}$ \\
$\begin{array}{l}\text { The Hadley Centre Coupled } \\
\text { Model version 3 (HadCM3) }\end{array}$ & $\begin{array}{l}\text { The Met Office Hadley Centre's } \\
\text { Regional Climate Model 3 }\end{array}$ & $\begin{array}{l}\text { CGCM3-WRF } \\
\text { (HRM3) }\end{array}$ \\
$\begin{array}{l}\text { The Geophysical Fluid } \\
\text { Dynamics Laboratory GCM } \\
\text { (GFDL) }\end{array}$ & $\begin{array}{l}\text { The Regional Cimate Model, } \\
\text { version 3 (RCM3) }\end{array}$ & $\begin{array}{l}\text { HadCM3-HRM3 } \\
\text { HadCM3-RSM }\end{array}$ \\
& $\begin{array}{l}\text { The Weather Research and } \\
\text { Forecasting Model (WRF) }\end{array}$ & $\begin{array}{l}\text { GFDL-HRM3 } \\
\text { GFDL-RCM3 }\end{array}$ \\
& $\begin{array}{l}\text { The Scripps Experimental } \\
\text { Climate Prediction Center } \\
\text { (ECPC) Regional Spectral }\end{array}$ & \\
& Model (RSM) & \\
& &
\end{tabular}

To generate a future weather file, this research used the output data from the combination of HadCM3 downscaled by HRM3 and forced by SRES A2 emission scenario. The reason for selection of this GCM-RCM combination was due to the fact the CCWorldWeatherGen tool (Section 3.2.1) uses the same GCM (HadCM3) for generating a statistically downscaled future weather file. This allows for a direct comparison of the statistical and dynamical downscaling techniques, as the climate models used are the same. Moreover, the HRM3 compared to other RCMs made available under NARCCAP exhibits a notable warming bias in all seasons and particularly in the winter, especially for central and northern Canada. Therefore, having acknowledged this warming bias, this study decided to choose this model to generate a future weather file for projecting the most warming as result of climate change. This is also consistent with the IPCC's emission scenarios selected throughout this work which lays on the higher end of factors such as economic development, technological development, energy use, population change, and land-use change. 


\subsubsection{Data Extraction}

The RCM output for various climate variables at 3-hour resolution are available in Network Common Data Form (NetCDF) format from NARCCAP archives ${ }^{3}$. Initially, modelled data for the HadCM3-HRM3 in NetCDF format was downloaded for five variables including surface air temperature, surface pressure, surface specific humidity, zonal surface wind speed, and meridional surface wind speed. These variables were selected due to their significance in projecting climate conditions in building energy performance. Figure 10 displays the surface temperature projection from HRM3 for the 2041-2070 period.

\footnotetext{
${ }^{3}$ Data available to download from ESG NARCCAP data catalog in NetCDF format. https://www.earthsystemgrid.org/project/NARCCAP.html
} 

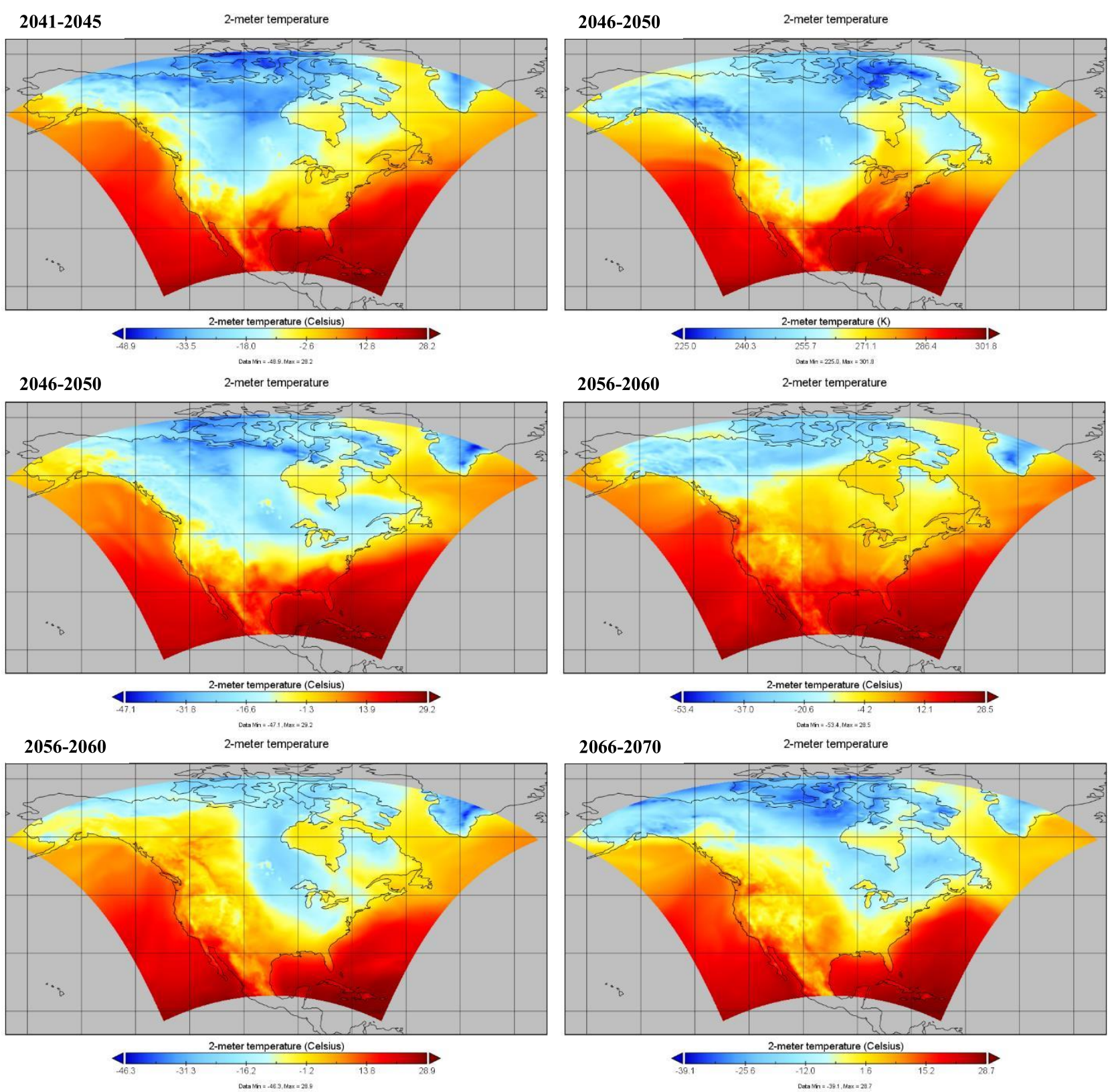

Figure 10. The surface air temperature projection for the 2041-2070 period extracted from the HRM3 (NARCCAP, 2010).

This research study chose to exclude cloud cover and solar radiation data. The limitations to include these parameters in generating a weather file arise from the output data from the NARCCAP for cloud cover and solar radiation of the future climate. The EPW files use both total cloud fraction and opaque cloud fraction as input. While total cloud fraction is the only variable available under NARCCAP, and both variables are directly related, modifying one variable 
without changing the other would be inconsistent. Similarly, the solar radiation in EPW file is divided into global horizontal radiation, direct normal radiation, diffuse horizontal variables. Even though it is possible to apply the effect of climate change to the incoming solar radiation, dividing these changes to the direct and diffuse variables would be arbitrary. For that reason, this study chose to leave cloud cover and solar radiation of the future weather file at their original weather file values.

The weather data that are used in building performance simulations are matrices that include:

1. Time: Its unit is in hour. The weather data downloaded from NARCCAP have been collected in 3 hours time resolution which require changing time-step to hourly data.

2. Air temperature: Its unit is degree Celsius. NARCCAP data is provided in Kelvin which requires conversion to Celsius. The air temperature values in Celsius are rounded to one decimal place.

3. Relative humidity: Its unit is percent. Relative humidity is not directly available from the HRM3 output data and needs to be calculated.

4. Atmospheric pressure: Its unit is Pascal. The atmospheric pressure is provided directly by the HRM3 output.

5. Extraterrestrial horizontal radiation, extraterrestrial direct normal radiation, horizontal infrared radiation intensity, global horizontal radiation, direct normal radiation, and diffuse horizontal radiation. Their units are $\mathrm{Wh} / \mathrm{m}^{2}$. As stated, these matrices are not directly available from HRM3 output and due to limited information available and cannot be calculated. These matrices for the future weather file are placed at their original weather file values.

6. Wind direction: Its unit is degrees. The wind direction is not directly available from HRM3 and needs to be calculated for building performance simulation. 
7. Wind speed: Its unit is in $\mathrm{m} / \mathrm{sec}$. The wind speed output from HRM3 is given as the zonal surface wind speed and meridional surface wind speed which needs to be changed for building performance simulation.

8. Total sky cover and opaque sky cover. Their units are in tenths of coverage-amount of sky dome in tenths covered by clouds. These matrices are not directly available from HRM3 output and due to limited information available and cannot be calculated.

It should be noted that OpenStudio, which uses the EnergyPlus dynamic simulation engine for simulations, is not capable of using other variables present in a TMY weather file, such as: global horizontal; direct normal illuminance; diffuse horizontal illuminance; zenith luminance; precipitation; aerosol depth; snow depth; and days since last snow fall. Therefore, the values for these variables can be set as 999999 , representing missing values, and will not affect the final results of the simulation.

Extraction, correction and conversion of HRM3 data from NARCCAP to the appropriate input data for building performance simulation was done by Microsoft Excel and coding in Python. This was done in four phases:

1. Extracting the five variables downloaded in a NetCDF format corresponding to the grid point closest to the latitude and longitude of the weather station for that GTA location using Python (Appendix A);

2. Correction of HRM3 output for periods of 1970-2000 and 2041-2070 due to HRM3 simulation assumption that each month is 30 days. In this case, the HRM3 output for each of the five variable overlooks the $31^{\text {st }}$ day of January, March, May, July, August, October and December. In addition, the HRM3 models 30 days for February, adding two extra days and ignoring the leap years. Accordingly, special attention was given to data organization in adding an extra day or eliminating the additional day/days from February in the HRM3 data;

3. The HRM3 output for the five climate variables at 3-hour resolution require changing time-step to hourly data for building performance simulation. Linear interpolation was applied to 3-hourly data, generating hourly weather data for the periods of 1970-2000 and 2041-2070 (Appendix B). Linear interpolation was selected due to its simplicity in 
calculating the missing hourly weather data. A comparison of other interpolation methods (e.g., Cubic spline and Polynomial) is illustrated in Appendix C;

4. The proper parameters used for building performance simulation such as relative humidity, dew-point temperature, wind speed, and wind direction that are not directly available from the HRM3 output data were calculated. The following procedures were used to find relative humidity, dew-point temperature as well as wind speed and direction from values made available by HRM3 variables. All equations used in this section, unless otherwise noted, is from Straube and Burnett (2005).

A. Relative Humidity $(\varnothing)$ is the ratio of partial water vapor pressure $\left(\mathrm{P}_{\mathrm{v}}\right)$ to the saturation vapor pressure $\left(\mathrm{P}_{\mathrm{v}, \mathrm{sat}}\right)$ at the same mixture temperature and pressure.

$$
\varnothing=\frac{P_{v}}{P_{v, s a t}}
$$

Saturation vapor pressure $\left(\mathrm{P}_{\mathrm{v}, \mathrm{sat}}\right)$ is calculated using:

$$
P_{v, \text { sat }}=1000 \cdot e^{\left(52.58-\frac{6790.5}{T}-5.028 \cdot \ln T\right)} \quad(\mathrm{k}, \mathrm{Pa})
$$

Mixing Ratio, W (also known as, moisture content or humidity ratio) is ratio of the mass of water vapor $\left(m_{\text {water vapor }}\right)$ to the mass of dry air $\left(m_{\text {dry air }}\right)$.

$$
\begin{gathered}
W=\frac{m_{\text {vapor }}}{m_{\text {air }}}=0.622\left(\frac{P_{v}}{P_{\text {total }}}\right) \quad(\mathrm{kg} / \mathrm{kg}, \mathrm{Pa}) \\
W=0.622\left(\frac{P}{P_{\text {air }}+P_{v}}\right)
\end{gathered}
$$

Where, 0.622 is the ratio of gas constants for dry air to that for water vapor.

By rearranging equation 3.3,

$$
P_{v}=\frac{P_{\text {Total }}}{\frac{0.622}{W}+1}
$$

Solving for equations 3.2 and 3.3 partial water vapor pressure $\left(\mathrm{P}_{\mathrm{v}}\right)$ and the saturation vapor pressure $\left(\mathrm{P}_{\mathrm{v}, \mathrm{sat}}\right)$ were calculated. As a result, relative humidity was then calculated from equation 3.1 . 
B. Dew-point temperatures $\left(t_{d}\right)$ were calculated using the following equation, having calculated the partial water vapor pressure $\left(\mathrm{P}_{\mathrm{v}}\right)$ from equation 3.3.

$$
t_{d}=\frac{4030}{18.689-\ln \left(\frac{P_{w}}{133}\right)}-235 \quad\left({ }^{\circ} \mathrm{C}, \mathrm{Pa}\right) \quad \text { Eq. } 3.4
$$

C. Wind speeds were calculated using the square root of the sum of the squares, given the zonal surface wind speed (u), and meridional surface wind speed (v).

$$
\text { Wind Speed }=\sqrt{u^{2}+v^{2}}
$$

It is worth noting that the speed data provided by HRM3 consists of two elements of the speed vector. The zonal surface wind speed $(\mathrm{u})$ has a vector in the horizontal direction that is a WestEast/East-west direction. The meridional surface wind (v), on the other hand, has a vector in the vertical direction that is from South-North/North-South direction.

D. Wind directions were calculated using the arctangent of the angle between two velocity elements ( $\mathrm{u}$ and $\mathrm{v}$ ). However, when $\mathrm{u}$ is zero, the arctan function is unable to calculate wind direction values. In addition, for each calculation based on the sign of $u$ and $v$ there is a need for adjustment for which quadrant the elements fall-in. As a result, using Microsoft Excel, atan2 function resolves the issues associated with the arctan. The Microsoft Excel function created and used for the calculation of wind directions is as follow:

Wind Direction = DEGREES(ATAN2(Meridional Surface Wind " $v "$, Zonal Wind Speed " $u$ ")

In order to adjust the wind direction to the proper angel for weather data, 360 degrees is added to the results.

\subsubsection{Evaluation of Model Performance}

There are three main uncertainties associated with the future climate projection: natural variability of the climate, future GHG emissions and aerosols, and the climate systems response to the changes in emission levels. However, in recent years, the increase in the application of regional climate models at higher resolution has introduced additional uncertainties. As a result, 
the present study used the back-casting technique to evaluate the ability of HRM3 to reproduce accurate climate data.

The dry bulb variables from HRM3 output for the period of 1971-2000 at 3-hour resolution were compared with the actual observed weather data from the GTA weather stations of the same period. To compare the model data with observed weather station data, the HRM3 output were converted from Greenwich Mean Time (GMT) time zone to the local time zone (GMT-5). Next, the mean absolute deviation (MAD), the mean-square error (MSE), the root-mean-square error (RMSE), and the mean absolute percentage error (MAPE) was calculated for the period of 19712000 (Appendix D). The results show that the model performance evaluation for the HRM3 data for Toronto were in compliance with the NARCCAP assessment of HRM3 climate model (Mearns et al., 2012). According to Mearns et al., (2012), the root-mean-square error (RMSEs) for seasonal temperature of the HRM3 was in the range of 3-6 which was similar to RMSEs calculated for the extracted temperature values for the city of Toronto. It is worth noting that the biases and RMSEs present in HRM3 are within the range found in many other regional climate models (Mearns et al., 2012).

\subsubsection{Calculation of projected climate change}

To quantify the magnitude of climate change for each weather variable from the coupled HadCM3-HRM3 model, two main approaches were used. Initially, the difference between the 2041-2070 values and 1971-2000 values were calculated for the interpolated hourly values. In other words, the 1971-2000 values for all variables are subtracted from 2041-2070 values. The difference between these two data were averaged over the 30 -year period for each individual month and added to each of the original CWEC files to produce a future typical meteorological year. Here, the morphing technique similar to that used by Belcher et al. (2005), was used to "shift" the climatic variables in the present-day recorded weather data (CWEC files) to produce new weather data that illustrate the average projected climate change in the future. Every variable was "shifted" by $\left(\Delta \mathrm{X}_{\mathrm{m}}\right)$, simply adding the projected change to the original CWEC value $\left(\mathrm{X}_{0}\right)$, as shown in equation 3.6.

$$
X=X_{0}+\Delta X_{m}
$$


In the second approach, the hourly averages of every single month for the 2041-2070 period were calculated for all variables (e.g., dry bulb, dew point, relative humidity, pressure, wind speed and direction). For instance, the $12^{\text {th }}$ hour of all Januarys from 2041-2070 were averaged, giving a single value for that hour of January. This was done for each hour of every month for the 30 -year period for the entire data set. In that case, the results were an averaged 30-year data set which created a 12-month weather data. The values of each variable calculated using this approach for all 12 months were then directly used to replace the values of dry bulb, dew point, relative humidity, pressure, wind speed and direction original CWEC weather files. This allows for the selection of different periods $(5,10,20$ years) for calculating of all monthly variable averages. However, using this technique, the natural daily/hourly variability of the climate typically present for each variable is lost.

As previously discussed, after months of communications and meeting with ARCADIS Consultants and the city of Toronto, the author of this study was unable to obtain the hourly weather climate projections on a $1 \mathrm{x} 1 \mathrm{~km}$ output grid across the Greater Toronto Area (GTA) for the years 2041 to 2049 .

\subsection{Building Performance Simulation}

For the purpose of the present research, building performance simulations using the OpenStudio 2.8.0 was carried out for the future climate of Toronto. The OpenStudio package contains the EnergyPlus program which is used as a dynamic simulation engine for generating simulation data. The OpenStudio software allows the user to work with pre-designed reference building models developed by the United States Department of Energy (DOE) (Field et al., 2010). These models are in compliance with ASHRAE 90.1-2013 standards and consist of 16 buildings with various dimensions and operations. The description for the 16 building prototype can be found in Appendix E. Figure 11 displays the rendering of the building models used in the OpenStudio software. Simulting 16 different buildings allow for the better understanding of which building types will be most affects by climate change. The results will also offer a reference point for various building types in Toronto as well as provide a much higher value on the importance of using future weather file for building energy simulation. 


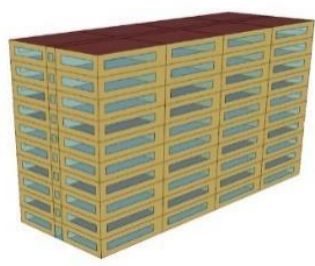

High-rise Apartment

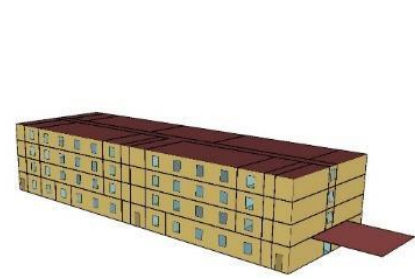

Small Hotel

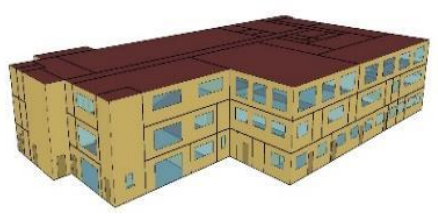

Outpatient HealthCare

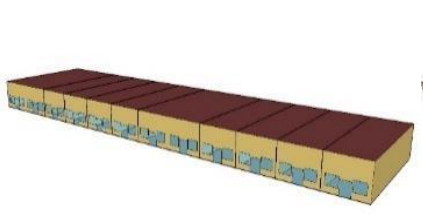

Strip mall Retail

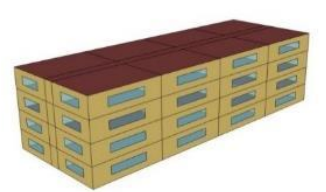

Mid-rise Apartment

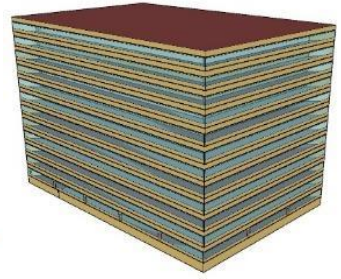

Large Office

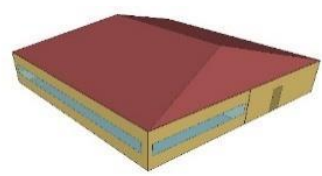

Fast food Restaurant

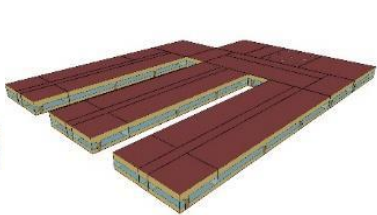

Primary School

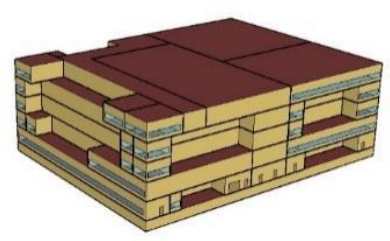

Hospital

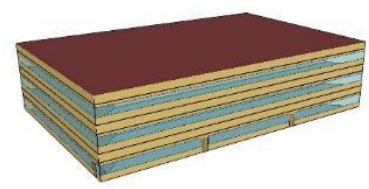

Medium Office

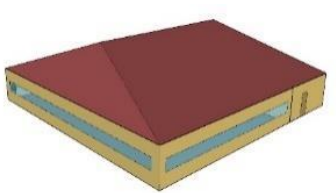

Sit-down Restaurant

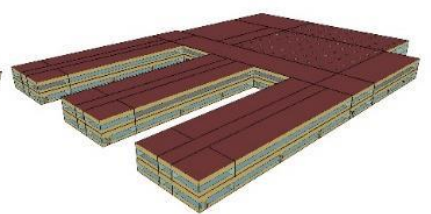

Secondary School

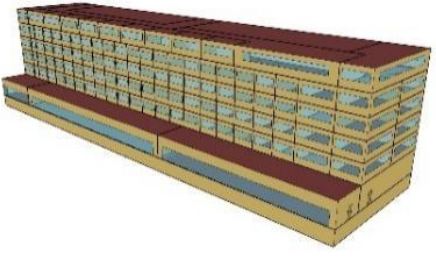

Large Hotel

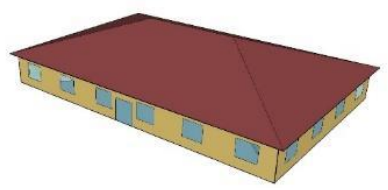

Small Office

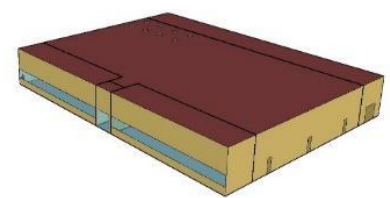

Standalone Retail

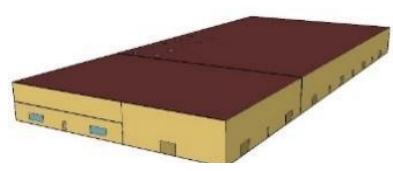

Warehouse

Figure 11. Prototype building models from the ASHRAE 90.1-2013 standards.

These building models are a relatively realistic representation of buildings and typical construction practices. They represent approximately $80 \%$ of the commercial building stock in the United States (DOE, 2018). In addition, as part of as representative of key building types within the scope of ASHRAE 90.1 and the commercial building energy codes, two residential prototype buildings (high-rise and mid-rise apartments) are also included in the pre-designed reference building models developed by the DOE. These building models provide a reference point to assess the impact of climate change on energy demand of different types of buildings according to Toronto's climate condition.

The technical descriptions for each of the building envelope components for the selected prototype building models are presented in Table 5. For the 16 prototype building models the roof 
U-factor is between $0.18\left(\mathrm{~W} /\left(\mathrm{m}^{2} \mathrm{~K}\right)\right)$ for typical insulation entirely above deck (IEAD) roofs and $0.15\left(\mathrm{~W} /\left(\mathrm{m}^{2} \mathrm{~K}\right)\right)$ for attic roofs ${ }^{4}$ with wood joist. Wall U-factor varies from 0.31 to $0.51\left(\mathrm{~W} /\left(\mathrm{m}^{2}\right.\right.$ $\mathrm{K})$ ) depending on wall type.

ASHRAE 90.1-2013 defines the U-factor (transmittance) as:

"the heat transmission in unit time through unit area of a material construction and the boundary air films, induced by unit temperature difference between the environments on each side" (ASHRAE, 2013),

and further defines the solar heat gain coefficient (SHGC) as:

"the ratio of the solar gain entering the space through fenestration area to the incident solar radiation" (ASHRAE, 2013).

The objective of this research is to assess the impacts of climate change on future buildings energy use under the assumption that no technological advancement takes place in buildings. Excluding technological advancement provides the opportunity to better understand how existing buildings will react to climate change, eliminating the uncertainties regarding improvements in the building characteristics that influence cooling, heating, and equipment electricity use. The results could then provide the opportunity to study what types of technological advancement would be feasible in the future.

\footnotetext{
${ }^{4}$ The small office as well as the fast food and sit-down restaurants have attics.
} 
Table 5. Building envelope components of pre-designed reference building models.

$$
\text { U-factor }\left(\mathrm{W} /\left(\mathrm{m}^{2} \mathrm{~K}\right)\right)
$$

Solar Heat Gain

Coefficient (SHGC)

Building Typology

\begin{tabular}{|c|c|c|c|c|c|c|c|}
\hline & & Roof & External & Glazing & & Glazing & \\
\hline & & & & Window & Skylight & Window & Skylight \\
\hline Apartment & High-rise & 0.18 & 0.31 & 2.65 & & 0.43 & \\
\hline & Mid-rise & 0.18 & 0.31 & 2.65 & & 0.43 & \\
\hline Hotel & Large & 0.18 & 0.45 & 2.65 & & 0.43 & \\
\hline & & & 0.51 & & & & \\
\hline & Small & 0.18 & 0.31 & 2.65 & & 0.43 & \\
\hline & & & & 2.85 & & 0.29 & \\
\hline Office & Large & 0.18 & 0.51 & 2.65 & & 0.43 & \\
\hline & Medium & 0.18 & 0.31 & 2.65 & & 0.43 & \\
\hline & Small & 0.15 & 0.29 & 2.65 & & 0.43 & \\
\hline Health & Hospital & 0.18 & 0.45 & 2.65 & & 0.43 & \\
\hline & & & 0.51 & & & & \\
\hline & Outpatient & 0.18 & 0.31 & 2.65 & & 0.43 & \\
\hline Restaurant & Fast food & 0.15 & 0.29 & 2.65 & & 0.43 & \\
\hline & Sit-down & 0.15 & 0.31 & 2.65 & & 0.43 & \\
\hline Retail & Stand-alone & 0.18 & 0.51 & 2.65 & 2.96 & 0.43 & 0.34 \\
\hline & Strip-mall & 0.18 & 0.31 & 2.65 & & 0.43 & \\
\hline School & Primary & 0.18 & 0.31 & 2.65 & & 0.43 & \\
\hline & Secondary & 0.18 & 0.31 & 2.65 & 2.96 & 0.43 & 0.34 \\
\hline Warehouse & & 0.21 & 0.28 & 2.65 & 2.96 & 0.43 & 0.34 \\
\hline & & 0.53 & 0.47 & & & & \\
\hline
\end{tabular}




\subsubsection{Summary of Inputs and Assumptions}

Initially, the pre-designed reference building models were imported to OpenStudio from the building component library. The shape, total area, floor height, and HVAC system type for each building were determined from the 1999 and 2003 Commercial Buildings Energy Consumption Survey (CBECS) dataset (EIA 2002, 2005) as well as previous studies of the existing building stock (as cited in Field et al., 2010) (see Appendix E). Similar to the weather files, the prototype building models change across various locations. As a result, the design and construction of the buildings are modified according to the location as well as applicable codes and practices. The 16 prototype building models used in this study were selected to be in compliance with ASHRAE 90.1-2013 standards and climate zone 5A that is defined as Cool - Humid, similar to the city of Toronto. Moreover, the HVAC sizing calculations to meet peak cooling and heating loads in OpenStudio are based on the "Design Days" weather data. As a result, to allow for climate change impact assessment, the design day used for autosizing HVAC equipment was kept the same for all building types. Using one identical design day for all buildings enables true quantification of building energy demand, highlighting the variation between historical and future weather files. The design day climate data summary for sizing HVAC equipment is based on the 1959-1989 weather file and is presented in Table 6. For cooling systems, dry-bulb at maximum wet-bulb $(\mathrm{DB}=>\mathrm{MWB})$ design day is used for chillers and air conditioners sizing calculation. Dewpoint at maximum dry-bulb ( $\mathrm{DP}=>\mathrm{MDB}$ ) is useful for humidity control application, such as desiccant cooling systems, cooling-based dehumidification, and fresh air ventilation systems. Enthalpy at maximum dry-bulb (ENTH=>MDB) is applied in cooling load calculation caused by infiltration and ventilation into buildings. The wet-bulb at maximum dry-bulb (WB=>MDB) design day is useful in cooling towers and evaporative coolers. For heating systems, dry-bulb (DB) is used for general heating applications. The dewpoint at mean coincident dry bulb ( $\mathrm{DP}=>\mathrm{MCDB}$ ) purpose is to size equipment for humification use. Wind speed at mean coincident dry bulb (WS=>MCDB) is used for assessing peak loads and accounting for infiltration. Further information on materials comprising the envelope of the 16 building models as well as detailed internal loads and schedules can be found in Appendix F. 
Table 6. The design day climate data for building simulation performance.

\begin{tabular}{|c|c|c|c|c|c|c|}
\hline & $\begin{array}{l}\text { Maximum } \\
\text { Dry Bulb } \\
\left({ }^{\circ} \mathrm{C}\right)\end{array}$ & $\begin{array}{l}\text { Daily } \\
\text { Temperature } \\
\text { Range }\left(\Delta^{\circ} \mathrm{C}\right)\end{array}$ & $\begin{array}{l}\text { Humidity } \\
\text { Value }\end{array}$ & $\begin{array}{l}\text { Humidity } \\
\text { Type }\end{array}$ & $\begin{array}{l}\text { Wind } \\
\text { Speed } \\
(\mathrm{m} / \mathrm{s})\end{array}$ & $\begin{array}{l}\text { Wind } \\
\text { Direction } \\
\text { (Degrees) }\end{array}$ \\
\hline $\begin{array}{l}\text { TORONTO } \\
\text { PEARSON INTL } \\
\text { AP ANN CLG } \\
.4 \% \text { CONDNS } \\
\text { DB=>MWB }\end{array}$ & 31.40 & 9.90 & 22.40 & $\begin{array}{l}\text { Wetbulb } \\
\left({ }^{\circ} \mathrm{C}\right)\end{array}$ & 5.80 & 270.00 \\
\hline $\begin{array}{l}\text { TORONTO } \\
\text { PEARSON INTL } \\
\text { AP ANN CLG } \\
.4 \% \text { CONDNS } \\
\text { DP=>MDB }\end{array}$ & 26.70 & 9.90 & 22.10 & $\begin{array}{l}\text { Dewpoint } \\
\left({ }^{\circ} \mathrm{C}\right)\end{array}$ & 5.80 & 270.00 \\
\hline $\begin{array}{l}\text { TORONTO } \\
\text { PEARSON INTL } \\
\text { AP ANN CLG } \\
.4 \% \text { CONDNS } \\
\text { ENTH=>MDB }\end{array}$ & 29.20 & 9.90 & 71900.00 & $\begin{array}{l}\text { Enthalpy } \\
(\mathrm{J} / \mathrm{kg})\end{array}$ & 5.80 & 270.00 \\
\hline $\begin{array}{l}\text { TORONTO } \\
\text { PEARSON INTL } \\
\text { AP ANN CLG } \\
.4 \% \text { CONDNS } \\
\text { WB=>MDB }\end{array}$ & 29.10 & 9.90 & 23.70 & $\begin{array}{l}\text { Wetbulb } \\
\left({ }^{\circ} \mathrm{C}\right)\end{array}$ & 5.80 & 270.00 \\
\hline $\begin{array}{l}\text { TORONTO } \\
\text { PEARSON INTL } \\
\text { AP ANN HTG } \\
99.6 \% \text { CONDNS } \\
\text { DB }\end{array}$ & -18.10 & 0.00 & -18.10 & $\begin{array}{l}\text { Drybulb } \\
\left({ }^{\circ} \mathrm{C}\right)\end{array}$ & 4.80 & 0.00 \\
\hline $\begin{array}{l}\text { TORONTO } \\
\text { PEARSON INTL } \\
\text { AP ANN HTG } \\
\text { WIND } 99.6 \% \\
\text { CONDNS } \\
\text { WS=>MCDB }\end{array}$ & -4.70 & 0.00 & -4.70 & $\begin{array}{l}\text { Wetbulb } \\
\left({ }^{\circ} \mathrm{C}\right)\end{array}$ & 14.20 & 0.00 \\
\hline $\begin{array}{l}\text { TORONTO } \\
\text { PEARSON INTL } \\
\text { AP ANN } \\
\text { HUM_N } 99.6 \% \\
\text { CONDNS } \\
\text { DP=>MCDB }\end{array}$ & -17.60 & 0.00 & -23.30 & $\begin{array}{l}\text { Dewpoint } \\
\left({ }^{\circ} \mathrm{C}\right)\end{array}$ & 4.80 & 0.00 \\
\hline
\end{tabular}


Finally, the outdoor climate data which have been introduced as the weather files at the beginning of this chapter are applied to the 16 prototype building models to simulate the building performance under future climate conditions. Both the current and future weather files generated in this study were used as input for the building performance simulation. A total of eight weather files (two historical and six future) were used. To investigate the impacts of climate change on building energy demand, each of the building models were simulated using the eight weather files, which resulted in a total of 128 simulations. The structure of the simulation runs is illustrated in Figure 12.

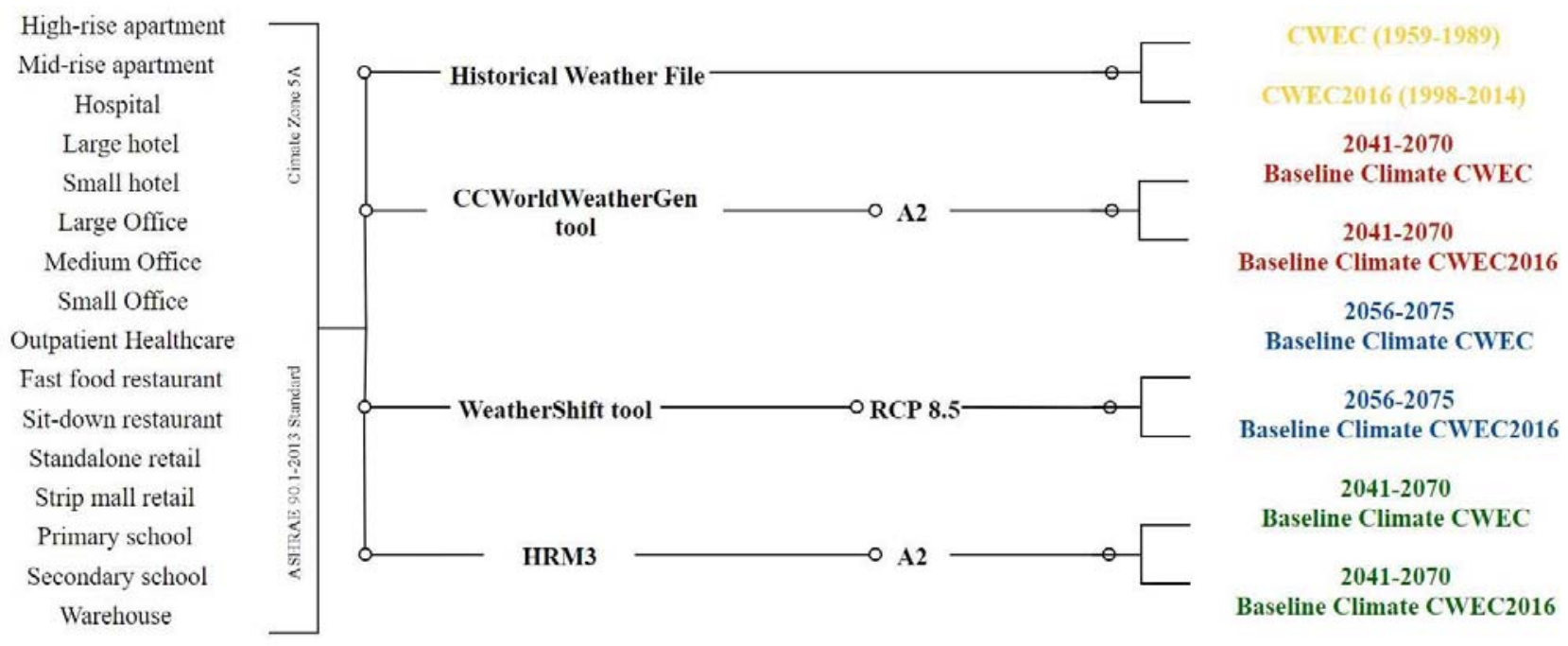

Figure 12. Configuration of simulation runs of 16 building prototype models used in this study under the historical and future weather files.

An overabundance of information is available within the OpenStudio output. Since the present research is mostly focused on the projection of climate change and their impacts on building energy demand, the emphasis will be on changes in heating and cooling energy consumption as well as thermal comfort. Chapter 4 presents the results of the weather file generation as well the impacts of climate change on building performance. 


\subsection{Limitations}

This work faced several limitations both in future weather file generation as well as building performance simulation. Initially, this study found that the CWEC and CN2014 weather files have zero extraterrestrial horizontal radiation for multiple hours during the day, while for the same hours there were values present for global horizontal radiation. It is hypothesized that these issues result from solar values given based on "solar time convention" rather than "local standard time convention". The only weather file exempt from this issue was CWEC2016. The CWEC files have been most commonly used for building energy simulation in Canada. As a result, it is recommended that the users check the quality of the input weather files used for building energy simulation specially in the case CWEC file for the city of Toronto. Secondly, this study was limited to the Toronto Pearson International Airport weather file due to the limitation in availability of historically recorded weather data as well as their compatibility with building performance simulation for other locations in Toronto.

Regarding climate models, North America lacks not only in the number of models accessible but also in spatial and temporal resolution for which these models can forecast future climate scenarios. Subsequently, this makes it much harder to focus on impacts of climate change at the local level where finer spatial resolution presents a more reliable representation of the regional boundary conditions. In addition, due to the limitations of output data availability from the NARCCAP regional model for cloud cover and solar radiation, the cloud cover and solar radiation of the future weather file were left at their original weather file values. It is also worth noting that the accurate representation of climate change is challenging, and the method described in this chapter regarding the evaluation of NARCCAP model performance does not entirely makes up for the quality of HRM3 and its sources of uncertainties. For instance, several uncertainties arise from the projected regional climate change itself that include uncertainty in GCM projection, downscaling a GCM using different RCMs, emissions scenario and aerosol radiative forcing, or different initial conditions that presented to the climate model. Therefore, making it impossible to accurately project future climate conditions using a single model or method.

This research was unable to perform the building performance simulation using EnergyPlus

directly, as the prototype building models developed by the United States DOE produced "severe errors" when simulated. These issues are believed to be due to the lack of update for the DOE 
building prototypes, making it imposible for EnergyPlus to autosize operating systems that are not feasible with the current ASHRAE standards. Alternatively, the OpenStudio software which contained the EnergyPlus program was used as a dynamic simulation engine for building performance simulation. The findings of this paper also determined that the 16 prototype building models available from OpenStudio library require upgrades in order to function properly with the newer versions of software. More specially, in the case of autosizing the HVAC systems based on the given design days, some of the functions were unavailable for the building models. Besides, as the results showed (see Section 4.2.4), for the hospital and large hotel building model simulation output indicated several problems for different zones. 


\section{Chapter 4: Results and Discussion}

This chapter is divided to two main parts. The first part illustrates the results of future weather file generation. It begins with the presentation of each weather file and the distribution of values for the hourly dry-bulb temperature. The second part consists of providing the simulation results on the impact study of climate change on building energy demand. The simulation output for each of the 16 prototype building models is presented, allowing for quantification of building heating and cooling energy use and GHG emission in the future.

\subsection{Weather Files Characteristics}

The EPW weather files contain hourly values for several weather variables that are directly used in building performance simulation. The six future weather files generated in this study as well as the two historical weather files contain weather variables such as dry-bulb temperature, dew-point temperature, solar radiation, wind speed and direction. These variables contain information on the effects of climate change. Figure 13 displays the hourly dry-bulb temperatures for the two historical weather files with different baseline climate.

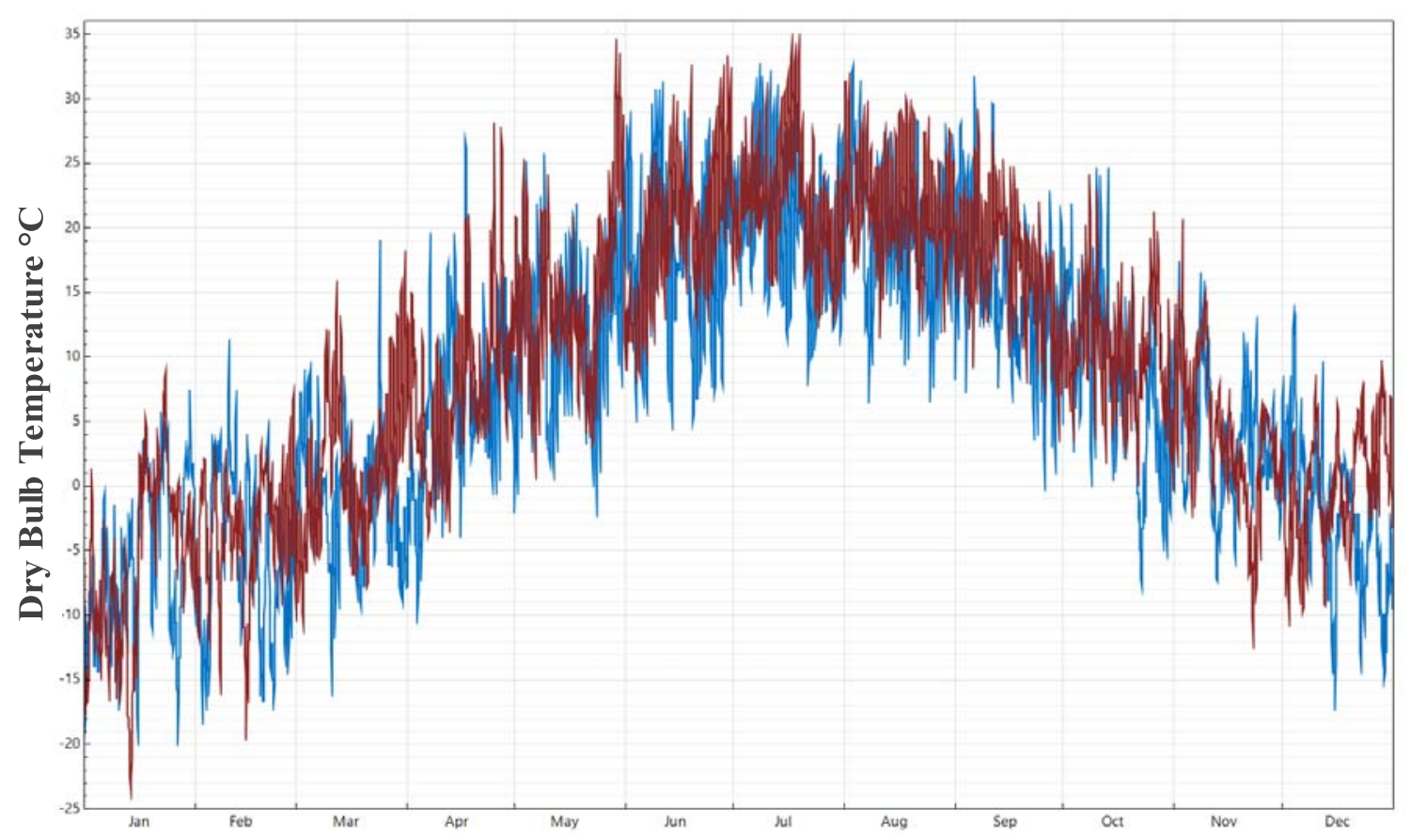

Figure 13. The hourly dry-bulb temperature for CWEC (blue) and CWEC2016 (red) historical weather files. The values are from 1959-1989 and 1998-2014 baseline climate. 
The dry-bulb temperatures of the two historical weather files indicate higher temperature values for the CWEC2016 (1998-2014 years) compared to the more historical CWEC (1959-1989 years). Moreover, according to the weather data summary in Appendix G, the average monthly values for the 12 months, except for January and November, is higher in CWEC2016 compared to CWEC weather file.

Heating and cooling degree days are commonly used indicators of energy demands for heating and cooling in buildings (CIBSE, 2006). In this thesis, HDDs reflect the number of degrees that a day's average temperature is below $18.3^{\circ} \mathrm{C}$. Table 7 shows the historically recorded annual HDDs for the CWEC and CWEC2016 weather files and their future projections. A clear warming trend is seen between the CWEC and CWEC2016 time period, and besides, the HDDs in the historically recoded data range are significantly lower in comparison to the future weather files data. The pattern seen here indicates that HDDs are decreasing and CDDs are increasing as a result of climate change. The resulting heating degree days are compatible with RWDI's assumption that Toronto's Climate Zone has seen a shift from Climate Zone 6 to Climate Zone 5 since the 1990s (Williams and Harmer, 2017). Furthermore, as an example, the climate change projections for HRM3 show an additional shift toward Climate Zone 4 in the future (Figure 14). The results demonstrate the need to modify and adapt building code guidelines as well as existing building modelling regulations such as those seen in TGS Version 3 to plan future buildings according to the future climate.

Table 7. Heating degree day (HDD), base $18.3^{\circ} \mathrm{C}$, for Toronto weather files.

\begin{tabular}{ll}
\hline Weather Files & HDD \\
\hline CWEC (1959-1989) & 4,179 \\
CCWorldWeatherGen tool & 3,427 \\
$\begin{array}{l}\text { (1959-1989) } \\
\text { WeatherShift tool }\end{array}$ & 3,157 \\
$\begin{array}{l}\text { (1959-1989) } \\
\text { HRM3 (1959-1989) }\end{array}$ & 3,509 \\
& \\
CWEC2016 (1998-2014) & 3,695 \\
CCWorldWeatherGen tool & 3,033 \\
$\begin{array}{l}\text { (1998-2014) } \\
\text { WeatherShift tool }\end{array}$ & 2,769 \\
(1998-2014) & \\
HRM3 (1998-2014) & 3,122 \\
\hline
\end{tabular}




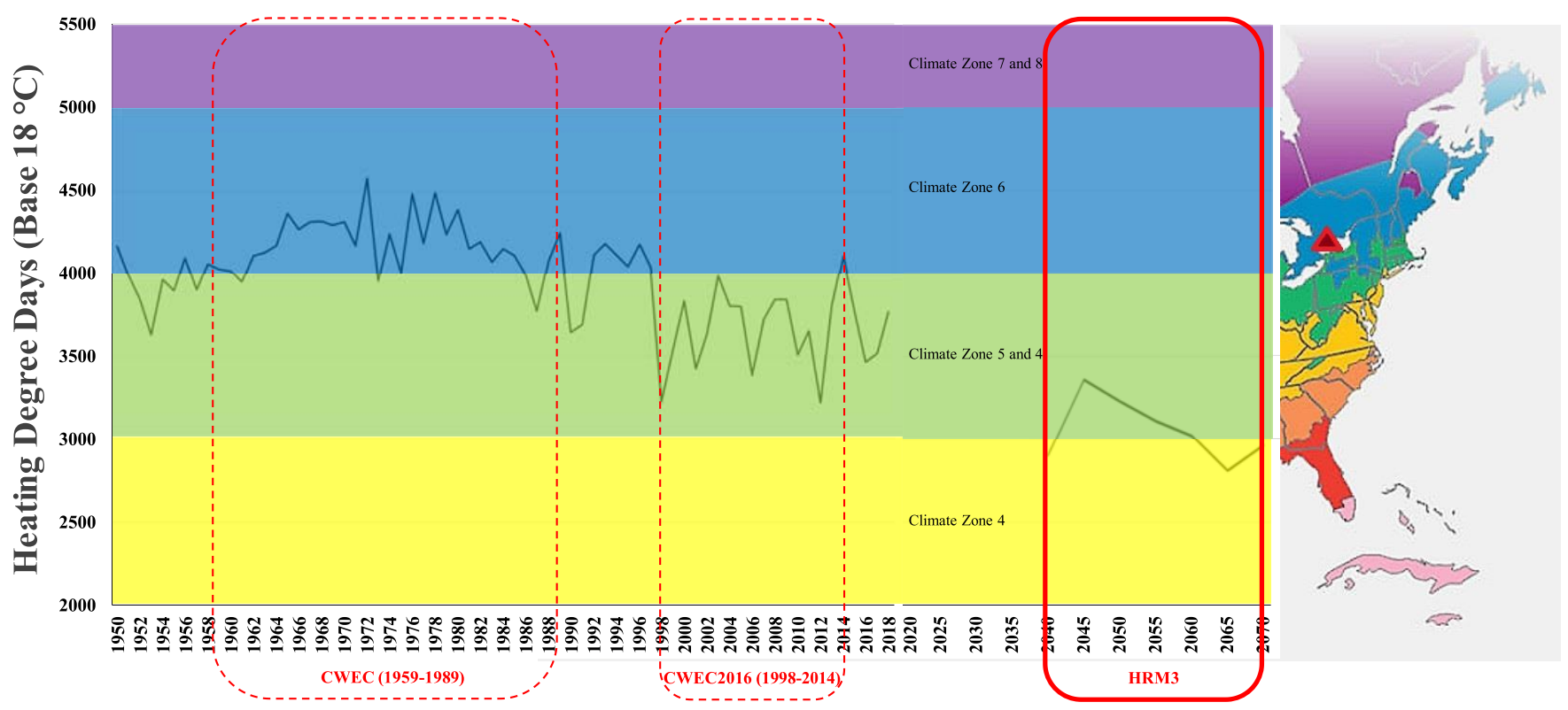

Figure 14. Climate change projections for HRM3 show an additional shift toward Climate Zone 4 in the future, in terms of HDDs (Base $18^{\circ} \mathrm{C}$ ).

Figures 15 displays the boxplot for the annual outdoor dry-bulb temperatures based on the future weather files generated using statistical and dynamical downscaling techniques according to the two historical baseline climates. They display the distribution of data based on the minimum, first quartile $\left(25^{\text {th }}\right.$ percentile), median, third quartile $\left(75^{\text {th }}\right.$ percentile), and maximum temperature values of each weather file. For the sake of harmonization, all graphs use yellow for historical weather files (both CWEC and CWEC2016), red for CCWorldWeatherGen tool's future weather files, blue for WeatherShift tool's future weather files, and green for the future weather files generated dynamically using HRM3. The future weather files project an average temperature increase of $3.7-4.5^{\circ} \mathrm{C}$ for the $2050 \mathrm{~s}$. These projections are slightly higher than the IPCC global mean surface temperature increase for the same period. 


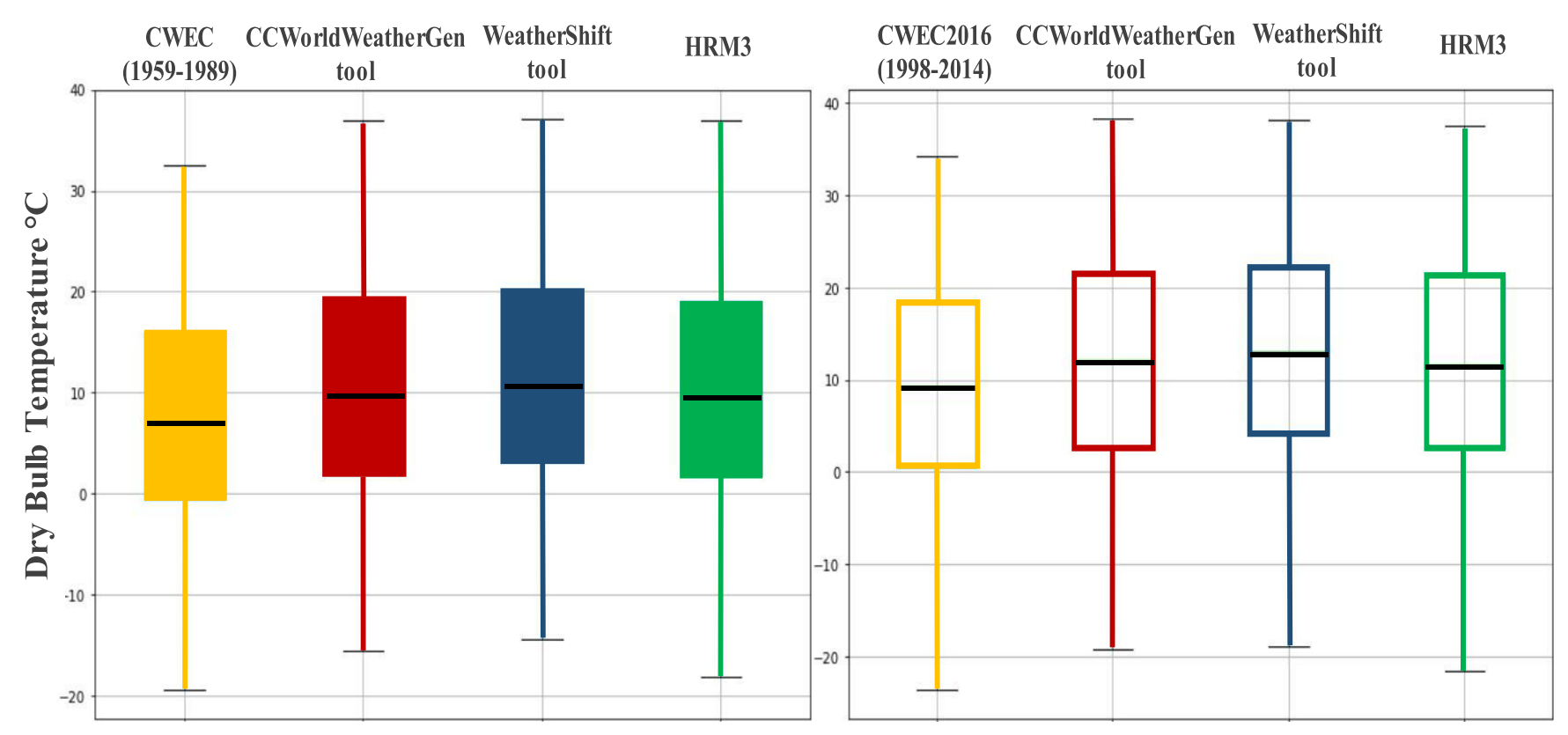

Figure 15. The boxplots present the outdoor dry-bulb temperature values for the historical weather file of CWEC (solid color) and CWEC2016 (hollow color), in addition to the three future weather files generated.

\subsubsection{CCWorldWeatherGen Tool's Future Weather Files}

The future weather file generated using CCWorldWeatherGen tool based on the CWEC baseline climate has a maximum dry-bulb value of $36.9^{\circ} \mathrm{C}$ and minimum dry-bulb value of $-15.5^{\circ} \mathrm{C}$ (Figure 15). Relative to the initial conditions of the 1959-1989 baseline, the maximum temperature increased from $32.5^{\circ} \mathrm{C}$ to $36.9^{\circ} \mathrm{C}$ and the minimum temperature increased from $-19.4^{\circ} \mathrm{C}$ to $-15.5^{\circ} \mathrm{C}$.

Furthermore, for CWEC2014 baseline climate, the maximum temperature of the future weather file generated using CCWorldWeatherGen tool is $38.4^{\circ} \mathrm{C}$ and the minimum temperature is $-19.2^{\circ} \mathrm{C}$. Relative to the initial conditions of the $1998-2014$ baseline, the maximum and minimum temperatures have increased by $4.1^{\circ} \mathrm{C}$ and $4.4^{\circ} \mathrm{C}$ respectively.

\subsubsection{WeatherShift Tool's Future Weather Files}

Regarding WeatherShift tool, Figure 15 presents a maximum dry-bulb value of $37.1^{\circ} \mathrm{C}$ and a minimum dry-bulb value of $-14.4^{\circ} \mathrm{C}$ for the future weather file generated using CWEC baseline climate. The maximum temperature is shown to increase by $4.6^{\circ} \mathrm{C}$ and minimum temperature by $5.0^{\circ} \mathrm{C}$ relative to the historical $1959-1989$ baseline. 
On the other hand, for the 1998-2014 baseline climate, the maximum and minimum values generated by the WeatherShift tool are $38.2^{\circ} \mathrm{C}$ and $-18.9^{\circ} \mathrm{C}$. The maximum temperature for the future weather file increased by $3.9^{\circ} \mathrm{C}$, from $34.3^{\circ} \mathrm{C}$ to $38.2^{\circ} \mathrm{C}$. The minimum temperature increased by $4.7^{\circ} \mathrm{C}$, from $-23.6^{\circ} \mathrm{C}$ to $-18.9^{\circ} \mathrm{C}$.

\subsubsection{HRM3 Future Weather Files}

The future weather file generated using dynamical downscaling display temperatures with a maximum dry-bulb value of $37^{\circ} \mathrm{C}$ and minimum dry-bulb value of $-18.1^{\circ} \mathrm{C}$. Compared to the 1959-1989 baseline climate, the maximum temperatures have increased by $4.5^{\circ} \mathrm{C}$ and the minimum temperatures by $0.9^{\circ} \mathrm{C}$ in the future.

The maximum and minimum dry-bulb temperature generated by HRM3 for the 1998-2014 baseline climate are $37.5^{\circ} \mathrm{C}$ and $-21.6^{\circ} \mathrm{C}$. Comparing the $1998-2014$ baseline climate to the future weather file shows an increase of $3.2^{\circ} \mathrm{C}$ for the maximum temperature as well as a decrease of $2^{\circ} \mathrm{C}$ for the minimum temperature in the future.

Table 8 was generated for each weather file to present the number of hours that the dry bulb temperatures were above $30^{\circ} \mathrm{C}$ and below $-10^{\circ} \mathrm{C}$. Weather files consist of 8760 hourly values for a typical year. Thus, the calculated percentages offer a measure for the number of hours extreme temperatures are present in each weather file. As illustrated, for both baseline years, the number of hours that the temperature is above $30^{\circ} \mathrm{C}$ significantly increases, whereas the number of hours that the temperature is below $-10^{\circ} \mathrm{C}$ reduces in the future.

Table 8 . The calculated annual hours that the dry bulb temperatures were above $30^{\circ} \mathrm{C}$ and below $-10^{\circ} \mathrm{C}$ for the weather files.

\begin{tabular}{|c|c|c|c|c|}
\hline Weather Files & $>\mathbf{3 0}{ }^{\circ} \mathrm{C}$ & $\%$ & $<-10^{\circ} \mathrm{C}$ & $\%$ \\
\hline CWEC (1960-1989) & $29 \mathrm{hrs}$ & 0.33 & $469 \mathrm{hrs}$ & 5.40 \\
\hline $\begin{array}{l}\text { CCWorldWeatherGen tool } \\
(1960-1989)\end{array}$ & $210 \mathrm{hrs}$ & 2.40 & $190 \mathrm{hrs}$ & 2.17 \\
\hline $\begin{array}{l}\text { WeatherShift tool } \\
(1960-1989)\end{array}$ & $263 \mathrm{hrs}$ & 3.00 & $126 \mathrm{hrs}$ & 1.44 \\
\hline HRM3 (1960-1989) & $179 \mathrm{hrs}$ & 2.05 & $315 \mathrm{hrs}$ & 3.60 \\
\hline CWEC2016 (1998-2014) & $93 \mathrm{hrs}$ & 1.06 & $308 \mathrm{hrs}$ & 3.52 \\
\hline $\begin{array}{l}\text { CCWorldWeatherGen tool } \\
(1998-2014)\end{array}$ & $351 \mathrm{hrs}$ & 4.01 & $142 \mathrm{hrs}$ & 1.62 \\
\hline $\begin{array}{l}\text { WeatherShift tool } \\
\text { (1998-2014) }\end{array}$ & $426 \mathrm{hrs}$ & 4.86 & $100 \mathrm{hrs}$ & 1.14 \\
\hline HRM3 (1998-2014) & $311 \mathrm{hrs}$ & 3.56 & $200 \mathrm{hrs}$ & 2.29 \\
\hline
\end{tabular}




\subsubsection{Summary}

Boxplots of the outdoor dry-bulb air temperature shows continuous increase in the average temperatures for the future and the impacts of climate change are clearly seen in the future weather files. The projections for the future are significantly higher in the weather files generated by the WeatherShift tool. Besides, for all future weather file projections, increases in maximum and minimum temperatures based on the 1998-2014 baseline is higher in comparison to the 1959-1989 period. This is because in statistical downscaling the baseline climate is used to superimpose the changing climate of the future to create the future weather file. Thus, higher temperature values observed for 1998-2014 baseline years directly influence future weather file generation, resulting in higher temperature values for the future. The general trend for increasing solar irradiance and decrease in relative humidity values are expected in the future (Appendix G). However, the changes in wind speed and direction for the future is rather complex and simple trends cannot be obtained from the results for these variables. Overall, the changes in solar irradiance, and relative humidity, as well as wind speed and direction in the future weather file compared with the baseline climate weather file are small in proportion. Previous studies have found the cross-correlations between these weather variables, illustrating that with an increase of solar irradiance, the air temperature would generally increase while relative humidity would decrease (Guan et al., 2007).

\subsection{Analysis of Building Simulation Results}

This section presents the simulation results of the 16 prototype building models. However, due to large number of simulation-runs, presenting all output results for each individual building model will be tedious. As a result, from the two baseline years used to generate future weather files, this thesis presents and discusses the simulation results of the CWEC historical weather file and the future weather files that use the 1959-1989 baseline. That is, the results for each individual building model simulated using the CWEC2016 weather file and its future weather files, using the 1998-2014 baseline, are provided in Appendix H. In fact, as pointed out in section 3.1, the CWEC weather file provides a better representation of the historical climate and has been recommended by the World Meteorological Organization (as cited in Shen, 2017). Additionally, CWEC is the weather file most frequently used in building performance simulation for buildings in Toronto and TGS Version 3 performance targets are established based on the 1959-1989 climate. The only 
distinction between the results of two baseline climates and their future weather files are due to higher temperature values observed for 1998-2014 baseline years, compared to the 1959-1989. Subsequently, higher temperatures of the future projections affect building total energy use, energy use intensity (EUI), heating and cooling loads, as well as thermal comfort levels. The results of the simulation-runs for the 1998-2014 baseline and their future climate projections (available in Appendix H) are used to evaluate and discuss the impacts of using different baseline climate in building energy simulation.

When comparing different buildings, it is essential to account for differences in floor area; therefore, the energy use intensity (EUI) is used and defined as the annual sum of the total energy used divided by the floor area. We begin by presenting heating and cooling EUI to assess the impacts of climate change on building energy performance. This is followed by total energy use to quantify the future trends of buildings energy demand as well as the GHG emissions associated with the cooling and heating EUI for each building type. Finally, to evaluate indoor thermal comfort, the last section discusses the number of hours that each building's heating and cooling setpoints were not met during occupied hours.

\subsubsection{Heating and Cooling Energy Use Intensity}

The impacts of future weather files on heating and cooling energy use per total building area, in relation to the 1959-1989 and 1998-2014 baseline cliamtes, are illustrated in Figure 16. As per the simulation results, rises in cooling EUI and decrease in heating EUI are found in all 16 prototype building models for both baseline climate due to temperature rise brought by the climate change. The magnitude of changes in heating and cooling EUI is highly dependent on baseline climate and building types. The results are consistent with IEA's report that building energy use have been dominated by the growth in space cooling and reduction in space heating since 2010 (IEA, 2018). 

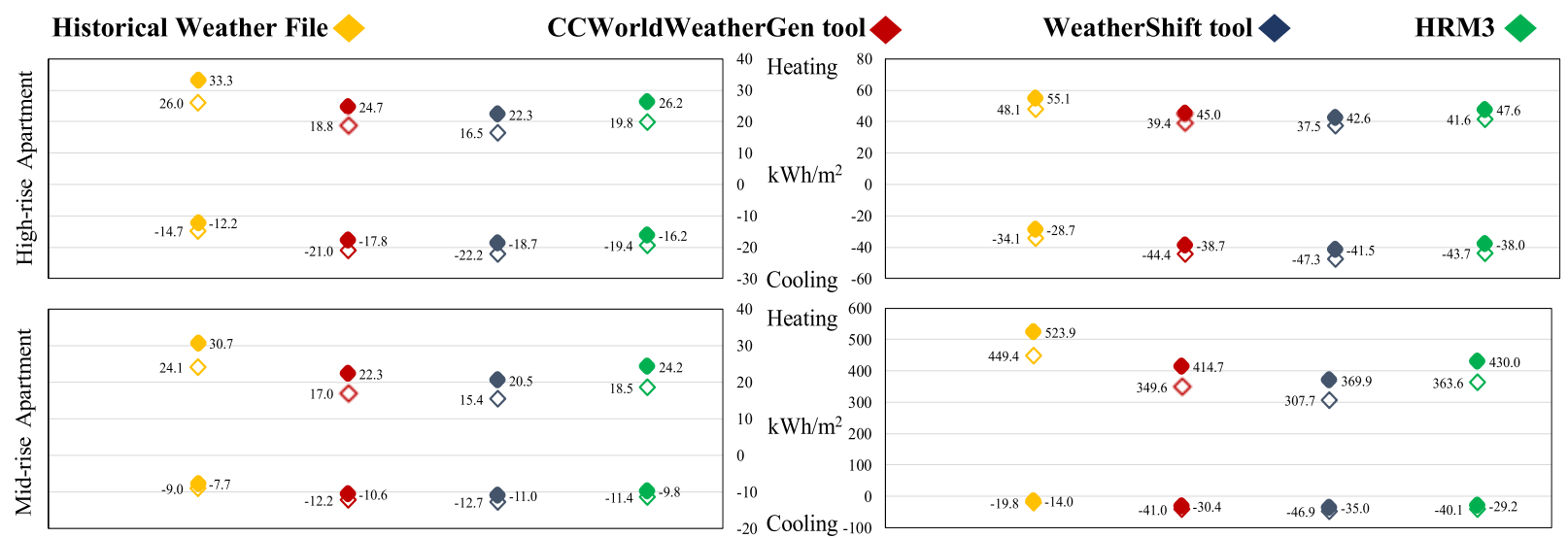

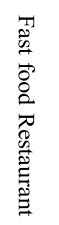
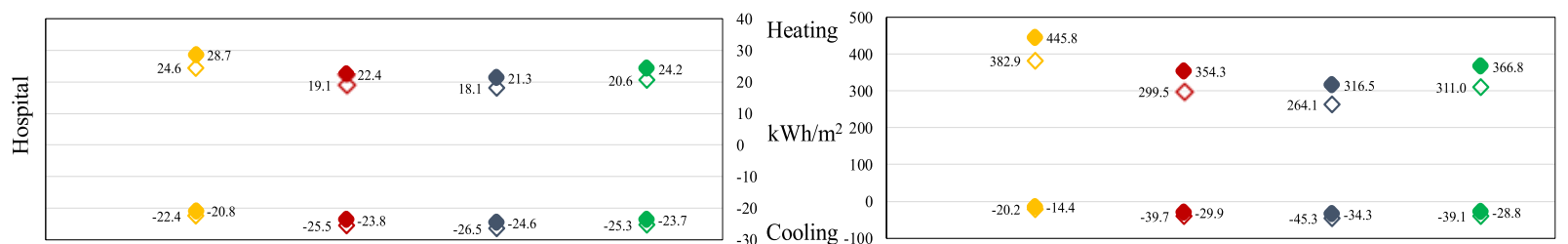

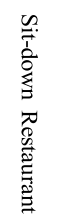
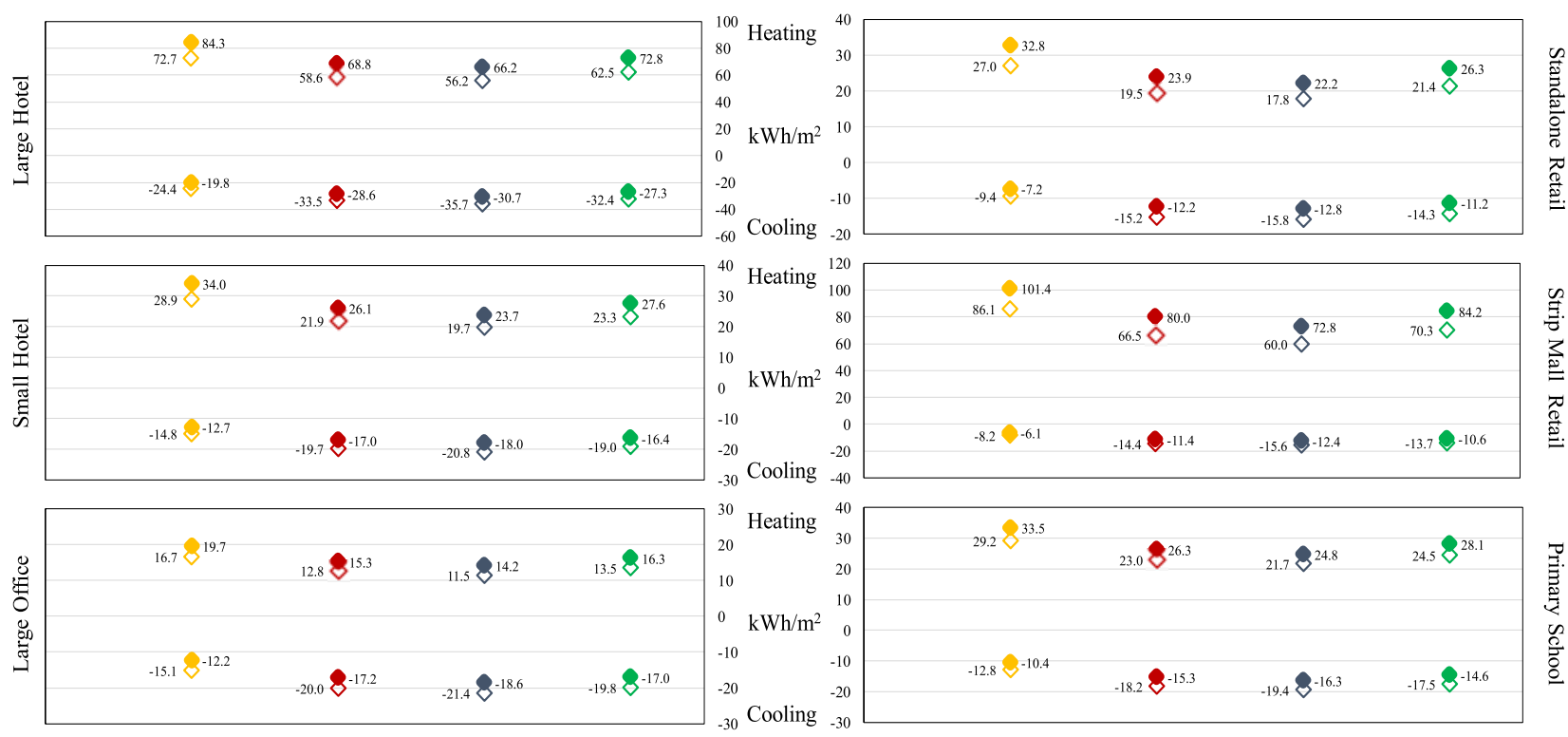

${ }_{20}^{30}$ Heating
10
$0 \quad \mathrm{kWh} / \mathrm{m}^{2}$
-10
-20
-30
Cooling
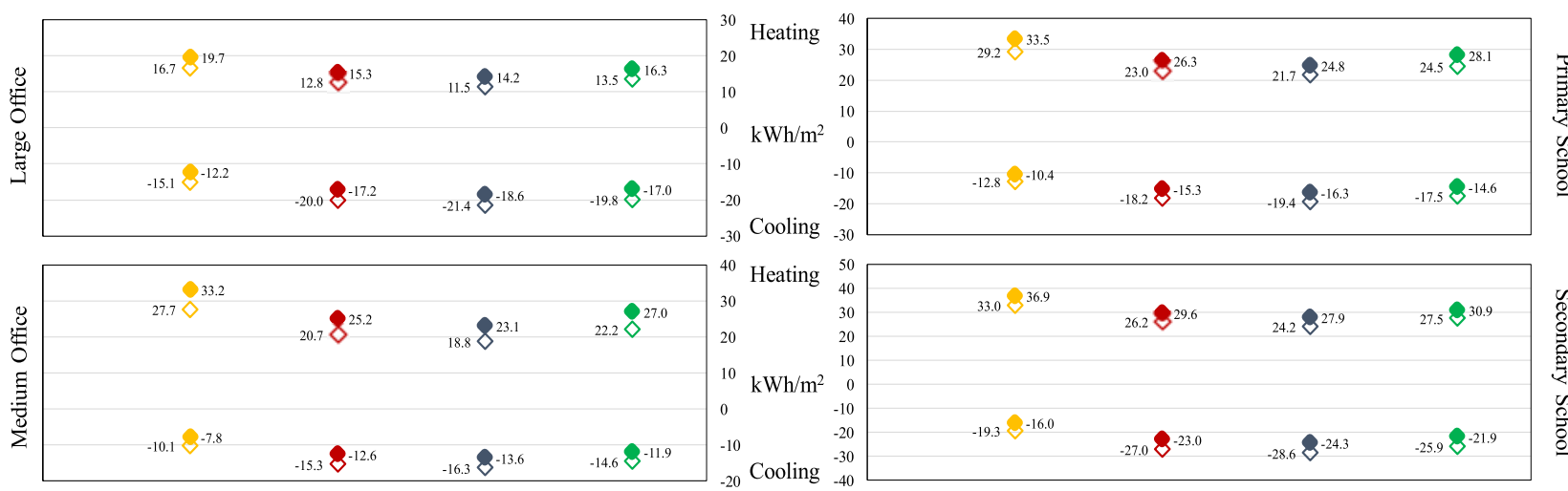

${ }_{30}^{40}$ Heating
20
${ }^{20} \mathrm{kWh} / \mathrm{m}^{2}$
${ }^{10}$
-10
-20
Cooling
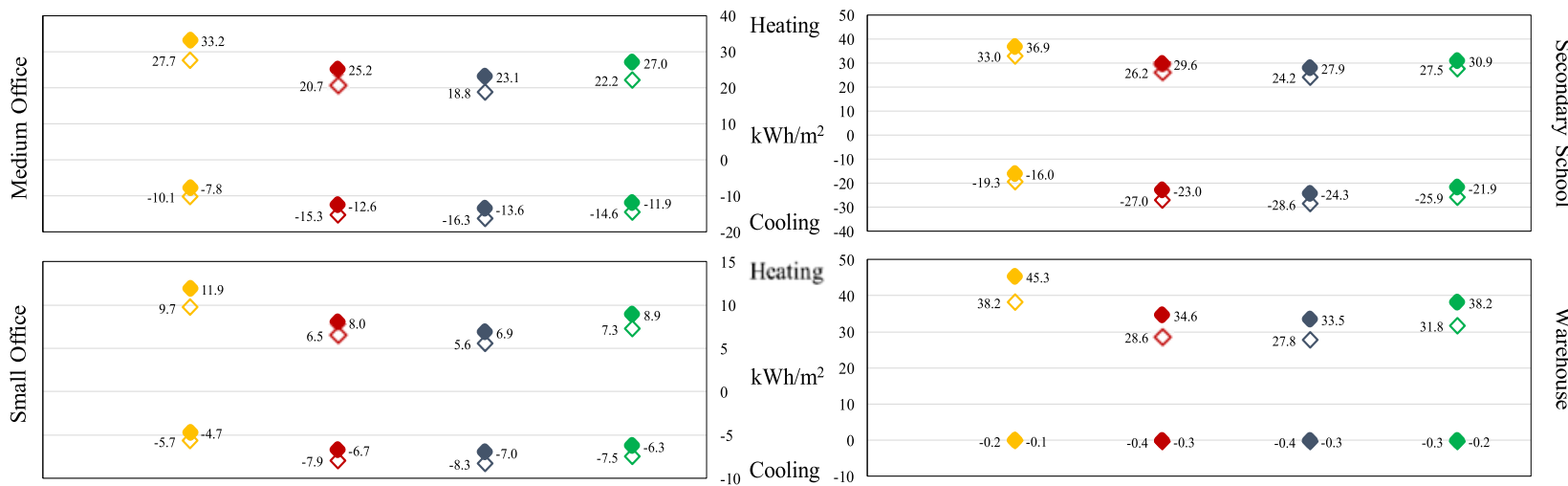

$\int_{-10}^{15} \begin{array}{ll}10 & \text { Heating } \\ 5 & \\ 0 & \mathrm{kWh} / \mathrm{m}^{2} \\ -5 & \\ { }_{-10} & \text { Cooling }\end{array}$

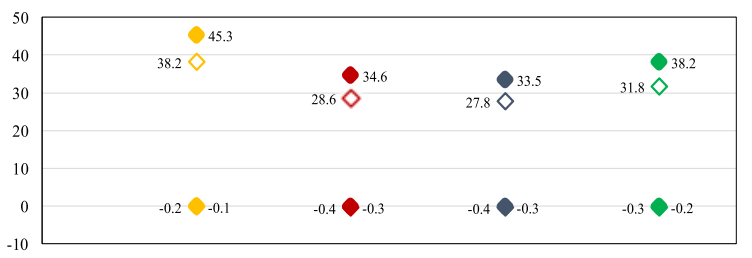

Figure 16. The scatterplots showing the distribution of values for the annual heating energy (positive values) and cooling energy (negative values) under historical and future weather data sets for all 16 prototype buildings. Values for the 1959-1989 baseline climate are presented in solid color markers and the 1998-2014 baseline climate in hollow color markers. 
As per the results presented in Figure 16, the large office building prototype model show lower heating EUI when compared to the medium office. This is in fact due to the extremely high internal load's of the electrical equipment present in the large office for its data center (484.38 $\mathrm{W} / \mathrm{m}^{2}$ and $215.28 \mathrm{~W} / \mathrm{m}^{2}$ ), which results in the generation of heat and thus a reduction in heating EUI of the large office building prototype when compared to the medium office. Furthermore, the extremely high heating EUI for the fast food restaurant, sit-down restaurant, standalone retail, strip mall retail and warehouse building prototypes could be explained by their type of HVAC system. For these building prototypes, the HVAC system is designed with a constant air volume (CAV), without reheating, providing constant volume of air to all parts of the building when the system is in operation. As an example, Figure 17 illustrates the HVAC system provided for the kitchen zone of the fast food restaurant by the DOE. As can be seen in Figure 17, the cooling coil is located before the heating gas coil and significant amount of energy is wasted when the heating and cooling coils operate at the same time, resulting in much higher EUI seen for these buildings prototypes. As a result, due to fan energy savings potential, variable air volume (VAV) systems are more common and other building prototype models use this system and have higher efficiency.

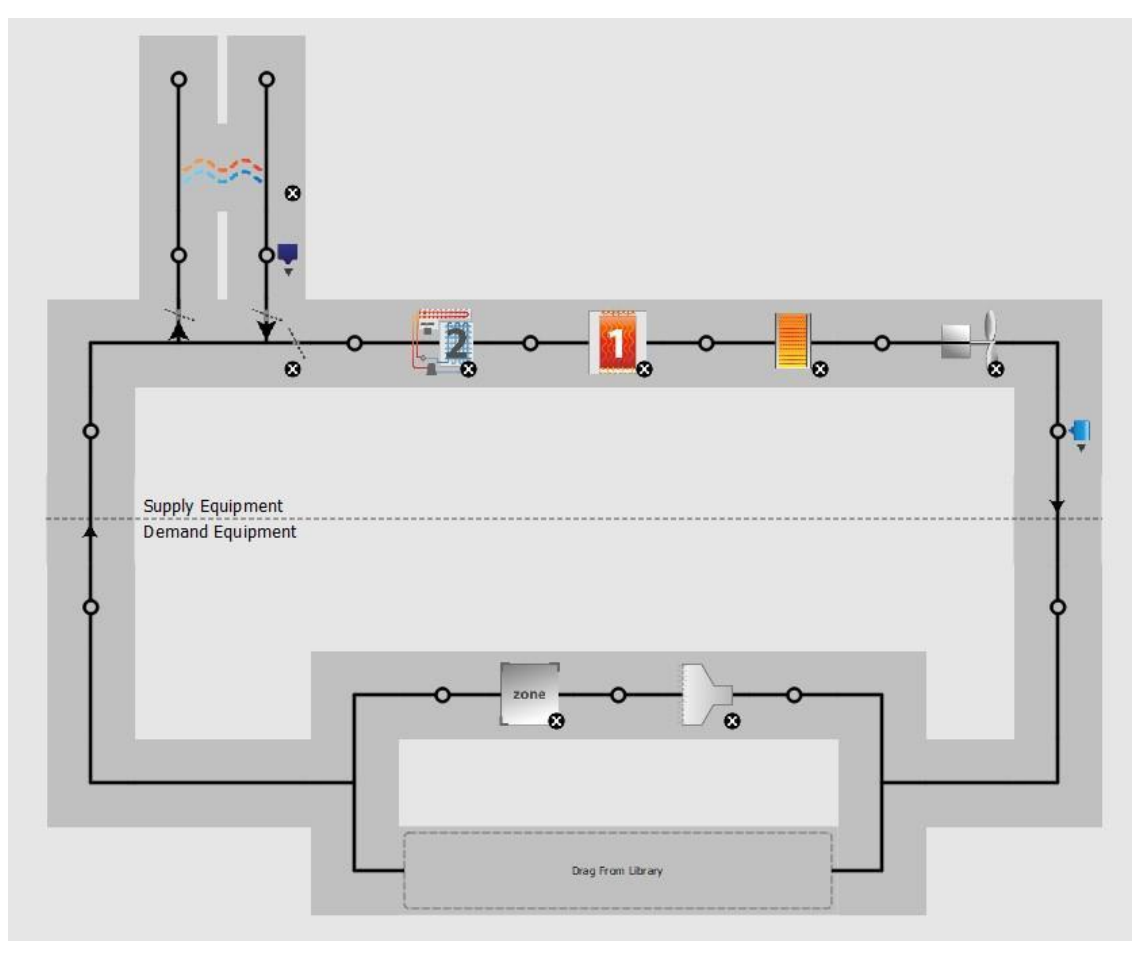

Figure 17. The fast food restaurant's kitchen HVAC system. 
Table 9 summarizes the average percentage decrease and increase in heating and cooling EUI illustrated by Figure 16. For the 1959-1989 baseline climate, the results indicate an average decrease in the range of $18-33 \%$ in heating EUI, and an average increase of $16-126 \%$ in cooling EUI, depending on the building type. When the two baseline climates are compared, heating EUI reduction was less and cooling EUI increase was more in CWEC weather file due to the historical recorded temperature values observed for the 1959-1989 period. In other words, as CWEC baseline climate is used to superimpose the changing climate of the future to create the future weather files, lower recorded temperature values directly influence future weather file generation, resulting in lower temperature values in the future. As a result, the future projections based on the 1959-1989 baseline shows smaller decrease in heating and greater increases in cooling when compared to the more recent CWEC2016 baseline climate.

Table 9. The average percentage decrease and increase in heating and cooling EUI for different building types in the future compared to the two-baseline climate.

\section{CWEC CWEC2016}

1959-1989 Baseline

1998-2014 Baseline

\begin{tabular}{lllll}
\hline Building Typology & Heating & Cooling & Heating & Cooling \\
\hline High-rise Apartment & $-27 \%$ & $44 \%$ & $-29 \%$ & $42 \%$ \\
Mid-rise Apartment & $-27 \%$ & $36 \%$ & $-30 \%$ & $34 \%$ \\
Hospital & $-21 \%$ & $16 \%$ & $-22 \%$ & $15 \%$ \\
Large Hotel & $-18 \%$ & $46 \%$ & $-19 \%$ & $39 \%$ \\
Small Hotel & $-24 \%$ & $35 \%$ & $-25 \%$ & $34 \%$ \\
Large Office & $-23 \%$ & $44 \%$ & $-24 \%$ & $36 \%$ \\
Medium Office & $-24 \%$ & $64 \%$ & $-26 \%$ & $52 \%$ \\
Small Office & $-33 \%$ & $41 \%$ & $-33 \%$ & $39 \%$ \\
Outpatient HealthCare & $-18 \%$ & $37 \%$ & $-18 \%$ & $32 \%$ \\
Fast Food Restaurant & $-23 \%$ & $126 \%$ & $-24 \%$ & $115 \%$ \\
Sit-down Restaurant & $-22 \%$ & $116 \%$ & $-24 \%$ & $105 \%$ \\
Standalone Retail & $-26 \%$ & $68 \%$ & $-28 \%$ & $61 \%$ \\
Strip Mall Retail & $-22 \%$ & $87 \%$ & $-24 \%$ & $78 \%$ \\
Primary School & $-21 \%$ & $48 \%$ & $-21 \%$ & $44 \%$ \\
Secondary School & $-20 \%$ & $44 \%$ & $-21 \%$ & $41 \%$ \\
Warehouse & $-22 \%$ & $110 \%$ & $-23 \%$ & $109 \%$ \\
\hline
\end{tabular}


Heating and cooling energy use for all 16 prototype buildings is found to be extremely susceptible to the effects of climate change. As Table 9 indicates, for the 1959-1989 baseline climate, the large hotel and outpatient healthcare building models experienced an average reduction of $18 \%$ in heating EUI for the future, the lowest among all building types. On the other hand, the largest reduction in heating EUI was for the small office building model, with an average of reduction of $33 \%$ in the future. These findings correspond to Xu et al. (2012) conclusion that the heating load of large buildings is not as sensitive to changes in climate conditions as small buildings due to envelope heat loss/gain making up a larger portion of small buildings heating and cooling load than that of large buildings.

Regarding cooling EUI, the hospital building model had the smallest increase in cooling EUI with $16 \%$, whereas the fast food restaurant building model had the largest increase by $126 \%$. For hospital building model the change in heating and cooling energy use is comparatively smaller because of larger internal load such as interior equipment and lighting that remain constant regardless of outdoor climate conditions. Moreover, the hospital model has a large ratio of zones to floor area and a small window-to-wall ratio (16\%) compared to other building models. As previously discussed, due to larger thermal inertia, the hospital building model experiences smaller changes in heating and cooling energy use in the future.

In the case of fast food and sit-down restaurants the large heating and cooling EUI values could be due to high ventilation rates in these buildings compared to others. Furthermore, the restaurant building models have uninsulated attics and all their zones are exposed to the outdoor conditions (Figure 11). Similarly, in the retail building models, all zones are directly exposed to the outdoors and high rate of air change is present. A comparison of high-rise and mid-rise apartment building models also shows that the decrease in heating and increase in cooling energy use are comparable, and the difference is associated with the higher internal load of the high-rise apartment compared to the mid-rise building. In fact, this is true in the case of large and small hotel building models, as well as primary and secondary school buildings. Finally, according to Figure 16, the cooling EUI of the warehouse building model is significantly low when compared to other building types, illustrating the fact that the climate conditions might not be the dominant force driving the energy use of this building model. Overall, building models with higher insulation 
level, larger zone ratio, smaller window-to-wall ratio, and lower outdoor air supply are less affected by the outdoor conditions and thus climate change.

As per the results, impacts of climate change on shifting heating and cooling EUI is present for all buildings but significantly varies in magnitude for each building type. Furthermore, the rise in cooling demand in hot months of July and August suggest that the summer peak load electricity will place enormous pressure on the electricity grid (Appendix H). From the results of the analysis, it is evident that mitigations measures related to HVAC operations such as changes to the room temperature setpoints, HVAC system's operation hours will be required in the future. Apart from HVAC systems, other methods including addition of thermal mass, improvements in windows, glazing and envelope insulation are recommended to help tackle some of the climate change challenges in the building sector.

\subsubsection{Total Energy Use}

Buildings require substantial amounts of energy to operate. Table 10 presents the results for the total energy use for each 16 prototype building models. This provides a reference point to quantify the future trends of energy demand for various building types in Toronto. The categorical classification of energy consumption by end-use for all 16 prototype building models are compatible with the energy use in residential, commercial and institutional buildings in Ontario (Figure 4). Most of the energy use is for heating purposes. Of the reported building types, the highest total energy use is associated with the hospital building model for the 1959-1989 baseline climate, while the small office building model shows the lowest energy use for the same period. This is primarily due to the size, internal loads and schedules of these two buildings. In addition, according to our simulation results, the total energy use for all building models except for the large office and secondary school is decreased in the future. It is believed that the increase in electricity energy use for cooling, fans, heat rejection, dehumidification and heat recovery is the primary reasons for the overall increase in energy use of these two building types. Other building energy end uses tend to stay the same in the future, as changes in the climate conditions do not have significant impact on their performance. 
Table 10. The total energy use of the 16 prototype building models, 1959-1989 baseline climate.

\begin{tabular}{|c|c|c|c|c|c|}
\hline \multicolumn{2}{|c|}{ Building Typology } & \multicolumn{4}{|c|}{ Total Energy Use (kWh) } \\
\hline & & $\begin{array}{l}\text { CWEC } \\
(1959-1989)\end{array}$ & $\begin{array}{l}\text { CCWorldWeatherGen } \\
\text { tool }\end{array}$ & $\begin{array}{l}\text { WeatherShift } \\
\text { tool }\end{array}$ & HRM3 \\
\hline \multirow[t]{2}{*}{ Apartment } & High-rise & $1,421,750$ & $1,400,469$ & $1,388,278$ & $1,398,317$ \\
\hline & Mid-rise & 508,561 & 491,336 & 486,772 & 494,761 \\
\hline \multirow[t]{2}{*}{ Hotel } & Large & $4,036,147$ & $3,968,414$ & $3,960,117$ & $3,994,819$ \\
\hline & Small & $1,023,375$ & $1,009,250$ & $1,003,014$ & $1,012,539$ \\
\hline \multirow[t]{3}{*}{ Office } & Large & $1,0048,736$ & $1,0153,253$ & $1,0177,119$ & $1,0178,625$ \\
\hline & Medium & 606,886 & 594,747 & 589,681 & 598,267 \\
\hline & Small & 50,267 & 49,275 & 48,806 & 49,522 \\
\hline \multirow[t]{2}{*}{ Health } & Hospital & $7,317,031$ & $7,255,317$ & $7,238,814$ & $7,280,389$ \\
\hline & Outpatient & $1,393,403$ & $1,385,914$ & $1,380,864$ & $1,390,378$ \\
\hline \multirow[t]{2}{*}{ Restaurant } & Fast food & 415,406 & 394,525 & 385,325 & 397,761 \\
\hline & Sit-down & 831,208 & 793,056 & 776,111 & 798,853 \\
\hline \multirow[t]{2}{*}{ Retail } & Stand-alone & 376,339 & 368,297 & 364,039 & 370,794 \\
\hline & Strip-mall & 498,319 & 464,325 & 451,286 & 471,458 \\
\hline \multirow[t]{2}{*}{ School } & Primary & $1,126,297$ & $1,114,758$ & $1,110,869$ & $1,120,311$ \\
\hline & Secondary & $3,563,414$ & $3,578,864$ & $3,566,953$ & $3,574,331$ \\
\hline Warehouse & & 393,975 & 343,383 & 336,372 & 359,578 \\
\hline
\end{tabular}

The increase in cooling energy use is not proportionate to the heating reduction in terms of kWh energy use and therefore accounts for total energy use reduction of the site seen for in majority of the prototype building models. In other words, the decrease in heating energy use, outweighing the cooling energy needs in the future. Furthermore, for a Canadian climate, the more heating energy a building consumes in the winter, the greater potential it has in magnitude of decrease in energy use in the future. Therefore, making buildings in cold Canadian climate capable of saving more energy in the future climate.

\subsubsection{Climate Change Implications on Greenhouse Gas Emissions}

The energy use breakdown for the 16 prototype building models available in Appendix $\mathrm{H}$ illustrates that heating uses primarily natural gas while cooling is generated entirely from electricity. Using total energy use data from Table 10 and the emission factors for electricity (36 
grams of $\mathrm{CO}_{2}$ per equivalent $\mathrm{kWh}$ ) and natural gas (179.95 grams of $\mathrm{CO}_{2}$ per equivalent $\mathrm{kWh}$ ), the total GHG emissions associated with each building model was calculated (The city of Toronto, 2018). According to the city of Toronto's Annual Energy Consumption and Greenhouse gas Emission Report (2017), the electricity emission factor value is from the United Nations National Inventory Report, as reported by Environment Canada, and the natural gas emission factor's value have remained steady over the years as the natural gas is directly burned at the site (Table 11).

Table 11. Electricity and natural gas emission factors for the city of Toronto, 2017 (The city of Toronto, 2018).

\begin{tabular}{llllll}
\hline \multicolumn{6}{l}{ Grams of $\mathrm{CO}_{2}$ per equivalent $\mathbf{k W h}$} \\
\hline & $\mathbf{2 0 1 7}$ & $\mathbf{2 0 1 6}$ & $\mathbf{2 0 1 5}$ & $\mathbf{2 0 1 4}$ & $\mathbf{2 0 1 3}$ \\
\hline Electricity & 36.00 & 36.00 & 40.00 & 41.00 & 77.00 \\
Natural Gas & 179.95 & 179.95 & 179.95 & 179.95 & 179.92 \\
\hline
\end{tabular}

Figure 18 details the total energy use emissions for the 16 prototype building models. It is evident that the building sector is accountable for a large share of energy consumption and the corresponding GHG emissions. However, it is worth noting that emission factor for electricity could vary substantially between provinces or cities. For instance, in Ontario, the baseload electricity is provided primarily with clean sources of energy such as wind, nuclear and hydro, and the peak load energy demand is fulfilled in large with natural gas.

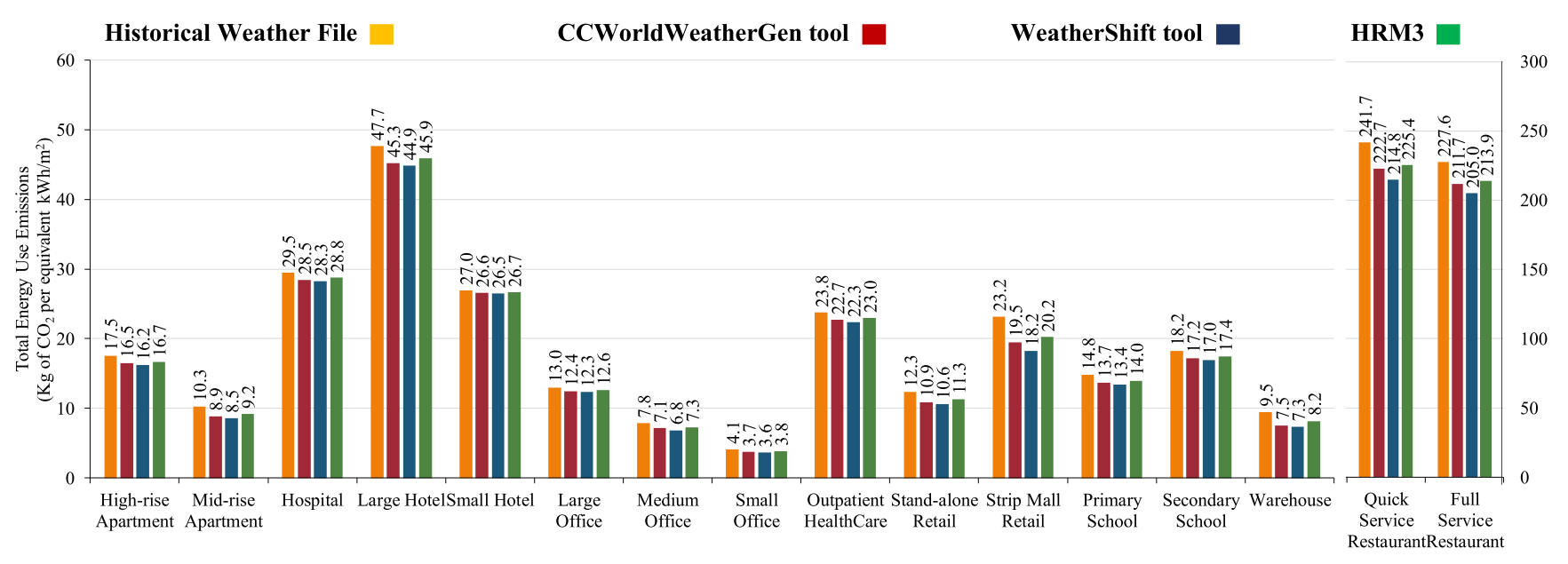

Figure 18. The total energy use emissions for the 16 prototype building models, 1959-1989 baseline climate. 
The Canadian federal government introduced a carbon pricing system of $\$ 20$ per tonne of $\mathrm{CO}_{2}$ in 2019. The carbon price will increase by $\$ 10$ per year until eventually rises to $\$ 50$ per tonne in 2022. It is expected that carbon pricing will provide a cost-effective measure for reducing GHG emissions by providing incentives for industries to innovate and find ways to lower their emissions. Under the assumption that the emission factors remain the same, the $\$ 50$ carbon price would translate into substantial costs in the future. Table 12 shows an estimate for the average cost of $\mathrm{CO}_{2}$ emissions for heating and cooling energy use in buildings.

Table 12. The average cost of $\mathrm{CO}_{2}$ emissions for the heating and cooling energy use in various building types under the Canadian carbon pricing system.

\begin{tabular}{lll}
\hline Building Typology & Average Cost (\$20 per tonne) & Average Cost (\$50 per tonne) \\
\hline High-rise Apartment & $\$ 691.04$ & $\$ 1,727.60$ \\
Mid-rise Apartment & $\$ 297.54$ & $\$ 743.85$ \\
Hospital & $\$ 2,322.80$ & $\$ 5,807.00$ \\
Large Hotel & $\$ 3,197.34$ & $\$ 7,993.34$ \\
Small Hotel & $\$ 212.96$ & $\$ 532.40$ \\
Large Office & $\$ 3,269.14$ & $\$ 8,172.84$ \\
Medium Office & $\$ 320.27$ & $\$ 800.68$ \\
Small Office & $\$ 9.04$ & $\$ 22.59$ \\
Outpatient HealthCare & $\$ 530.74$ & $\$ 1,326.86$ \\
Fast Food Restaurant & $\$ 367.98$ & $\$ 919.96$ \\
Sit-down Restaurant & $\$ 692.09$ & $\$ 1,730.22$ \\
Standalone Retail & $\$ 235.22$ & $\$ 588.05$ \\
Strip Mall Retail & $\$ 651.66$ & $\$ 1,629.15$ \\
Primary School & $\$ 766.99$ & $\$ 1,917.47$ \\
Secondary School & $\$ 2,510.88$ & $\$ 6,277.21$ \\
Warehouse & $\$ 660.44$ & $\$ 1,651.09$ \\
\hline
\end{tabular}

Figure 19 was developed to better understand the impacts of climate change on buildings emission simply in terms of heating and cooling energy use. The results indicate that the decline in future GHG emission is closely correlated with an increase in global temperatures and the reduction in building heating energy which primarily uses natural gas. 


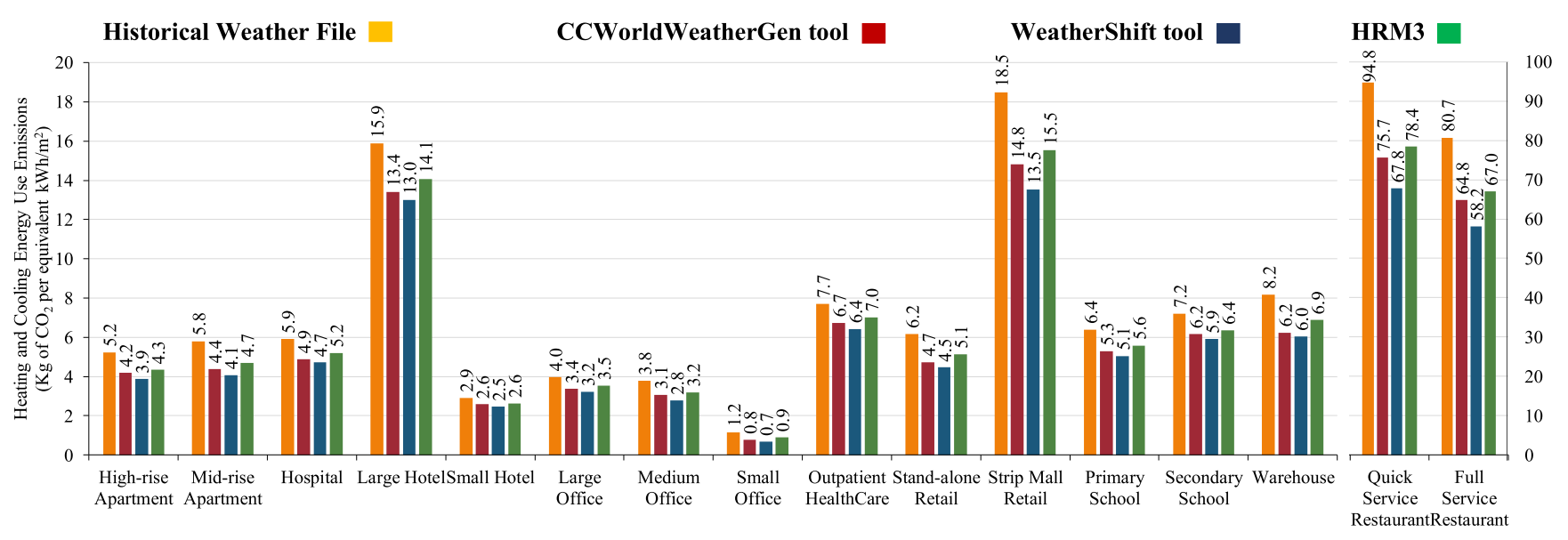

Figure 19. Heating and cooling energy use emissions for the 16 prototype building models, 1959-1989 baseline climate.

Although the fast food and sit-down restaurants have smaller floor area compared to other building models, they surpass all other buildings in GHG emissions. This is because of the large heating requirements in these buildings which is supplied by natural gas. And as previously noted (see section 4.2.1), the large heating requirement in these two buildings is primarily due to their type of HVAC systems. Overall, as per the GHG emission results, the electrification of heating could be a solution for further reduction in emissions and savings in carbon pricing costs. Moreover, with a grid that increasingly run on clean sources of energy, cooling emissions could foreseeably be eliminated altogether.

\subsubsection{Indoor Comfort}

One of the most commonly used metrics in measuring occupants' indoor thermal comfort are air temperature, relative humidity, and air circulation. Sometimes air temperature for a conditioned space, mostly controlled by HVAC systems, cannot be maintained within thermal comfort range for cooling or heating. The number of hours in a year that the operational temperature requirement was not met by the HVAC systems, serving different zones, are shown in Table 13. In this study, the scheduled temperature setpoints were set at $21^{\circ} \mathrm{C}$ to $24^{\circ} \mathrm{C}$, and the default tolerance was $\pm 0.2^{\circ} \mathrm{C}$, allowing for flexibility in accepting OpenStudio outputs. As it was predicted and indicated by Table 13, the unmet load hours are increased for cooling and decreased for heating in the future. In other words, the increase in outdoor temperature due to climate change has direct negative impacts on the HVAC systems, resulting in failure of maintaining the indoor temperatures within the thermal comfort range. These projections are in-line with the global mean 
surface temperature increase predicted, as well as the HDDs reduction and CDDs increase. With the goal of meeting the ASHRAE standards, which requires the unmet load for the chosen setpoint temperature to be less than 300 hours, the results of this study indicate that buildings such as hotels, offices, hospitals, outpatient healthcare and secondary schools will require larger HVAC systems to improve indoor thermal comfort in the future.

The only building models that the unmet load hours decreased for both cooling and heating are the hospital and large hotel building. Having analyzed the output results of the hospital simulation-run, it is believed that the reason for significantly high values for unmet heating hours are due to the kitchen zone. And for unmet cooling hours, the problem is believed to be in several zones. This is also true with respect to the 1998-2014 baseline and its future weather files. Regarding the large hotel, this work was unable to determine the reasons for reduction in the unmet load hours for cooling and heating. Finding a solution for these issues are beyond the scope of this research, however, it is suggested future work should be undertaken to eliminate any problems that currently might exist in the DOE's 16 prototype building models. Furthermore, as previously noted, the heating EUI for the fast food restaurant, sit-down restaurant, standalone retail, strip mall retail and warehouse building prototypes are enormously high and concerning compared to other building prototype models. In future studies special care must be taken when using these prototype models and it is highly recommended that for a more accurate simulation results a VAV system should be used. 
Table 13. Unmet load hours for 16 prototype building models during occupied cooling and heating hours.

Building Typology

Hours

\begin{tabular}{|c|c|c|c|c|c|c|}
\hline & & & CWEC & $\begin{array}{l}\text { CCWorldWeatherGen } \\
\text { tool }\end{array}$ & $\begin{array}{l}\text { WeatherShift } \\
\text { tool }\end{array}$ & HRM3 \\
\hline \multirow[t]{4}{*}{ Apartment } & \multirow[t]{2}{*}{ High-rise } & Cooling & 0 & 41.5 & 52.75 & 10.25 \\
\hline & & Heating & 2.25 & 1 & 1.75 & 2 \\
\hline & \multirow[t]{2}{*}{ Mid-rise } & Cooling & 0.00 & 56.75 & 61.75 & 5.50 \\
\hline & & Heating & 0.00 & 0.00 & 0.00 & 0.00 \\
\hline \multirow[t]{4}{*}{ Hotel } & \multirow[t]{2}{*}{ Large } & Cooling & 2067.17 & 1986.83 & 1876.67 & 1922.17 \\
\hline & & Heating & 25.83 & 21.50 & 23.83 & 24.83 \\
\hline & \multirow[t]{2}{*}{ Small } & Cooling & 1494.25 & 1658.00 & 1645.75 & 1645.50 \\
\hline & & Heating & 200.50 & 173.00 & 161.25 & 187.00 \\
\hline \multirow[t]{6}{*}{ Office } & \multirow[t]{2}{*}{ Large } & Cooling & 850.67 & 891.17 & 898.17 & 840.67 \\
\hline & & Heating & 262.83 & 187.17 & 173.50 & 208.50 \\
\hline & \multirow[t]{2}{*}{ Medium } & Cooling & 77.83 & 180.50 & 190.83 & 114.67 \\
\hline & & Heating & 575.00 & 471.33 & 437.67 & 501.00 \\
\hline & \multirow[t]{2}{*}{ Small } & Cooling & 5.67 & 32.83 & 35.67 & 17.17 \\
\hline & & Heating & 38.00 & 25.17 & 22.83 & 30.83 \\
\hline \multirow[t]{4}{*}{ Health } & \multirow[t]{2}{*}{ Hospital } & Cooling & 563.50 & 388.17 & 329.50 & 424.67 \\
\hline & & Heating & 1068.17 & 841.50 & 847.17 & 935.17 \\
\hline & \multirow{2}{*}{ Outpatient } & Cooling & 140.50 & 299.83 & 332.67 & 242.33 \\
\hline & & Heating & 2260.50 & 2084.17 & 2095.17 & 2144.67 \\
\hline \multirow[t]{4}{*}{ Restaurant } & \multirow[t]{2}{*}{ Fast food } & Cooling & 0.33 & 0.33 & 1.50 & 0.33 \\
\hline & & Heating & 11.83 & 8.00 & 8.00 & 10.00 \\
\hline & \multirow[t]{2}{*}{ Sit-down } & Cooling & 0.00 & 5.83 & 15.67 & 5.17 \\
\hline & & Heating & 0.00 & 0.00 & 0.00 & 0.00 \\
\hline \multirow[t]{4}{*}{ Retail } & \multirow[t]{2}{*}{ Stand-alone } & Cooling & 0.33 & 2.50 & 2.33 & 1.67 \\
\hline & & Heating & 0.00 & 0.00 & 0.00 & 0.00 \\
\hline & \multirow[t]{2}{*}{ Strip-mall } & Cooling & 4.33 & 10.83 & 15.67 & 7.50 \\
\hline & & Heating & 38.33 & 33.67 & 35.00 & 36.33 \\
\hline \multirow[t]{4}{*}{ School } & \multirow[t]{2}{*}{ Primary } & Cooling & 3.50 & 67.50 & 81.83 & 48.83 \\
\hline & & Heating & 0.00 & 0.00 & 0.00 & 0.00 \\
\hline & \multirow[t]{2}{*}{ Secondary } & Cooling & 266.33 & 328.17 & 274.83 & 262.83 \\
\hline & & Heating & 0.17 & 0.17 & 0.17 & 0.17 \\
\hline \multirow[t]{2}{*}{ Warehouse } & & Cooling & 11.33 & 22.00 & 21.83 & 16.00 \\
\hline & & Heating & 154.50 & 139.83 & 141.83 & 143.17 \\
\hline
\end{tabular}




\section{Chapter 5: Conclusions}

This study described the results of climate change impact assessment on the energy performance of 16 ASHRAE prototype building models for a Canadian climate. Several general conclusions based on the results are presented in the following sections.

\subsection{Future Weather Files}

Future weather data was generated using statistical and dynamical downscaling techniques. In statistical downscaling, morphing method described in Belcher et al. (2005) was used to generated hourly weather information during the year of 2041- 2070 using HadCM3 model output through the application of the CCWorldWeatherGen tool. In addition, WeatherShift tool was used to generated future weather files for the 2056-2075 period. This tool also simulates and superimposes the changes in the future climate conditions, creating a future weather file by applying the morphing technique to $14 \mathrm{GCMs}$. In dynamical downscaling, RCM output developed under NARCCAP was used to generate a future weather file for the 2041-2070 period by projecting climate change information based on the coupled HadCM3-HRM3. In the morphing method, a baseline climate is needed for superimposing the changes in the future climate conditions. The baseline climate is a present-day weather data averaged over a period of 15 to 30 years. Given the limitations of historically recorded weather data and the availability of long-term hourly time resolution for every location, two CWEC files generated by Environment and Climate Change Canada were selected for this study. Furthermore, considering the ongoing climate change trends, $\mathrm{CO}_{2}$ emission scenario characterized by rapid economic growth and emphasis on fossil fuel was selected for all climate projections. The generated future weather files project an average temperature increase of $3.7-4.5^{\circ} \mathrm{C}$ for the years 2040 to 2070 .

Overall, the findings establish the importance of considering future weather file for building performance simulation. In statistical downscaling, it is evident that different baseline climate can project diverse future climate conditions. Therefore, it is important to consider appropriate historical data periods for generating future weather file. Moreover, in dynamical downscaling, as assessment of building energy performance tends to focus on impacts of climate change at the local level, and thus finer spatial resolution generated by RCM present a more reliable representation of the regional boundary conditions. As per the future weather file results, 
this study concludes that the use of multiple GCMs rather than just a single model for future weather file generation creates statistically significant results. And, the use of RCM provides a more reliable representation of the regional boundary conditions than those of GCM. Therefore, a combination of multiple GCM, as seen in WeatherShift tool, alongside RCM, such as HRM3, provides the most accurate climate prediction for the future.

The application of future weather files enables for climate change impact studies on building performance in the future, as well as allows for designers to consider future performance during the design process. Moreover, the results of temperature increase produce changes in heating and cooling degree days which affect building heating and cooling energy use. The impacts of climate change were also seen in prolonged cooling seasons while diminishing the duration of heating season. The resulting future HDDs illustrates a shift in Climate Zone classification for the city of Toronto, demonstrating the need to modify and adapt building code guidelines and building modelling regulations.

\subsection{Building Energy Simulation}

In order to quantify and better assess the impacts of climate change on building heating and cooling energy use, building simulation was carried out for 16 prototype building models under future weather data sets. These models were in compliance with ASHRAE 90.1-2013 standards. The simulation results showed a drop in annual heating EUI and increase in cooling EUI in all building models for all baseline years. However, the impacts of climate change varied significantly among different types of buildings. For example, the largest heating EUI reduction was for the small office building model, whereas the largest cooling EUI increase was in fast food restaurant building model. On the other hand, the smallest heating EUI reduction was seen in the large hotel and outpatient healthcare and the smallest cooling EUI increase was modelled for the hospital building. It was concluded that, buildings with higher insulation level, larger zone ratio, smaller window-to-wall ratio, and lower outdoor air supply are less affected by the outdoor conditions and thus climate change.

In the future, according to the simulation results, the annual total energy use ( $\mathrm{kWh}$ ) would decrease for all building models except for the large office and secondary school. This was 
primarily due to heating energy use savings that offset cooling energy needs. While it is conclusive but inclusive, the future energy use in buildings illustrate great tendency toward electricity rather than natural gas. The potential increase in cooling energy demand and summer peak load electricity in summer months offer a warning sign to the local governments and electricity providers. It is evident that the building sector is accountable for a large share of energy consumption and the corresponding GHG emissions, and with the introduction of carbon pricing, substantial costs must be anticipated by building owners in the future.

For the city of Toronto, climate change will result in increases in building heat gain, impacting the occupants' indoor comfort. The results described in this paper establishes the importance of considering future weather file for building energy simulation, especially in sizing and HVAC system selection. The energy use forecast for the 16 prototype building models demonstrate the need for consideration of future design options to maximise energy efficiency, reduce GHG emissions, and limit the cost of future changes. Therefore, as buildings tend to exist for decades, it is essential to evaluate how design decisions made today can meet the demands of a more extreme and varying climate in the future. Only then, applicable long-term strategies and policies in response to climate change can be developed.

In future work, it is suggested to use the weather files developed in this study to assess the climate change mitigation measures on various building types. Future studies should also include multiple cities across Canada with different climate conditions, as building energy use as well as GHG emissions vary significantly across the region. In addition, it is suggested to consider the effects of urban climate along with extreme conditions to fully understand the impacts of climate change on buildings energy performance. Finally, with the implementation of future weather files in building's climate change impact study, it is essential to develop climate models with higher temporal and spatial resolution for Canada. Moreover, high resolution climate models should deliver values for all climate variables important in projecting climate conditions. Building energy simulations tends to focus on impacts of climate change at the local level, and therefore, finer spatial resolution generated by climate models can give a more reliable representation of the regional boundary conditions. 


\section{Appendices}

\section{Appendix A. Python code for extracting variable based on geographic location from the NetCDF file.}

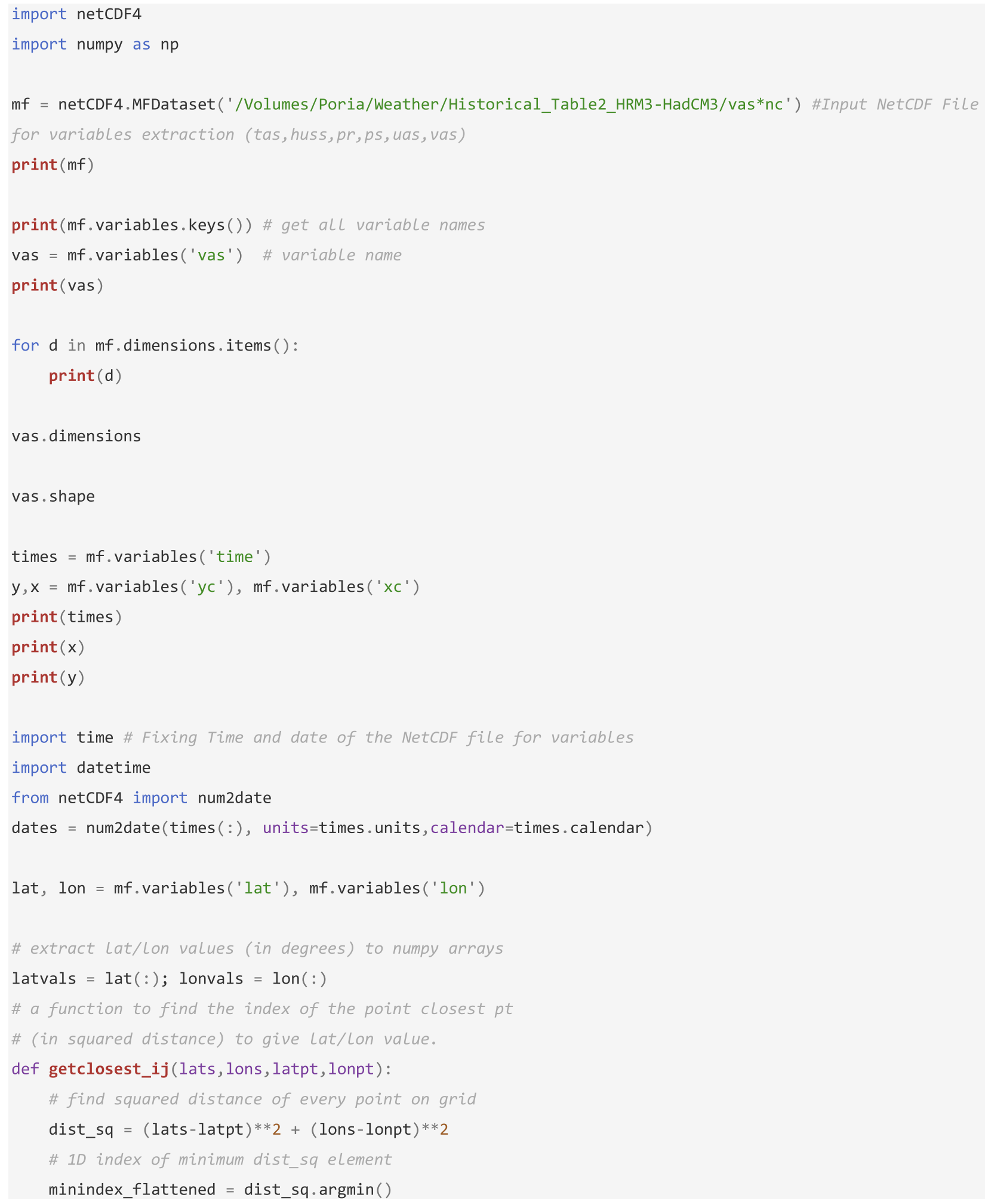


\# Get 2D index for Latvals and Lonvals arrays from 1D index

return np.unravel_index(minindex_flattened, lats.shape)

iy_min, ix_min = getclosest_ij(latvals, lonvals, 43.677, -79.631) \#Longitute and Latitude for the Location print (iy_min)

print (ix_min)

import xlsxwriter

\# Create a workbook and add a worksheet.

workbook $=$ xlsxwriter.Workbook ('M-WindSpeed-H.xlsx') \#Excel Workbook saving name

worksheet $=$ workbook.add_worksheet $($ )

row $=0$

worksheet.write $(0,0, \quad$ 'Time')

worksheet.write (0, 1, 'M-WindSpeed ')

row $+=1$

for $i$ in range(len(dates)):

worksheet.write(row, 0, $\operatorname{str(dates(i)))~}$

worksheet.write(row, 1, vas(i, iy_min, ix_min)) \# Variables (tas, huss, pr, ps, uas, vas)

row $+=1$

workbook.close() \#Saving the data in Excel format 
Appendix B. Python code for applying linear interpolation to the to 3-hourly data to generate hourly weather data.

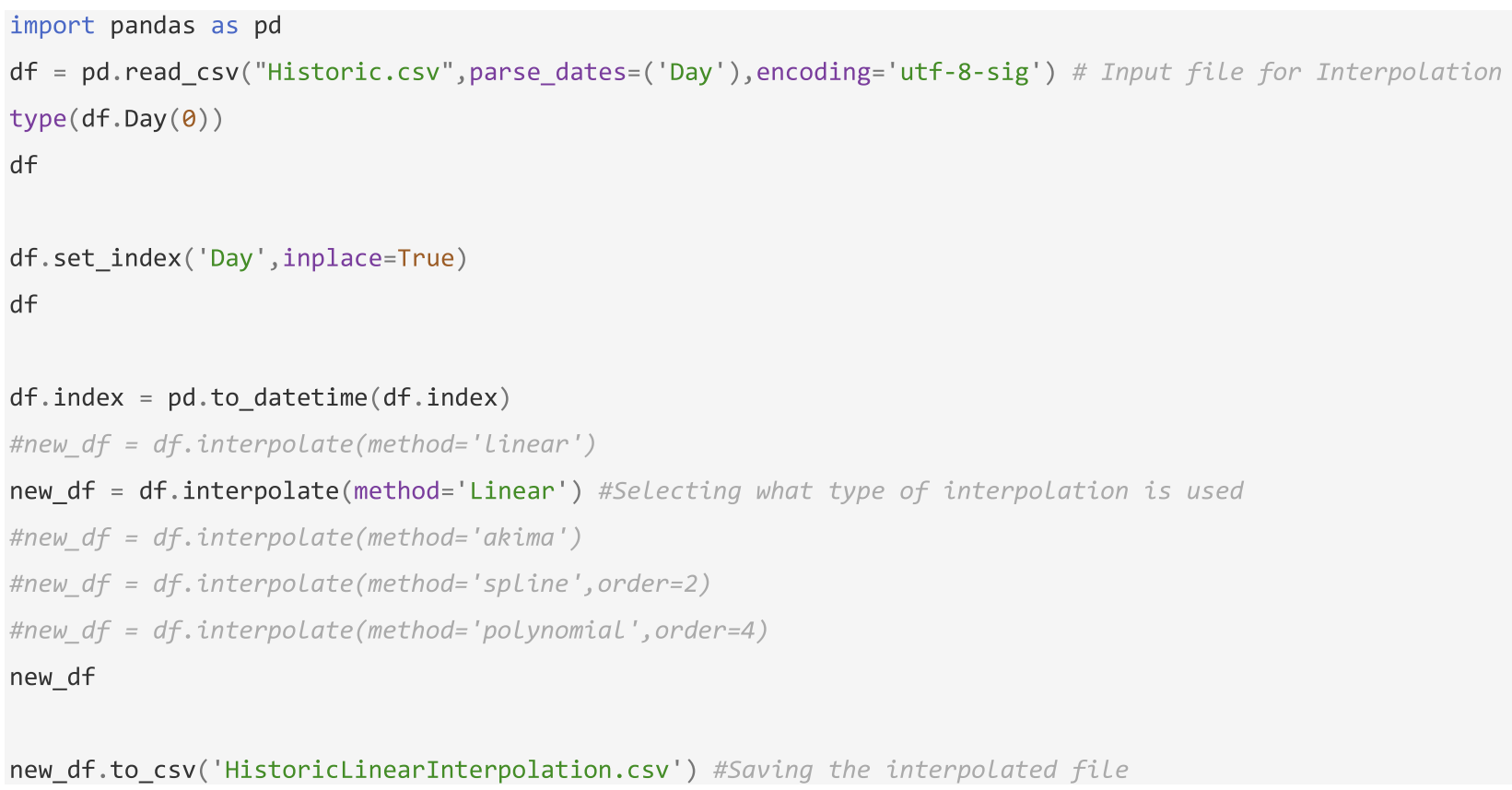


Appendix C. A comparison of three different interpolation method for estimating the missing hourly values for 24 hours (a) and 1 week (b).
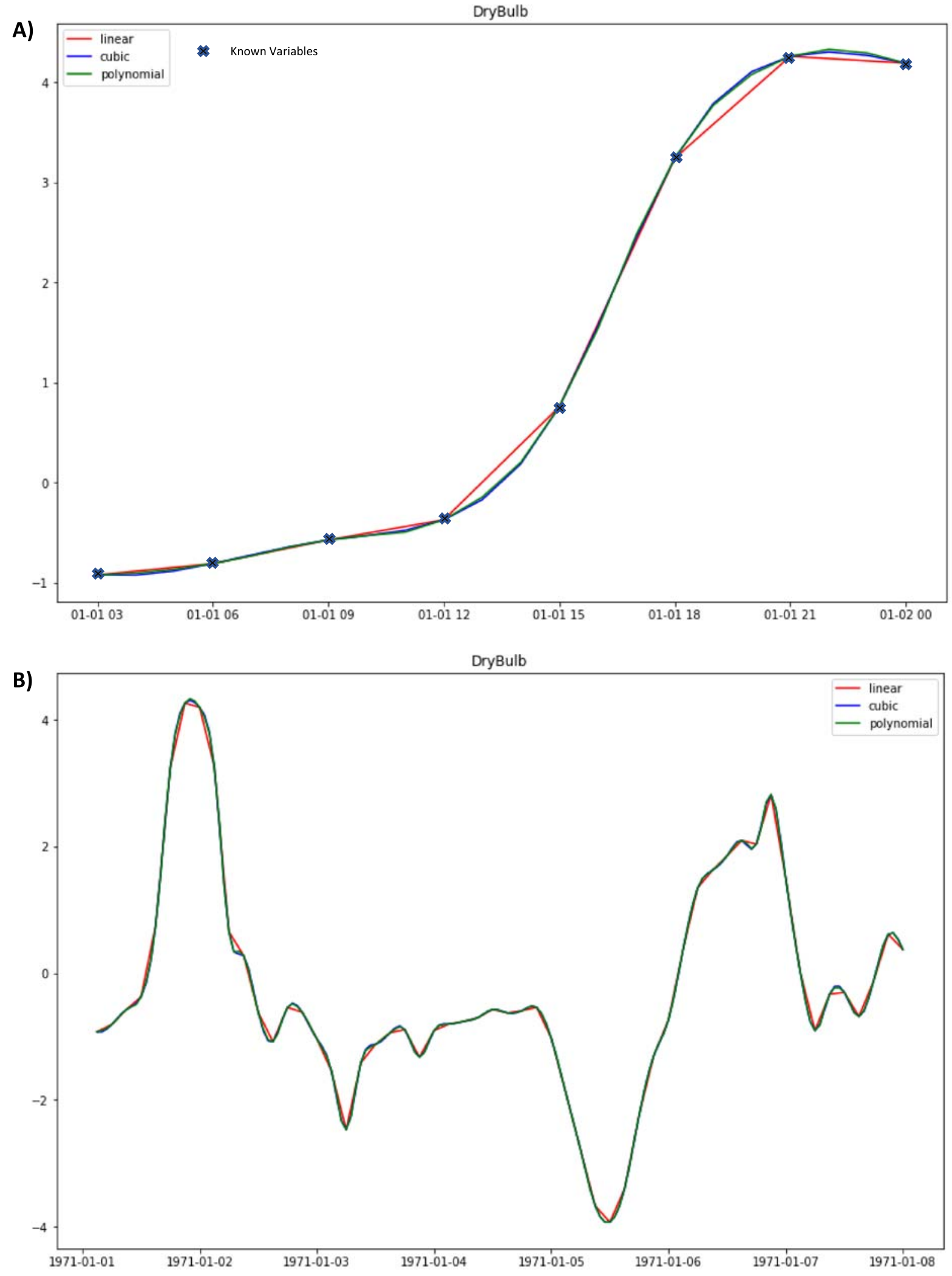


\section{Appendix D. Model performance evaluation.}

$$
\begin{aligned}
\mathrm{MAD} & =\frac{\sum_{t=1}^{n}\left|A_{t}-F_{t}\right|}{n} \\
\mathrm{MSE} & =\frac{\sum_{t=1}^{n}\left(A_{t}-F_{t}\right)^{2}}{n}
\end{aligned}
$$

$\mathrm{RMSE}=\sqrt{\frac{\sum_{t=1}^{n}\left(A_{t}-F_{t}\right)^{2}}{n}}$ MAPE $=\frac{\sum_{t=1}^{n}\left|\frac{A_{t}-F_{t}}{A_{t}}\right|}{n} \times 100$
The mean absolute deviation (MAD) is the sum of absolute differences between the actual value and the forecast divided by the number of observations.

Mean square error (MSE) is probably the most commonly used error metric. It penalizes larger errors because squaring larger numbers has a greater impact than squaring smaller numbers. The MSE is the sum of the squared errors divided by the number of observations.

The root mean square error (RMSE) is the square root of the MSE.

Mean absolute percentage error (MAPE) is the average of absolute errors divided by actual observation values (the issue of zero ' 0 ' at denominator)

Calculated MAD, MSE, RMSE, and MAPE for the dry bulb variables for the period of 1971-2000 at 3-hour resolution for the GTA's actual observed weather data from and HRM3 output data.

\begin{tabular}{|l|l|l|l|l|}
\hline Years & $\begin{array}{l}\text { Mean Absolute } \\
\text { Deviation }\end{array}$ & Mean Square Error & $\begin{array}{l}\text { Root Mean Square } \\
\text { Error }\end{array}$ & $\begin{array}{l}\text { Mean Absolute } \\
\text { percentage error }\end{array}$ \\
\hline $\mathbf{1 9 7 1}$ & 4.802886 & 36.96673 & 6.080027 & 963.4983 \\
\hline $\mathbf{1 9 7 2}$ & 4.880415 & 39.83215 & 6.311272 & 962.779 \\
\hline $\mathbf{1 9 7 3}$ & 4.753798 & 37.1945 & 6.098729 & 1167.744 \\
\hline $\mathbf{1 9 7 4}$ & 4.671911 & 34.06746 & 5.836734 & 1374.272 \\
\hline $\mathbf{1 9 7 5}$ & 4.651531 & 34.67819 & 5.888819 & 1047.344 \\
\hline $\mathbf{1 9 7 6}$ & 4.971391 & 40.44338 & 6.359511 & 848.1487 \\
\hline $\mathbf{1 9 7 7}$ & 4.872032 & 39.30201 & 6.269132 & 330.6734 \\
\hline $\mathbf{1 9 7 8}$ & 4.433712 & 31.48846 & 5.611458 & 445.3334 \\
\hline $\mathbf{1 9 7 9}$ & 5.160851 & 45.42161 & 6.739556 & 321.423 \\
\hline $\mathbf{1 9 8 0}$ & 4.374087 & 33.12563 & 5.755487 & 343.4022 \\
\hline $\mathbf{1 9 8 1}$ & 4.723283 & 37.44648 & 6.119353 & 580.9202 \\
\hline $\mathbf{1 9 8 2}$ & 5.048901 & 43.50299 & 6.59568 & 367.8567 \\
\hline $\mathbf{1 9 8 3}$ & 4.679682 & 36.06177 & 6.005145 & 322.7421 \\
\hline $\mathbf{1 9 8 4}$ & 4.673155 & 35.79623 & 5.982995 & 413.7735 \\
\hline $\mathbf{1 9 8 5}$ & 4.457508 & 32.03155 & 5.659642 & 363.1367 \\
\hline $\mathbf{1 9 8 6}$ & 4.190294 & 30.95622 & 5.563832 & 289.2062 \\
\hline $\mathbf{1 9 8 7}$ & 4.4215 & 32.61542 & 5.710991 & 214.1256 \\
\hline $\mathbf{1 9 8 8}$ & 4.718977 & 36.10812 & 6.009003 & 267.9374 \\
\hline $\mathbf{1 9 8 9}$ & 5.119437 & 43.06325 & 6.56226 & 355.6121 \\
\hline $\mathbf{1 9 9 0}$ & 4.50011 & 33.25785 & 5.766962 & 290.7026 \\
\hline $\mathbf{1 9 9 1}$ & 4.779344 & 36.40706 & 6.033826 & 377.1526 \\
\hline $\mathbf{1 9 9 2}$ & 4.554198 & 33.19015 & 5.761089 & 403.3977 \\
\hline $\mathbf{1 9 9 3}$ & 4.587816 & 33.90914 & 5.823155 & 391.6597 \\
\hline $\mathbf{1 9 9 4}$ & 4.731567 & 39.72302 & 6.30262 & 238.5893 \\
\hline $\mathbf{1 9 9 5}$ & 4.593886 & 35.34834 & 5.945447 & 422.4712 \\
\hline $\mathbf{1 9 9 6}$ & 4.604577 & 37.12737 & 6.093224 & 489.9269 \\
\hline $\mathbf{1 9 9 7}$ & 4.594456 & 34.59369 & 5.88164 & 305.6196 \\
\hline $\mathbf{1 9 9 8}$ & 4.238531 & 29.13172 & 5.39738 & 201.7801 \\
\hline $\mathbf{1 9 9 9}$ & 4.281089 & 29.91289 & 5.469268 & 129.9668 \\
\hline $\mathbf{2 0 0 0}$ & 4.848534 & 39.28493 & 6.267769 & 191.5474 \\
\hline & & & & \\
\hline
\end{tabular}




\begin{tabular}{|c|c|c|c|c|c|}
\hline $\begin{array}{l}\stackrel{0}{\mathscr{z}} \\
\stackrel{0}{N} \\
\dot{0} \\
z\end{array}$ & $\bar{\sim}$ & $\hat{\sim}$ & $n$ & N & 6 \\
\hline ن் & 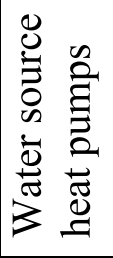 & 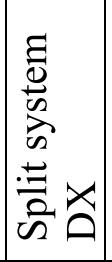 & 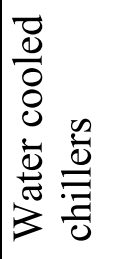 & 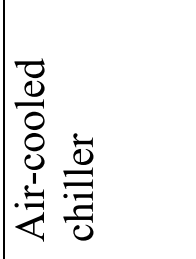 & 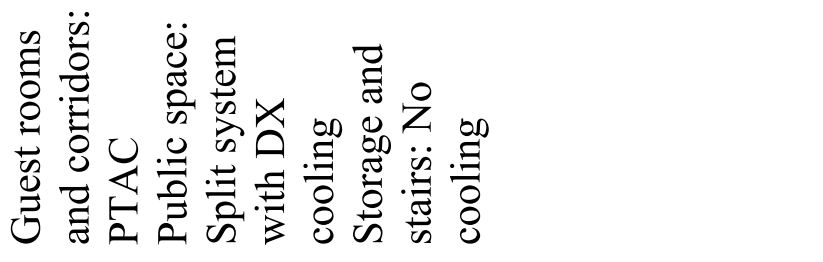 \\
\hline 茵 & 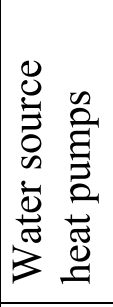 & 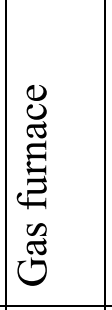 & $\begin{array}{l}\overline{0} \\
: \overline{0} \\
0 \\
0 \\
\tilde{0} \\
0 \\
0\end{array}$ & $\begin{array}{l}\frac{\dot{0}}{\overline{0}} \\
\overline{0} \\
\overline{0} \\
\tilde{0}\end{array}$ & 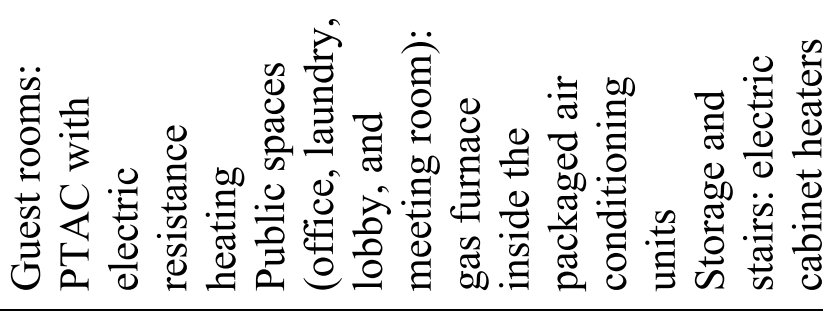 \\
\hline 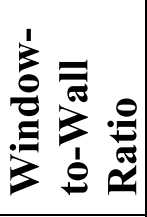 & ஓें & ஓें & bo & $\begin{array}{l}\stackrel{0}{0} \\
\text { ஸे } \\
\stackrel{\text { n}}{ }\end{array}$ & \\
\hline 吾 & $m$ & $m$ & 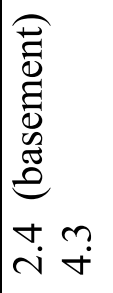 & 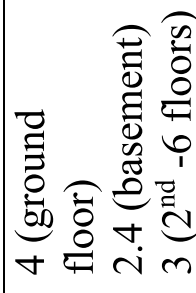 & 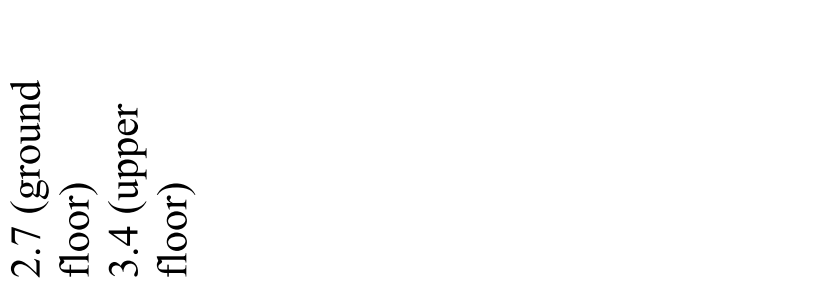 \\
\hline 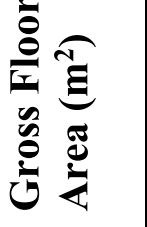 & \begin{tabular}{l}
$\infty$ \\
\multirow{0}{0}{} \\
6 \\
$\infty$ \\
$\infty$ \\
$r$
\end{tabular} & $\begin{array}{l}n \\
\dot{n} \\
\tilde{n} \\
m\end{array}$ & 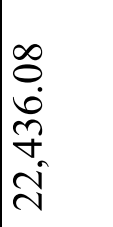 & $\begin{array}{l}\text { సे } \\
\text { ñ } \\
\text { ma } \\
=\end{array}$ & $\begin{array}{l}\infty \\
n \\
\stackrel{n}{n} \\
\vdots \\
\sigma \\
\sigma\end{array}$ \\
\hline 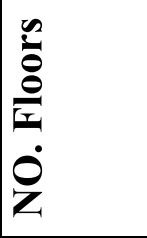 & $\stackrel{0}{\underline{1}}$ & $\nabla$ & 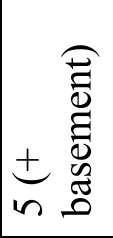 & 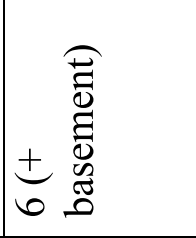 & $\nabla$ \\
\hline 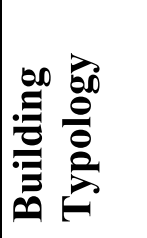 & 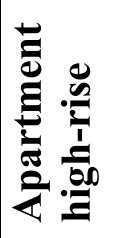 & 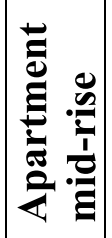 & 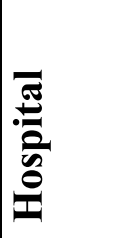 & 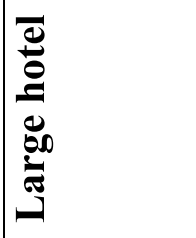 & 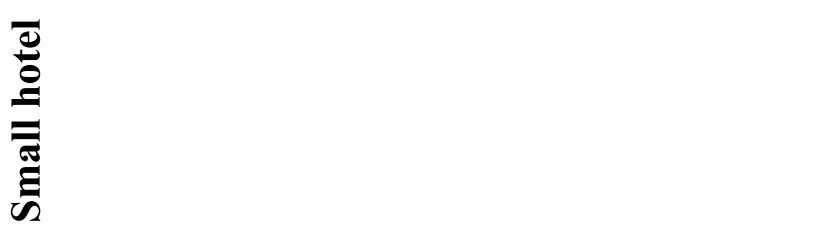 \\
\hline
\end{tabular}




\begin{tabular}{|c|c|c|c|c|c|}
\hline$\approx$ & $\stackrel{\infty}{\Perp}$ & 0 & $\stackrel{\infty}{\exists}$ & $m$ & $m$ \\
\hline 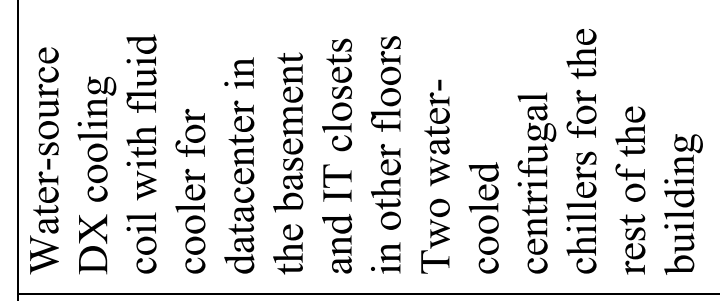 & 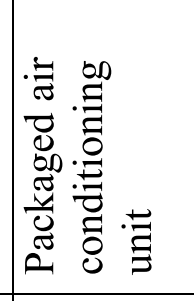 & 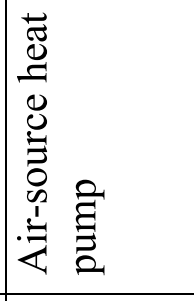 & 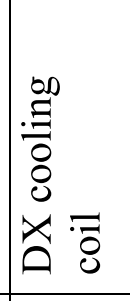 & 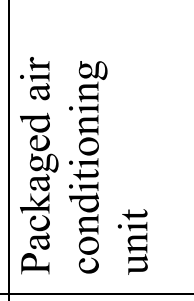 & 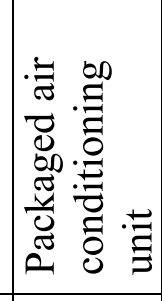 \\
\hline 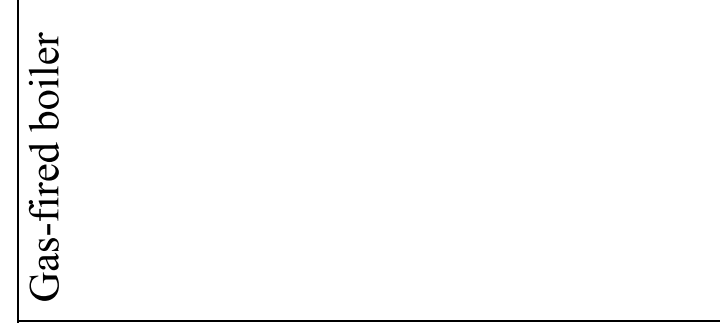 & 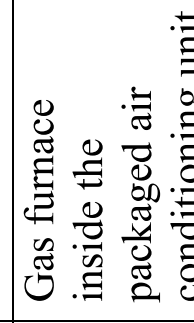 & 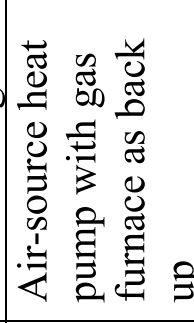 & 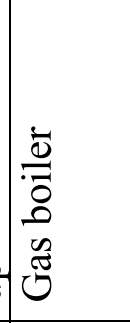 & 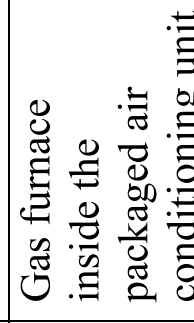 & 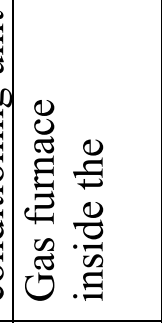 \\
\hline 究 & 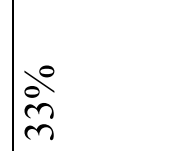 & 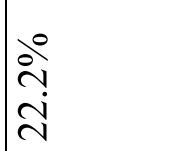 & ఫें & in & $\frac{\stackrel{\circ}{\vec{N}}}{\text { वे }}$ \\
\hline$\hat{i}$ & $\hat{i}$ & $m$ & $m$ & $m$ & $m$ \\
\hline 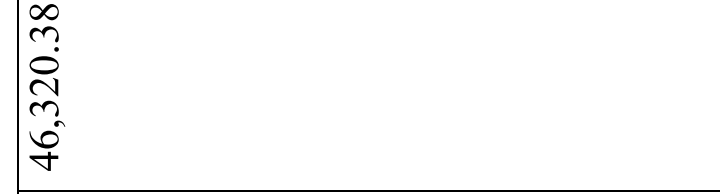 & $\begin{array}{l}\partial \vec{\partial} \\
\dot{1} \\
\alpha \\
\partial \\
\dot{\sigma}\end{array}$ & 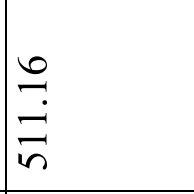 & $\begin{array}{l}\vec{b} \\
\dot{d} \\
\dot{\infty} \\
n_{0} \\
\dot{n}\end{array}$ & 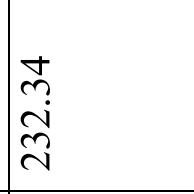 & 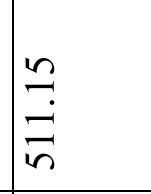 \\
\hline 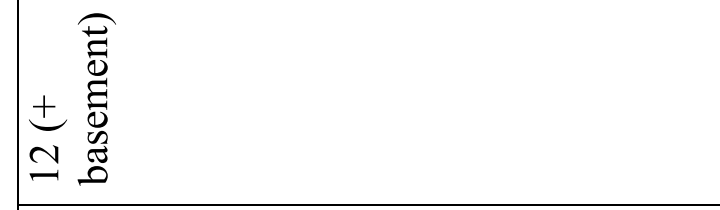 & $m$ & - & $m$ & - & - \\
\hline 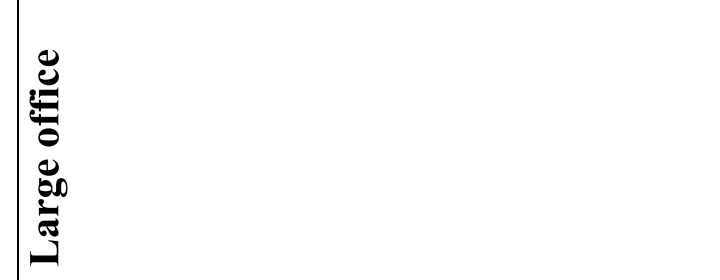 & 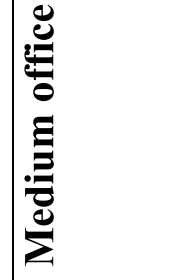 & 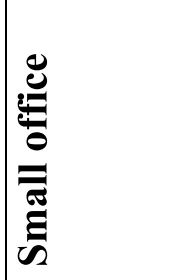 & 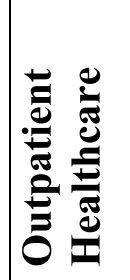 & 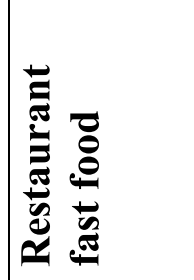 & 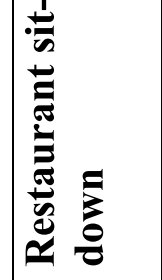 \\
\hline
\end{tabular}




\begin{tabular}{|c|c|c|c|c|c|}
\hline & in & $\stackrel{0}{\circ}$ & $\approx$ & \& & $m$ \\
\hline & 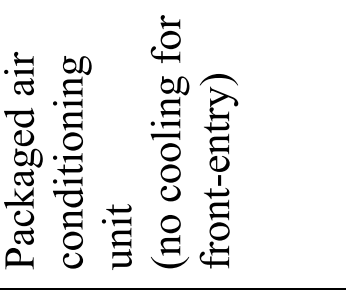 & 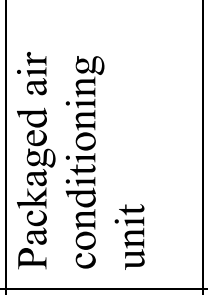 & 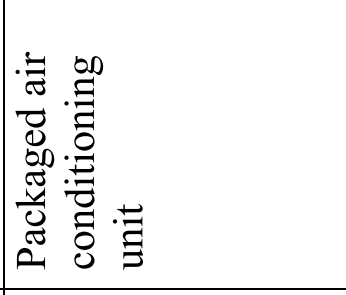 & 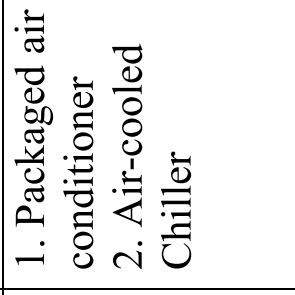 & 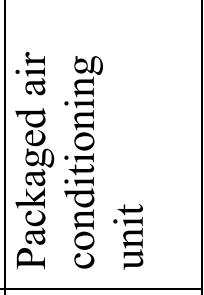 \\
\hline 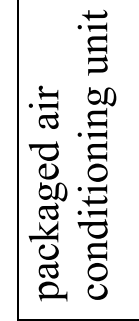 & 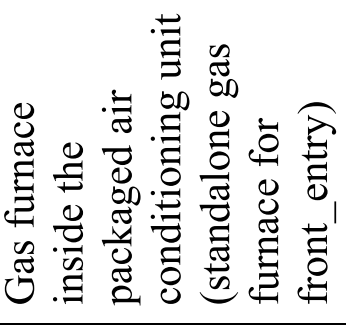 & 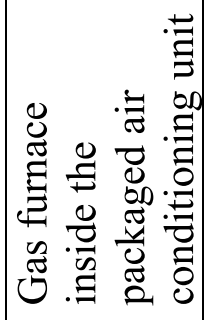 & 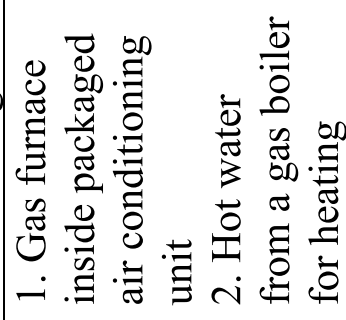 & 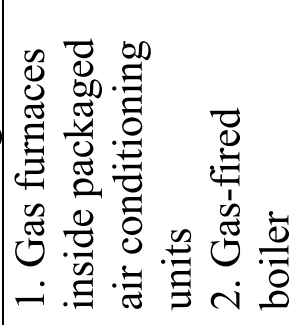 & 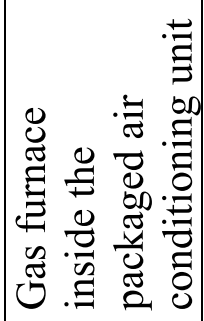 \\
\hline & $\frac{\circ}{\frac{0}{r}}$ & 离 & $\begin{array}{l}\stackrel{0}{i} \\
\text { in }\end{array}$ & 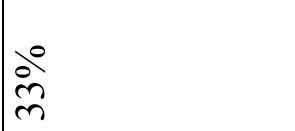 & $\frac{\partial}{i}$ \\
\hline & 7 & in & | & $\nabla$ & 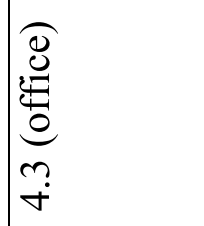 \\
\hline & 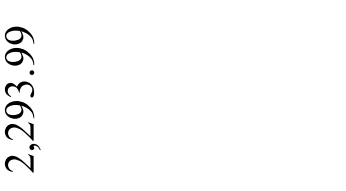 & 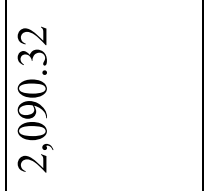 & $\begin{array}{l}8 \\
\dot{0} \\
\dot{\alpha} \\
0 \\
0\end{array}$ & $\begin{array}{l}8 \\
i \\
\alpha \\
n \\
2 \\
2\end{array}$ & $\begin{array}{l}m \\
\cdots \\
\infty \\
\infty \\
\dot{\sigma} \\
\dot{\sigma}\end{array}$ \\
\hline & - & - & - & $N$ & - \\
\hline & 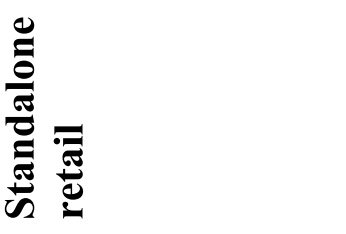 & 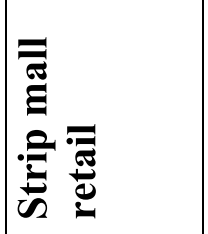 & 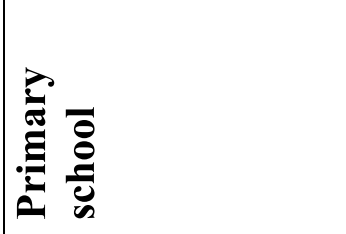 & 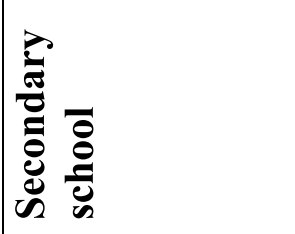 & 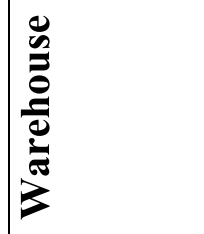 \\
\hline
\end{tabular}




\section{Appendix F. Information on buildings envelope material, internal loads and schedules}

Further information on materials comprising the envelope of the 16 building models as well as detailed internal loads and schedules are too excessive to provide hard copies. Thus, the main text is intended to provide enough information for comprehensive understanding of this thesis and its results. Moreover, a digital appendix is provided containing the 16 prototype building models, information on envelope material, as well as internal loads and schedules. Additional information can be made available upon request. 


\section{Appendix G. Detailed weather data summary for the eight weather files.}

a) CWEC (1959-1989)

\begin{tabular}{|c|c|c|c|c|c|c|c|c|c|c|c|c|c|}
\hline MONTHLY MEANS & JAN & FEB & MAR & APR & MAY & JUN & JUL & AUG & SEP & ОСТ & NOV & DEC & \\
\hline Global Horiz Radiation (Avg Hourly) & 161 & 221 & 268 & 329 & 384 & 404 & 405 & 376 & 333 & 239 & 136 & 122 & Wh/sq.m \\
\hline Direct Normal Radiation (Avg Hourly) & 230 & 265 & 270 & 307 & 324 & 323 & 361 & 316 & 347 & 249 & 130 & 172 & Wh/sq.m \\
\hline Diffuse Radiation (Avg Hourly) & 85 & 112 & 127 & 143 & 172 & 185 & 164 & 178 & 141 & 126 & 86 & 67 & Wh/sq.m \\
\hline Global Horiz Radiation (Max Hourly) & 474 & 651 & 875 & 931 & 974 & 1003 & 980 & 907 & 827 & 655 & 516 & 417 & Wh/sq.m \\
\hline Direct Normal Radiation (Max Hourly) & 879 & 947 & 1022 & 1028 & 959 & 948 & 927 & 932 & 931 & 870 & 861 & 872 & Wh/sq.m \\
\hline Diffuse Radiation (Max Hourly) & 238 & 368 & 439 & 431 & 594 & 545 & 458 & 431 & 385 & 328 & 250 & 195 & Wh/sq.m \\
\hline Global Horiz Radiation (Avg Daily Total) & 1468 & 2262 & 3181 & 4347 & 5599 & 6138 & 6035 & 5163 & 4099 & 2568 & 1300 & 1072 & Wh/sq.m \\
\hline Direct Normal Radiation (Avg Daily Total) & 2097 & 2703 & 3207 & 4041 & 4728 & 4918 & 5384 & 4336 & 4251 & 2663 & 1249 & 1519 & Wh/sq.m \\
\hline Diffuse Radiation (Avg Daily Total) & 783 & 1151 & 1506 & 1900 & 2513 & 2818 & 2441 & 2453 & 1745 & 1358 & 818 & 591 & Wh/sq.m \\
\hline Global Horiz Illumination (Avg Hourly) & 18043 & 24998 & 30402 & 37172 & 43543 & 45839 & 45796 & 42702 & 37681 & 27169 & 15572 & 13688 & lux \\
\hline Direct Normal Illumination (Avg Hourly) & 22576 & 27019 & 28334 & 32402 & 34319 & 34073 & 37965 & 33408 & 36306 & 25747 & 13364 & 17190 & lux \\
\hline Dry Bulb Temperature (Avg Monthly) & -5 & -5 & 0 & 5 & 11 & 17 & 20 & 19 & 14 & 8 & 3 & -2 & degrees $\mathrm{C}$ \\
\hline Dew Point Temperature (Avg Monthly) & -8 & -9 & -4 & 0 & 4 & 11 & 14 & 13 & 10 & 4 & 0 & -5 & degrees $C$ \\
\hline Relative Humidity (Avg Monthly) & 78 & 75 & 74 & 70 & 62 & 68 & 70 & 70 & 75 & 77 & 83 & 79 & percent \\
\hline Wind Direction (Monthly Mode) & 250 & 270 & 270 & 90 & 340 & 0 & 330 & 340 & 330 & 250 & 250 & 250 & degrees \\
\hline Wind Speed (Avg Monthly) & 4 & 5 & 5 & 4 & 4 & 3 & 3 & 2 & 3 & 4 & 4 & 5 & $\mathrm{~m} / \mathrm{s}$ \\
\hline Ground Temperature (Avg Monthly of 3 Depths) & 0 & -1 & 0 & 0 & 5 & 10 & 14 & 15 & 15 & 12 & 7 & 3 & degrees $C$ \\
\hline
\end{tabular}

b) CWEC2016 (1998-2014)

\begin{tabular}{|c|c|c|c|c|c|c|c|c|c|c|c|c|c|}
\hline MONTHLY MEANS & JAN & FEB & MAR & APR & MAY & JUN & JUL & AUG & SEP & Ост & NOV & DEC & \\
\hline Global Horiz Radiation (Avg Hourly) & 183 & 244 & 337 & 362 & 391 & 393 & 407 & 368 & 321 & 242 & 175 & 145 & Wh/sq.m \\
\hline Direct Normal Radiation (Avg Hourly) & 246 & 285 & 395 & 336 & 323 & 311 & 339 & 316 & 312 & 253 & 198 & 200 & Wh/sq.m \\
\hline Diffuse Radiation (Avg Hourly) & 108 & 127 & 131 & 153 & 175 & 176 & 171 & 167 & 140 & 124 & 103 & 83 & Wh/sq.m \\
\hline Global Horiz Radiation (Max Hourly) & 490 & 646 & 844 & 934 & 972 & 958 & 938 & 890 & 816 & 671 & 541 & 391 & Wh/sq.m \\
\hline Direct Normal Radiation (Max Hourly) & 886 & 950 & 961 & 937 & 908 & 878 & 869 & 856 & 862 & 859 & 855 & 786 & Wh/sq.m \\
\hline Diffuse Radiation (Max Hourly) & 233 & 343 & 366 & 388 & 450 & 469 & 427 & 431 & 370 & 304 & 236 & 197 & Wh/sq.m \\
\hline Global Horiz Radiation (Avg Daily Total) & 1678 & 2500 & 3980 & 4814 & 5698 & 5983 & 6059 & 5059 & 3971 & 2610 & 1664 & 1281 & Wh/sq.m \\
\hline Direct Normal Radiation (Avg Daily Total) & 2251 & 2937 & 4665 & 4460 & 4697 & 4745 & 5046 & 4351 & 3870 & 2731 & 1903 & 1768 & Wh/sq.m \\
\hline Diffuse Radiation (Avg Daily Total) & 995 & 1291 & 1546 & 2039 & 2559 & 2674 & 2554 & 2307 & 1729 & 1338 & 971 & 736 & Wh/sq.m \\
\hline Global Horiz Illumination (Avg Hourly) & 20581 & 27632 & 38793 & 41933 & 45496 & 45819 & 47388 & 42727 & 37217 & 27689 & 19622 & 16215 & lux \\
\hline Direct Normal Illumination (Avg Hourly) & 12181 & 17018 & 26678 & 24276 & 22659 & 21379 & 22534 & 20010 & 19812 & 15439 & 10984 & 10041 & lux \\
\hline Dry Bulb Temperature (Avg Monthly) & -6 & -3 & 1 & 7 & 14 & 19 & 22 & 21 & 17 & 10 & 3 & 0 & degrees $\mathrm{C}$ \\
\hline Dew Point Temperature (Avg Monthly) & -9 & -8 & -5 & -1 & 7 & 12 & 16 & 15 & 11 & 5 & 0 & -4 & degrees $C$ \\
\hline Relative Humidity (Avg Monthly) & 75 & 68 & 61 & 54 & 66 & 63 & 69 & 67 & 72 & 73 & 75 & 73 & percent \\
\hline Wind Direction (Monthly Mode) & 250 & 250 & 320 & 90 & 160 & 0 & 140 & 0 & 270 & 310 & 250 & 290 & degrees \\
\hline Wind Speed (Avg Monthly) & 4 & 4 & 5 & 5 & 4 & 3 & 3 & 3 & 4 & 4 & 4 & 4 & $\mathrm{~m} / \mathrm{s}$ \\
\hline Ground Temperature (Avg Monthly of 3 Depths) & 1 & 0 & 0 & 1 & 7 & 12 & 16 & 18 & 17 & 14 & 9 & 4 & degrees $\mathrm{C}$ \\
\hline
\end{tabular}


c) CCWorldWeatherGen tool. The hourly dry-bulb temperature for the future weather file generated based on the 1959-1989 baseline period.

\begin{tabular}{|c|c|c|c|c|c|c|c|c|c|c|c|c|c|}
\hline MONTHLY MEANS & JAN & FEB & MAR & APR & MAY & JUN & JUL & AUG & SEP & OCT & NOV & DEC & \\
\hline Global Horiz Radiation (Avg Hourly) & 150 & 204 & 246 & 329 & 404 & 427 & 432 & 403 & 352 & 248 & 132 & 110 & Wh/sq.m \\
\hline Direct Normal Radiation (Avg Hourly) & 190 & 241 & 231 & 323 & 382 & 378 & 436 & 397 & 417 & 281 & 111 & 126 & Wh/sq.m \\
\hline Diffuse Radiation (Avg Hourly) & 90 & 108 & 125 & 135 & 155 & 168 & 144 & 158 & 127 & 122 & 89 & 70 & Wh/sq.m \\
\hline Global Horiz Radiation (Max Hourly) & 446 & 604 & 802 & 933 & 1025 & 1061 & 1046 & 975 & 875 & 682 & 498 & 376 & Wh/sq.m \\
\hline Direct Normal Radiation (Max Hourly) & 744 & 940 & 876 & 1077 & 1100 & 1041 & 1031 & 1035 & 1041 & 1012 & 863 & 736 & Wh/sq.m \\
\hline Diffuse Radiation (Max Hourly) & 242 & 308 & 353 & 420 & 466 & 484 & 441 & 460 & 410 & 350 & 268 & 204 & Wh/sq.m \\
\hline Global Horiz Radiation (Avg Daily Total) & 1374 & 2089 & 2913 & 4350 & 5891 & 6488 & 6432 & 5542 & 4328 & 2671 & 1256 & 968 & Wh/sq.m \\
\hline Direct Normal Radiation (Avg Daily Total) & 1739 & 2463 & 2751 & 4250 & 5567 & 5745 & 6495 & 5436 & 5104 & 3005 & 1061 & 1110 & Wh/sq.m \\
\hline Diffuse Radiation (Avg Daily Total) & 822 & 1111 & 1483 & 1794 & 2266 & 2561 & 2150 & 2181 & 1569 & 1314 & 851 & 620 & Wh/sq.m \\
\hline Global Horiz Illumination (Avg Hourly) & 16162 & 22058 & 26716 & 35634 & 43703 & 46600 & 47361 & 44301 & 38438 & 26933 & 14492 & 11930 & lux \\
\hline Direct Normal Illumination (Avg Hourly) & 16098 & 21428 & 21757 & 30867 & 36812 & 35375 & 40811 & 36778 & 38888 & 25461 & 9628 & 10715 & Iux \\
\hline Dry Bulb Temperature (Avg Monthly) & -3 & -3 & 1 & 8 & 14 & 20 & 23 & 23 & 18 & 11 & 5 & 0 & degrees $C$ \\
\hline Dew Point Temperature (Avg Monthly) & -6 & -7 & -2 & 1 & 6 & 13 & 16 & 16 & 13 & 7 & 2 & -2 & degrees $C$ \\
\hline Relative Humidity (Avg Monthly) & 77 & 74 & 71 & 67 & 59 & 65 & 66 & 65 & 72 & 75 & 81 & 78 & percent \\
\hline Wind Direction (Monthly Mode) & 250 & 270 & 270 & 90 & 340 & 0 & 330 & 340 & 330 & 250 & 250 & 250 & degrees \\
\hline Wind Speed (Avg Monthly) & 4 & 5 & 5 & 4 & 4 & 3 & 3 & 2 & 3 & 4 & 4 & 5 & $\mathrm{~m} / \mathrm{s}$ \\
\hline Ground Temperature (Avg Monthly of 3 Depths) & 0 & -1 & 0 & 0 & 5 & 10 & 14 & 15 & 15 & 12 & 7 & 3 & degrees $C$ \\
\hline
\end{tabular}

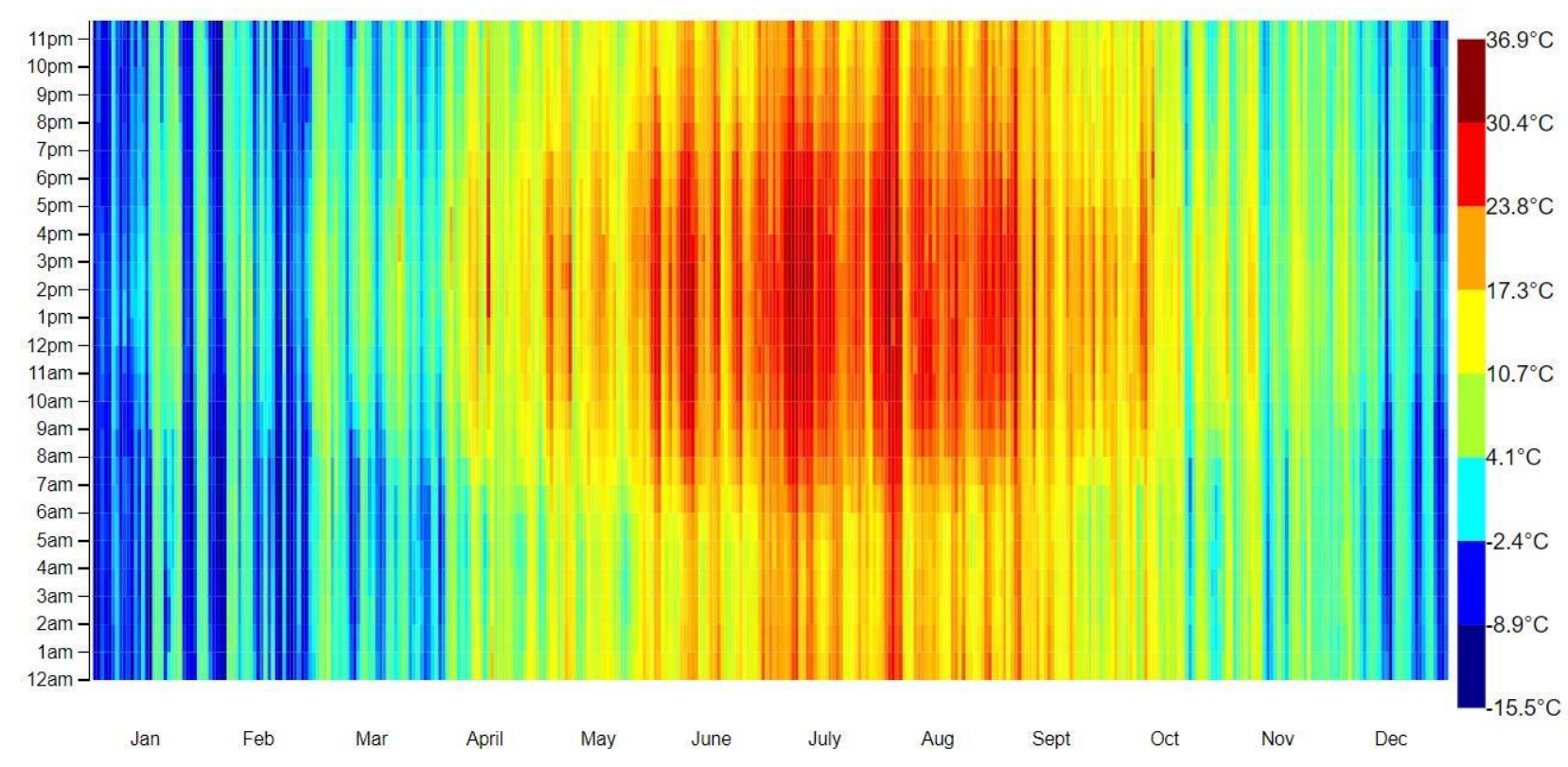


d) CCWorldWeatherGen tool. The hourly dry-bulb temperature for the future weather file generated based on the 1998-2014 baseline period.

\begin{tabular}{|c|c|c|c|c|c|c|c|c|c|c|c|c|c|}
\hline MONTHLY MEANS & JAN & FEB & MAR & APR & MAY & JUN & JUL & AUG & SEP & Ост & NOV & DEC & \\
\hline Global Horiz Radiation (Avg Hourly) & 173 & 228 & 315 & 363 & 411 & 416 & 435 & 396 & 340 & 252 & 170 & 133 & Wh/sq.m \\
\hline Direct Normal Radiation (Avg Hourly) & 186 & 235 & 336 & 358 & 381 & 371 & 401 & 382 & 368 & 282 & 178 & 138 & Wh/sq.m \\
\hline Diffuse Radiation (Avg Hourly) & 115 & 127 & 136 & 140 & 156 & 160 & 158 & 153 & 127 & 120 & 105 & 90 & Wh/sq.m \\
\hline Global Horiz Radiation (Max Hourly) & 465 & 604 & 788 & 935 & 1022 & 1015 & 1001 & 959 & 865 & 698 & 539 & 364 & Wh/sq.m \\
\hline Direct Normal Radiation (Max Hourly) & 764 & 973 & 842 & 956 & 998 & 961 & 951 & 962 & 955 & 940 & 854 & 646 & Wh/sq.m \\
\hline Diffuse Radiation (Max Hourly) & 219 & 292 & 382 & 443 & 472 & 513 & 511 & 452 & 393 & 336 & 264 & 206 & Wh/sq.m \\
\hline Global Horiz Radiation (Avg Daily Total) & 1591 & 2334 & 3714 & 4820 & 5990 & 6338 & 6466 & 5445 & 4206 & 2715 & 1621 & 1179 & Wh/sq.m \\
\hline Direct Normal Radiation (Avg Daily Total) & 1706 & 2420 & 3970 & 4756 & 5540 & 5647 & 5964 & 5260 & 4573 & 3045 & 1721 & 1223 & Wh/sq.m \\
\hline Diffuse Radiation (Avg Daily Total) & 1055 & 1301 & 1604 & 1860 & 2282 & 2441 & 2351 & 2110 & 1562 & 1296 & 988 & 799 & Wh/sq.m \\
\hline Global Horiz Illumination (Avg Hourly) & 18646 & 24532 & 33834 & 39207 & 44819 & 45916 & 48047 & 43556 & 37165 & 27340 & 18499 & 14453 & lux \\
\hline Direct Normal Illumination (Avg Hourly) & 15560 & 21570 & 31823 & 34645 & 36935 & 35947 & 38510 & 36047 & 34929 & 26032 & 15541 & 11507 & lux \\
\hline Dry Bulb Temperature (Avg Monthly) & -3 & -1 & 3 & 10 & 17 & 22 & 25 & 25 & 20 & 13 & 6 & 2 & degrees $\mathrm{C}$ \\
\hline Dew Point Temperature (Avg Monthly) & -6 & -6 & -3 & 0 & 9 & 14 & 18 & 17 & 14 & 7 & 1 & -1 & degrees $C$ \\
\hline Relative Humidity (Avg Monthly) & 74 & 67 & 58 & 51 & 63 & 60 & 65 & 63 & 69 & 71 & 73 & 72 & percent \\
\hline Wind Direction (Monthly Mode) & 250 & 250 & 320 & 90 & 160 & 0 & 140 & 0 & 270 & 310 & 250 & 290 & degrees \\
\hline Wind Speed (Avg Monthly) & 4 & 4 & 5 & 5 & 3 & 3 & 3 & 3 & 3 & 4 & 4 & 4 & $\mathrm{~m} / \mathrm{s}$ \\
\hline Ground Temperature (Avg Monthly of 3 Depths) & 1 & 0 & 0 & 1 & 7 & 12 & 16 & 18 & 17 & 14 & 9 & 4 & degrees $\mathrm{C}$ \\
\hline
\end{tabular}

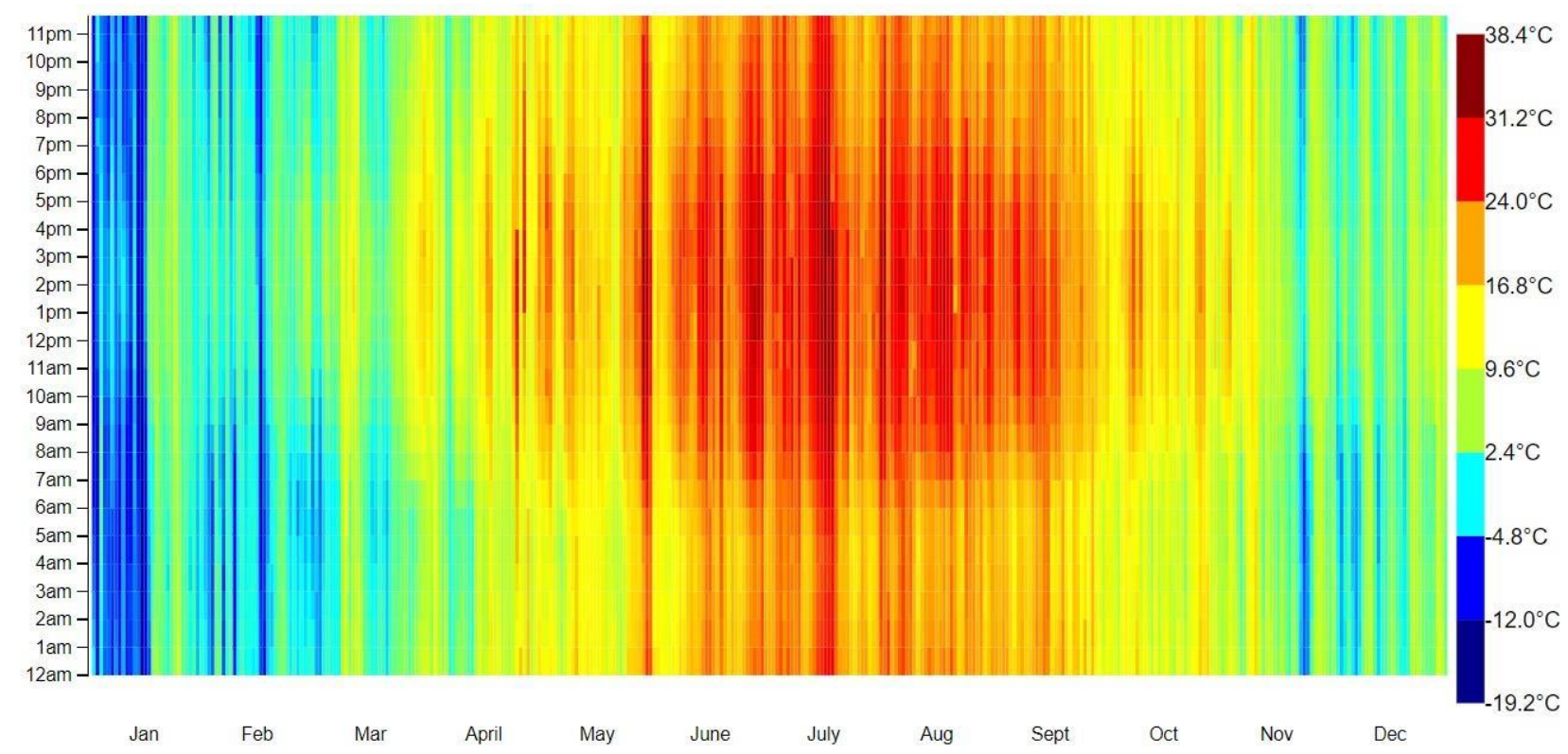


e) WeatherShift tool. The hourly dry-bulb temperature for the future weather file generated based on the 19591989 baseline period.

\begin{tabular}{|c|c|c|c|c|c|c|c|c|c|c|c|c|c|}
\hline MONTHLY MEANS & JAN & FEB & MAR & APR & MAY & JUN & JUL & AUG & SEP & Ост & NOV & DEC & \\
\hline Global Horiz Radiation (Avg Hourly) & 146 & 199 & 270 & 346 & 402 & 433 & 421 & 408 & 354 & 260 & 139 & 122 & Wh/sq.m \\
\hline Direct Normal Radiation (Avg Hourly) & 215 & 243 & 272 & 325 & 342 & 353 & 377 & 349 & 367 & 270 & 134 & 173 & Wh/sq.m \\
\hline Diffuse Radiation (Avg Hourly) & 71 & 91 & 129 & 160 & 189 & 215 & 179 & 210 & 162 & 148 & 89 & 67 & Wh/sq.m \\
\hline Global Horiz Radiation (Max Hourly) & 432 & 587 & 881 & 981 & 1019 & 1077 & 1018 & 985 & 877 & 714 & 528 & 418 & Wh/sq.m \\
\hline Direct Normal Radiation (Max Hourly) & 824 & 870 & 1029 & 1088 & 1011 & 1036 & 967 & 1028 & 986 & 946 & 882 & 873 & Wh/sq.m \\
\hline Diffuse Radiation (Max Hourly) & 198 & 297 & 446 & 484 & 655 & 633 & 502 & 509 & 440 & 384 & 259 & 196 & Wh/sq.m \\
\hline Global Horiz Radiation (Avg Daily Total) & 1338 & 2041 & 3203 & 4582 & 5857 & 6592 & 6268 & 5607 & 4348 & 2800 & 1330 & 1074 & Wh/sq.m \\
\hline Direct Normal Radiation (Avg Daily Total) & 1967 & 2482 & 3229 & 4276 & 4986 & 5372 & 5617 & 4780 & 4500 & 2895 & 1279 & 1521 & Wh/sq.m \\
\hline Diffuse Radiation (Avg Daily Total) & 651 & 929 & 1528 & 2135 & 2771 & 3272 & 2673 & 2898 & 1994 & 1590 & 848 & 591 & Wh/sq.m \\
\hline Global Horiz Illumination (Avg Hourly) & 18043 & 24998 & 30402 & 37172 & 43543 & 45839 & 45796 & 42702 & 37681 & 27169 & 15572 & 13688 & lux \\
\hline Direct Normal Illumination (Avg Hourly) & 22576 & 27019 & 28334 & 32402 & 34319 & 34073 & 37965 & 33408 & 36306 & 25747 & 13364 & 17190 & lux \\
\hline Dry Bulb Temperature (Avg Monthly) & -1 & -1 & 2 & 9 & 15 & 21 & 24 & 24 & 18 & 12 & 6 & 1 & degrees C \\
\hline Dew Point Temperature (Avg Monthly) & -4 & -5 & -1 & 2 & 7 & 14 & 18 & 17 & 13 & 7 & 3 & -2 & degrees $\mathrm{C}$ \\
\hline Relative Humidity (Avg Monthly) & 77 & 74 & 71 & 68 & 60 & 65 & 69 & 66 & 72 & 74 & 82 & 75 & percent \\
\hline Wind Direction (Monthly Mode) & 250 & 270 & 270 & 90 & 340 & 0 & 330 & 340 & 330 & 250 & 250 & 250 & degrees \\
\hline Wind Speed (Avg Monthly) & 4 & 5 & 5 & 4 & 4 & 3 & 3 & 2 & 3 & 4 & 4 & 5 & $\mathrm{~m} / \mathrm{s}$ \\
\hline Ground Temperature (Avg Monthly of 3 Depths) & 0 & -1 & 0 & 0 & 5 & 10 & 14 & 15 & 15 & 12 & 7 & 3 & degrees $\mathrm{C}$ \\
\hline
\end{tabular}

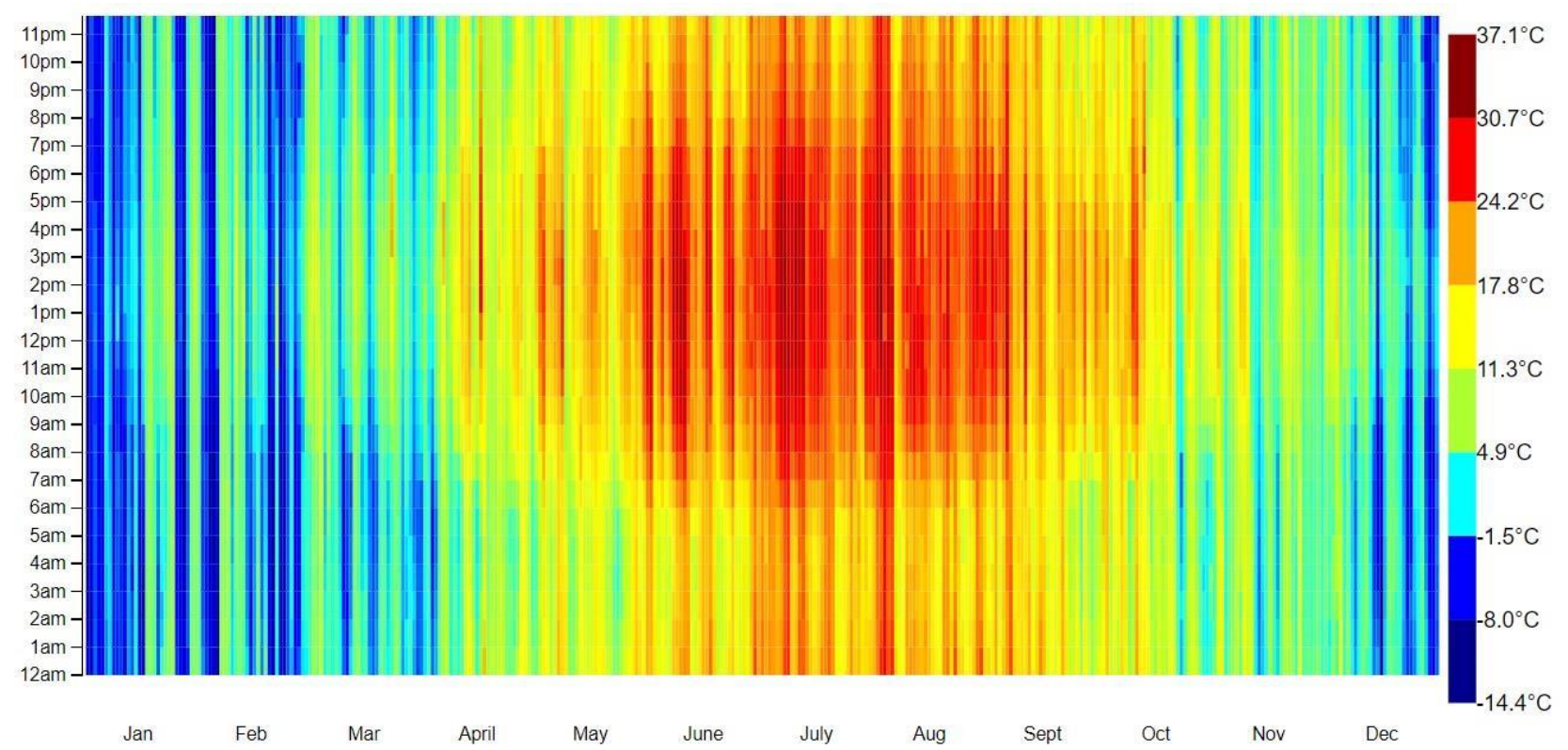


f) WeatherShift tool. The hourly dry-bulb temperature for the future weather file generated based on the 19982014 baseline period.

\begin{tabular}{|c|c|c|c|c|c|c|c|c|c|c|c|c|c|}
\hline MONTHLY MEANS & JAN & FEB & MAR & APR & MAY & JUN & JUL & AUG & SEP & OCT & NOV & DEC & \\
\hline Global Horiz Radiation (Avg Hourly) & 169 & 222 & 339 & 380 & 409 & 423 & 423 & 400 & 341 & 264 & 178 & 145 & Wh/sq.m \\
\hline Direct Normal Radiation (Avg Hourly) & 231 & 264 & 397 & 354 & 341 & 341 & 355 & 349 & 332 & 274 & 201 & 200 & Wh/sq.m \\
\hline Diffuse Radiation (Avg Hourly) & 94 & 105 & 133 & 171 & 193 & 205 & 187 & 200 & 161 & 146 & 106 & 83 & Wh/sq.m \\
\hline Global Horiz Radiation (Max Hourly) & 452 & 589 & 849 & 980 & 1016 & 1031 & 974 & 968 & 867 & 731 & 551 & 392 & Wh/sq.m \\
\hline Direct Normal Radiation (Max Hourly) & 835 & 878 & 966 & 986 & 958 & 962 & 909 & 943 & 917 & 932 & 869 & 787 & Wh/sq.m \\
\hline Diffuse Radiation (Max Hourly) & 202 & 284 & 371 & 433 & 495 & 549 & 466 & 514 & 423 & 357 & 243 & 198 & Wh/sq.m \\
\hline Global Horiz Radiation (Avg Daily Total) & 1547 & 2278 & 4003 & 5049 & 5956 & 6437 & 6292 & 5503 & 4220 & 2842 & 1694 & 1282 & Wh/sq.m \\
\hline Direct Normal Radiation (Avg Daily Total) & 2121 & 2716 & 4687 & 4696 & 4956 & 5199 & 5279 & 4796 & 4119 & 2963 & 1933 & 1770 & Wh/sq.m \\
\hline Diffuse Radiation (Avg Daily Total) & 864 & 1070 & 1569 & 2274 & 2817 & 3128 & 2787 & 2752 & 1978 & 1570 & 1001 & 736 & Wh/sq.m \\
\hline Global Horiz Illumination (Avg Hourly) & 20581 & 27632 & 38793 & 41933 & 45496 & 45819 & 47388 & 42727 & 37217 & 27689 & 19622 & 16215 & lux \\
\hline Direct Normal Illumination (Avg Hourly) & 12181 & 17018 & 26678 & 24276 & 22659 & 21379 & 22534 & 20010 & 19812 & 15439 & 10984 & 10041 & lux \\
\hline Dry Bulb Temperature (Avg Monthly) & -1 & 0 & 4 & 10 & 18 & 23 & 26 & 26 & 20 & 14 & 6 & 3 & degrees $C$ \\
\hline Dew Point Temperature (Avg Monthly) & -5 & -4 & -3 & 0 & 10 & 15 & 19 & 18 & 14 & 8 & 2 & -1 & degrees $C$ \\
\hline Relative Humidity (Avg Monthly) & 74 & 67 & 58 & 52 & 64 & 60 & 68 & 64 & 69 & 71 & 74 & 70 & percent \\
\hline Wind Direction (Monthly Mode) & 250 & 250 & 320 & 90 & 160 & 0 & 140 & 0 & 270 & 310 & 250 & 290 & degrees \\
\hline Wind Speed (Avg Monthly) & 4 & 4 & 5 & 5 & 4 & 3 & 3 & 3 & 4 & 4 & 4 & 4 & $\mathrm{~m} / \mathrm{s}$ \\
\hline Ground Temperature (Avg Monthly of 3 Depths) & 1 & 0 & 0 & 1 & 7 & 12 & 16 & 18 & 17 & 14 & 9 & 4 & degrees $C$ \\
\hline
\end{tabular}

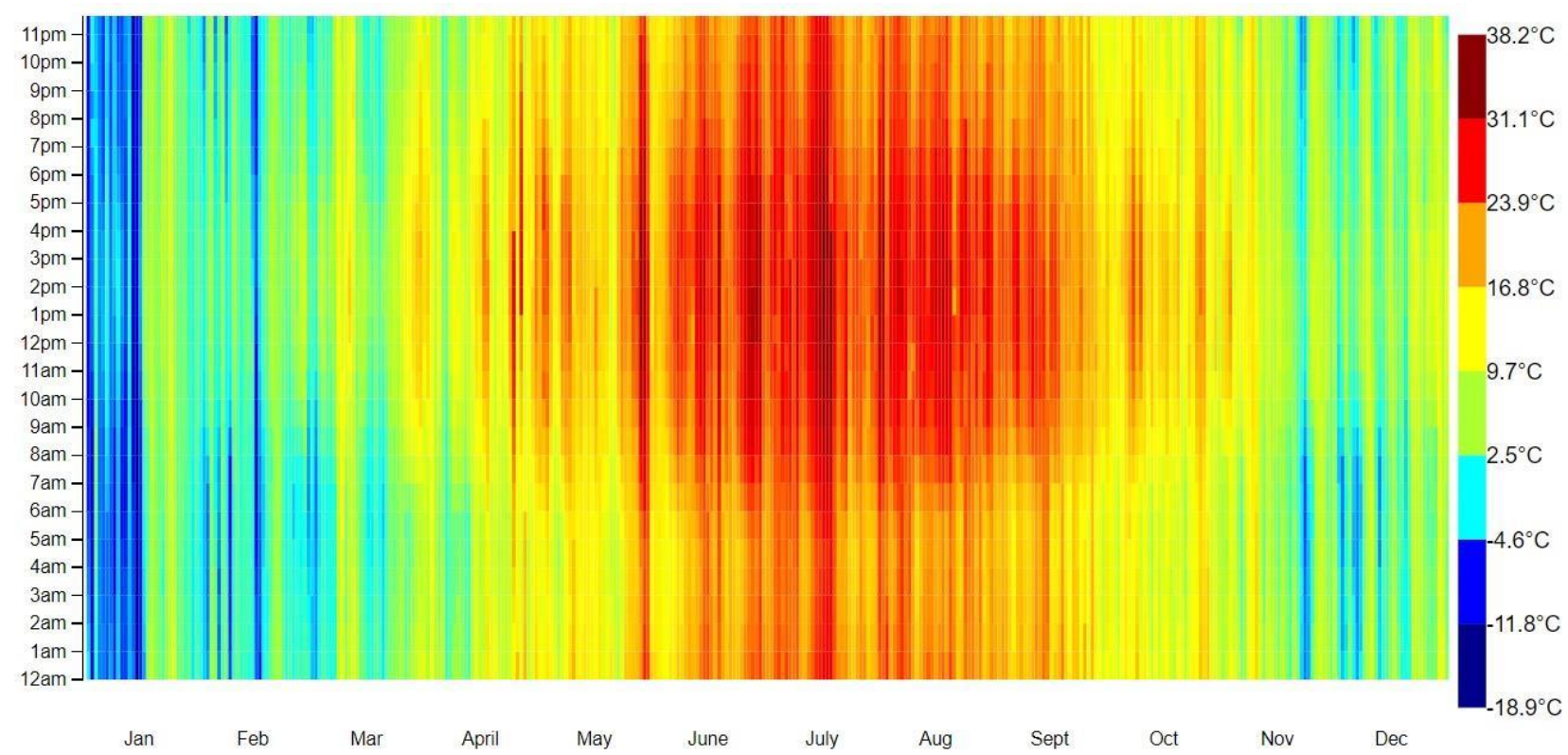


g) HRM3. The hourly dry-bulb temperature for the future weather file generated based on the 1959-1989 baseline period.

\begin{tabular}{|c|c|c|c|c|c|c|c|c|c|c|c|c|c|}
\hline MONTHLY MEANS & JAN & FEB & MAR & APR & MAY & JUN & JUL & AUG & SEP & ОСТ & NOV & DEC & \\
\hline Global Horiz Radiation (Avg Hourly) & 161 & 221 & 268 & 329 & 384 & 404 & 405 & 376 & 333 & 239 & 136 & 122 & Wh/sq.m \\
\hline Direct Normal Radiation (Avg Hourly) & 230 & 265 & 270 & 307 & 324 & 323 & 361 & 316 & 347 & 249 & 130 & 172 & Wh/sq.m \\
\hline Diffuse Radiation (Avg Hourly) & 85 & 112 & 127 & 143 & 172 & 185 & 164 & 178 & 141 & 126 & 86 & 67 & Wh/sq.m \\
\hline Global Horiz Radiation (Max Hourly) & 474 & 651 & 875 & 931 & 974 & 1003 & 980 & 907 & 827 & 655 & 516 & 417 & Wh/sq.m \\
\hline Direct Normal Radiation (Max Hourly) & 879 & 947 & 1022 & 1028 & 959 & 948 & 927 & 932 & 931 & 870 & 861 & 872 & Wh/sq.m \\
\hline Diffuse Radiation (Max Hourly) & 238 & 368 & 439 & 431 & 594 & 545 & 458 & 431 & 385 & 328 & 250 & 195 & Wh/sq.m \\
\hline Global Horiz Radiation (Avg Daily Total) & 1468 & 2262 & 3181 & 4347 & 5599 & 6138 & 6035 & 5163 & 4099 & 2568 & 1300 & 1072 & Wh/sq.m \\
\hline Direct Normal Radiation (Avg Daily Total) & 2097 & 2703 & 3207 & 4041 & 4728 & 4918 & 5384 & 4336 & 4251 & 2663 & 1249 & 1519 & Wh/sq.m \\
\hline Diffuse Radiation (Avg Daily Total) & 783 & 1151 & 1506 & 1900 & 2513 & 2818 & 2441 & 2453 & 1745 & 1358 & 818 & 591 & Wh/sq.m \\
\hline Global Horiz Illumination (Avg Hourly) & 18043 & 24998 & 30402 & 37172 & 43543 & 45839 & 45796 & 42702 & 37681 & 27169 & 15572 & 13688 & lux \\
\hline Direct Normal Illumination (Avg Hourly) & 22576 & 27019 & 28334 & 32402 & 34319 & 34073 & 37965 & 33408 & 36306 & 25747 & 13364 & 17190 & lux \\
\hline Dry Bulb Temperature (Avg Monthly) & -3 & -3 & 1 & 7 & 14 & 20 & 23 & 23 & 18 & 11 & 6 & 0 & degrees $\mathrm{C}$ \\
\hline Dew Point Temperature (Avg Monthly) & -6 & -6 & -2 & 1 & 6 & 13 & 17 & 16 & 13 & 6 & 3 & -3 & degrees $\mathrm{C}$ \\
\hline Relative Humidity (Avg Monthly) & 80 & 76 & 74 & 68 & 61 & 65 & 68 & 69 & 74 & 75 & 82 & 81 & percent \\
\hline Wind Direction (Monthly Mode) & 140 & 140 & 140 & 150 & 150 & 140 & 130 & 160 & 140 & 140 & 140 & 140 & degrees \\
\hline Wind Speed (Avg Monthly) & 4 & 5 & 5 & 4 & 4 & 3 & 3 & 2 & 3 & 4 & 4 & 5 & $\mathrm{~m} / \mathrm{s}$ \\
\hline Ground Temperature (Avg Monthly of 3 Depths) & 0 & -1 & 0 & 0 & 5 & 10 & 14 & 15 & 15 & 12 & 7 & 3 & degrees $C$ \\
\hline
\end{tabular}

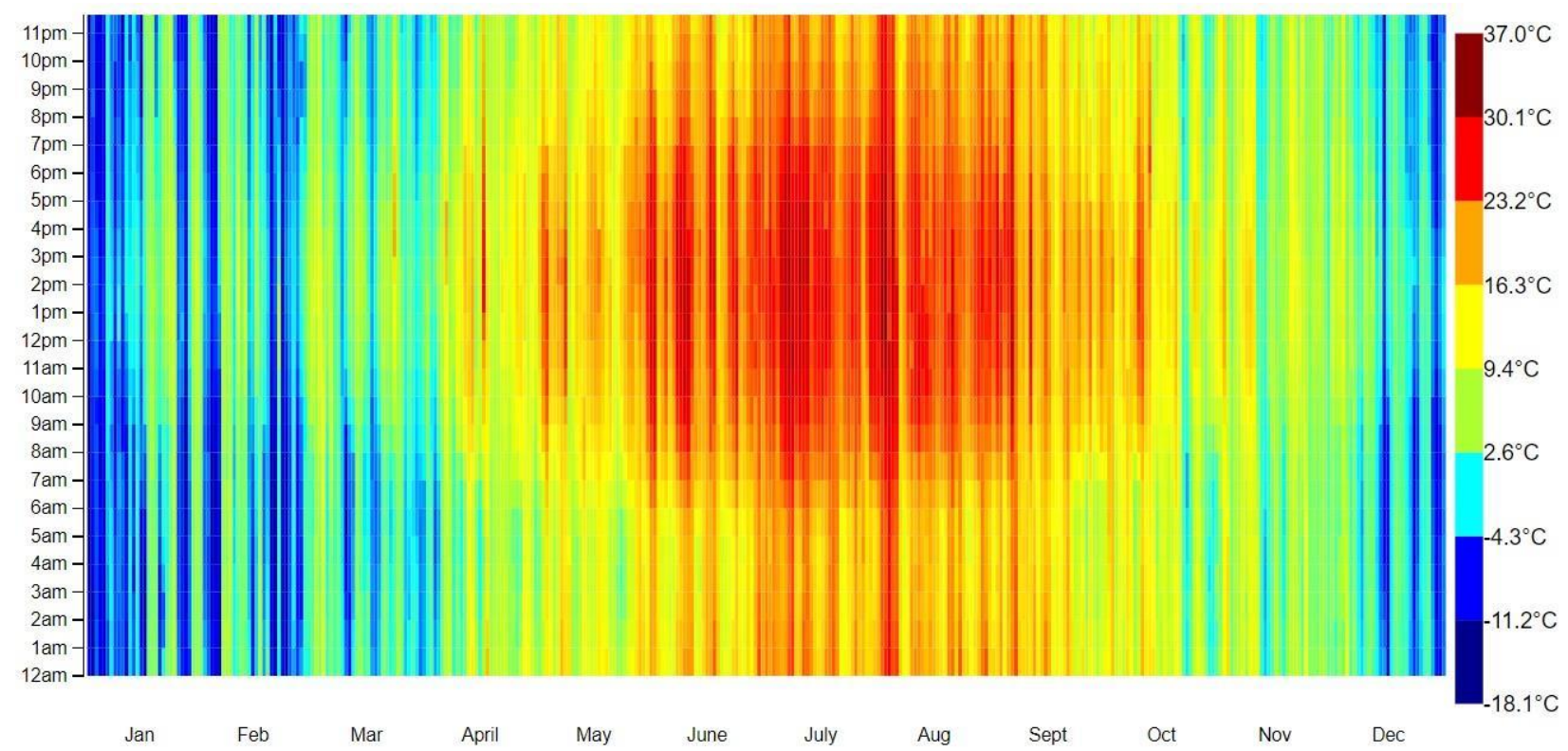


h) HRM3. The hourly dry-bulb temperature for the future weather file generated based on the 1998-2014 baseline period.

\begin{tabular}{|c|c|c|c|c|c|c|c|c|c|c|c|c|c|}
\hline MONTHLY MEANS & JAN & FEB & MAR & APR & MAY & JUN & JUL & AUG & SEP & OCT & Nov & DEC & \\
\hline Global Horiz Radiation (Avg Hourly) & 183 & 244 & 337 & 362 & 391 & 393 & 407 & 368 & 321 & 242 & 175 & 145 & Wh/sq.m \\
\hline Direct Normal Radiation (Avg Hourly) & 246 & 285 & 395 & 336 & 323 & 311 & 339 & 316 & 312 & 253 & 198 & 200 & Wh/sq.m \\
\hline Diffuse Radiation (Avg Hourly) & 108 & 127 & 131 & 153 & 175 & 176 & 171 & 167 & 140 & 124 & 103 & 83 & Wh/sq.m \\
\hline Global Horiz Radiation (Max Hourly) & 490 & 646 & 844 & 934 & 972 & 958 & 938 & 890 & 816 & 671 & 541 & 391 & Wh/sq.m \\
\hline Direct Normal Radiation (Max Hourly) & 886 & 950 & 961 & 937 & 908 & 878 & 869 & 856 & 862 & 859 & 855 & 786 & Wh/sq.m \\
\hline Diffuse Radiation (Max Hourly) & 233 & 343 & 366 & 388 & 450 & 469 & 427 & 431 & 370 & 304 & 236 & 197 & Wh/sq.m \\
\hline Global Horiz Radiation (Avg Daily Total) & 1678 & 2500 & 3980 & 4814 & 5698 & 5983 & 6059 & 5059 & 3971 & 2610 & 1664 & 1281 & Wh/sq.m \\
\hline Direct Normal Radiation (Avg Daily Total) & 2251 & 2937 & 4665 & 4460 & 4697 & 4745 & 5046 & 4351 & 3870 & 2731 & 1903 & 1768 & Wh/sq.m \\
\hline Diffuse Radiation (Avg Daily Total) & 995 & 1291 & 1546 & 2039 & 2559 & 2674 & 2554 & 2307 & 1729 & 1338 & 971 & 736 & Wh/sq.m \\
\hline Global Horiz Illumination (Avg Hourly) & 20581 & 27632 & 38793 & 41933 & 45496 & 45819 & 47388 & 42727 & 37217 & 27689 & 19622 & 16215 & lux \\
\hline Direct Normal Illumination (Avg Hourly) & 12181 & 17018 & 26678 & 24276 & 22659 & 21379 & 22534 & 20010 & 19812 & 15439 & 10984 & 10041 & lux \\
\hline Dry Bulb Temperature (Avg Monthly) & -3 & -1 & 3 & 9 & 17 & 22 & 25 & 25 & 20 & 13 & 6 & 1 & degrees $\mathrm{C}$ \\
\hline Dew Point Temperature (Avg Monthly) & -7 & -5 & -3 & 0 & 10 & 14 & 18 & 18 & 14 & 7 & 2 & -2 & degrees $C$ \\
\hline Relative Humidity (Avg Monthly) & 76 & 69 & 61 & 53 & 66 & 61 & 68 & 66 & 71 & 72 & 75 & 75 & percent \\
\hline Wind Direction (Monthly Mode) & 140 & 140 & 140 & 150 & 140 & 140 & 130 & 160 & 140 & 140 & 140 & 140 & degrees \\
\hline Wind Speed (Avg Monthly) & 4 & 4 & 5 & 5 & 4 & 3 & 3 & 3 & 3 & 4 & 4 & 4 & $\mathrm{~m} / \mathrm{s}$ \\
\hline Ground Temperature (Avg Monthly of 3 Depths) & 1 & 0 & 0 & 1 & 7 & 12 & 16 & 18 & 17 & 14 & 9 & 4 & degrees $C$ \\
\hline
\end{tabular}

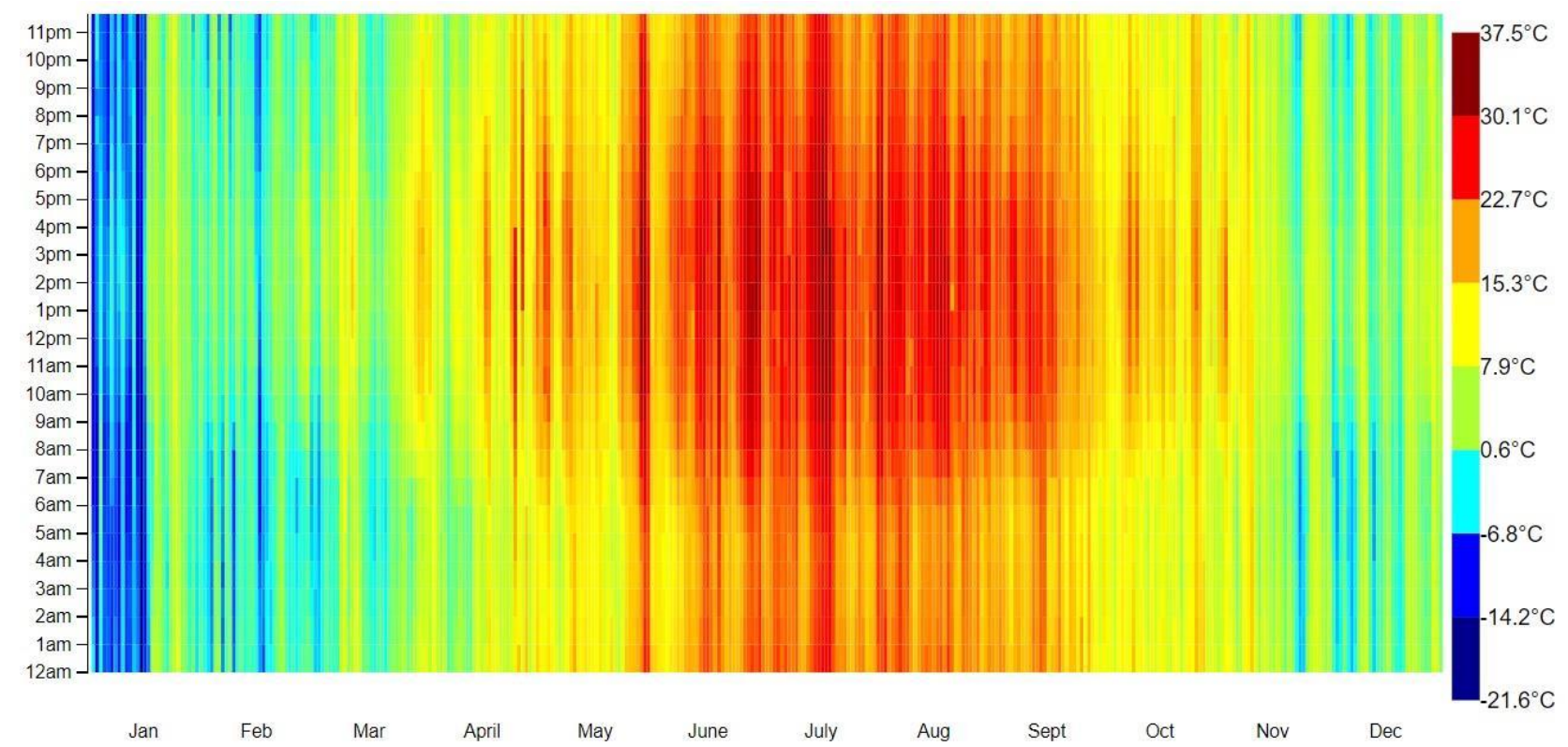


Appendix H. The results for each individual building model simulated using 1959-1989 and 1998-2014 baseline and its future weather files.

High-rise apartment building model

a) CWEC (1959-1989)

\begin{tabular}{lllll}
\hline & & $\begin{array}{l}\text { Total Energy } \\
\mathbf{( k W h )}\end{array}$ & $\begin{array}{l}\text { Energy Per Total } \\
\text { Building Area } \\
\left.\mathbf{( k W h} / \mathbf{m}^{\mathbf{2}}\right)\end{array}$ & $\begin{array}{l}\text { Energy Per } \\
\text { Conditioned } \\
\text { Building Area } \\
\left.\mathbf{( k W h} / \mathbf{m}^{2}\right)\end{array}$ \\
\hline $\begin{array}{l}\text { Total Site } \\
\text { Energy }\end{array}$ & CWEC (1959-1989) & $1,421,750$ & 181.4 & 201.4 \\
& CCWorldWeatherGen tool & $1,400,469$ & 178.7 & 198.4 \\
& WeatherShift tool & $1,388,278$ & 177.2 & 196.6 \\
& HRM3 & $1,398,317$ & 178.4 & 198.1 \\
\hline
\end{tabular}
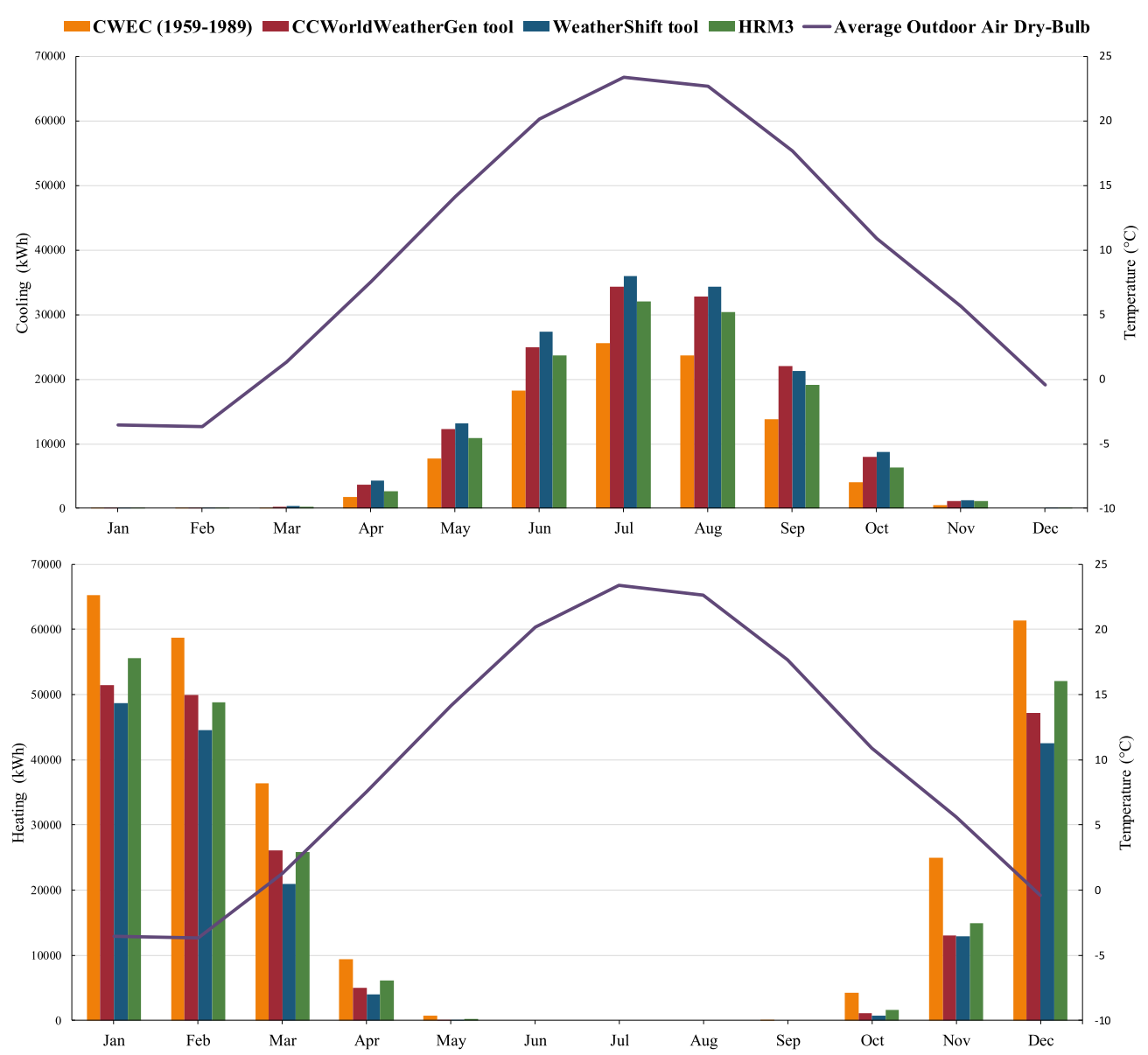

Monthly heating and cooling energy use of the high-rise apartment building model, 1959-1989 baseline. 


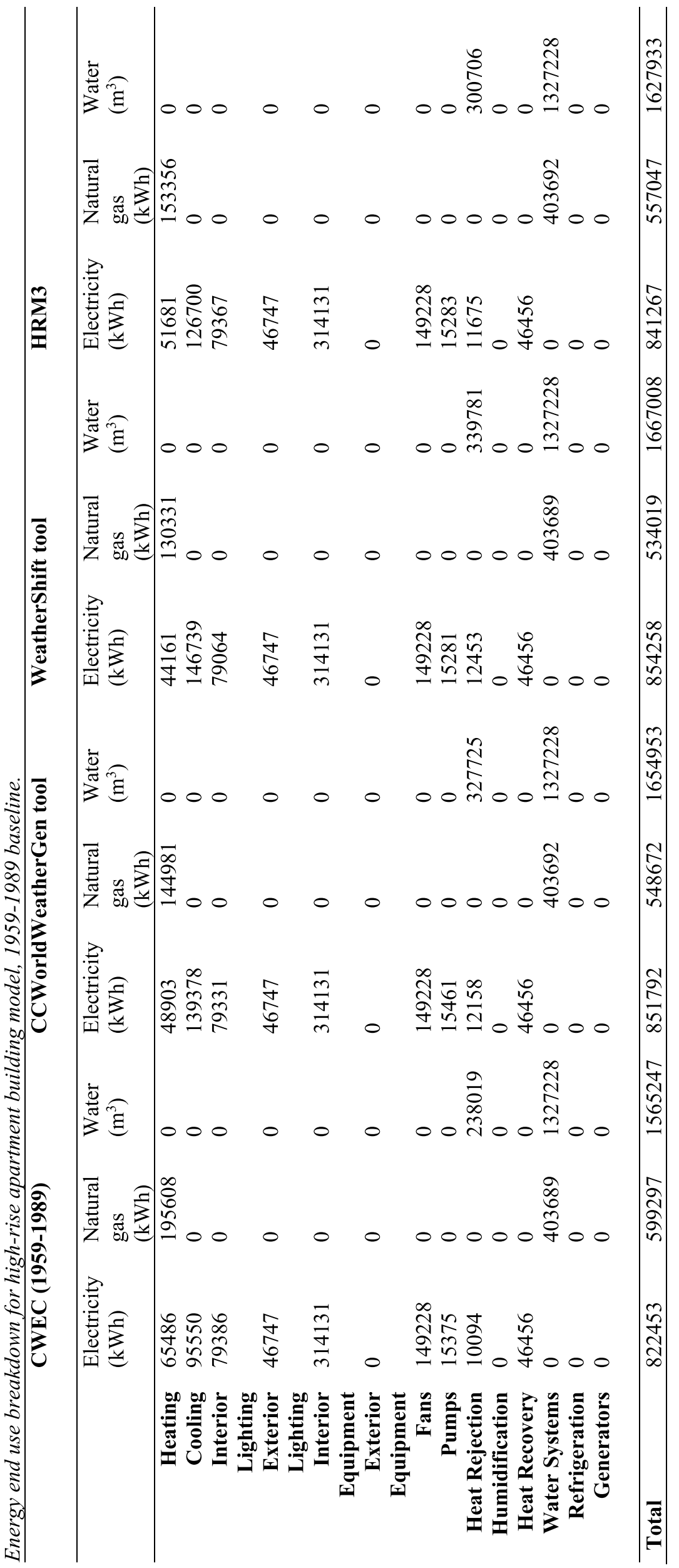


b) CWEC (1998-2014)

\begin{tabular}{|c|c|c|c|c|}
\hline & Weather Files & $\begin{array}{l}\text { Total Energy } \\
\text { (kWh) }\end{array}$ & $\begin{array}{l}\text { Energy Per Total } \\
\text { Building Area } \\
\left(\mathbf{k W h} / \mathbf{m}^{2}\right)\end{array}$ & $\begin{array}{l}\text { Energy Per } \\
\text { Conditioned } \\
\text { Building Area } \\
\left(\mathbf{k W h} / \mathbf{m}^{2}\right)\end{array}$ \\
\hline \multirow{4}{*}{$\begin{array}{l}\text { Total Site } \\
\text { Energy }\end{array}$} & CWEC2016 (1998-2014) & $1,384,481$ & 176.7 & 196.1 \\
\hline & CCWorldWeatherGen tool & $1,379,517$ & 176 & 195.4 \\
\hline & WeatherShift tool & $1,371,183$ & 175 & 194.2 \\
\hline & HRM3 & $1,373,950$ & 175.3 & 194.6 \\
\hline
\end{tabular}
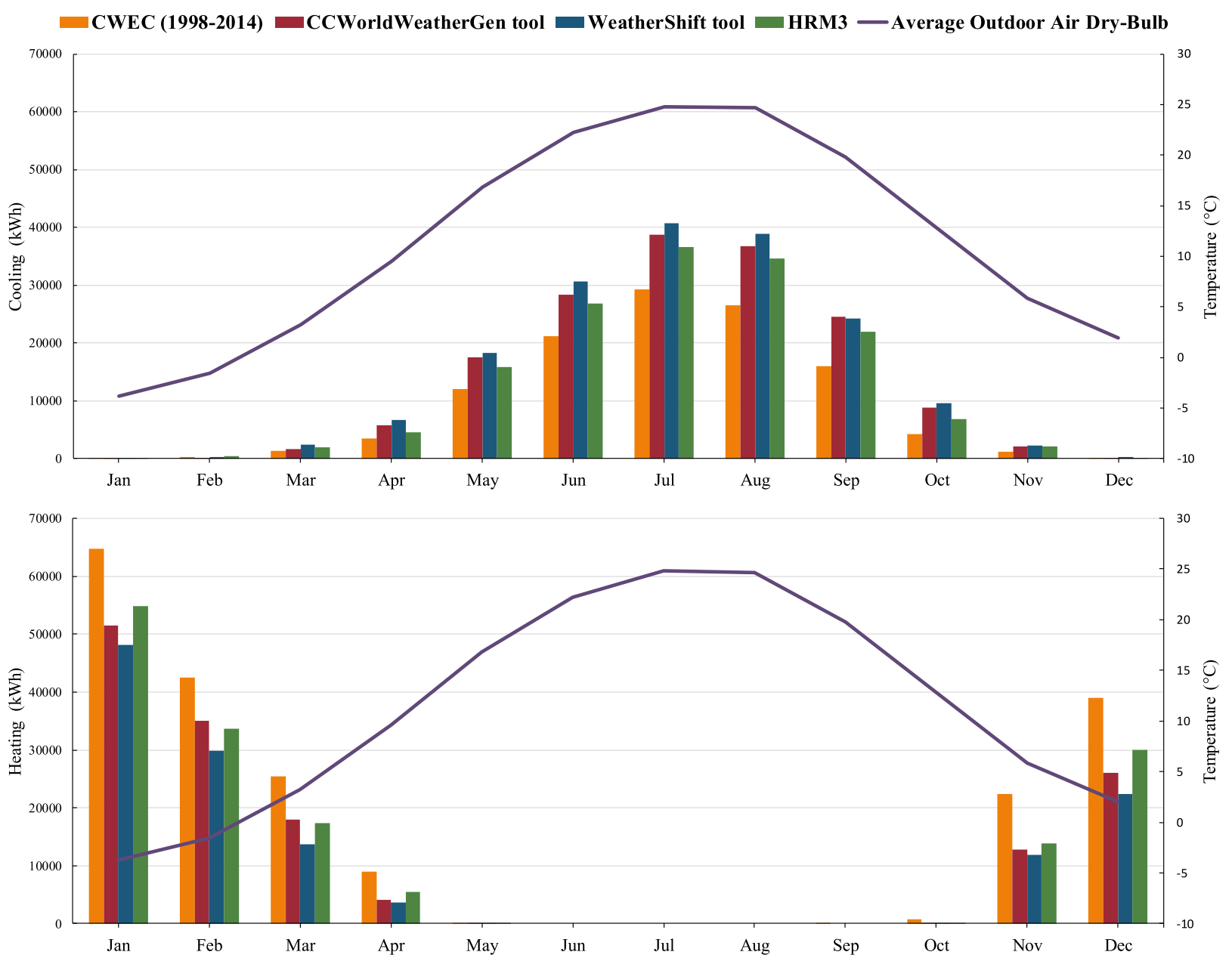

Monthly heating and cooling energy use of the high-rise apartment building model, 1998-2014 baseline. 
$\underline{\text { Mid-rise apartment building model }}$

a) CWEC (1959-1989)

\begin{tabular}{|c|c|c|c|c|}
\hline & & $\begin{array}{l}\text { Total Energy } \\
(\mathbf{k W h})\end{array}$ & $\begin{array}{l}\text { Energy Per Total } \\
\text { Building Area } \\
\left(\mathbf{k W h} / \mathbf{m}^{2}\right)\end{array}$ & $\begin{array}{l}\text { Energy Per } \\
\text { Conditioned } \\
\text { Building Area } \\
\left(\mathbf{k W h} / \mathbf{m}^{2}\right)\end{array}$ \\
\hline \multirow{4}{*}{$\begin{array}{l}\text { Total Site } \\
\text { Energy }\end{array}$} & CWEC (1959-1989) & 508,561 & 162.2 & 180.1 \\
\hline & CCWorldWeatherGen tool & 491,336 & 156.7 & 174 \\
\hline & WeatherShift tool & 486,772 & 155.3 & 172.4 \\
\hline & HRM3 & 494,761 & 157.8 & 175.2 \\
\hline
\end{tabular}
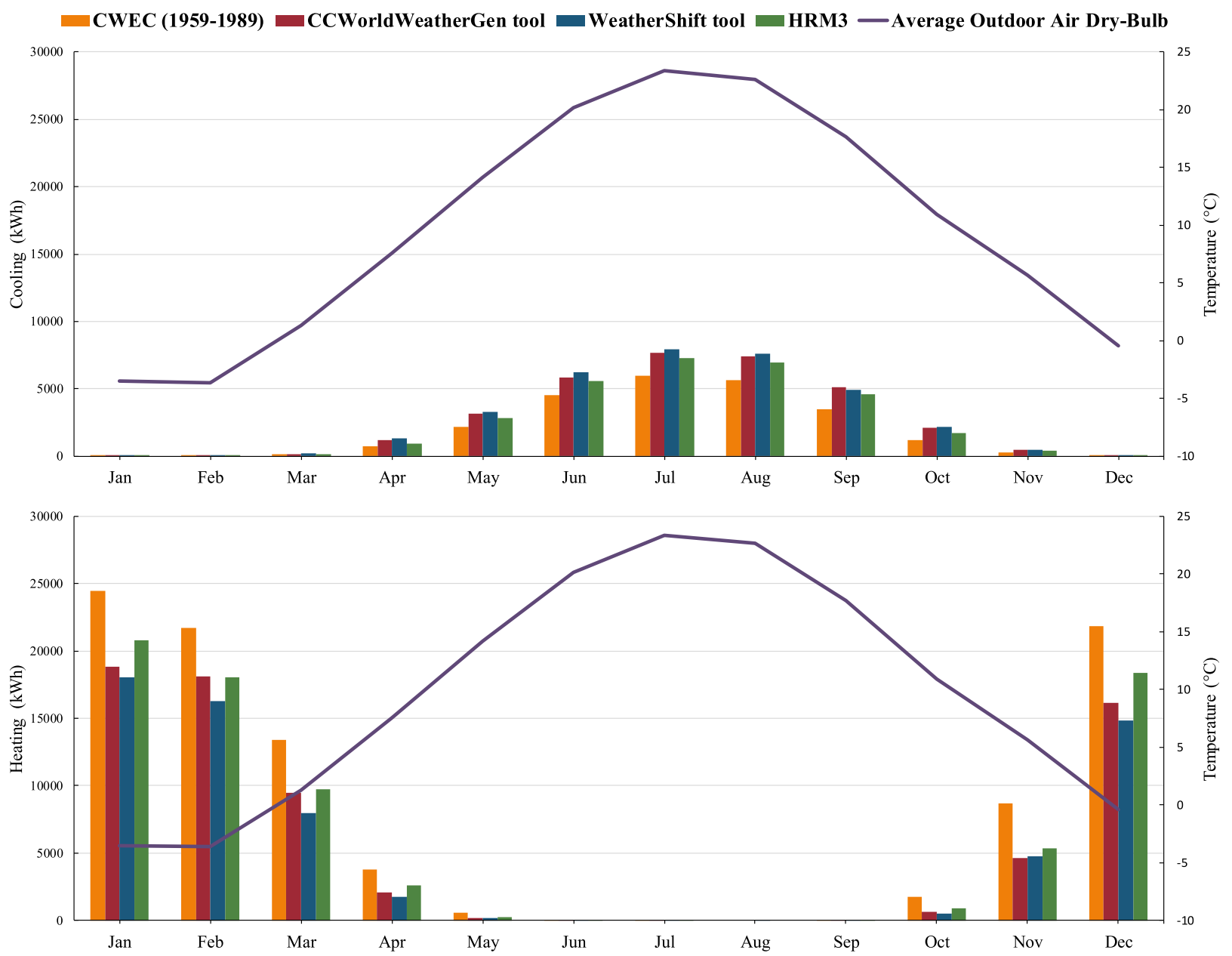


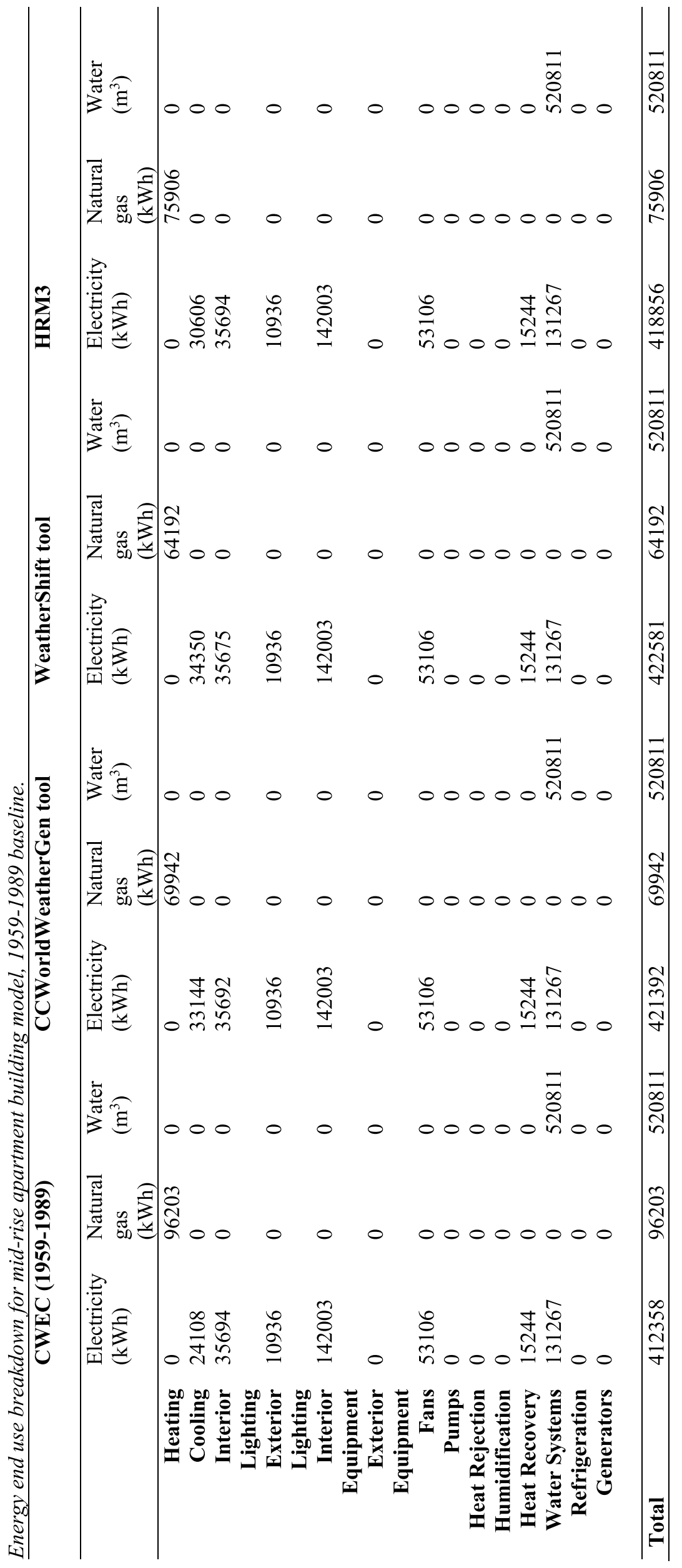


b) CWEC (1998-2014)

\begin{tabular}{|c|c|c|c|c|}
\hline & Weather Files & $\begin{array}{l}\text { Total Energy } \\
\text { (kWh) }\end{array}$ & $\begin{array}{l}\text { Energy Per Total } \\
\text { Building Area } \\
\left(\mathbf{k W h} / \mathbf{m}^{2}\right)\end{array}$ & $\begin{array}{l}\text { Energy Per } \\
\text { Conditioned } \\
\text { Building Area } \\
\left(\mathbf{k W h} / \mathbf{m}^{2}\right)\end{array}$ \\
\hline \multirow{4}{*}{$\begin{array}{l}\text { Total Site } \\
\text { Energy }\end{array}$} & CWEC2016 (1998-2014) & 492,169 & 157 & 174.3 \\
\hline & CCWorldWeatherGen tool & 479,786 & 153.1 & 169.9 \\
\hline & WeatherShift tool & 476,183 & 151.9 & 168.6 \\
\hline & HRM3 & 481,914 & 153.7 & 170.7 \\
\hline
\end{tabular}
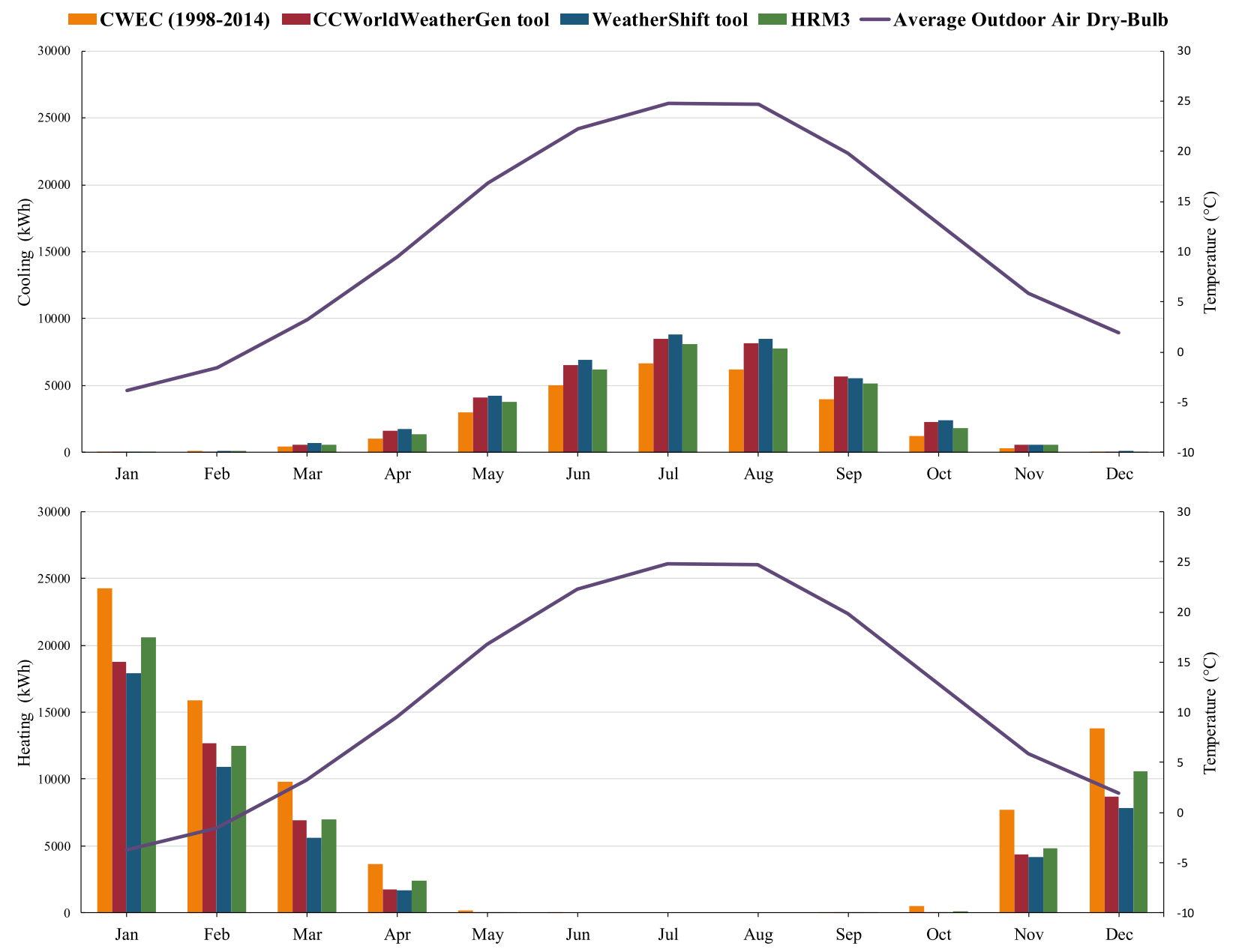


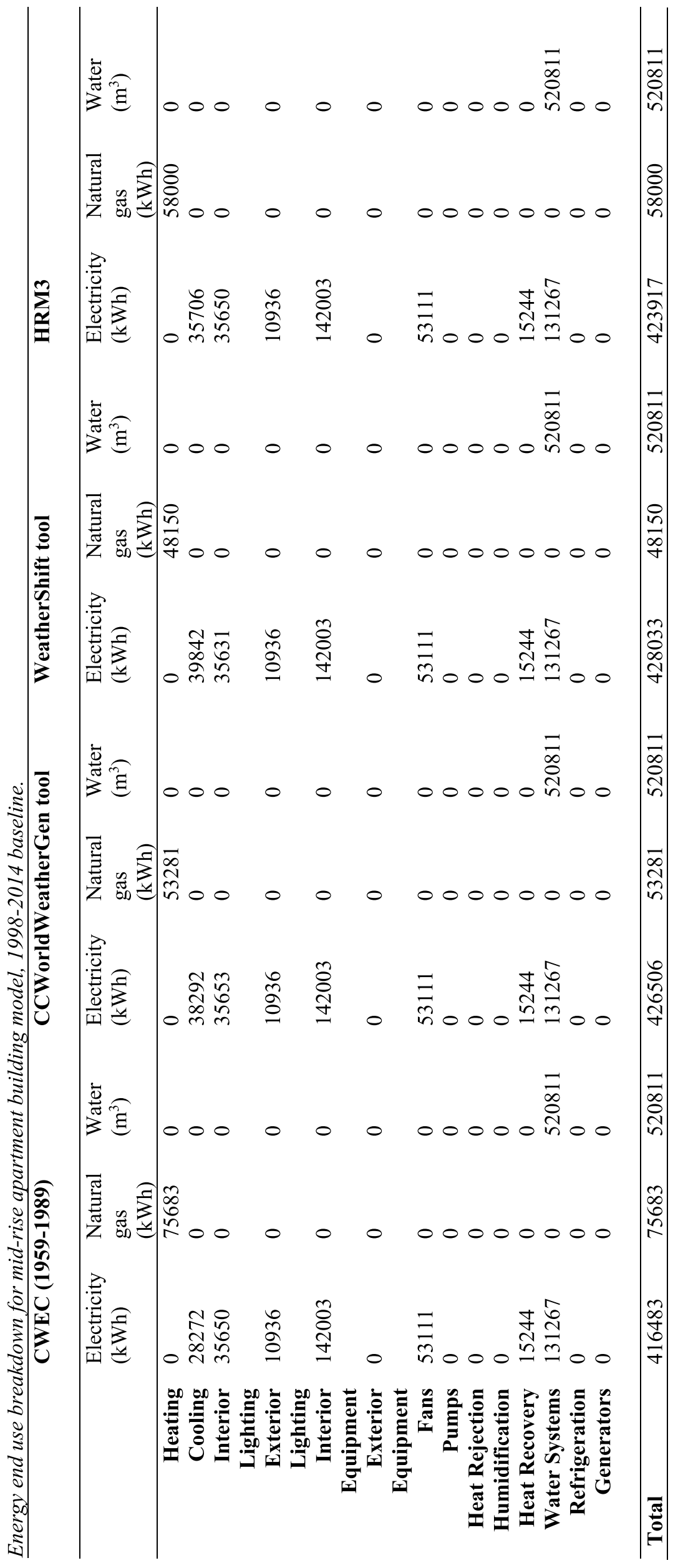




\section{Hospital building model}

a) CWEC (1959-1989)

\begin{tabular}{|c|c|c|c|c|}
\hline & & $\begin{array}{l}\text { Total Energy } \\
\text { (kWh) }\end{array}$ & $\begin{array}{l}\text { Energy Per Total } \\
\text { Building Area } \\
\left(\mathbf{k W h} / \mathbf{m}^{2}\right)\end{array}$ & $\begin{array}{l}\text { Energy Per } \\
\text { Conditioned } \\
\text { Building Area } \\
\left(\mathbf{k W h} / \mathbf{m}^{2}\right)\end{array}$ \\
\hline \multirow{4}{*}{$\begin{array}{l}\text { Total Site } \\
\text { Energy }\end{array}$} & CWEC (1959-1989) & $7,317,031$ & 326.1 & 326.1 \\
\hline & CCWorldWeatherGen tool & $7,255,317$ & 323.4 & 323.4 \\
\hline & WeatherShift tool & $7,238,814$ & 322.6 & 322.6 \\
\hline & HRM3 & $7,280,389$ & 324.5 & 324.5 \\
\hline
\end{tabular}
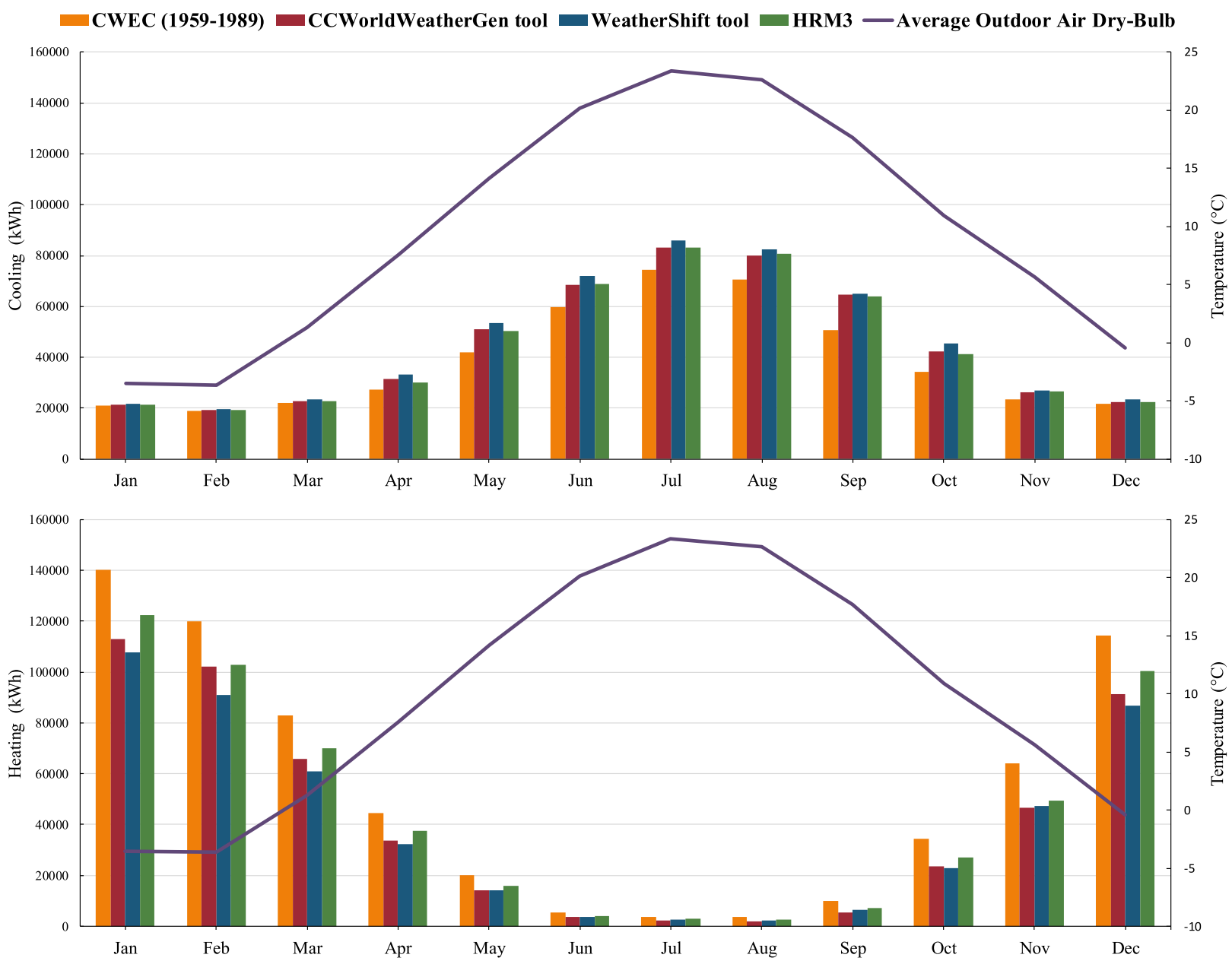
b) CWEC (1998-2014)

\begin{tabular}{lllll}
\hline & Weather Files & $\begin{array}{l}\text { Total Energy } \\
\mathbf{( k W h )}\end{array}$ & $\begin{array}{l}\text { Energy Per Total } \\
\text { Building Area } \\
\left.\mathbf{( k W h} / \mathbf{m}^{\mathbf{2}}\right)\end{array}$ & $\begin{array}{l}\text { Energy Per } \\
\text { Conditioned } \\
\text { Building Area } \\
\mathbf{( k W h / \mathbf { m } ^ { 2 } )}\end{array}$ \\
\hline $\begin{array}{l}\text { Total Site } \\
\text { Energy }\end{array}$ & CWEC2016 (1998-2014) & $7,274,622$ & 324.2 & 324.2 \\
& CCWorldWeatherGen tool & $7,234,956$ & 322.5 & 322.5 \\
& WeatherShift tool & $7,226,031$ & 322.1 & 322.1 \\
& HRM3 & $7,252,753$ & 323.3 & 323.3 \\
\hline
\end{tabular}
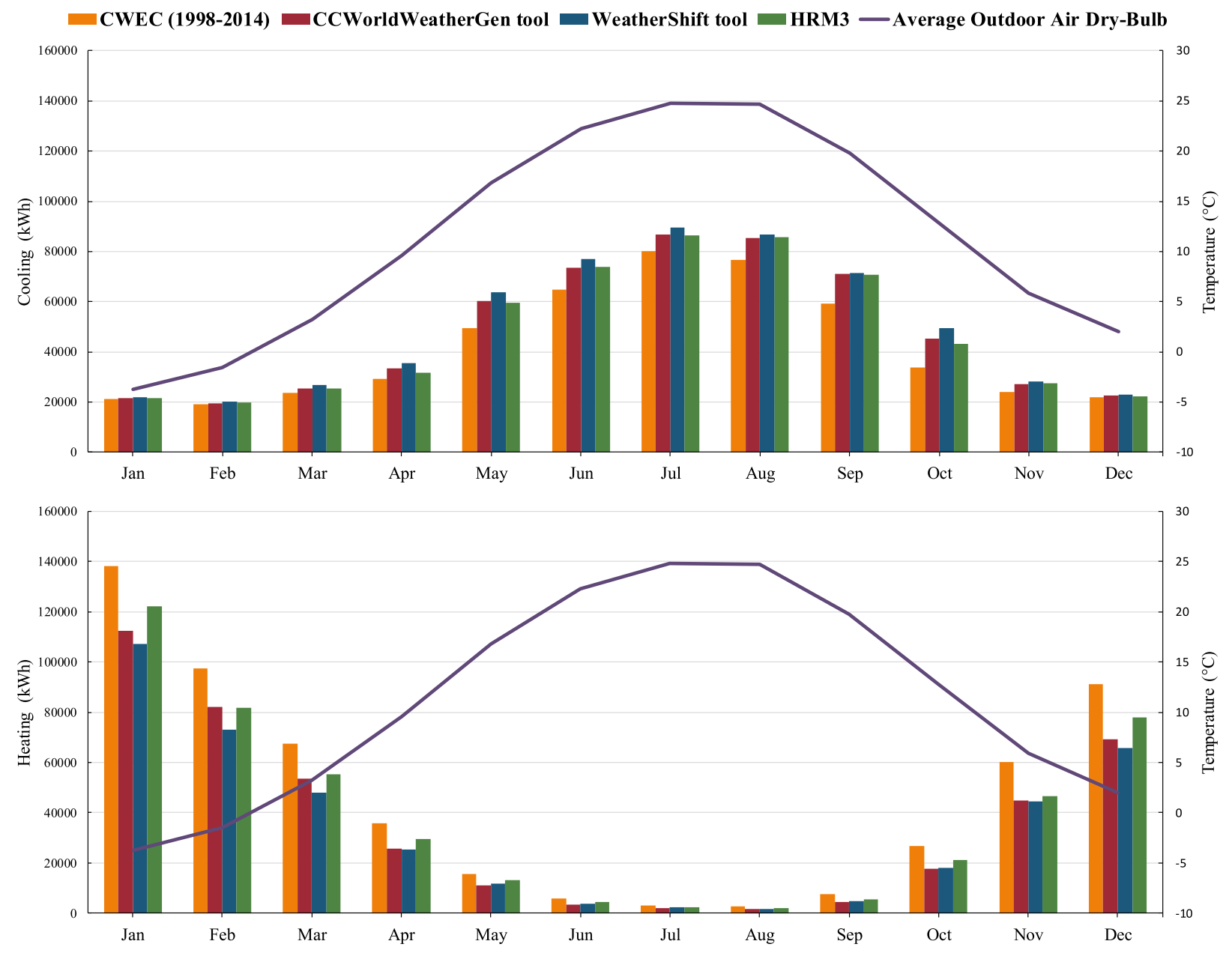


\section{$\underline{\text { Large hotel building model }}$}

a) CWEC (1959-1989)

\begin{tabular}{|c|c|c|c|c|}
\hline & & $\begin{array}{l}\text { Total Energy } \\
\text { (kWh) }\end{array}$ & $\begin{array}{l}\text { Energy Per Total } \\
\text { Building Area } \\
\left(\mathbf{k W h} / \mathbf{m}^{2}\right)\end{array}$ & $\begin{array}{l}\text { Energy Per } \\
\text { Conditioned } \\
\text { Building Area } \\
\left(\mathbf{k W h} / \mathbf{m}^{2}\right)\end{array}$ \\
\hline \multirow{4}{*}{$\begin{array}{l}\text { Total Site } \\
\text { Energy }\end{array}$} & CWEC (1959-1989) & $4,036,147$ & 355.8 & 355.8 \\
\hline & CCWorldWeatherGen tool & $3,968,414$ & 349.8 & 349.8 \\
\hline & WeatherShift tool & $3,960,117$ & 349.1 & 349.1 \\
\hline & HRM3 & $3,994,819$ & 352.1 & 352.1 \\
\hline
\end{tabular}
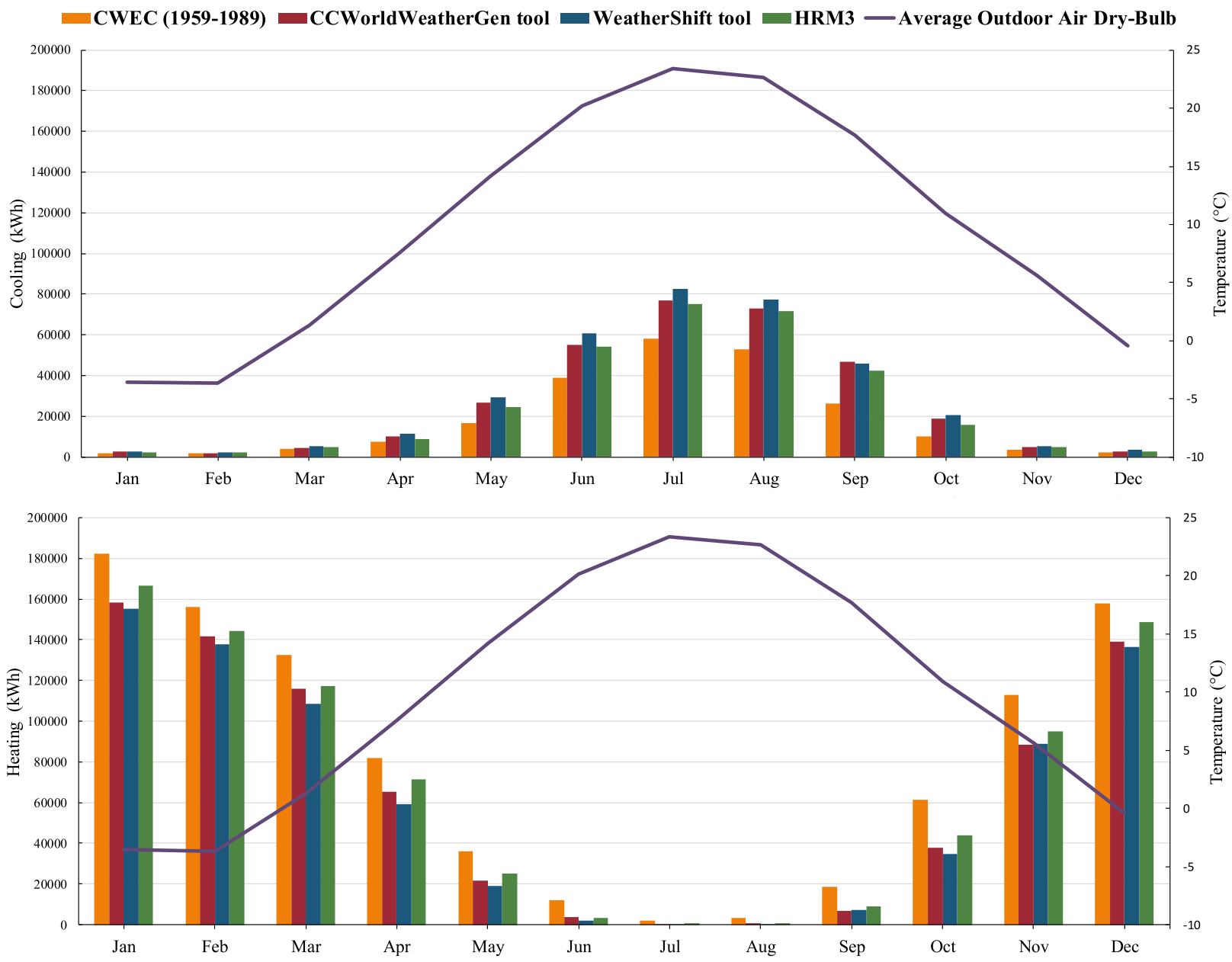


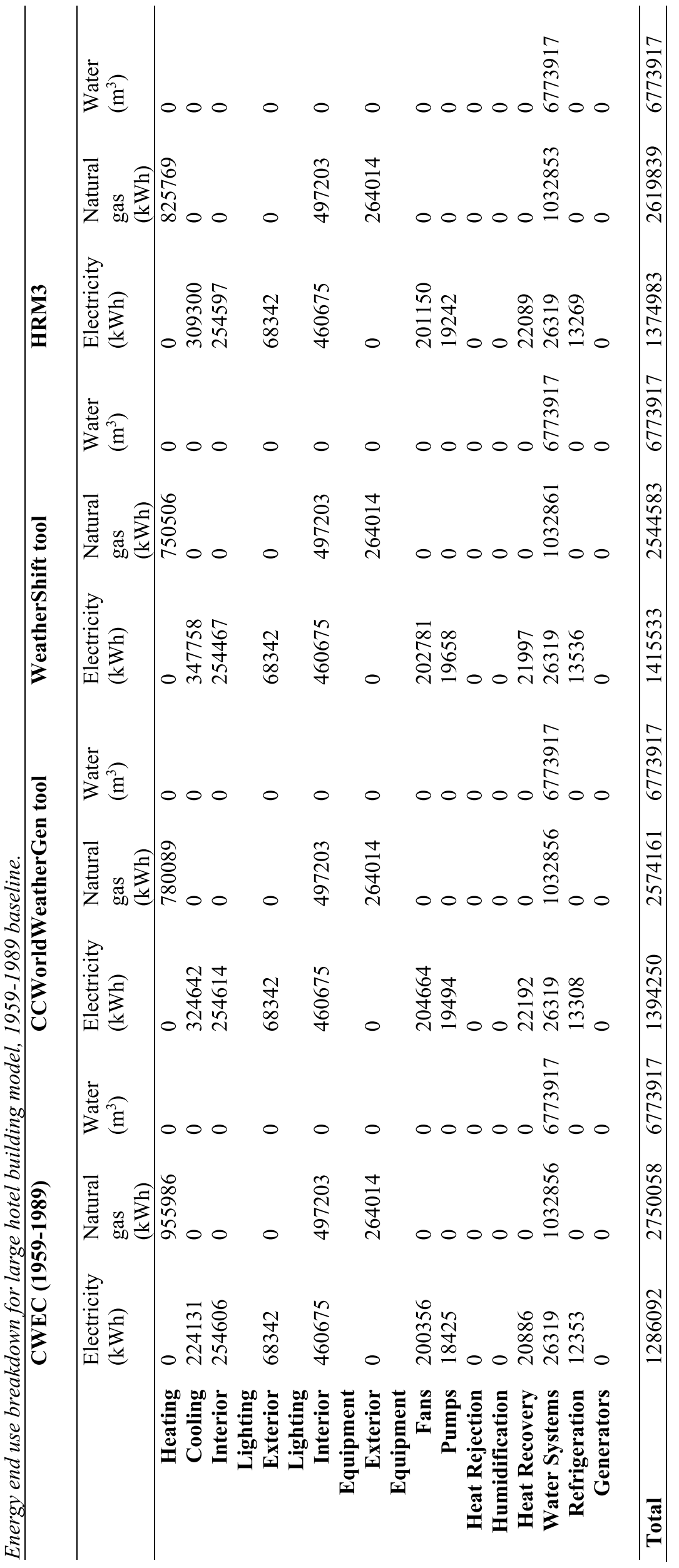


b) CWEC (1998-2014)

\begin{tabular}{|c|c|c|c|c|}
\hline & Weather Files & $\begin{array}{l}\text { Total Energy } \\
(\mathrm{kWh})\end{array}$ & $\begin{array}{l}\text { Energy Per Total } \\
\text { Building Area } \\
\left(\mathbf{k W h} / \mathbf{m}^{2}\right)\end{array}$ & $\begin{array}{l}\text { Energy Per } \\
\text { Conditioned } \\
\text { Building Area } \\
\left(\mathbf{k W h} / \mathbf{m}^{2}\right)\end{array}$ \\
\hline \multirow{4}{*}{$\begin{array}{l}\text { Total Site } \\
\text { Energy }\end{array}$} & CWEC2016 (1998-2014) & $3,957,578$ & 348.8 & 348.8 \\
\hline & CCWorldWeatherGen tool & $3,912,014$ & 344.8 & 344.8 \\
\hline & WeatherShift tool & $3,908,719$ & 344.5 & 344.5 \\
\hline & HRM3 & $3,939,492$ & 347.2 & 347.2 \\
\hline
\end{tabular}
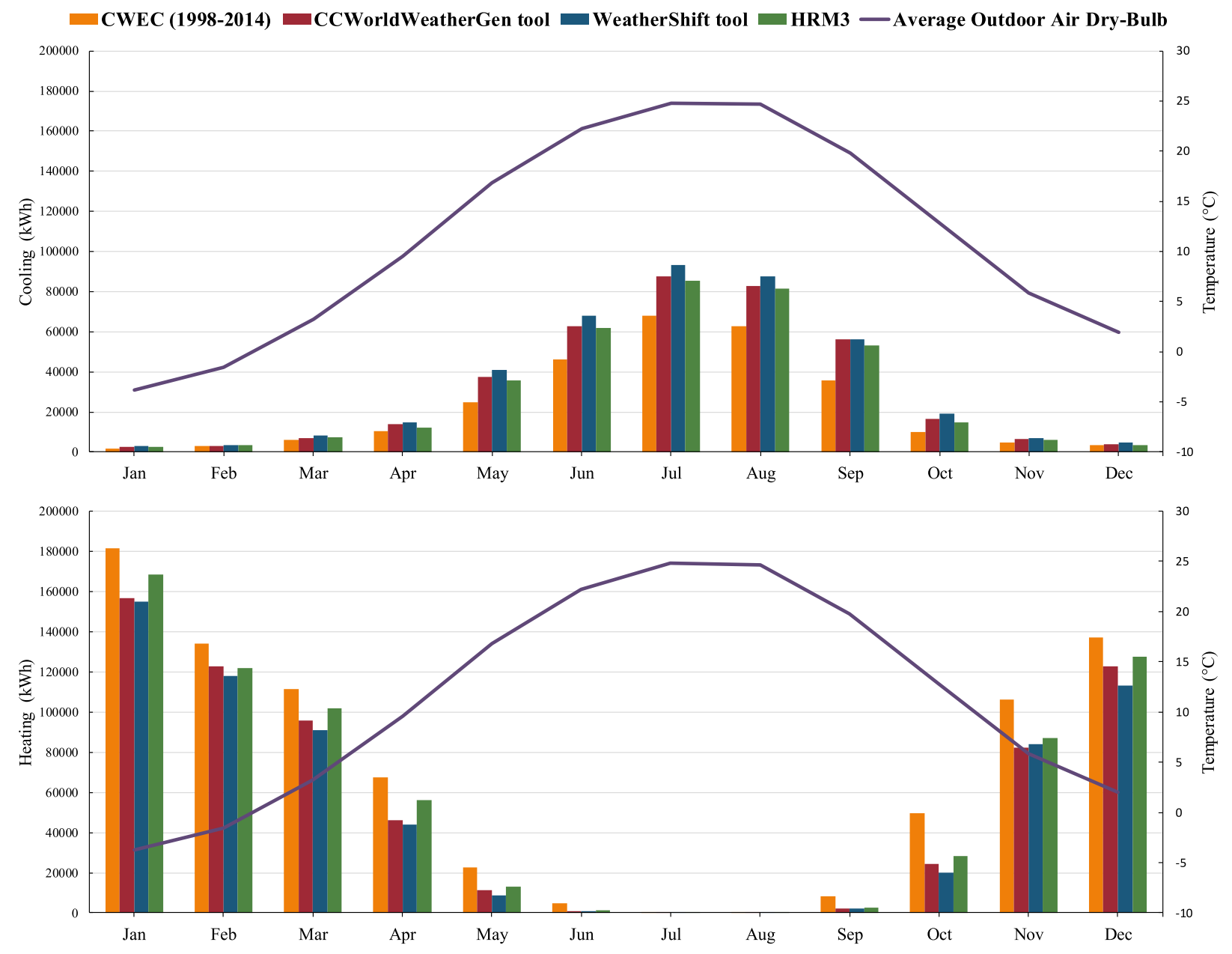


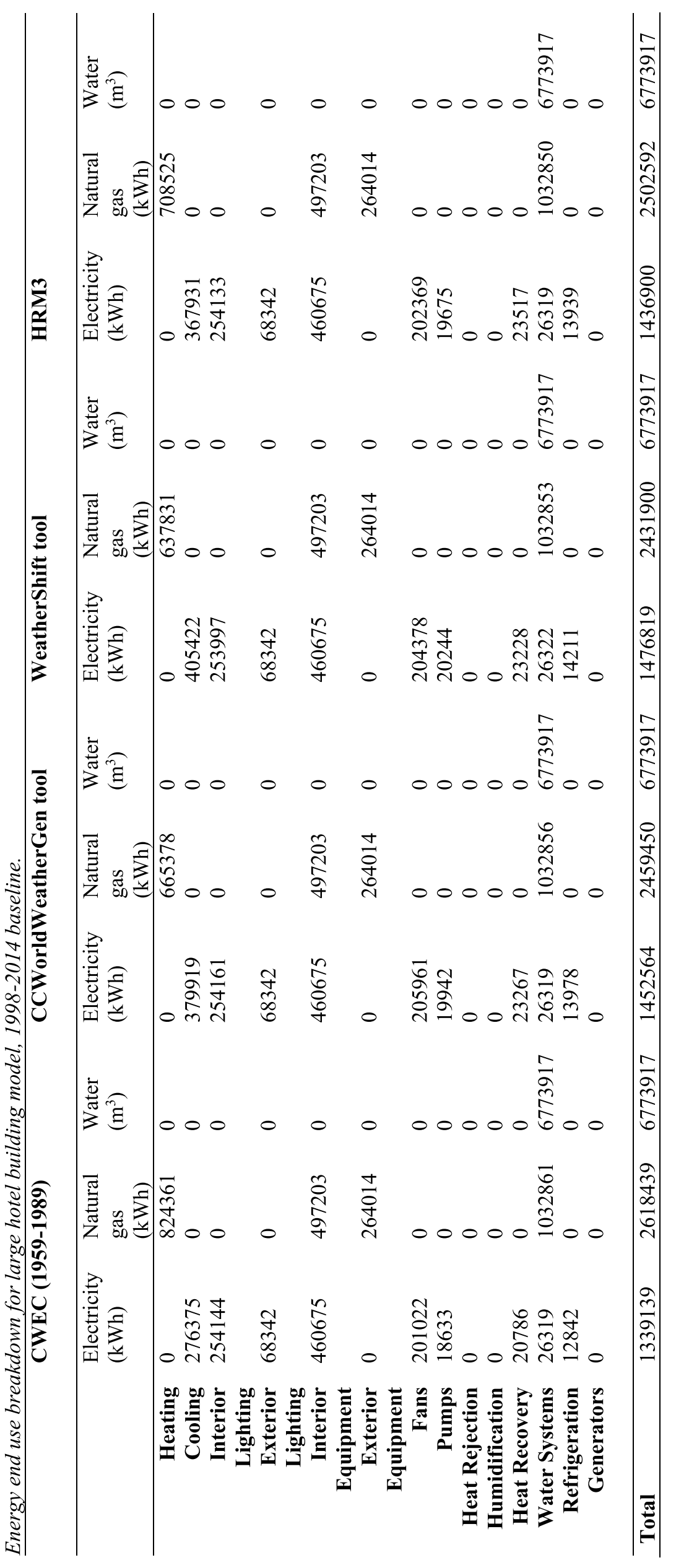




\section{Small hotel building model}

a) CWEC (1959-1989)

\begin{tabular}{|c|c|c|c|c|}
\hline & & $\begin{array}{l}\text { Total Energy } \\
(\mathbf{k W h})\end{array}$ & $\begin{array}{l}\text { Energy Per Total } \\
\text { Building Area } \\
\left(\mathbf{k W h} / \mathbf{m}^{2}\right)\end{array}$ & $\begin{array}{l}\text { Energy Per } \\
\text { Conditioned } \\
\text { Building Area } \\
\left(\mathbf{k W h} / \mathbf{m}^{2}\right) \\
\end{array}$ \\
\hline \multirow{4}{*}{$\begin{array}{l}\text { Total Site } \\
\text { Energy }\end{array}$} & CWEC (1959-1989) & $1,023,375$ & 255 & 274.7 \\
\hline & CCWorldWeatherGen tool & $1,009,250$ & 251.5 & 270.9 \\
\hline & WeatherShift tool & $1,003,014$ & 249.9 & 269.3 \\
\hline & HRM3 & $1,012,539$ & 252.3 & 271.8 \\
\hline
\end{tabular}
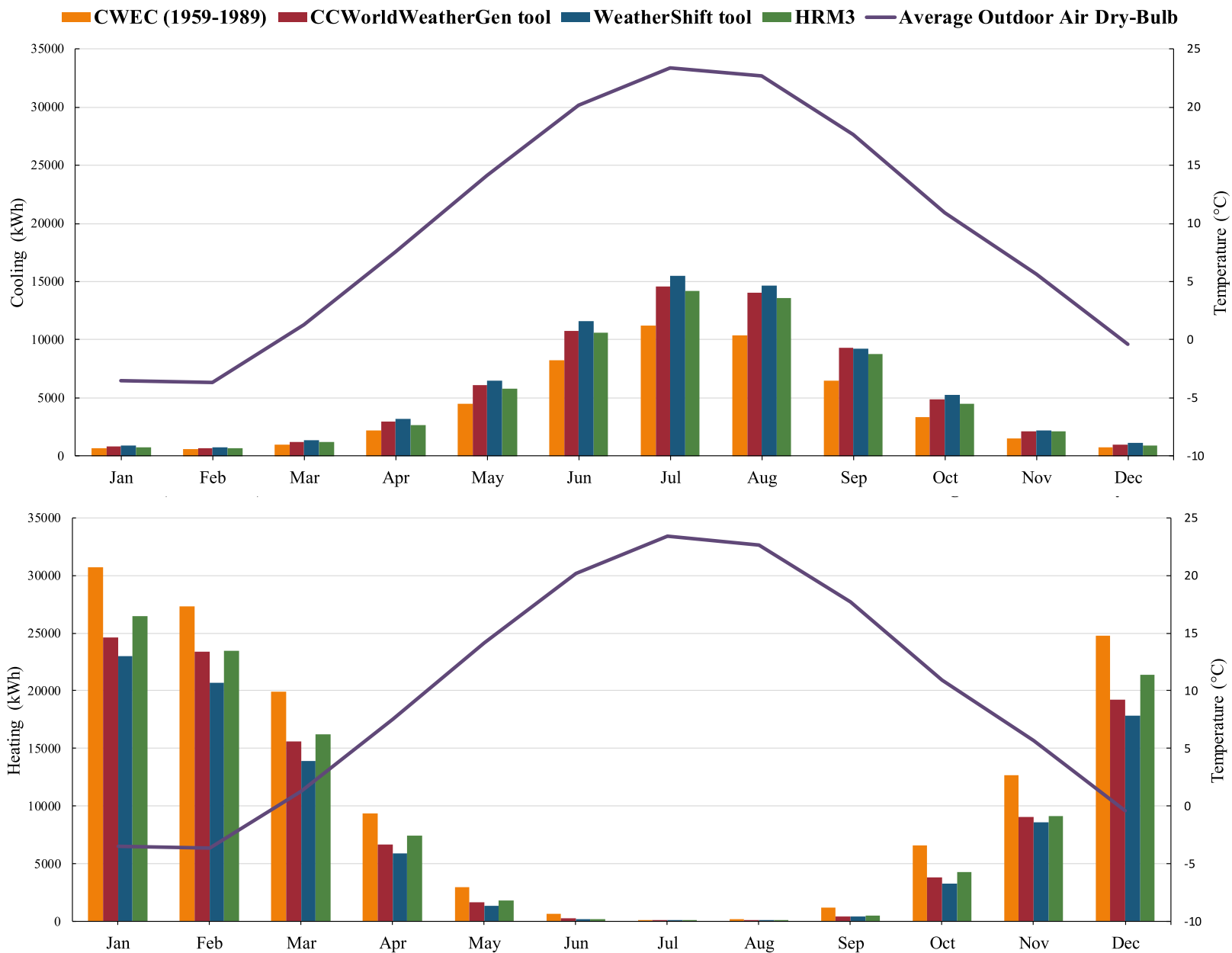


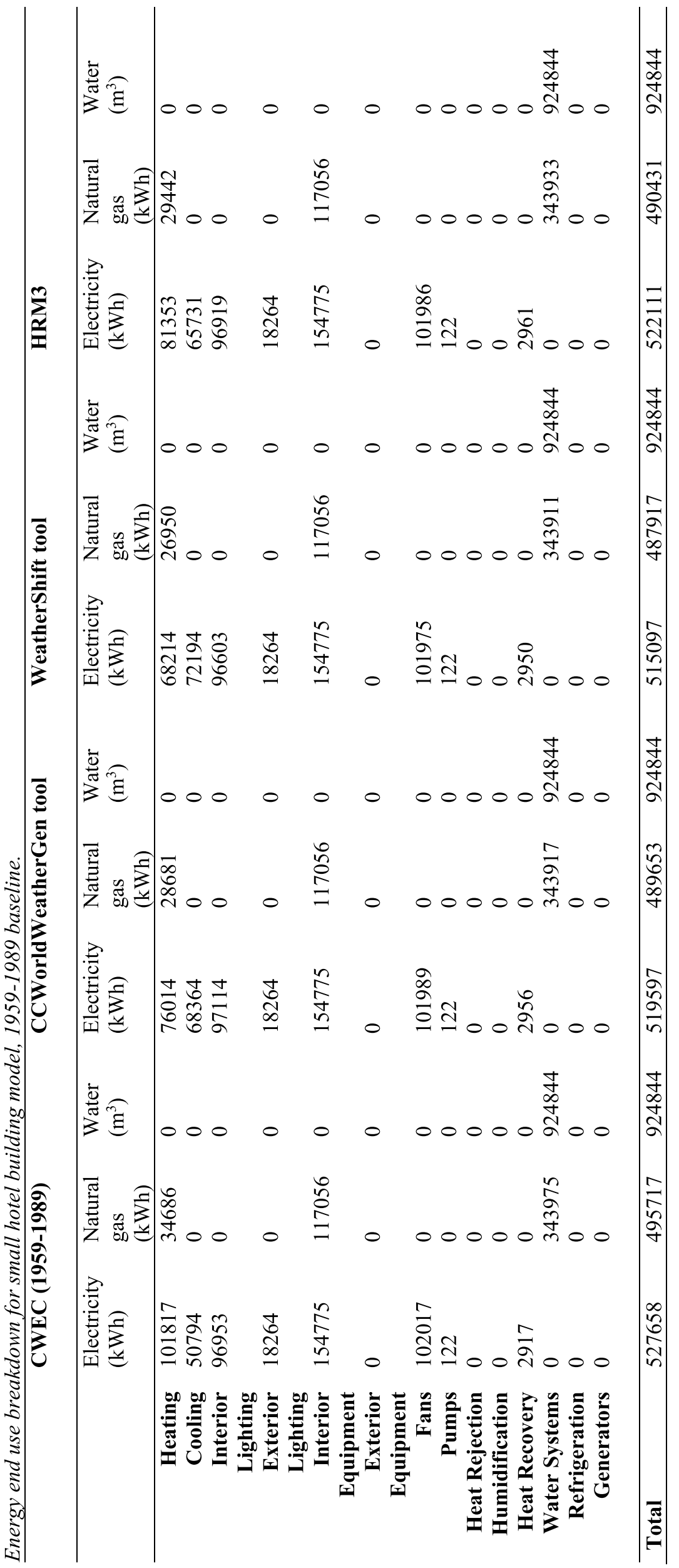


b) CWEC (1998-2014)

\begin{tabular}{|c|c|c|c|c|}
\hline & Weather Files & $\begin{array}{l}\text { Total Energy } \\
(\mathrm{kWh})\end{array}$ & $\begin{array}{l}\text { Energy Per Total } \\
\text { Building Area } \\
\left(\mathbf{k W h} / \mathbf{m}^{2}\right)\end{array}$ & $\begin{array}{l}\text { Energy Per } \\
\text { Conditioned } \\
\text { Building Area } \\
\left(\mathbf{k W h} / \mathbf{m}^{2}\right)\end{array}$ \\
\hline \multirow{4}{*}{$\begin{array}{l}\text { Total Site } \\
\text { Energy }\end{array}$} & CWEC2016 (1998-2014) & $1,010,792$ & 251.8 & 271.3 \\
\hline & CCWorldWeatherGen tool & $1,002,619$ & 249.8 & 269.2 \\
\hline & WeatherShift tool & 997,703 & 248.6 & 267.8 \\
\hline & HRM3 & $1,005,069$ & 250.4 & 269.8 \\
\hline
\end{tabular}
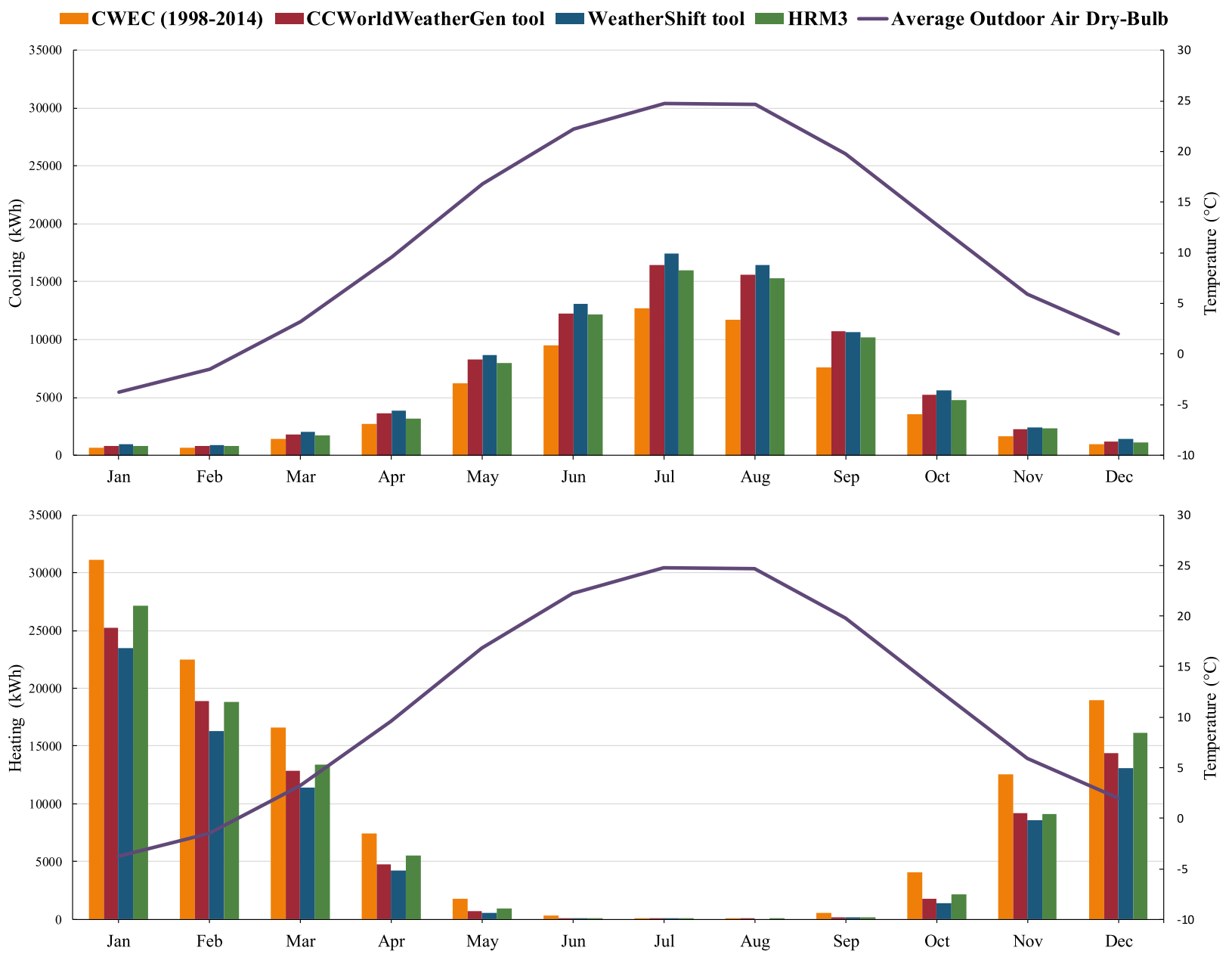


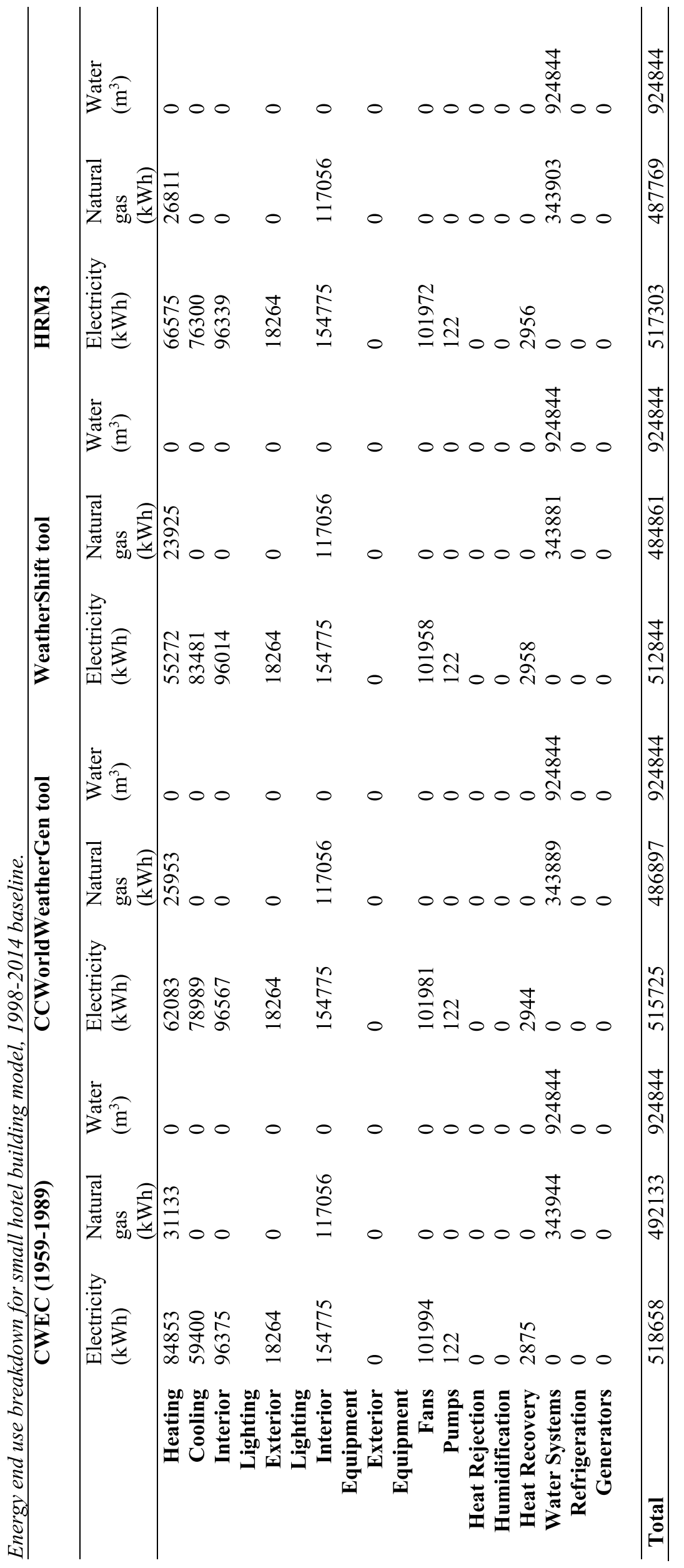


a) CWEC (1959-1989)

\begin{tabular}{|c|c|c|c|c|}
\hline & & $\begin{array}{l}\text { Total Energy } \\
\text { (kWh) }\end{array}$ & $\begin{array}{l}\text { Energy Per Total } \\
\text { Building Area } \\
\left(\mathbf{k W h} / \mathbf{m}^{2}\right)\end{array}$ & $\begin{array}{l}\text { Energy Per } \\
\text { Conditioned } \\
\text { Building Area } \\
\left(\mathbf{k W h} / \mathbf{m}^{2}\right)\end{array}$ \\
\hline \multirow{4}{*}{$\begin{array}{l}\text { Total Site } \\
\text { Energy }\end{array}$} & CWEC (1959-1989) & $1,0048,736$ & 216.9 & 216.9 \\
\hline & CCWorldWeatherGen tool & $1,0153,253$ & 219.2 & 219.2 \\
\hline & WeatherShift tool & $1,0177,119$ & 219.7 & 219.7 \\
\hline & HRM3 & $1,0178,625$ & 219.7 & 219.7 \\
\hline
\end{tabular}
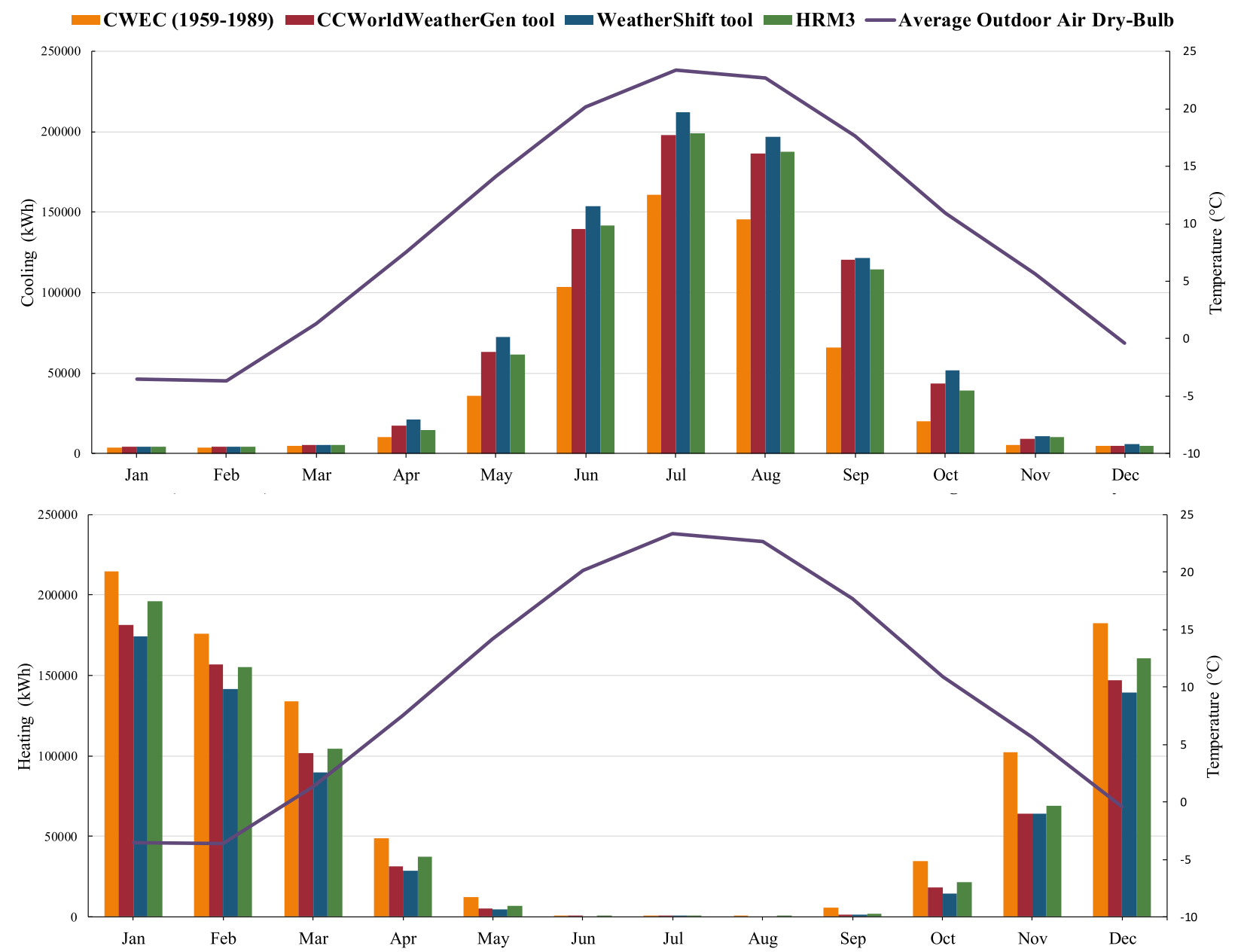
b) CWEC (1998-2014)

\begin{tabular}{|c|c|c|c|c|}
\hline & Weather Files & $\begin{array}{l}\text { Total Energy } \\
\text { (kWh) }\end{array}$ & $\begin{array}{l}\text { Energy Per Total } \\
\text { Building Area } \\
\left(\mathbf{k W h} / \mathbf{m}^{\mathbf{2}}\right)\end{array}$ & $\begin{array}{l}\text { Energy Per } \\
\text { Conditioned } \\
\text { Building Area } \\
\left(\mathbf{k W h} / \mathbf{m}^{2}\right)\end{array}$ \\
\hline \multirow{4}{*}{$\begin{array}{l}\text { Total Site } \\
\text { Energy }\end{array}$} & CWEC2016 (1998-2014) & $1,0056,700$ & 217.1 & 217.1 \\
\hline & CCWorldWeatherGen tool & $1,0193,000$ & 220.1 & 220.1 \\
\hline & WeatherShift tool & $1,0206,197$ & 220.3 & 220.3 \\
\hline & HRM3 & $1,0204,364$ & 220.3 & 220.3 \\
\hline
\end{tabular}
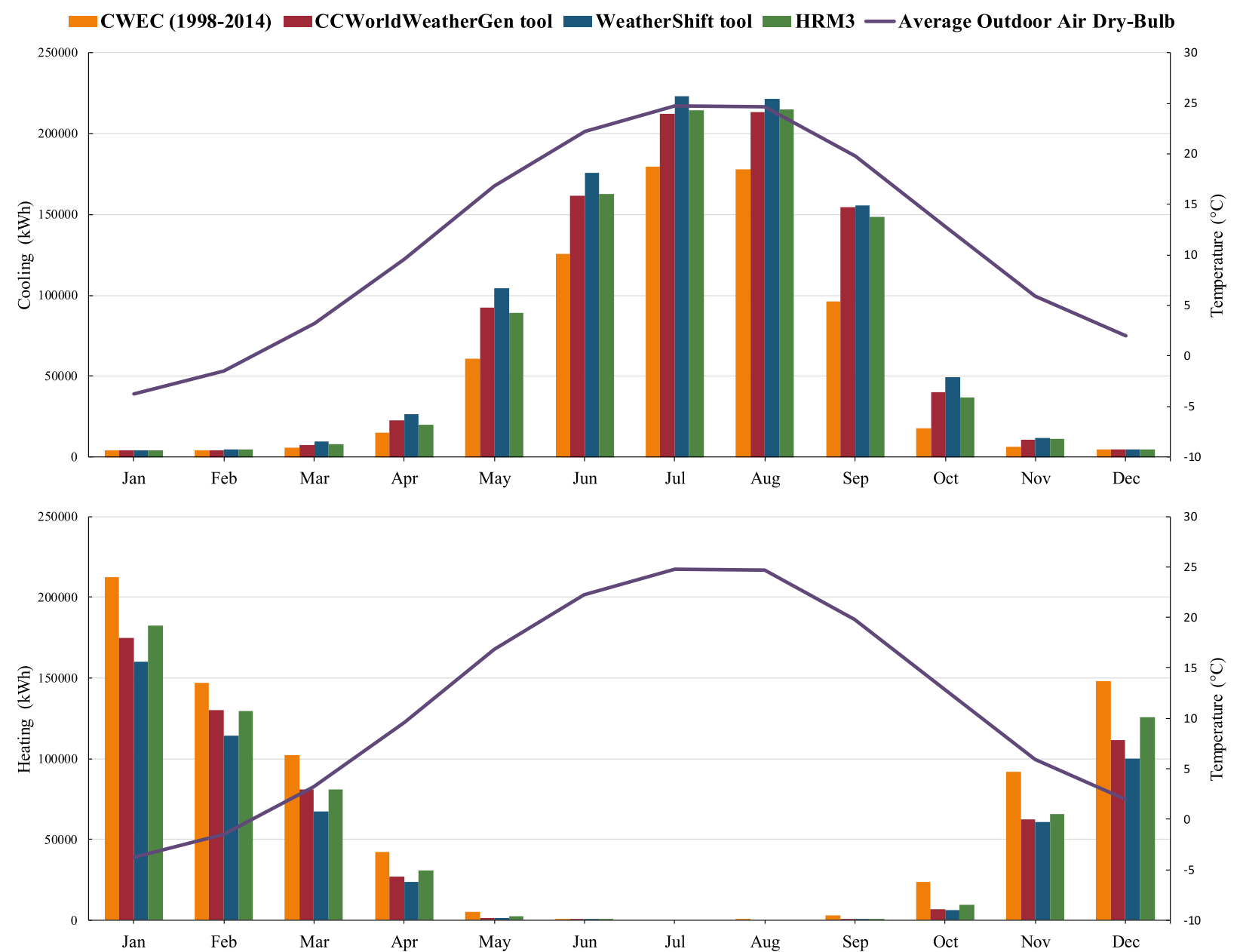
$\underline{\text { Medium office building model }}$

a) CWEC (1959-1989)

\begin{tabular}{|c|c|c|c|c|}
\hline & & $\begin{array}{l}\text { Total Energy } \\
\text { (kWh) }\end{array}$ & $\begin{array}{l}\text { Energy Per Total } \\
\text { Building Area } \\
\left(\mathbf{k W h} / \mathbf{m}^{2}\right)\end{array}$ & $\begin{array}{l}\text { Energy Per } \\
\text { Conditioned } \\
\text { Building Area } \\
\left(\mathbf{k W h} / \mathbf{m}^{2}\right)\end{array}$ \\
\hline \multirow{4}{*}{$\begin{array}{l}\text { Total Site } \\
\text { Energy }\end{array}$} & CWEC (1959-1989) & 606,886 & 121.8 & 121.8 \\
\hline & CCWorldWeatherGen tool & 594,747 & 119.4 & 119.4 \\
\hline & WeatherShift tool & 589,681 & 118.4 & 118.4 \\
\hline & HRM3 & 598,267 & 120.1 & 120.1 \\
\hline
\end{tabular}
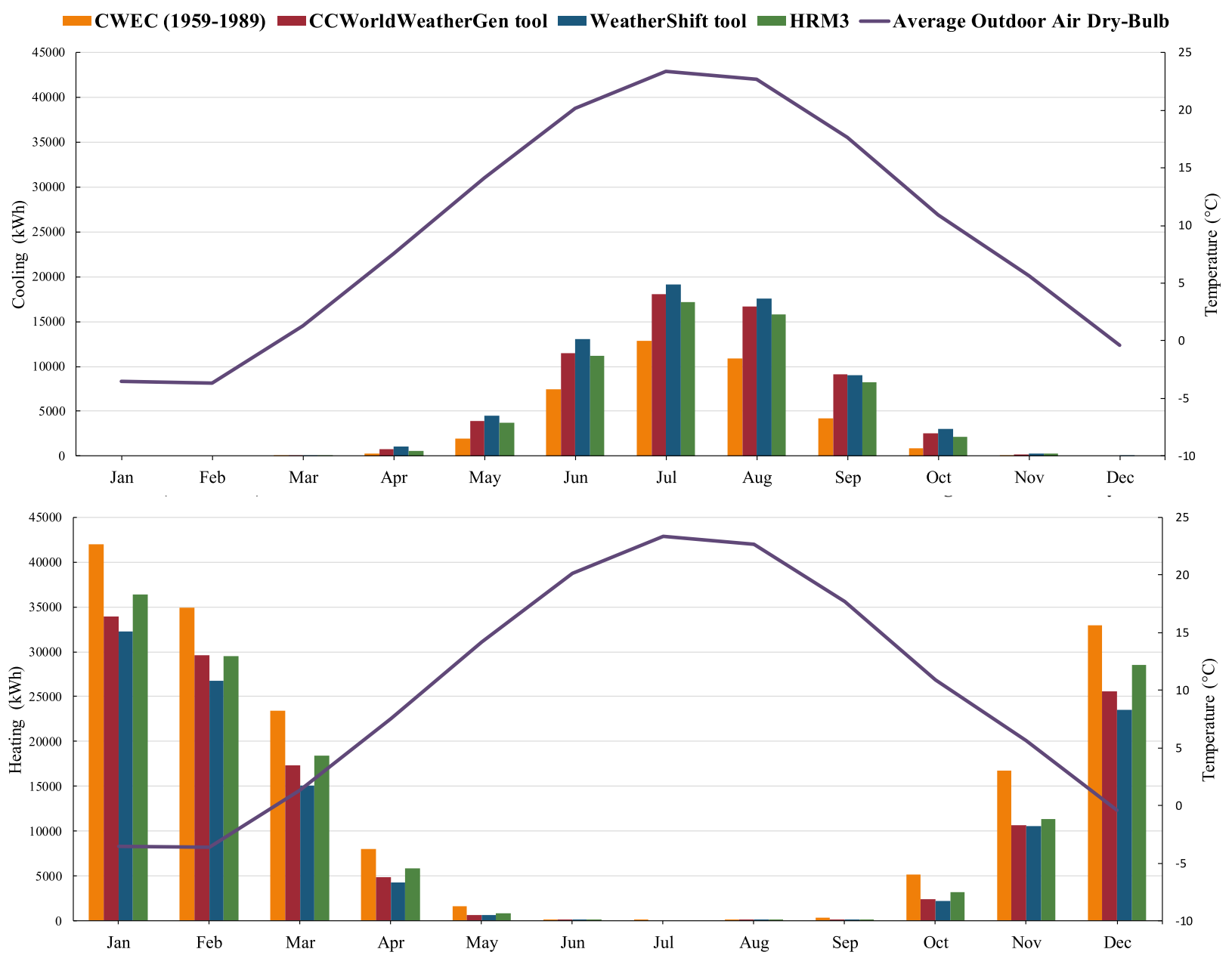


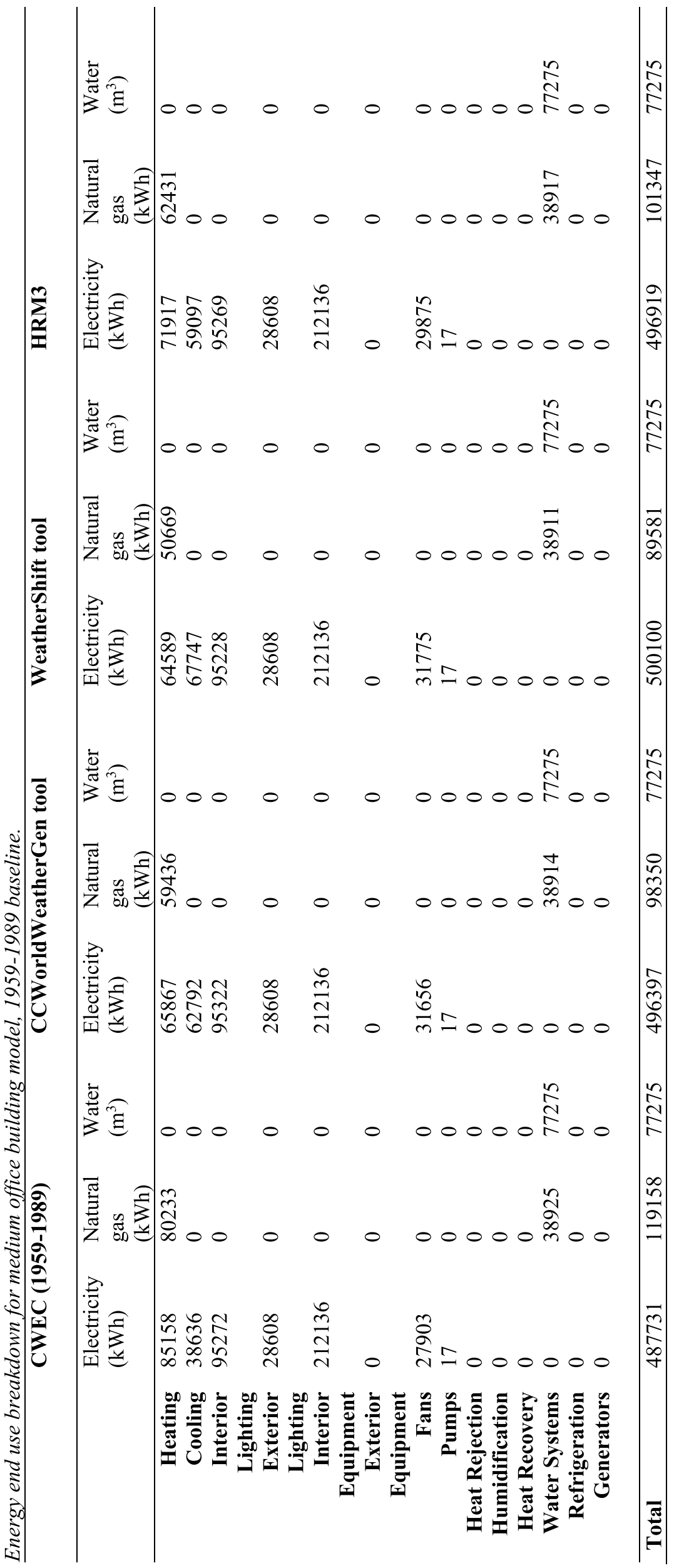


b) CWEC (1998-2014)

\begin{tabular}{|c|c|c|c|c|}
\hline & Weather Files & $\begin{array}{l}\text { Total Energy } \\
\text { (kWh) }\end{array}$ & $\begin{array}{l}\text { Energy Per Total } \\
\text { Building Area } \\
\left(\mathbf{k W h} / \mathbf{m}^{2}\right)\end{array}$ & $\begin{array}{l}\text { Energy Per } \\
\text { Conditioned } \\
\text { Building Area } \\
\left(\mathbf{k W h} / \mathbf{m}^{2}\right)\end{array}$ \\
\hline \multirow{4}{*}{$\begin{array}{l}\text { Total Site } \\
\text { Energy }\end{array}$} & CWEC2016 (1998-2014) & 591,722 & 118.8 & 118.8 \\
\hline & CCWorldWeatherGen tool & 586,764 & 117.8 & 117.8 \\
\hline & WeatherShift tool & 582,169 & 116.9 & 116.9 \\
\hline & HRM3 & 588,325 & 118.1 & 118.1 \\
\hline
\end{tabular}
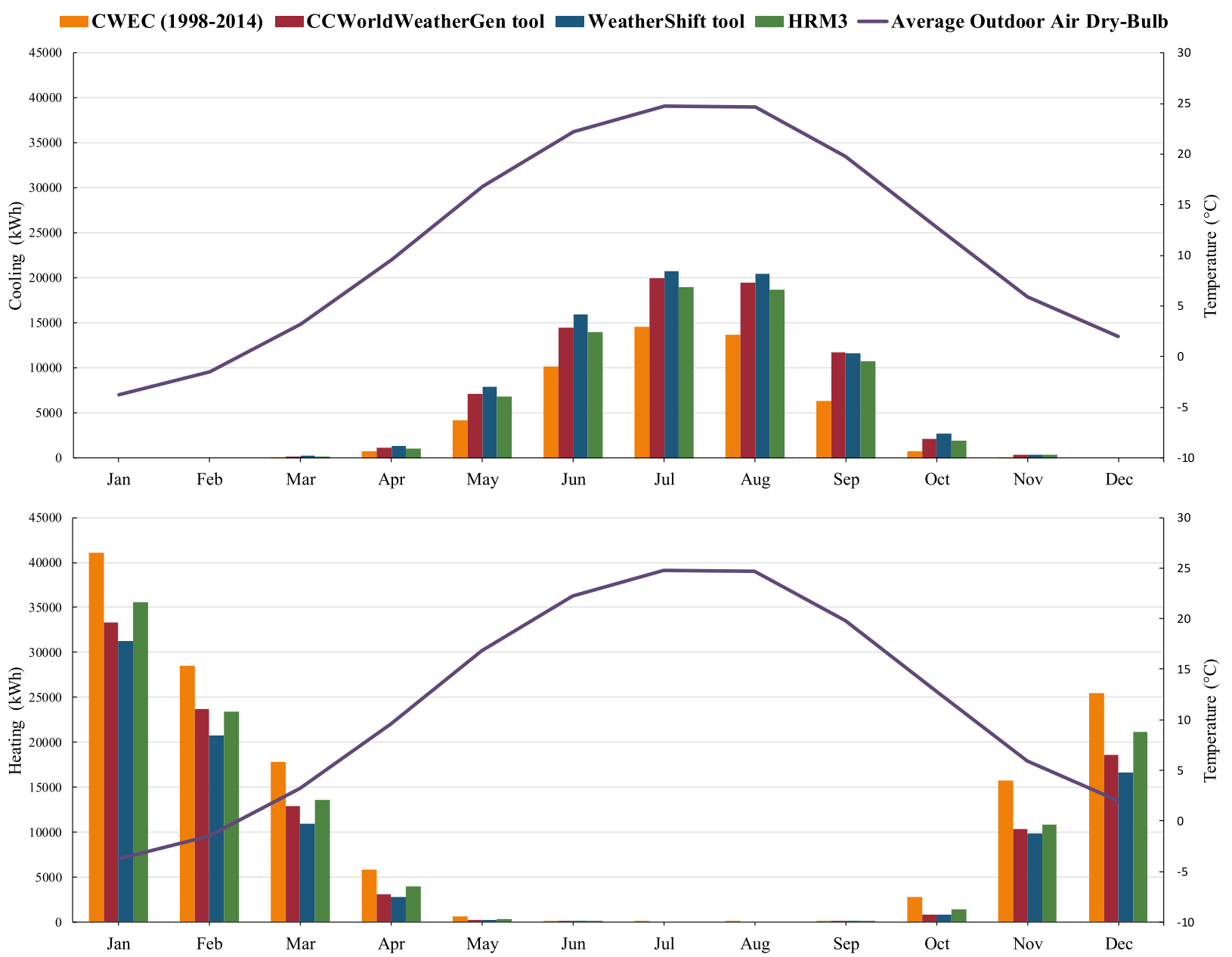


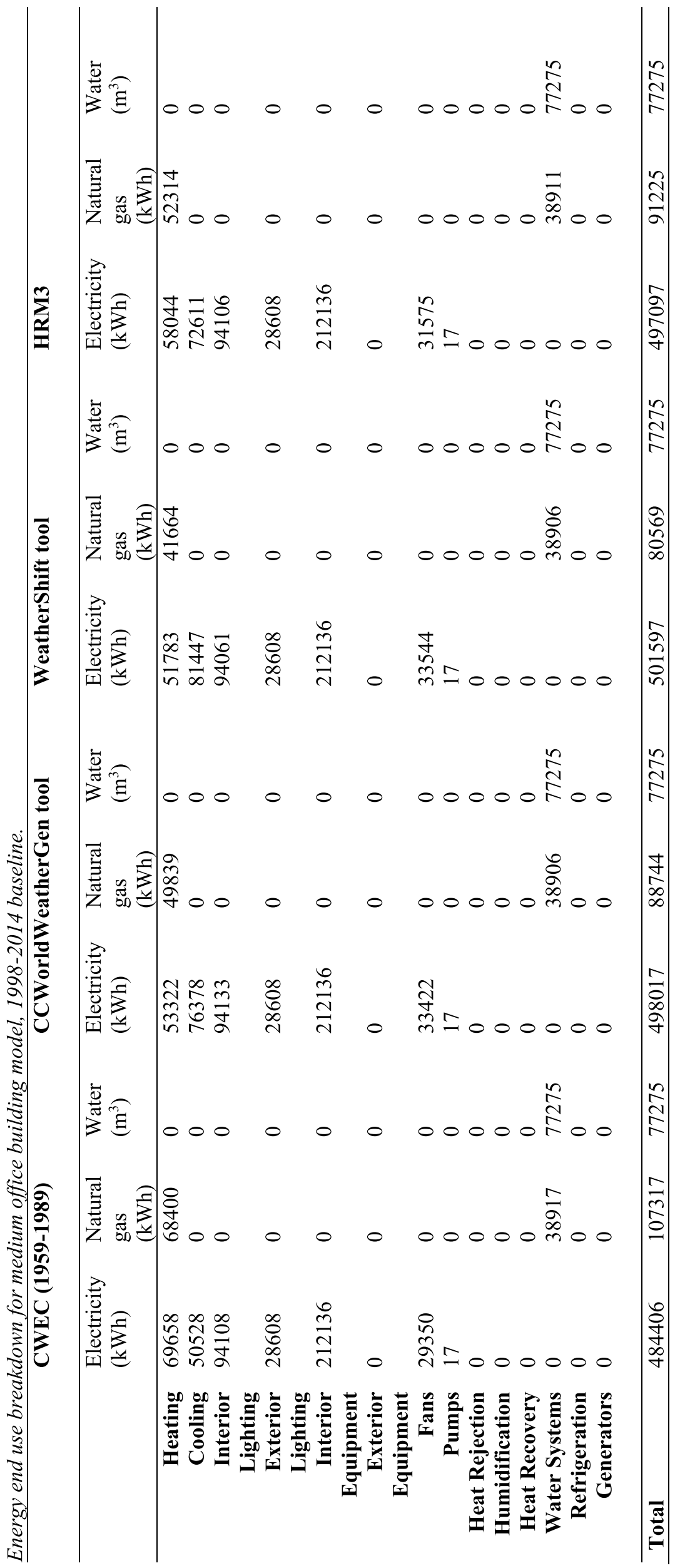


$\underline{\text { Small office building model }}$

a) CWEC (1959-1989)

\begin{tabular}{lllll}
\hline & & $\begin{array}{l}\text { Total Energy } \\
\mathbf{( k W h )}\end{array}$ & $\begin{array}{l}\text { Energy Per Total } \\
\text { Building Area } \\
\left(\mathbf{k W h} / \mathbf{m}^{2}\right)\end{array}$ & $\begin{array}{l}\text { Energy Per } \\
\text { Conditioned } \\
\text { Building Area } \\
\left(\mathbf{k W h} / \mathbf{m}^{2}\right)\end{array}$ \\
\hline $\begin{array}{l}\text { Total Site } \\
\text { Energy }\end{array}$ & CWEC (1959-1989) & 50,267 & 98.3 & 98.3 \\
& CCWorldWeatherGen tool & 49,275 & 96.4 & 96.4 \\
& WeatherShift tool & 48,806 & 95.5 & 95.5 \\
& HRM3 & 49,522 & 96.9 & 96.9 \\
\hline
\end{tabular}
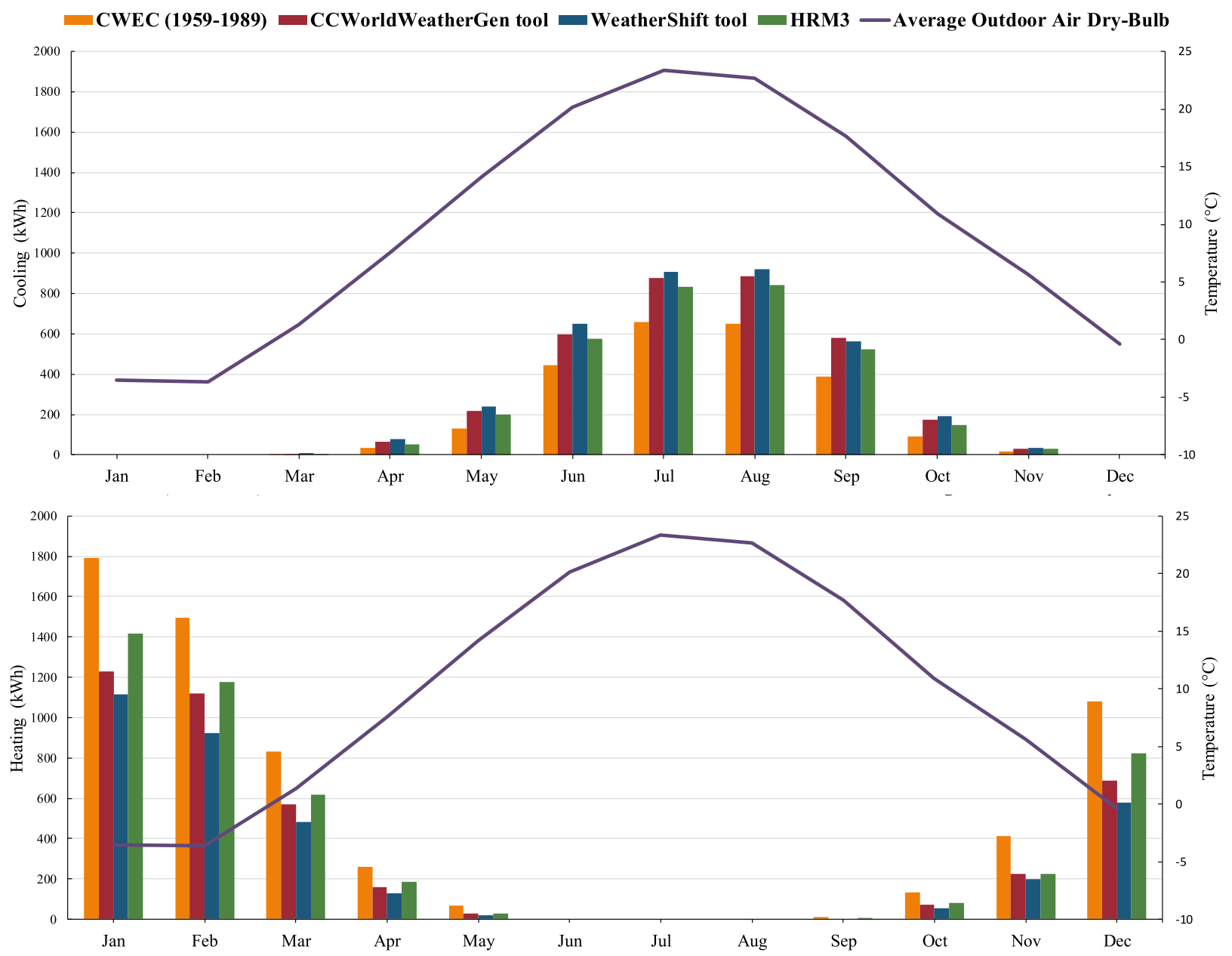


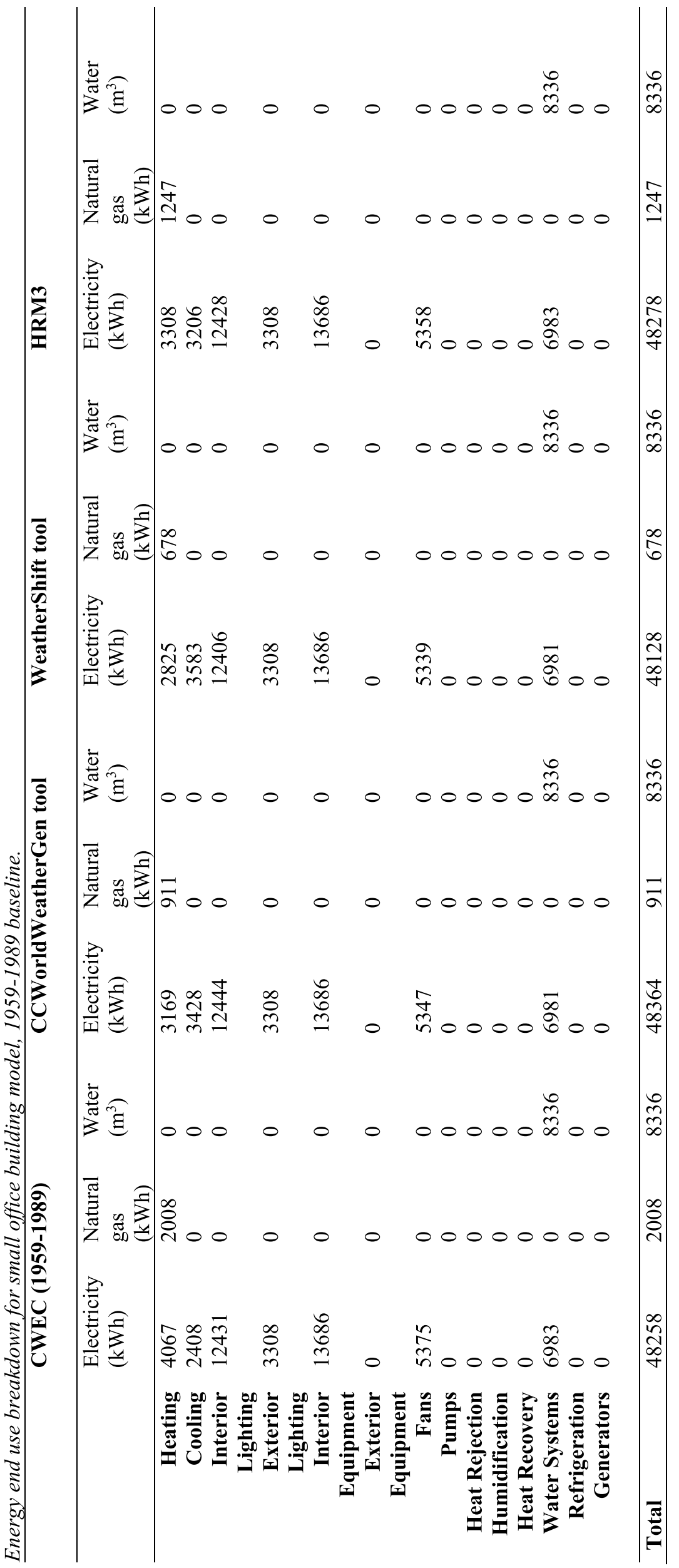


b) CWEC (1998-2014)

\begin{tabular}{|c|c|c|c|c|}
\hline & Weather Files & $\begin{array}{l}\text { Total Energy } \\
\text { (kWh) }\end{array}$ & $\begin{array}{l}\text { Energy Per Total } \\
\text { Building Area } \\
\left(\mathbf{k W h} / \mathbf{m}^{\mathbf{2}}\right)\end{array}$ & $\begin{array}{l}\text { Energy Per } \\
\text { Conditioned } \\
\text { Building Area } \\
\left(\mathbf{k W h} / \mathbf{m}^{2}\right)\end{array}$ \\
\hline \multirow{4}{*}{$\begin{array}{l}\text { Total Site } \\
\text { Energy }\end{array}$} & CWEC2016 (1998-2014) & 49,533 & 96.9 & 96.9 \\
\hline & CCWorldWeatherGen tool & 49,047 & 96 & 96 \\
\hline & WeatherShift tool & 48,703 & 95.3 & 95.3 \\
\hline & HRM3 & 49,192 & 96.2 & 96.2 \\
\hline
\end{tabular}
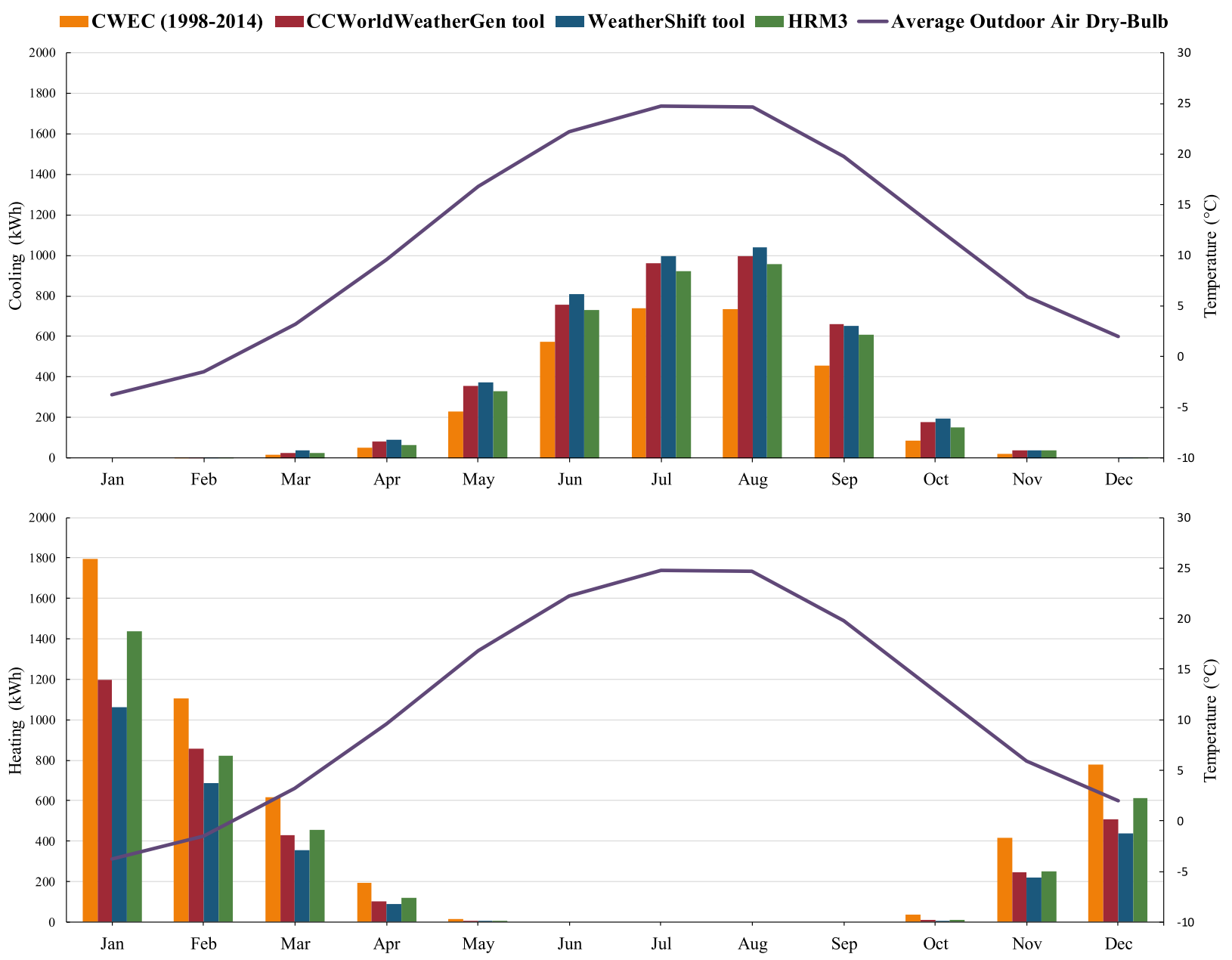


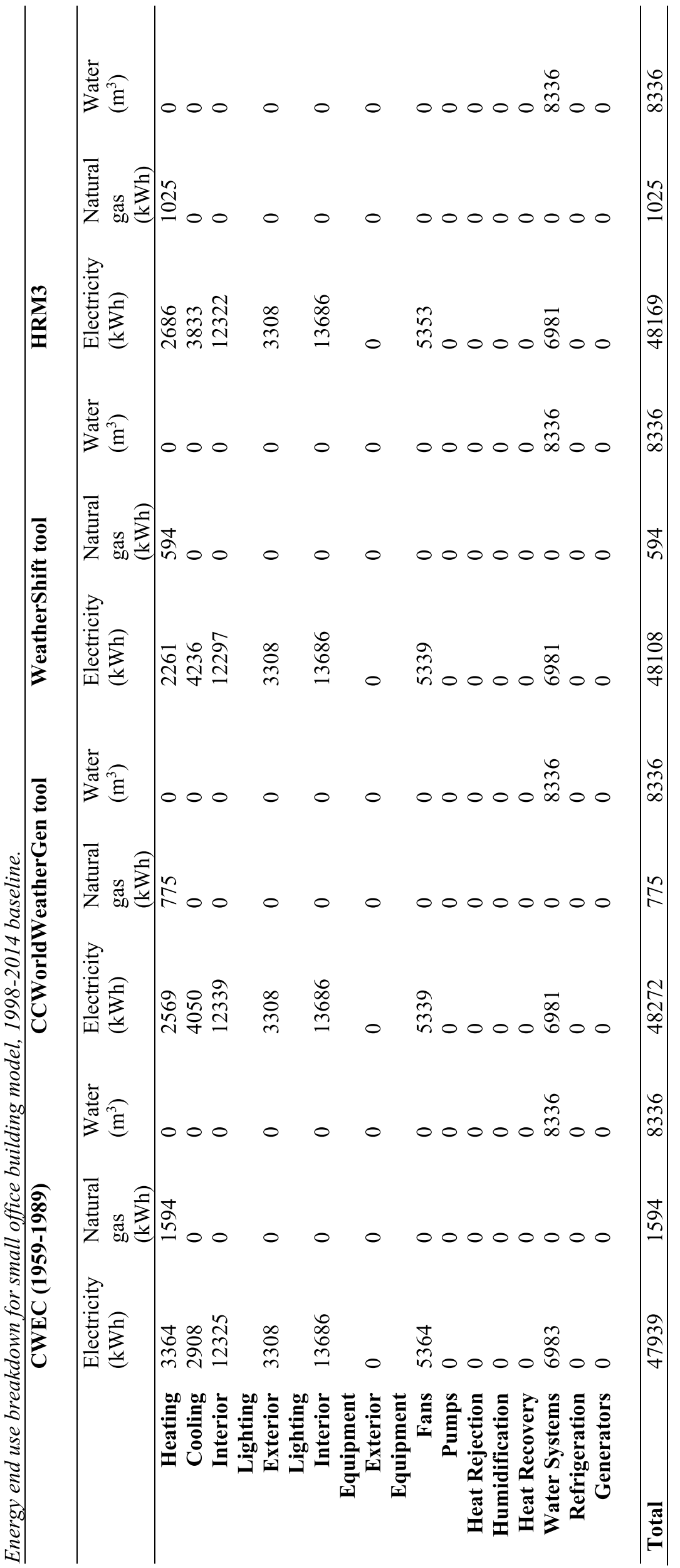




\section{Outpatient Healthcare building model}

a) CWEC (1959-1989)

\begin{tabular}{|c|c|c|c|c|}
\hline & & $\begin{array}{l}\text { Total Energy } \\
(\mathbf{k W h})\end{array}$ & $\begin{array}{l}\text { Energy Per Total } \\
\text { Building Area } \\
\left(\mathbf{k W h} / \mathbf{m}^{2}\right)\end{array}$ & $\begin{array}{l}\text { Energy Per } \\
\text { Conditioned } \\
\text { Building Area } \\
\left(\mathbf{k W h} / \mathbf{m}^{2}\right) \\
\end{array}$ \\
\hline \multirow{4}{*}{$\begin{array}{l}\text { Total Site } \\
\text { Energy }\end{array}$} & CWEC (1959-1989) & $1,393,403$ & 366.3 & 366.3 \\
\hline & CCWorldWeatherGen tool & $1,385,914$ & 364.3 & 364.3 \\
\hline & WeatherShift tool & $1,380,864$ & 363 & 363 \\
\hline & HRM3 & $1,390,378$ & 365.5 & 365.5 \\
\hline
\end{tabular}
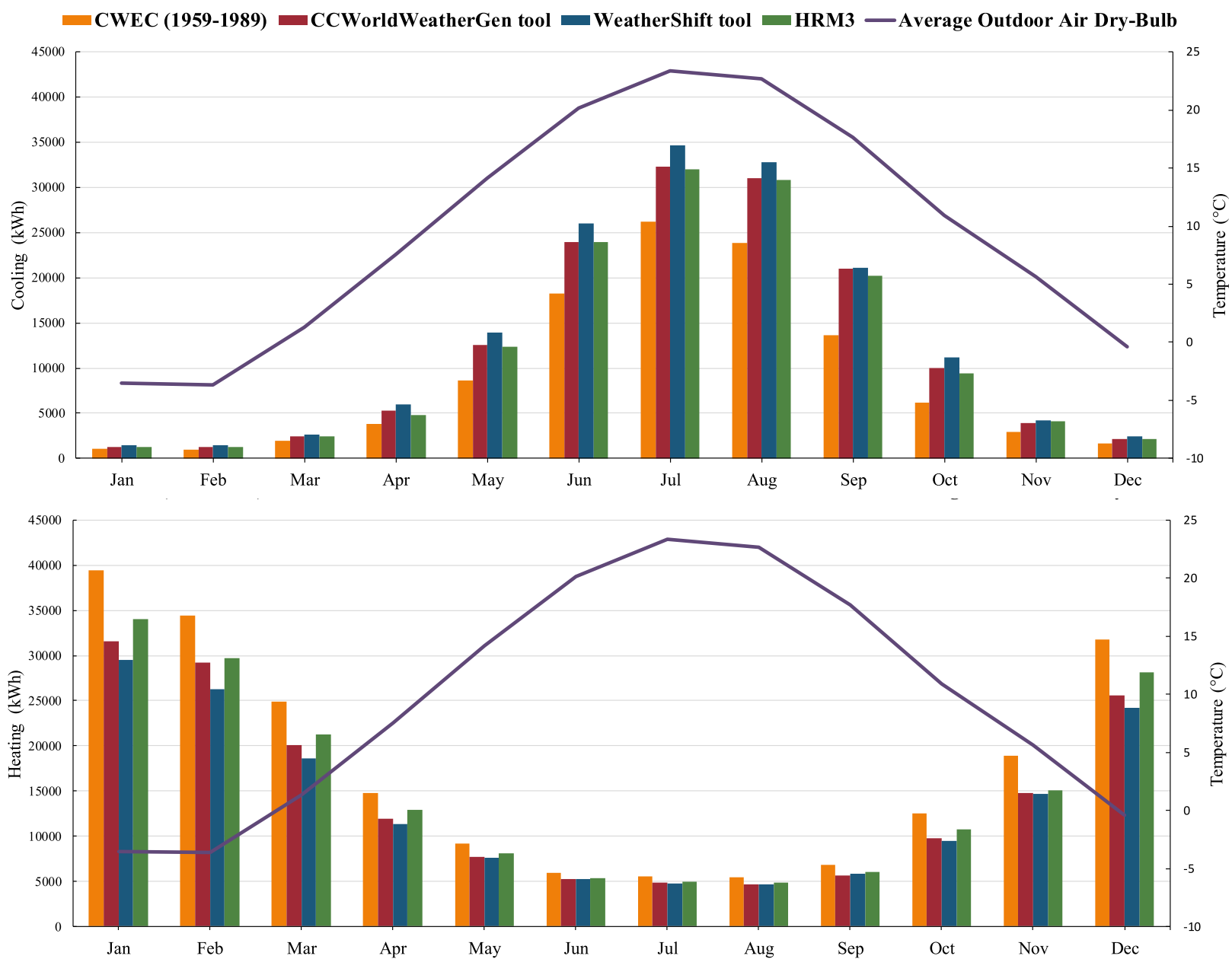


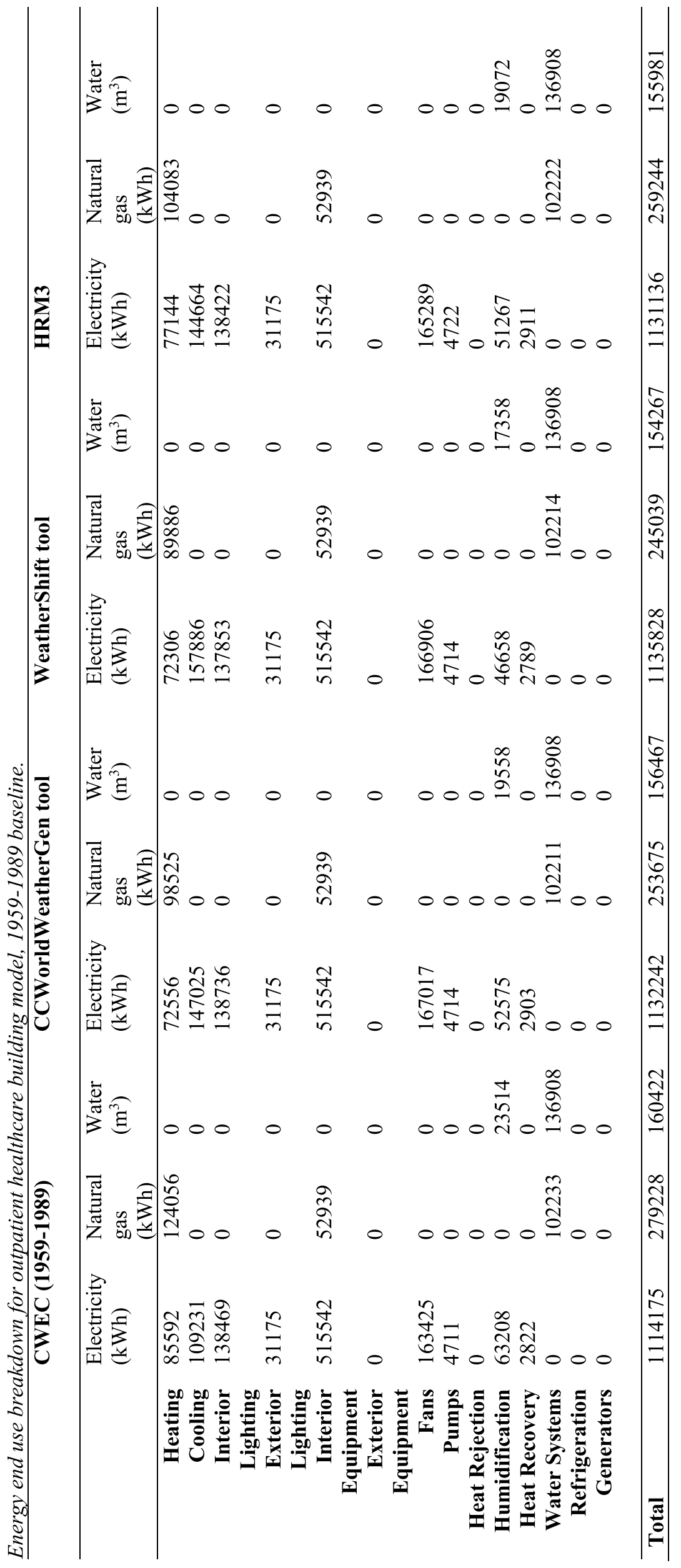


b) CWEC (1998-2014)

\begin{tabular}{|c|c|c|c|c|}
\hline & & $\begin{array}{l}\text { Total Energy } \\
\text { (kWh) }\end{array}$ & $\begin{array}{l}\text { Energy Per Total } \\
\text { Building Area } \\
\left(\mathbf{k W h} / \mathbf{m}^{2}\right)\end{array}$ & $\begin{array}{l}\text { Energy Per } \\
\text { Conditioned } \\
\text { Building Area } \\
\left(\mathbf{k W h} / \mathbf{m}^{2}\right)\end{array}$ \\
\hline \multirow{4}{*}{$\begin{array}{l}\text { Total Site } \\
\text { Energy }\end{array}$} & CWEC (1959-1989) & $1,386,903$ & 364.6 & 364.6 \\
\hline & CCWorldWeatherGen tool & $1,388,022$ & 364.9 & 364.9 \\
\hline & WeatherShift tool & $1,385,031$ & 364.1 & 364.1 \\
\hline & HRM3 & $1,390,650$ & 365.6 & 365.6 \\
\hline
\end{tabular}
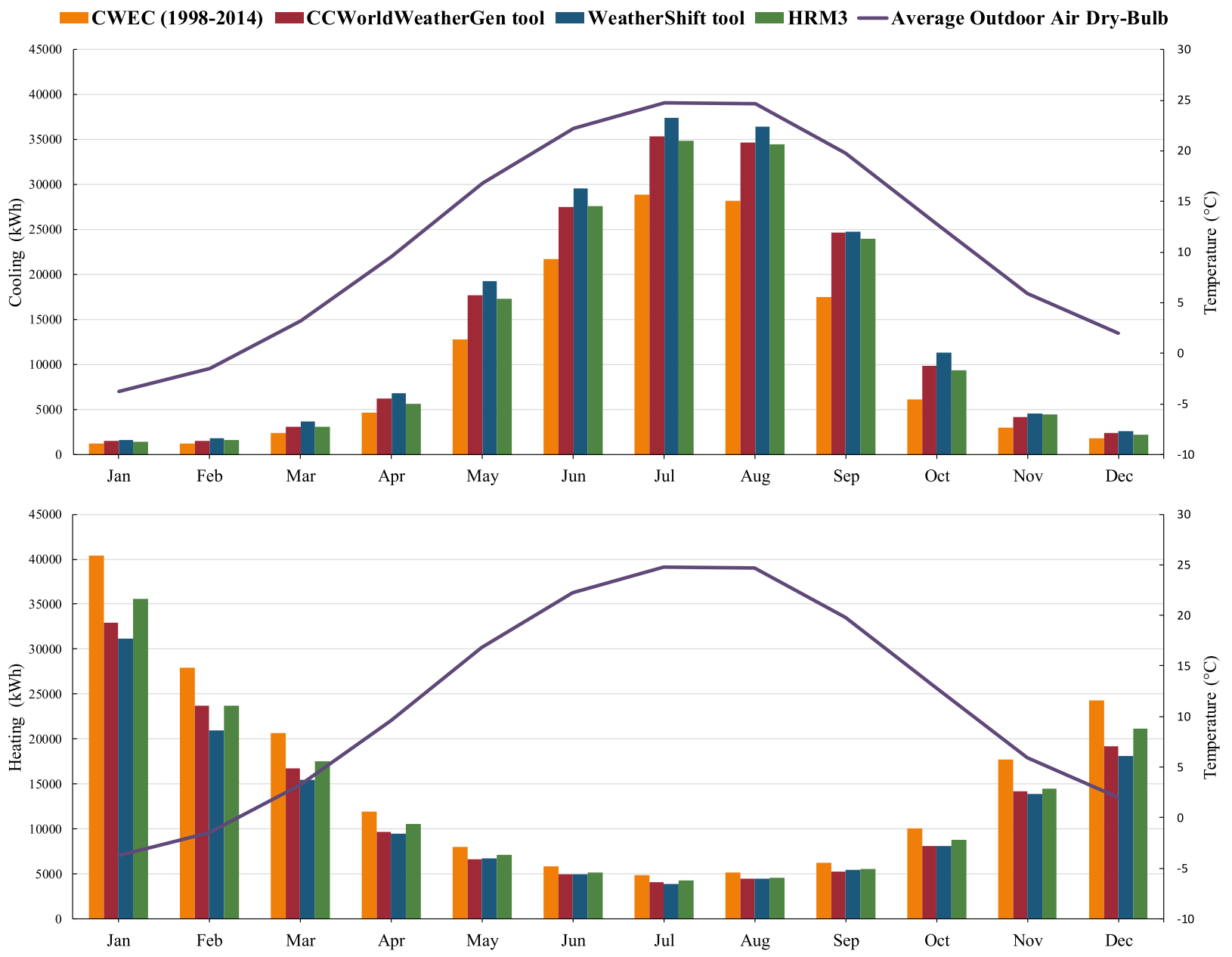


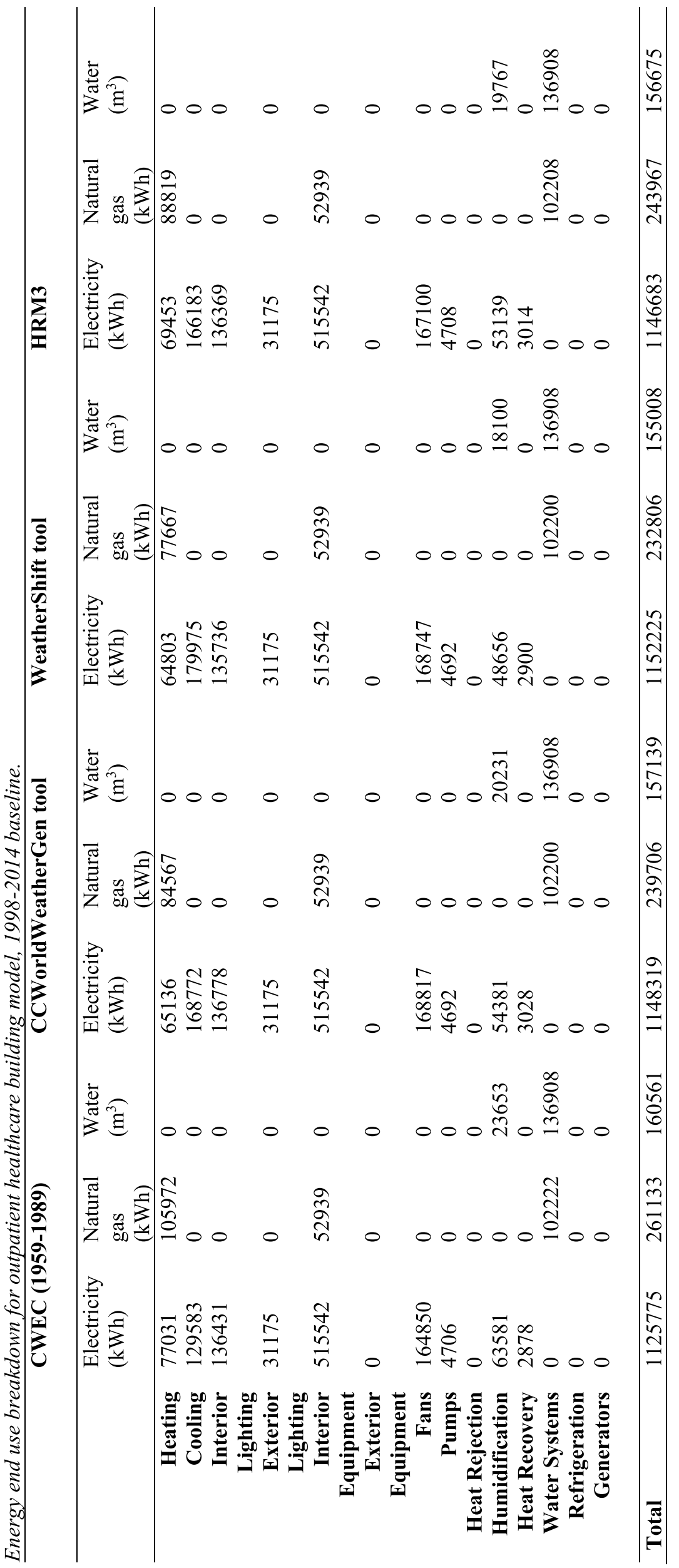


Fast food restaurant building model

a) CWEC (1959-1989)

Total energy use and EUI of fast food restaurant building model.

\begin{tabular}{|c|c|c|c|c|}
\hline & & $\begin{array}{l}\text { Total Energy } \\
\text { (kWh) }\end{array}$ & $\begin{array}{l}\text { Energy Per Total } \\
\text { Building Area } \\
\left(\mathbf{k W h} / \mathbf{m}^{2}\right)\end{array}$ & $\begin{array}{l}\text { Energy Per } \\
\text { Conditioned } \\
\text { Building Area } \\
\left(\mathbf{k W h} / \mathbf{m}^{2}\right)\end{array}$ \\
\hline \multirow{4}{*}{$\begin{array}{l}\text { Total Site } \\
\text { Energy }\end{array}$} & CWEC (1959-1989) & 415,406 & $1,787.9$ & 1787.9 \\
\hline & CCWorldWeatherGen tool & 394,525 & $1,698.1$ & 1698 \\
\hline & WeatherShift tool & 385,325 & $1,658.5$ & 1658.4 \\
\hline & HRM3 & 397,761 & 1,712 & 1712 \\
\hline
\end{tabular}
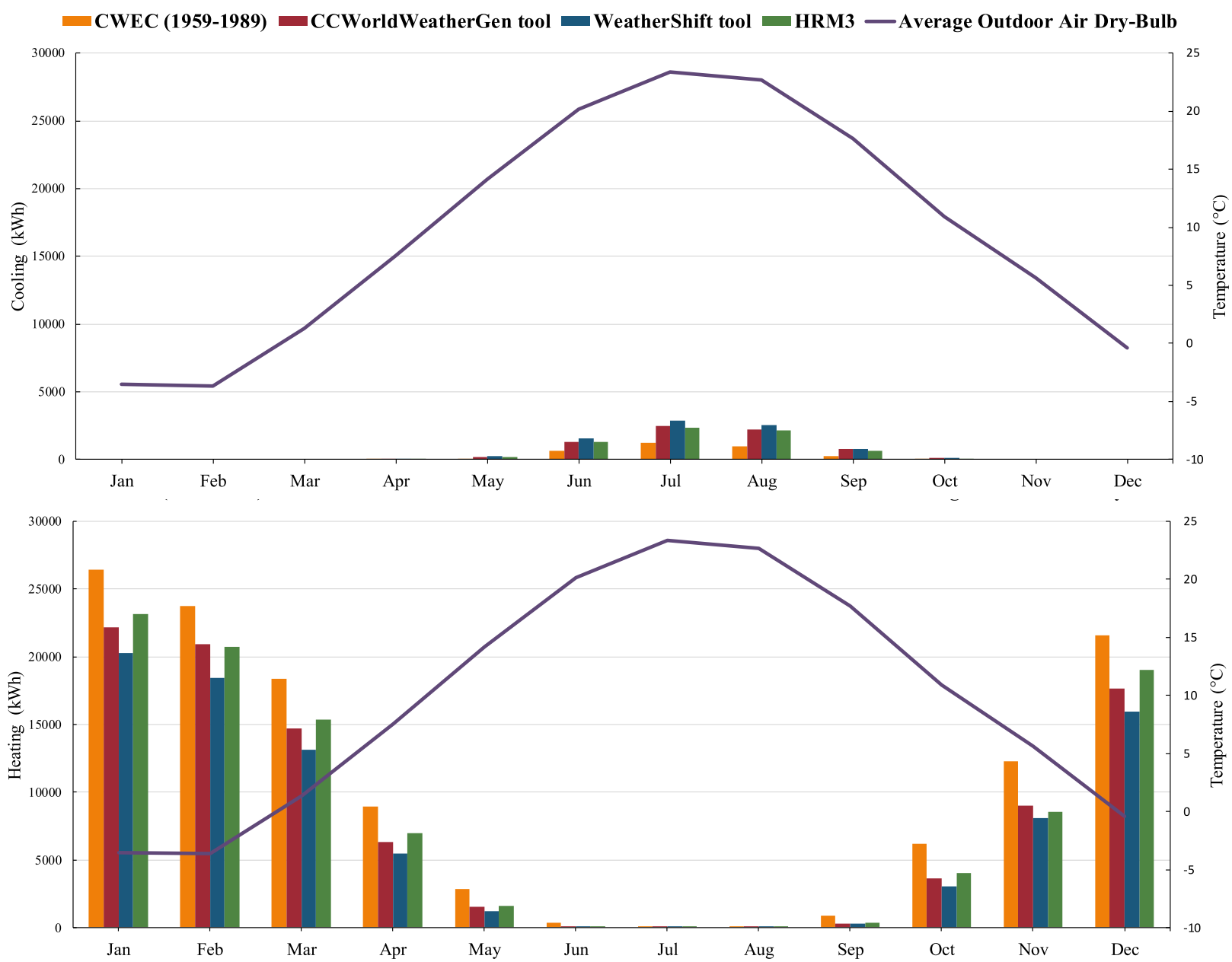


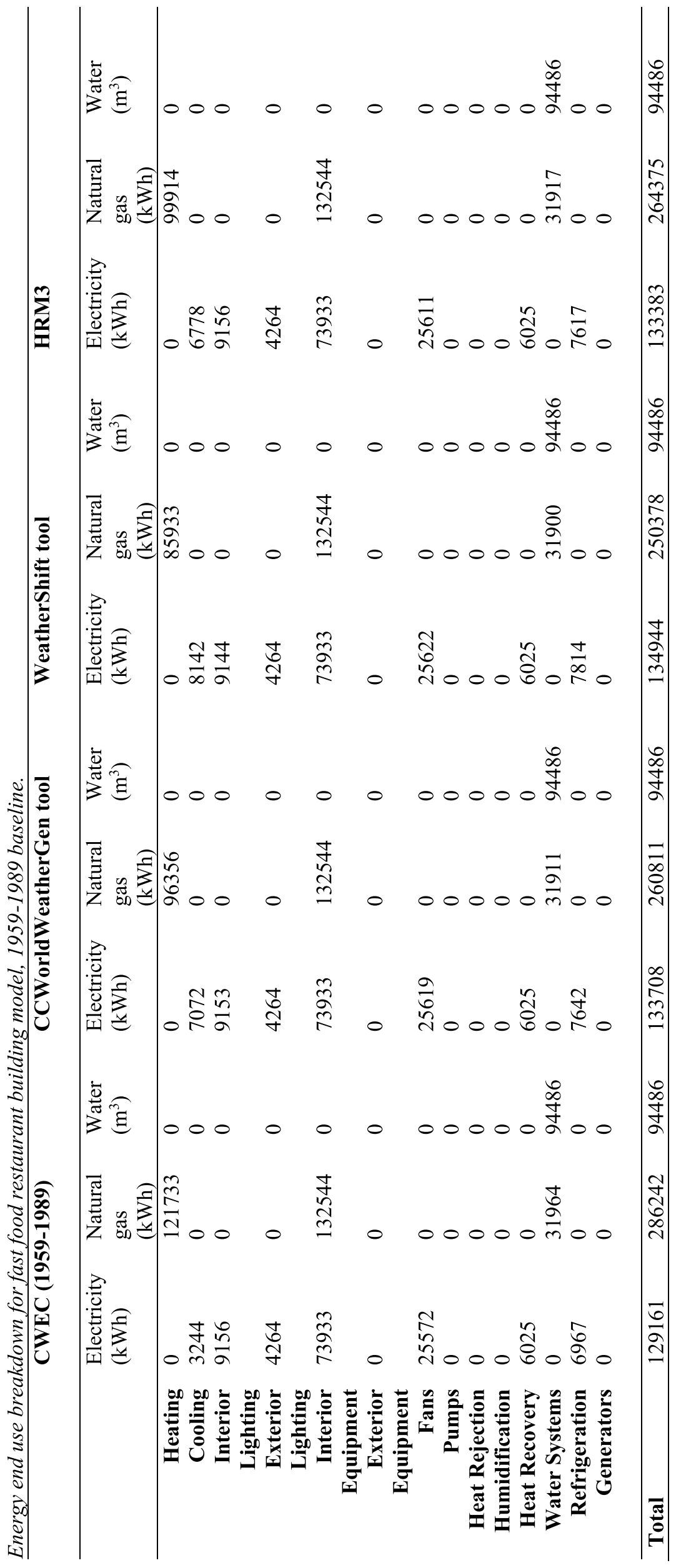


b) CWEC (1998-2014)

\begin{tabular}{lllll}
\hline & & $\begin{array}{l}\text { Total Energy } \\
\mathbf{( k W h )}\end{array}$ & $\begin{array}{l}\text { Energy Per Total } \\
\text { Building Area } \\
\left(\mathbf{k W h} / \mathbf{m}^{\mathbf{2}}\right)\end{array}$ & $\begin{array}{l}\text { Energy Per } \\
\text { Conditioned } \\
\text { Building Area } \\
\mathbf{( k W h / \mathbf { m } ^ { 2 } )}\end{array}$ \\
\hline $\begin{array}{l}\text { Total Site } \\
\text { Energy }\end{array}$ & CWEC (1959-1989) & 399,653 & $1,720.1$ & $1,720.1$ \\
& CCWorldWeatherGen tool & 382,197 & 1,645 & 1,645 \\
& WeatherShift tool & 374,006 & $1,609.7$ & $1,609.7$ \\
& HRM3 & 385,217 & 1,658 & 1,658 \\
\hline
\end{tabular}
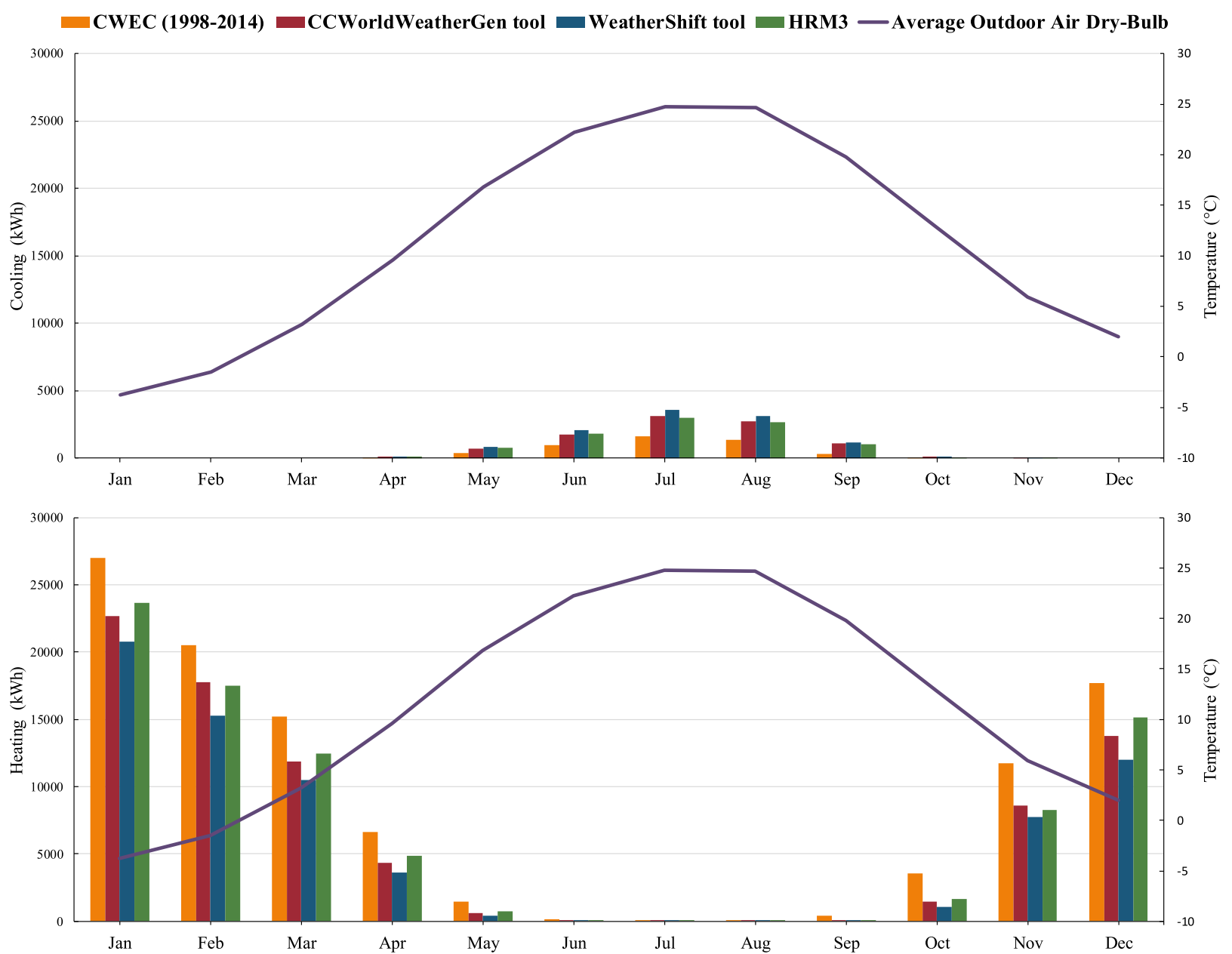


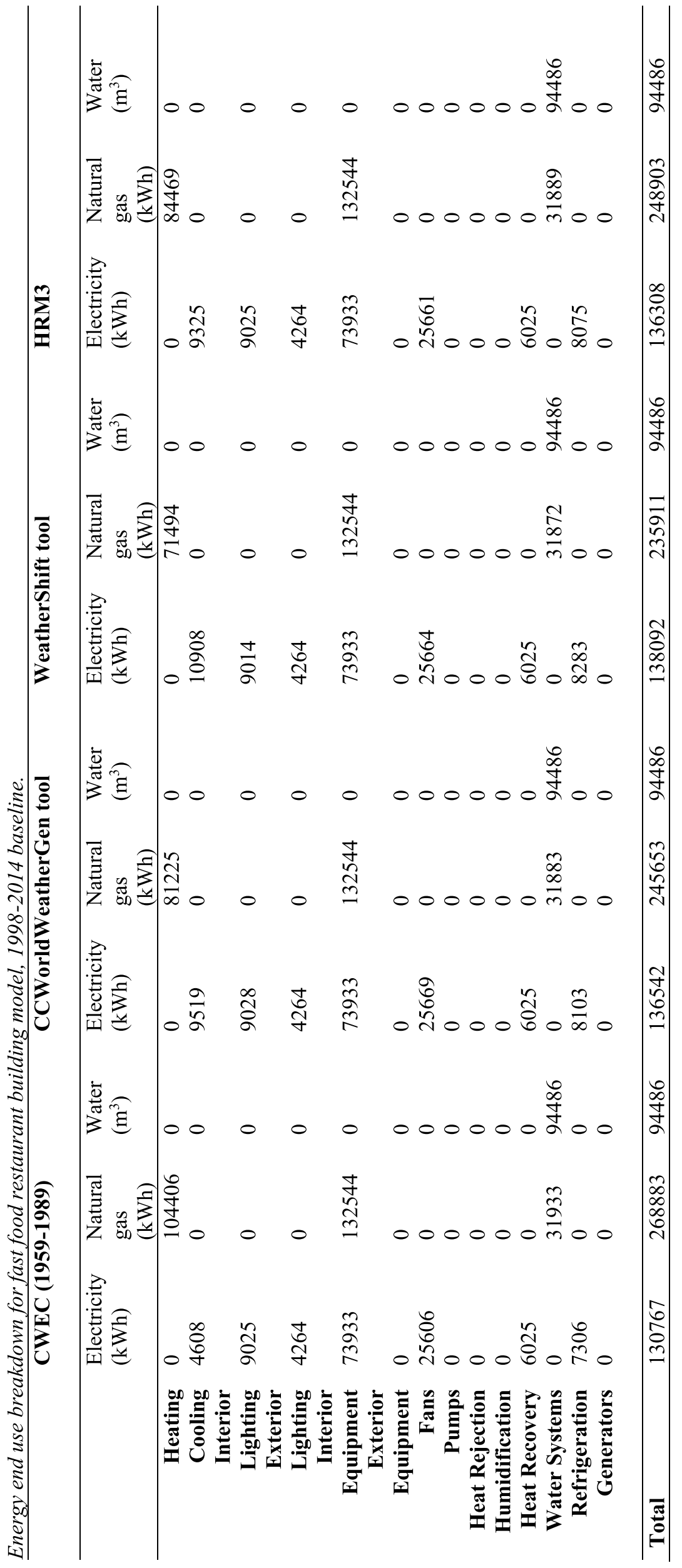


$\underline{\text { Sit-down restaurant building model }}$

a) CWEC (1959-1989)

\begin{tabular}{|c|c|c|c|c|}
\hline & & $\begin{array}{l}\text { Total Energy } \\
(\mathbf{k W h})\end{array}$ & $\begin{array}{l}\text { Energy Per Total } \\
\text { Building Area } \\
\left(\mathbf{k W h} / \mathbf{m}^{2}\right)\end{array}$ & $\begin{array}{l}\text { Energy Per } \\
\text { Conditioned } \\
\text { Building Area } \\
\left(\mathbf{k W h} / \mathbf{m}^{2}\right) \\
\end{array}$ \\
\hline \multirow{4}{*}{$\begin{array}{l}\text { Total Site } \\
\text { Energy }\end{array}$} & CWEC (1959-1989) & 831,208 & $1,626.2$ & $1,626.1$ \\
\hline & CCWorldWeatherGen tool & 793,056 & $1,551.5$ & $1,551.5$ \\
\hline & WeatherShift tool & 776,111 & $1,518.4$ & $1,518.4$ \\
\hline & HRM3 & 798,853 & $1,562.9$ & $1,562.8$ \\
\hline
\end{tabular}
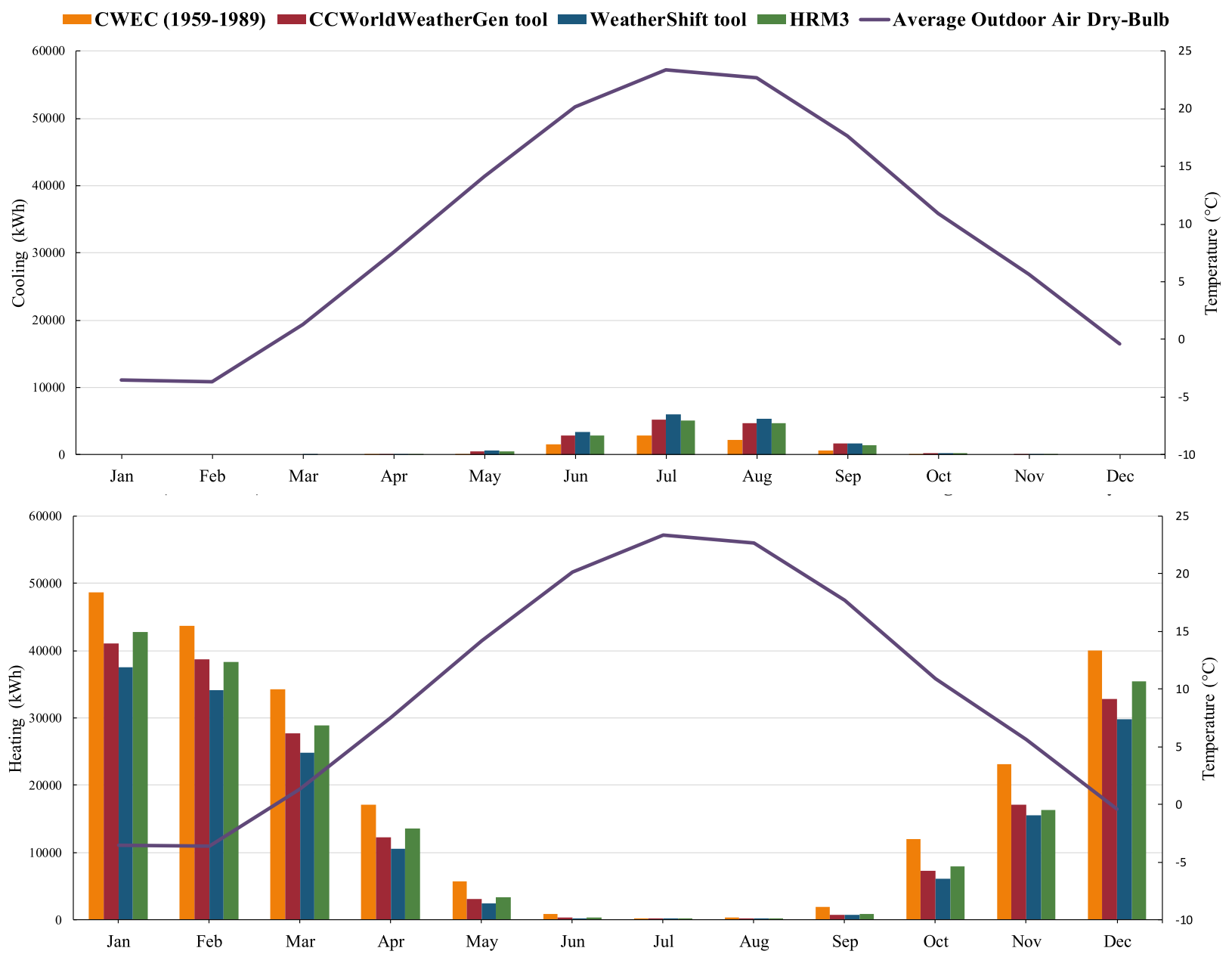


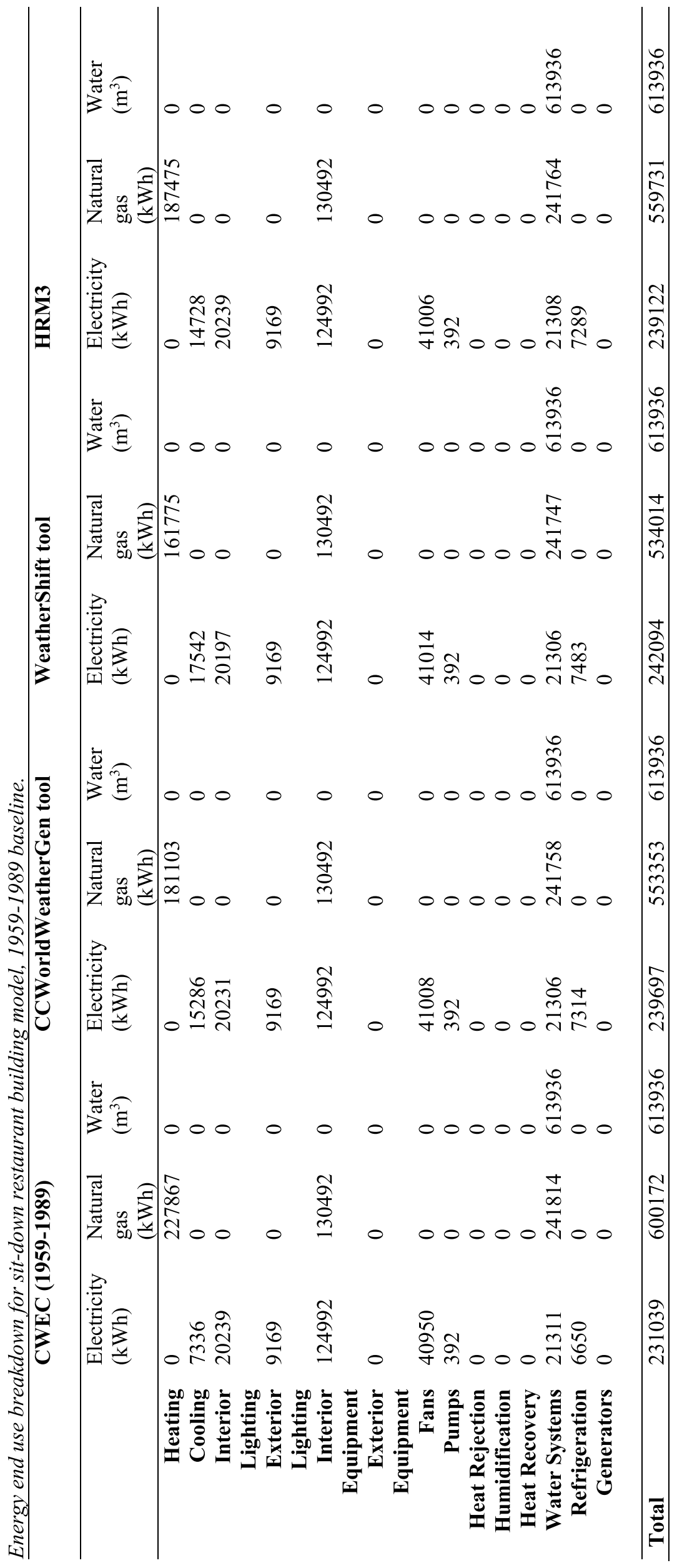


b) CWEC (1998-2014)

\begin{tabular}{|c|c|c|c|c|}
\hline & & $\begin{array}{l}\text { Total Energy } \\
\text { (kWh) }\end{array}$ & $\begin{array}{l}\text { Energy Per Total } \\
\text { Building Area } \\
\left(\mathbf{k W h} / \mathbf{m}^{2}\right)\end{array}$ & $\begin{array}{l}\text { Energy Per } \\
\text { Conditioned } \\
\text { Building Area } \\
\left(\mathbf{k W h} / \mathbf{m}^{2}\right)\end{array}$ \\
\hline \multirow{4}{*}{$\begin{array}{l}\text { Total Site } \\
\text { Energy }\end{array}$} & CWEC (1959-1989) & 801,958 & $1,568.9$ & $1,568.9$ \\
\hline & CCWorldWeatherGen tool & 770,133 & $1,506.7$ & $1,506.7$ \\
\hline & WeatherShift tool & 755,050 & $1,477.2$ & $1,477.2$ \\
\hline & HRM3 & 775,683 & $1,517.5$ & $1,517.5$ \\
\hline
\end{tabular}
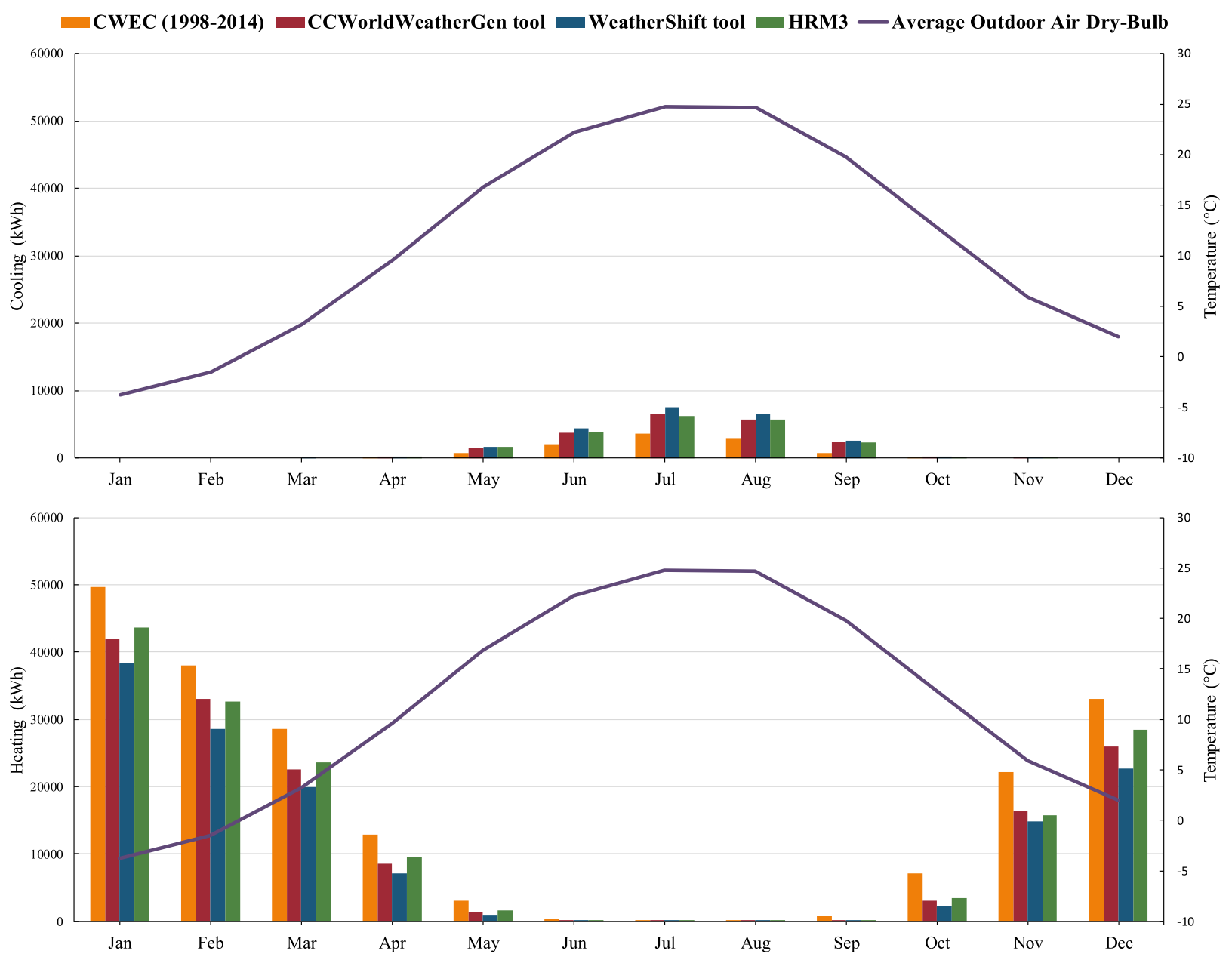


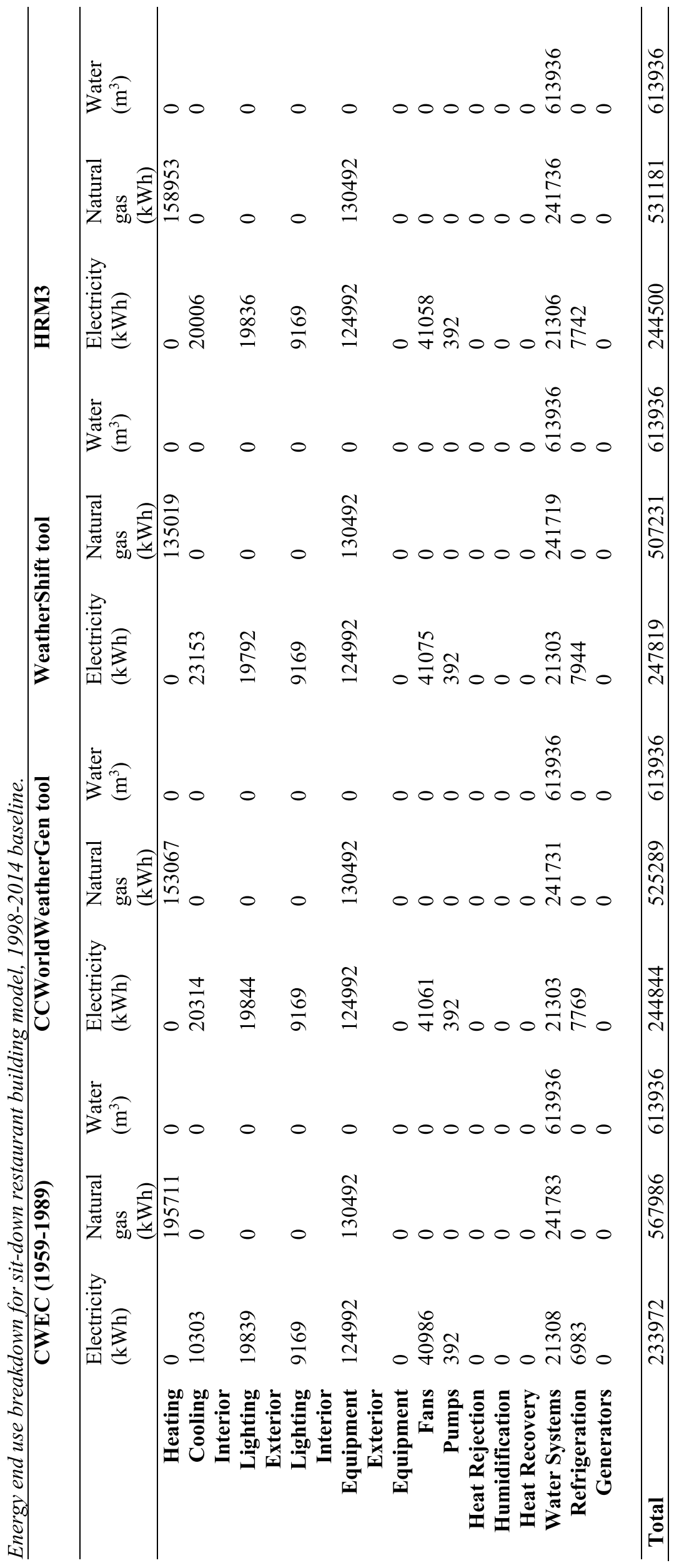




\section{$\underline{\text { Standalone retail building model }}$}

a) CWEC (1959-1989)

\begin{tabular}{|c|c|c|c|c|}
\hline & & $\begin{array}{l}\text { Total Energy } \\
\text { (kWh) }\end{array}$ & $\begin{array}{l}\text { Energy Per Total } \\
\text { Building Area } \\
\left(\mathbf{k W h} / \mathbf{m}^{2}\right)\end{array}$ & $\begin{array}{l}\text { Energy Per } \\
\text { Conditioned } \\
\text { Building Area } \\
\left(\mathbf{k W h} / \mathbf{m}^{2}\right)\end{array}$ \\
\hline \multirow{4}{*}{$\begin{array}{l}\text { Total Site } \\
\text { Energy }\end{array}$} & CWEC (1959-1989) & 376,339 & 164.1 & 164.1 \\
\hline & CCWorldWeatherGen tool & 368,297 & 160.5 & 160.5 \\
\hline & WeatherShift tool & 364,039 & 158.7 & 158.7 \\
\hline & HRM3 & 370,794 & 161.6 & 161.6 \\
\hline
\end{tabular}
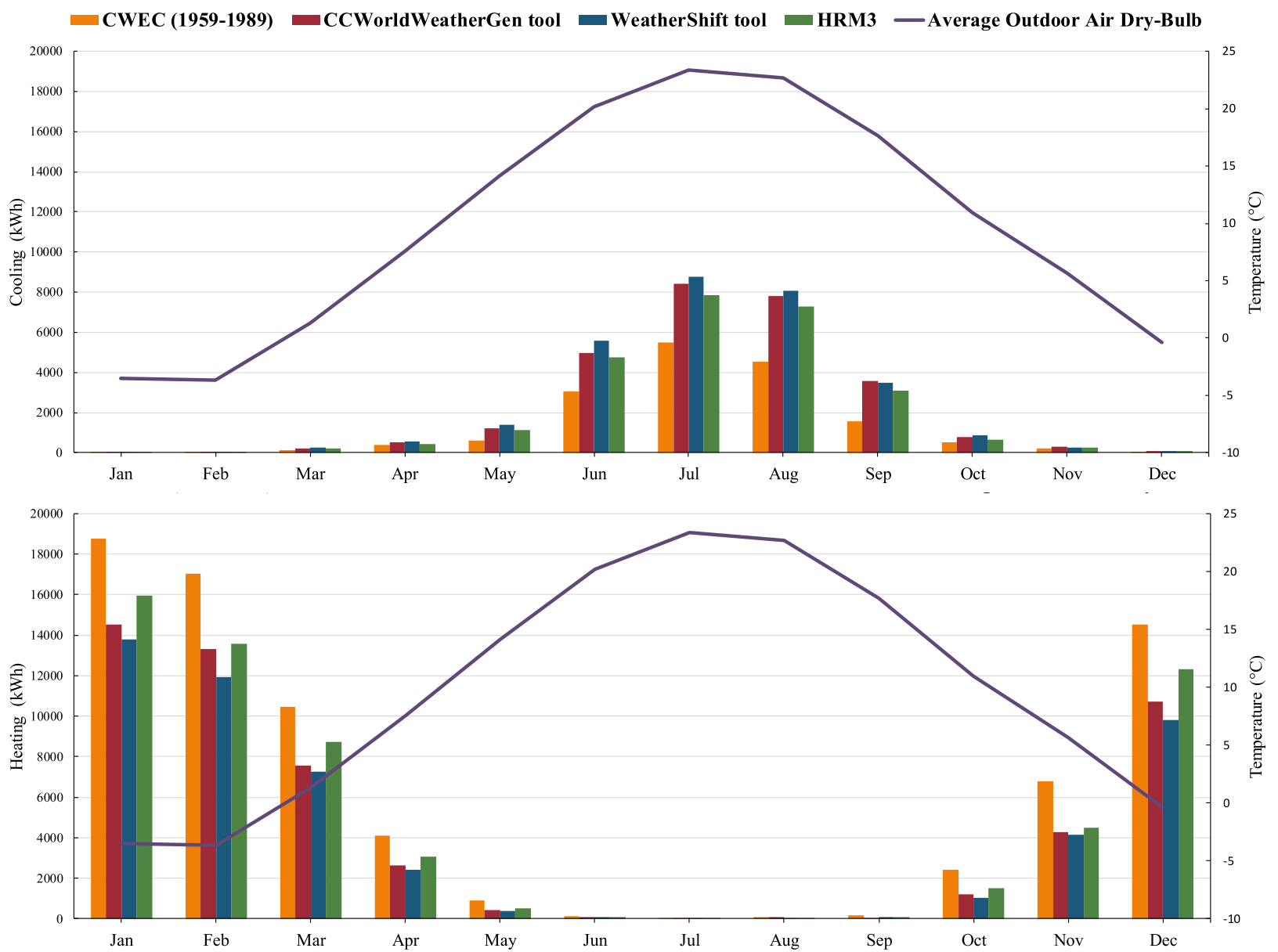


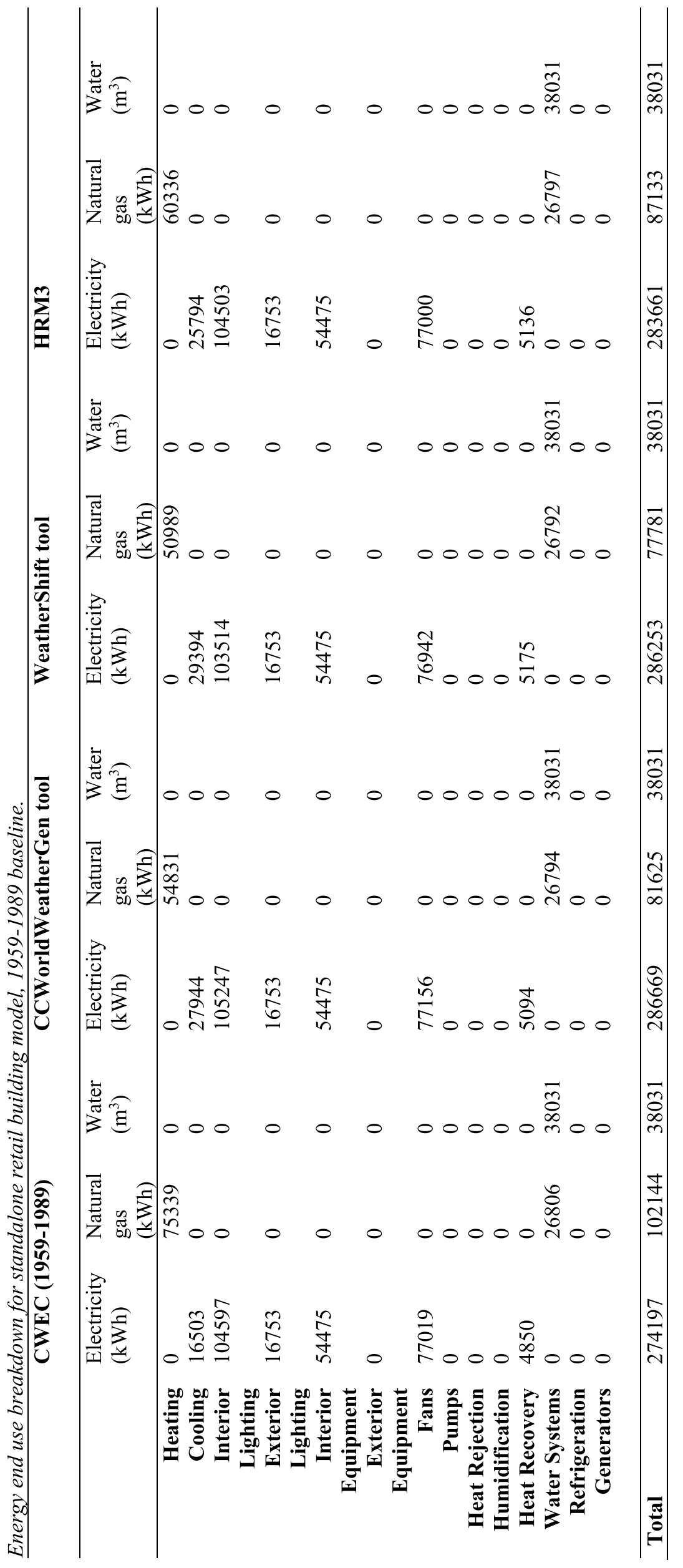


b) CWEC (1998-2014)

\begin{tabular}{|c|c|c|c|c|}
\hline & & $\begin{array}{l}\text { Total Energy } \\
\text { (kWh) }\end{array}$ & $\begin{array}{l}\text { Energy Per Total } \\
\text { Building Area } \\
\left(\mathbf{k W h} / \mathbf{m}^{2}\right)\end{array}$ & $\begin{array}{l}\text { Energy Per } \\
\text { Conditioned } \\
\text { Building Area } \\
\left(\mathbf{k W h} / \mathbf{m}^{2}\right)\end{array}$ \\
\hline \multirow{4}{*}{$\begin{array}{l}\text { Total Site } \\
\text { Energy }\end{array}$} & CWEC (1959-1989) & 367,650 & 160.3 & 160.3 \\
\hline & CCWorldWeatherGen tool & 364,886 & 159.1 & 159.1 \\
\hline & WeatherShift tool & 360,525 & 157.2 & 157.2 \\
\hline & HRM3 & 366,392 & 159.7 & 159.7 \\
\hline
\end{tabular}
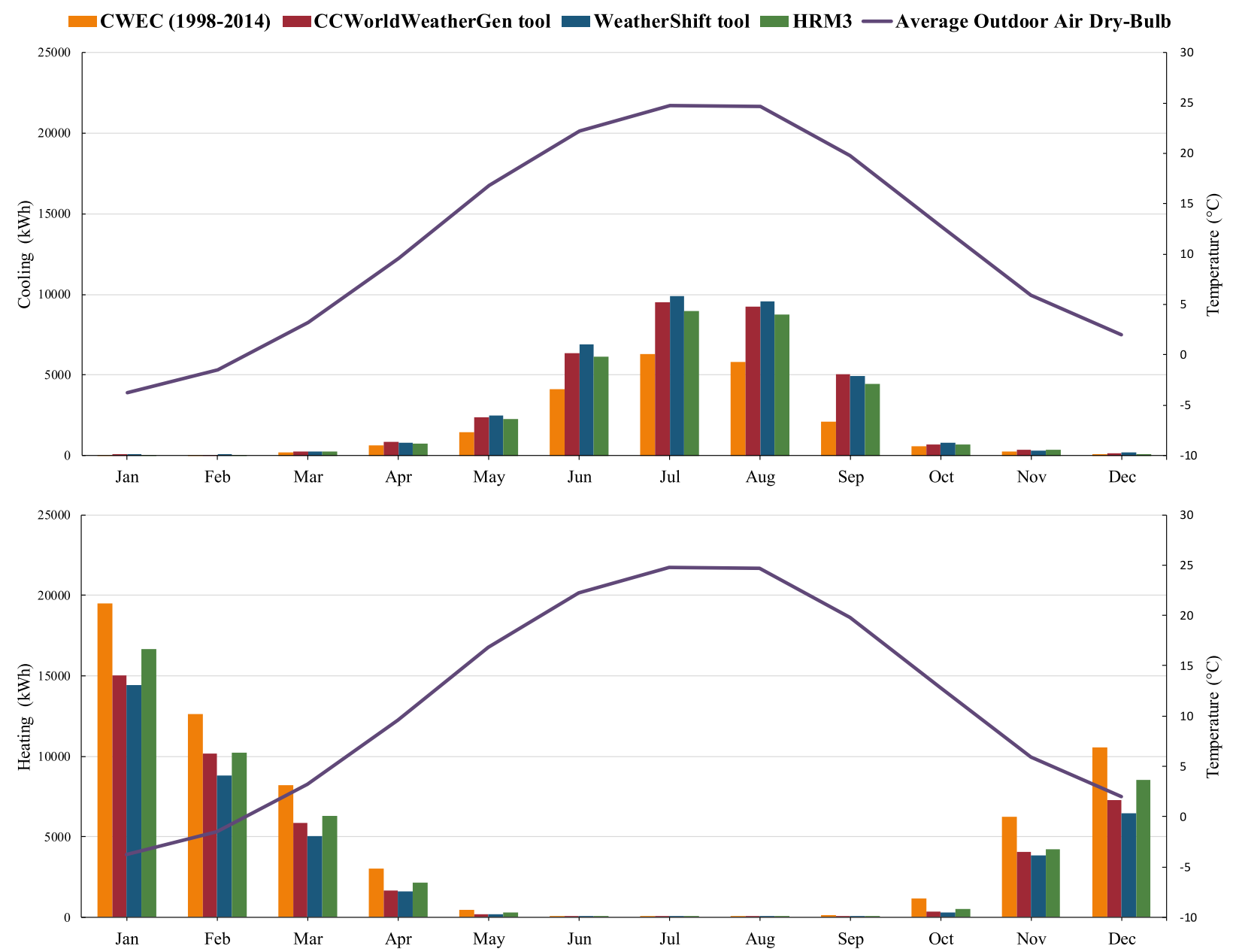


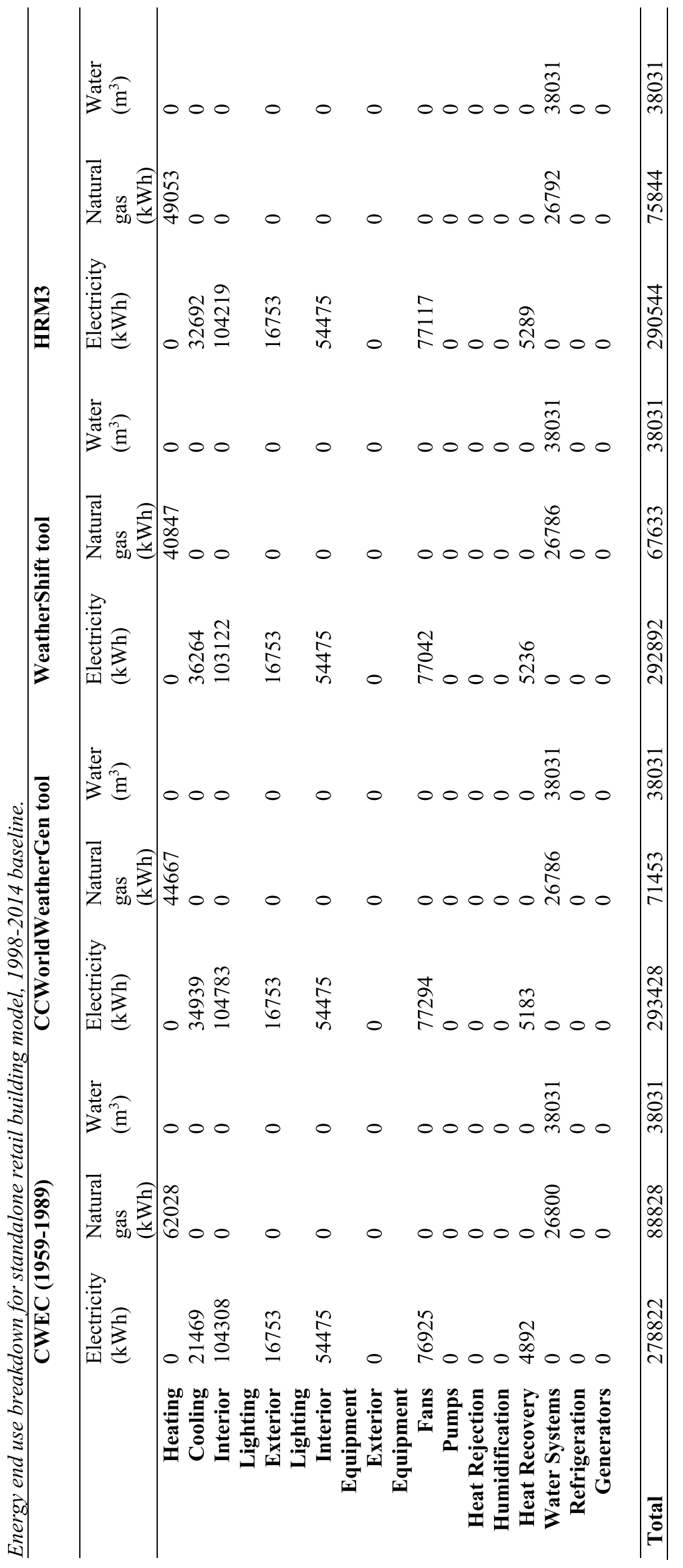




\section{$\underline{\text { Strip mall retail building model }}$}

a) CWEC (1959-1989)

\begin{tabular}{|c|c|c|c|c|}
\hline & & $\begin{array}{l}\text { Total Energy } \\
(\mathbf{k W h})\end{array}$ & $\begin{array}{l}\text { Energy Per Total } \\
\text { Building Area } \\
\left(\mathbf{k W h} / \mathbf{m}^{2}\right)\end{array}$ & $\begin{array}{l}\text { Energy Per } \\
\text { Conditioned } \\
\text { Building Area } \\
\left(\mathbf{k W h} / \mathbf{m}^{2}\right)\end{array}$ \\
\hline \multirow{4}{*}{$\begin{array}{l}\text { Total Site } \\
\text { Energy }\end{array}$} & CWEC (1959-1989) & 498,319 & 238.4 & 238.4 \\
\hline & CCWorldWeatherGen tool & 464,325 & 222.1 & 222.1 \\
\hline & WeatherShift tool & 451,286 & 215.9 & 215.9 \\
\hline & HRM3 & 471,458 & 225.5 & 225.5 \\
\hline
\end{tabular}
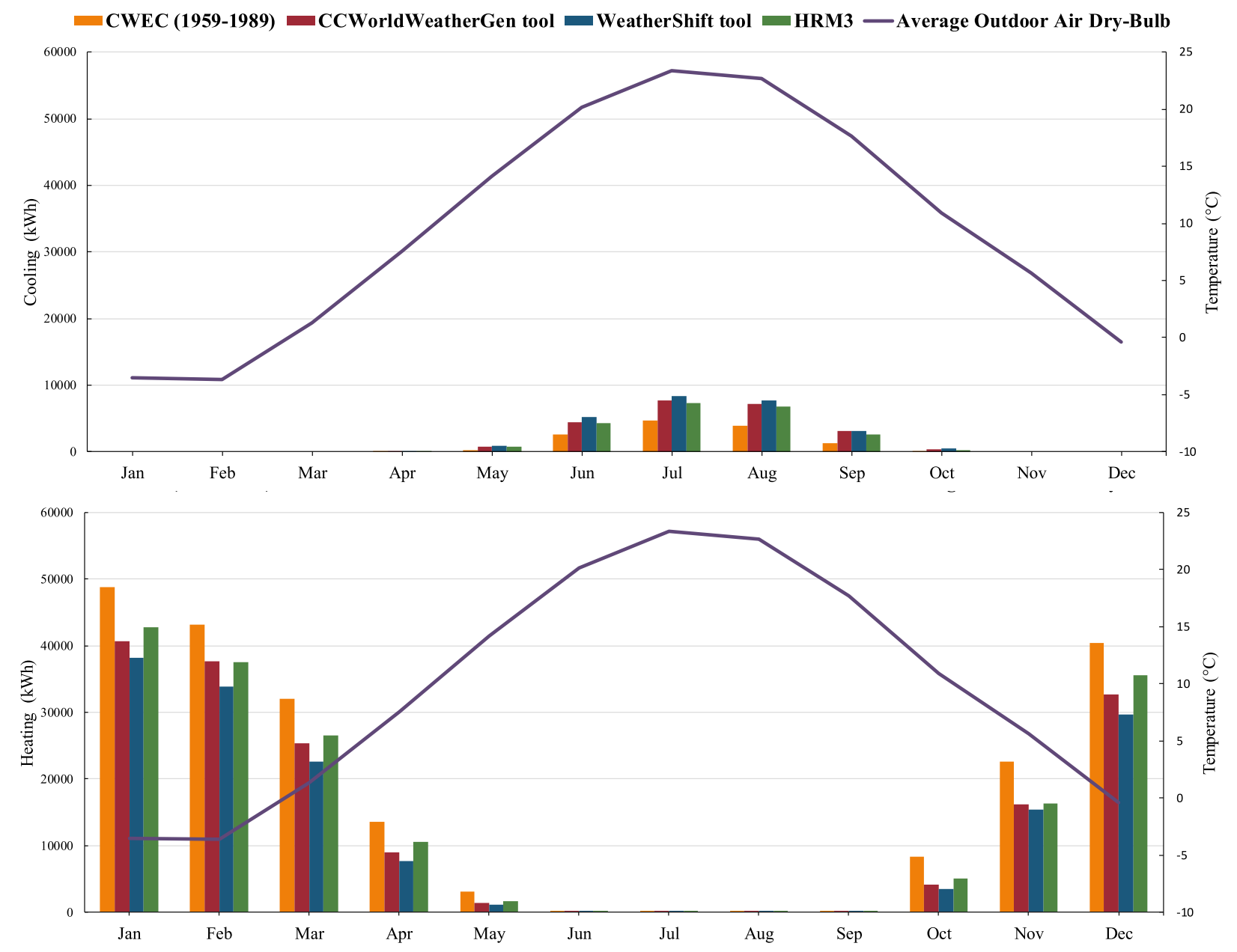


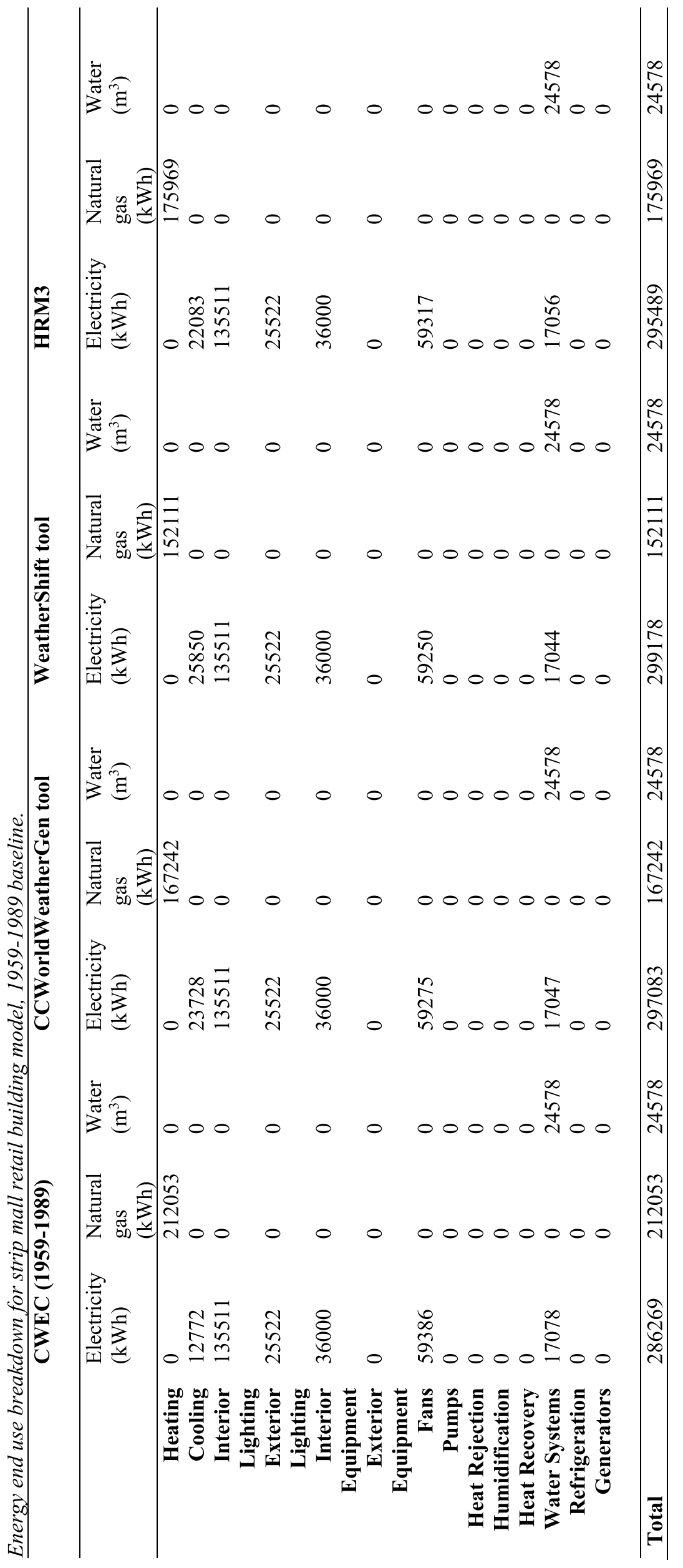


b) CWEC (1998-2014)

\begin{tabular}{|c|c|c|c|c|}
\hline & & $\begin{array}{l}\text { Total Energy } \\
\text { (kWh) }\end{array}$ & $\begin{array}{l}\text { Energy Per Total } \\
\text { Building Area } \\
\left(\mathbf{k W h} / \mathbf{m}^{2}\right)\end{array}$ & $\begin{array}{l}\text { Energy Per } \\
\text { Conditioned } \\
\text { Building Area } \\
\left(\mathbf{k W h} / \mathbf{m}^{2}\right)\end{array}$ \\
\hline \multirow{4}{*}{$\begin{array}{l}\text { Total Site } \\
\text { Energy }\end{array}$} & CWEC (1959-1989) & 470,461 & 225.1 & 225.1 \\
\hline & CCWorldWeatherGen tool & 442,467 & 211.7 & 211.7 \\
\hline & WeatherShift tool & 431,336 & 206.3 & 206.4 \\
\hline & HRM3 & 449,003 & 214.8 & 214.8 \\
\hline
\end{tabular}
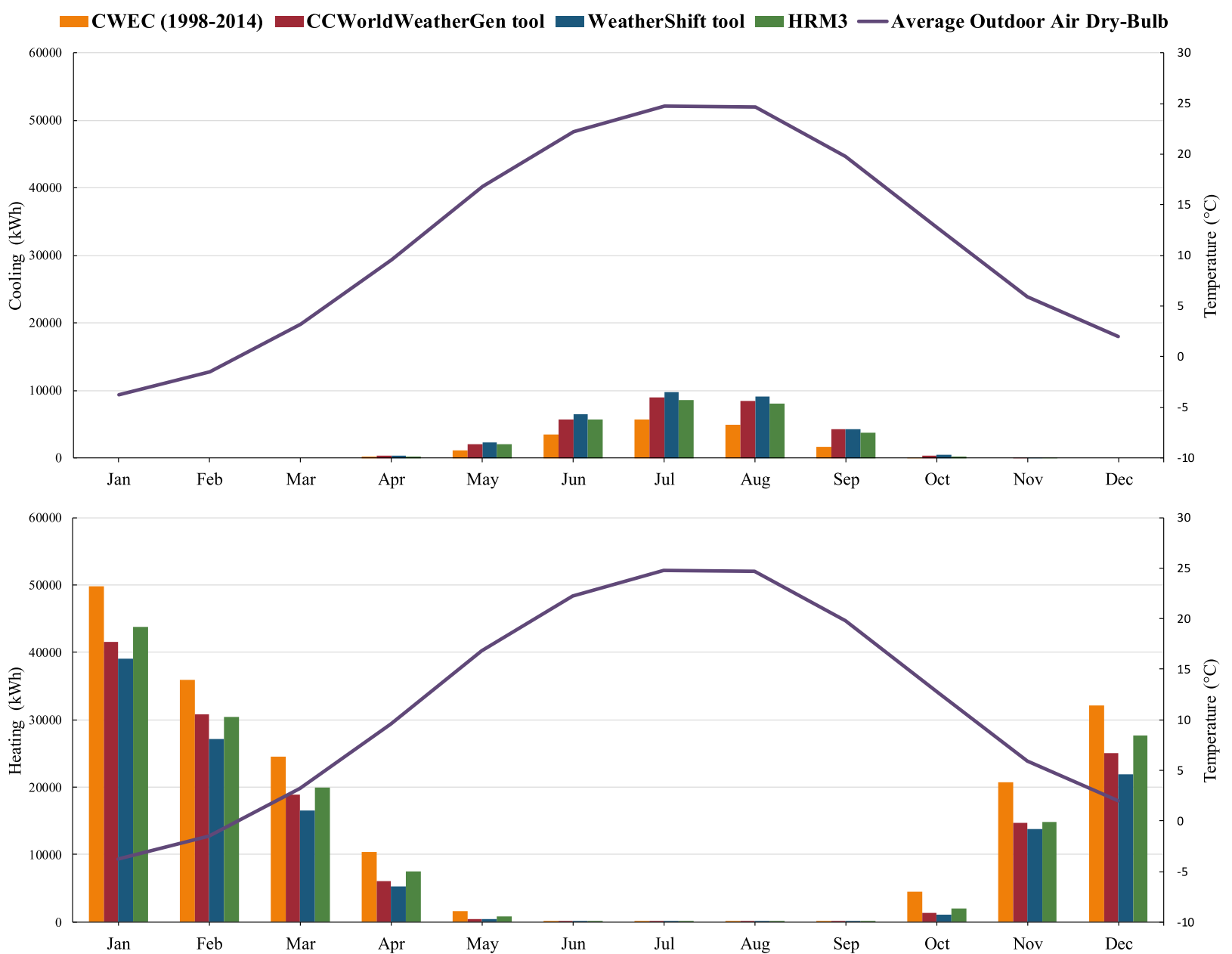


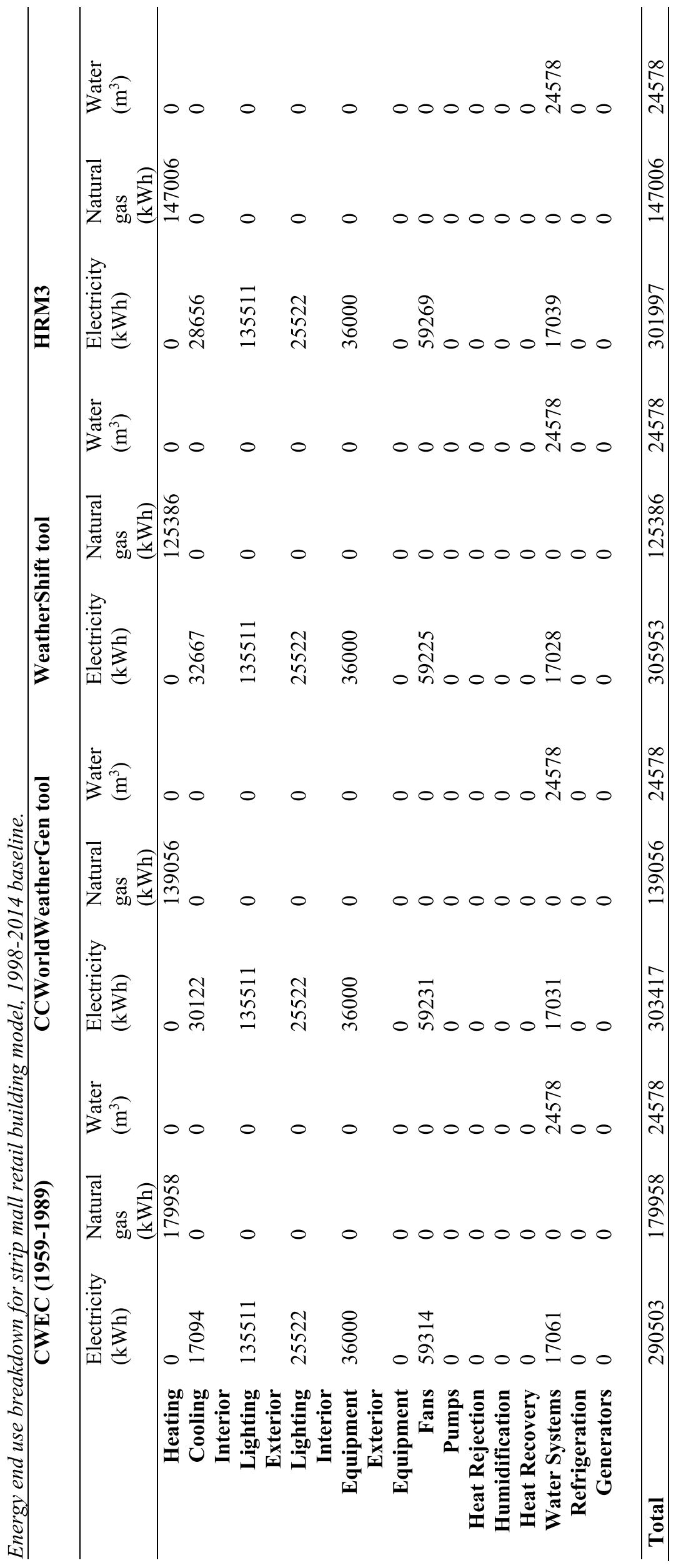




\section{Primary school building model}

a) CWEC (1959-1989)

\begin{tabular}{|c|c|c|c|c|}
\hline & & $\begin{array}{l}\text { Total Energy } \\
(\mathbf{k W h})\end{array}$ & $\begin{array}{l}\text { Energy Per Total } \\
\text { Building Area } \\
\left(\mathbf{k W h} / \mathbf{m}^{2}\right)\end{array}$ & $\begin{array}{l}\text { Energy Per } \\
\text { Conditioned } \\
\text { Building Area } \\
\left(\mathbf{k W h} / \mathbf{m}^{2}\right) \\
\end{array}$ \\
\hline \multirow{4}{*}{$\begin{array}{l}\text { Total Site } \\
\text { Energy }\end{array}$} & CWEC (1959-1989) & $1,126,297$ & 163.9 & 163.9 \\
\hline & CCWorldWeatherGen tool & $1,114,758$ & 162.2 & 162.2 \\
\hline & WeatherShift tool & $1,110,869$ & 161.7 & 161.7 \\
\hline & HRM3 & $1,120,311$ & 163 & 163.1 \\
\hline
\end{tabular}
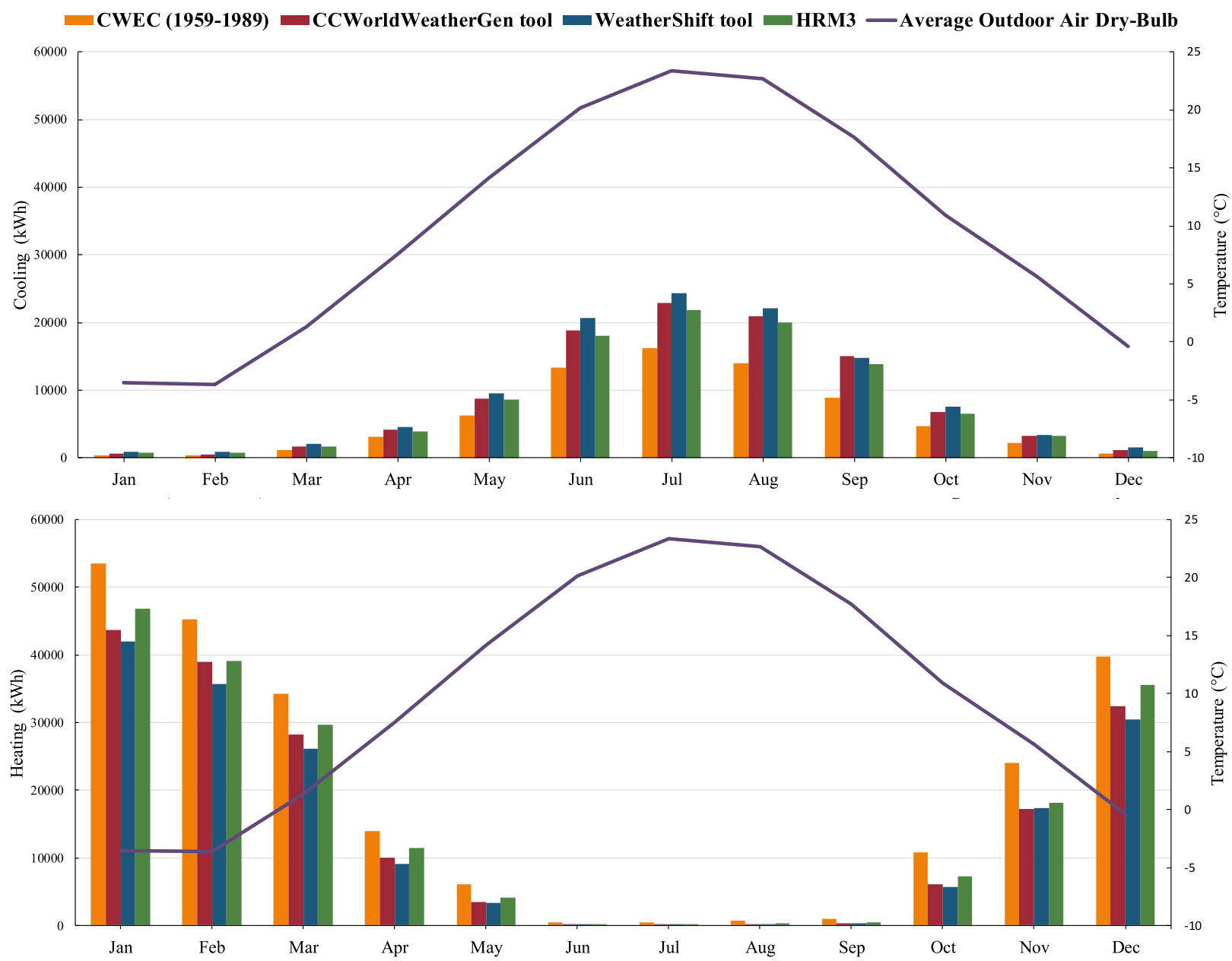


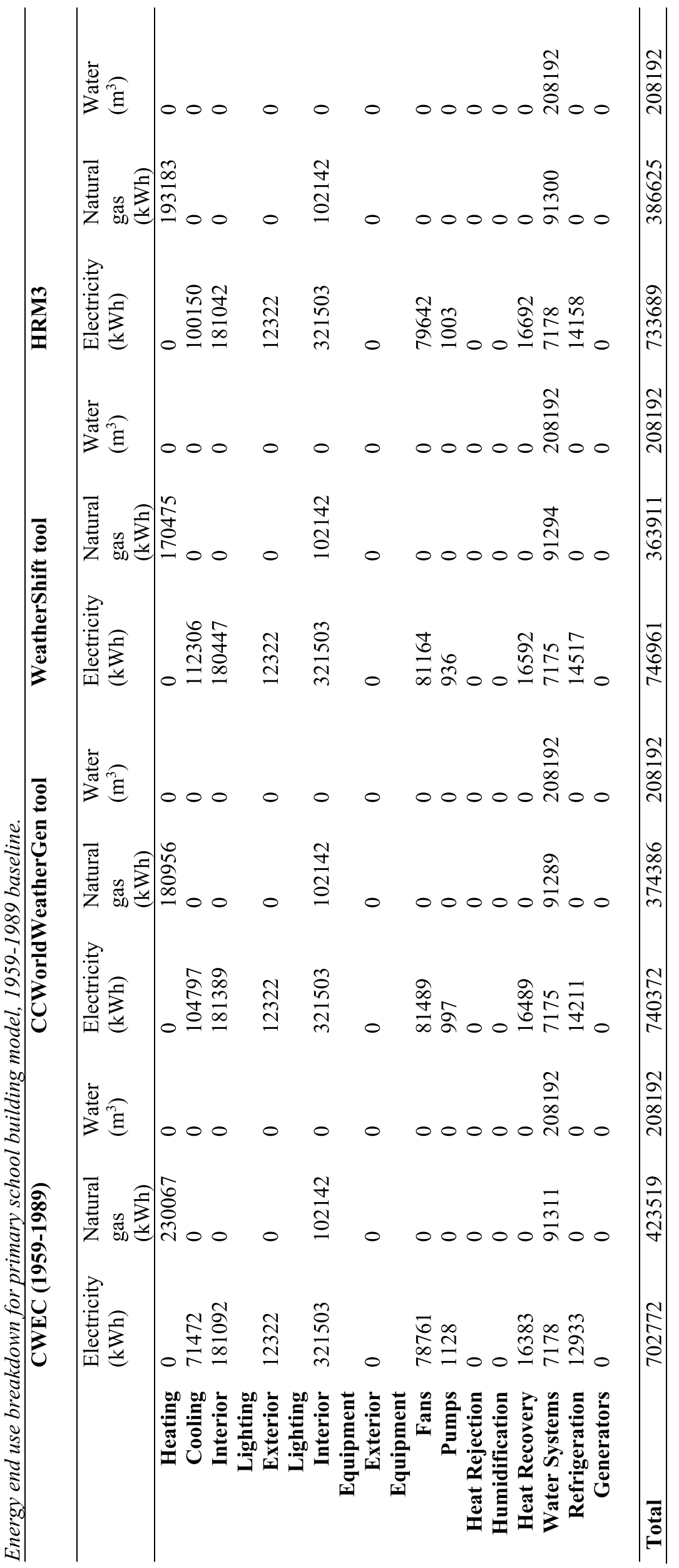


b) CWEC (1998-2014)

\begin{tabular}{|c|c|c|c|c|}
\hline & & $\begin{array}{l}\text { Total Energy } \\
\text { (kWh) }\end{array}$ & $\begin{array}{l}\text { Energy Per Total } \\
\text { Building Area } \\
\left(\mathbf{k W h} / \mathbf{m}^{2}\right)\end{array}$ & $\begin{array}{l}\text { Energy Per } \\
\text { Conditioned } \\
\text { Building Area } \\
\left(\mathbf{k W h} / \mathbf{m}^{2}\right)\end{array}$ \\
\hline \multirow{4}{*}{$\begin{array}{l}\text { Total Site } \\
\text { Energy }\end{array}$} & CWEC (1959-1989) & $1,110,967$ & 161.7 & 161.7 \\
\hline & CCWorldWeatherGen tool & $1,111,300$ & 161.7 & 161.7 \\
\hline & WeatherShift tool & $1,110,317$ & 161.6 & 161.6 \\
\hline & HRM3 & $1,114,353$ & 162.2 & 162.2 \\
\hline
\end{tabular}
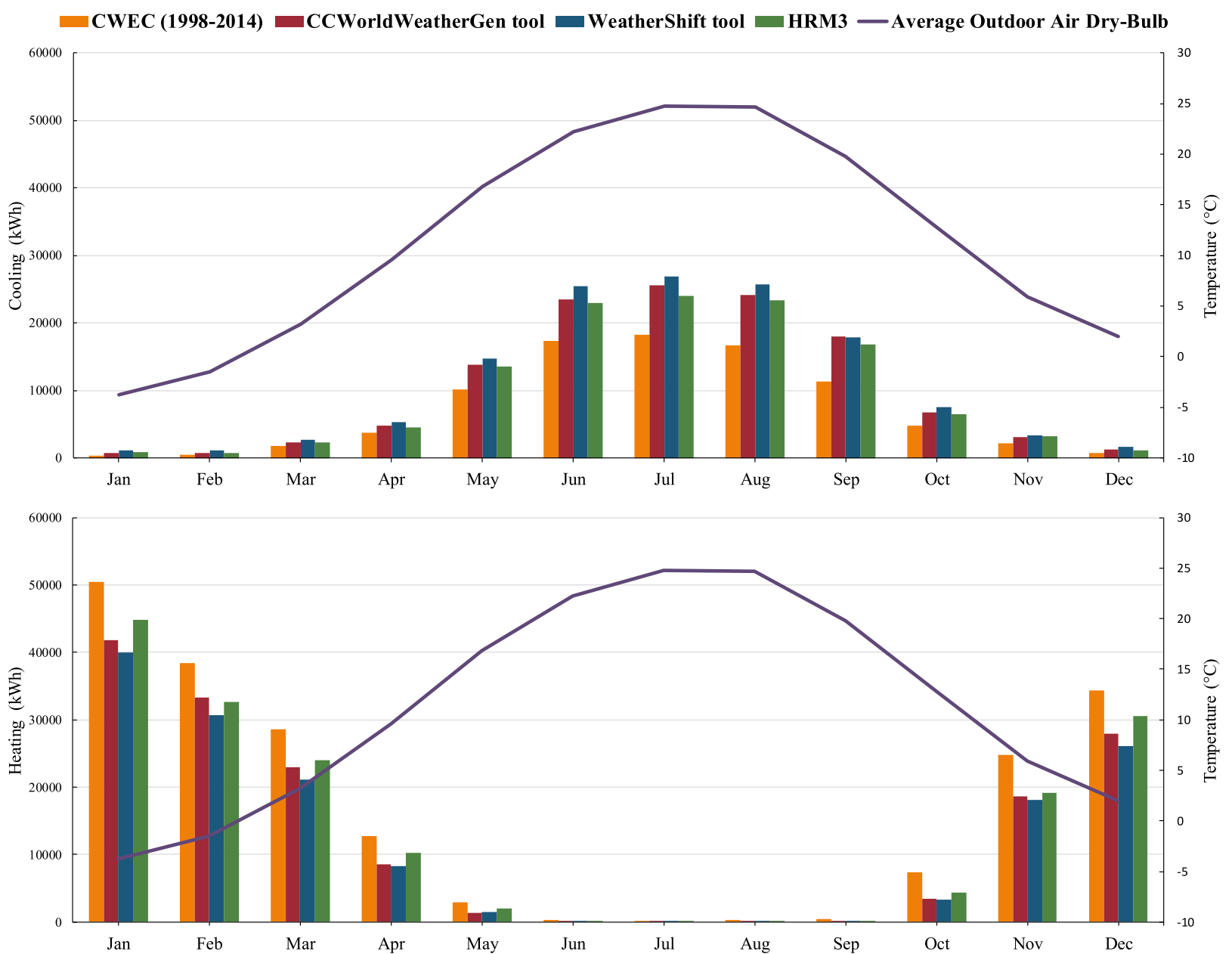


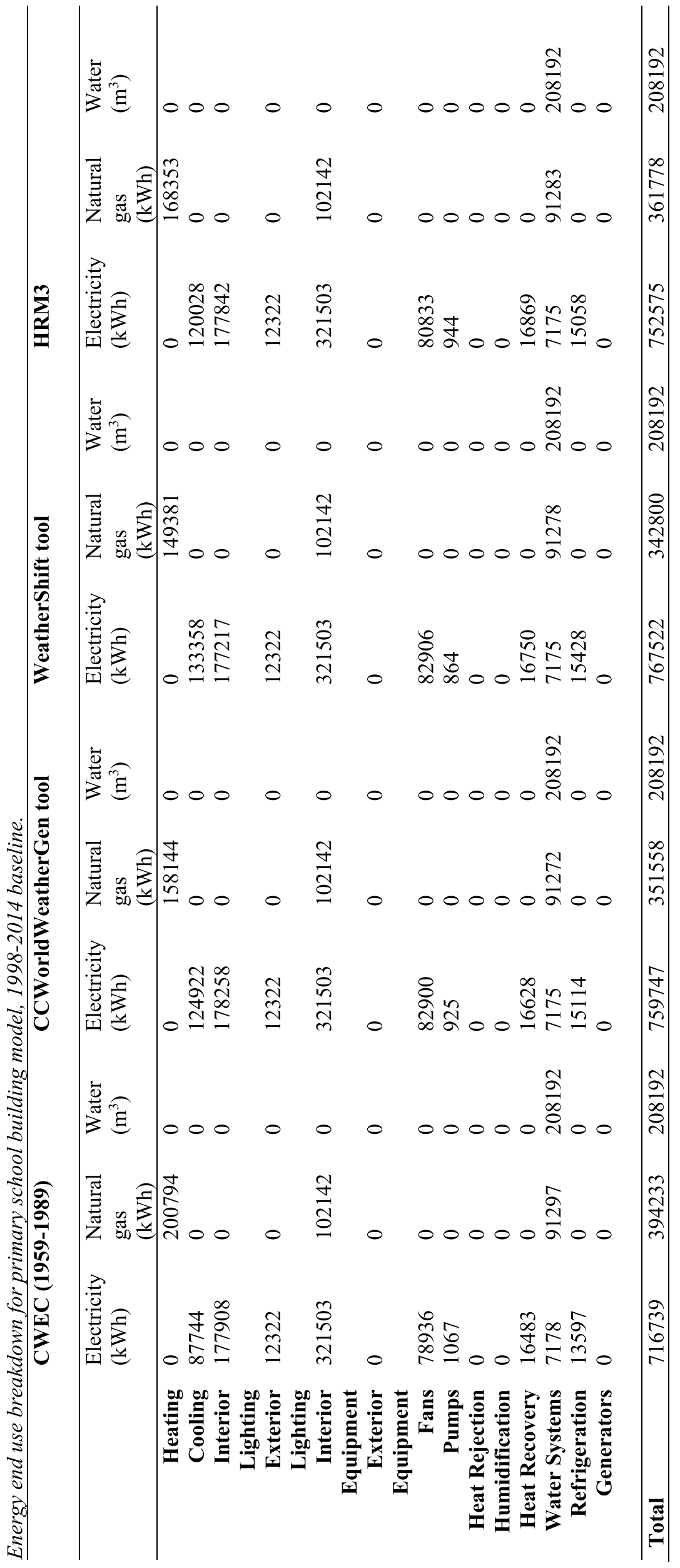


Secondary School building model

a) CWEC (1959-1989)

\begin{tabular}{|c|c|c|c|c|}
\hline & & $\begin{array}{l}\text { Total Energy } \\
(\mathbf{k W h})\end{array}$ & $\begin{array}{l}\text { Energy Per Total } \\
\text { Building Area } \\
\left(\mathbf{k W h} / \mathbf{m}^{2}\right)\end{array}$ & $\begin{array}{l}\text { Energy Per } \\
\text { Conditioned } \\
\text { Building Area } \\
\left(\mathbf{k W h} / \mathbf{m}^{2}\right) \\
\end{array}$ \\
\hline \multirow{4}{*}{$\begin{array}{l}\text { Total Site } \\
\text { Energy }\end{array}$} & CWEC (1959-1989) & $3,563,414$ & 181.9 & 181.9 \\
\hline & CCWorldWeatherGen tool & $3,578,864$ & 182.7 & 182.7 \\
\hline & WeatherShift tool & $3,566,953$ & 182.1 & 182.1 \\
\hline & HRM3 & $3,574,331$ & 182.4 & 182.4 \\
\hline
\end{tabular}
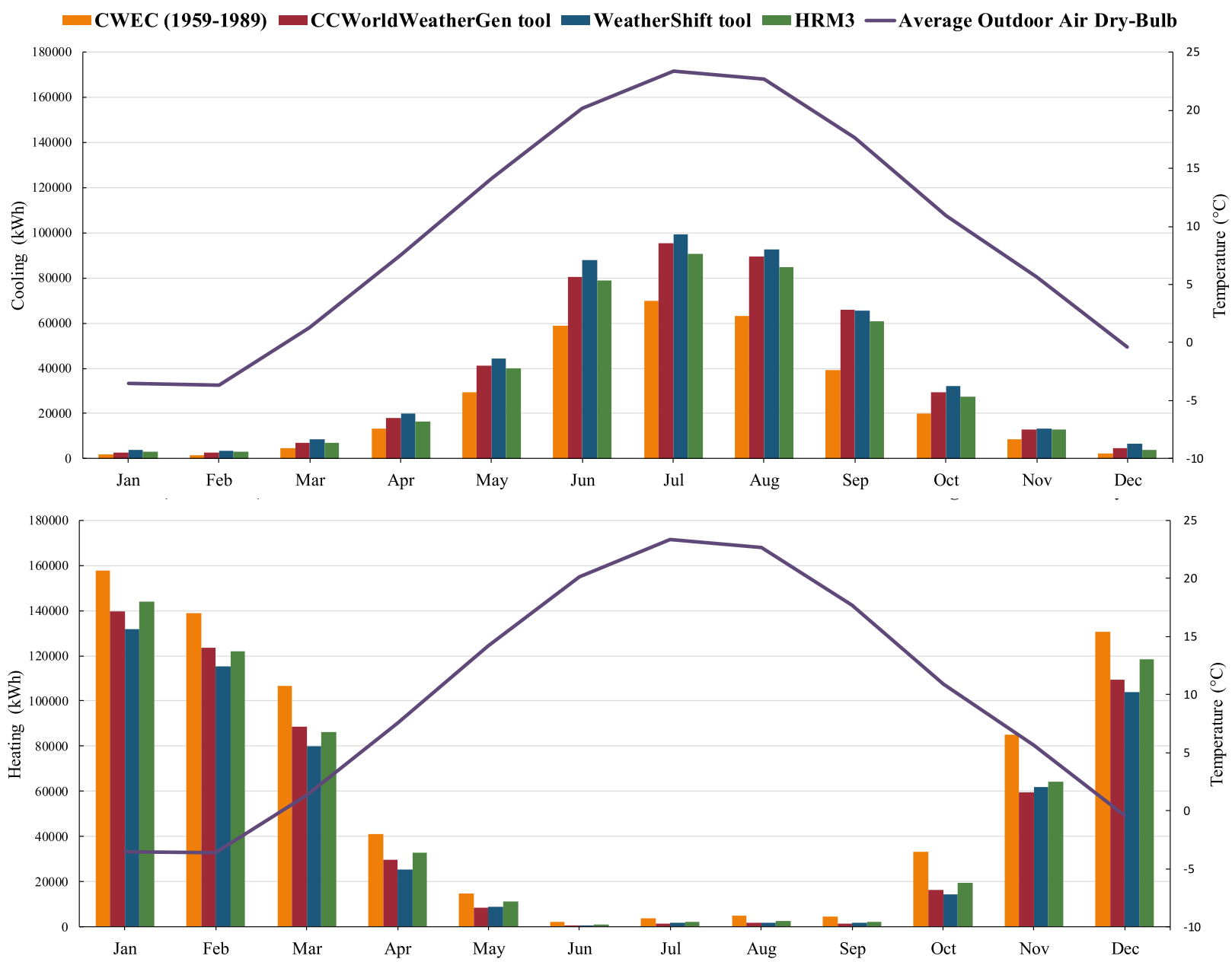


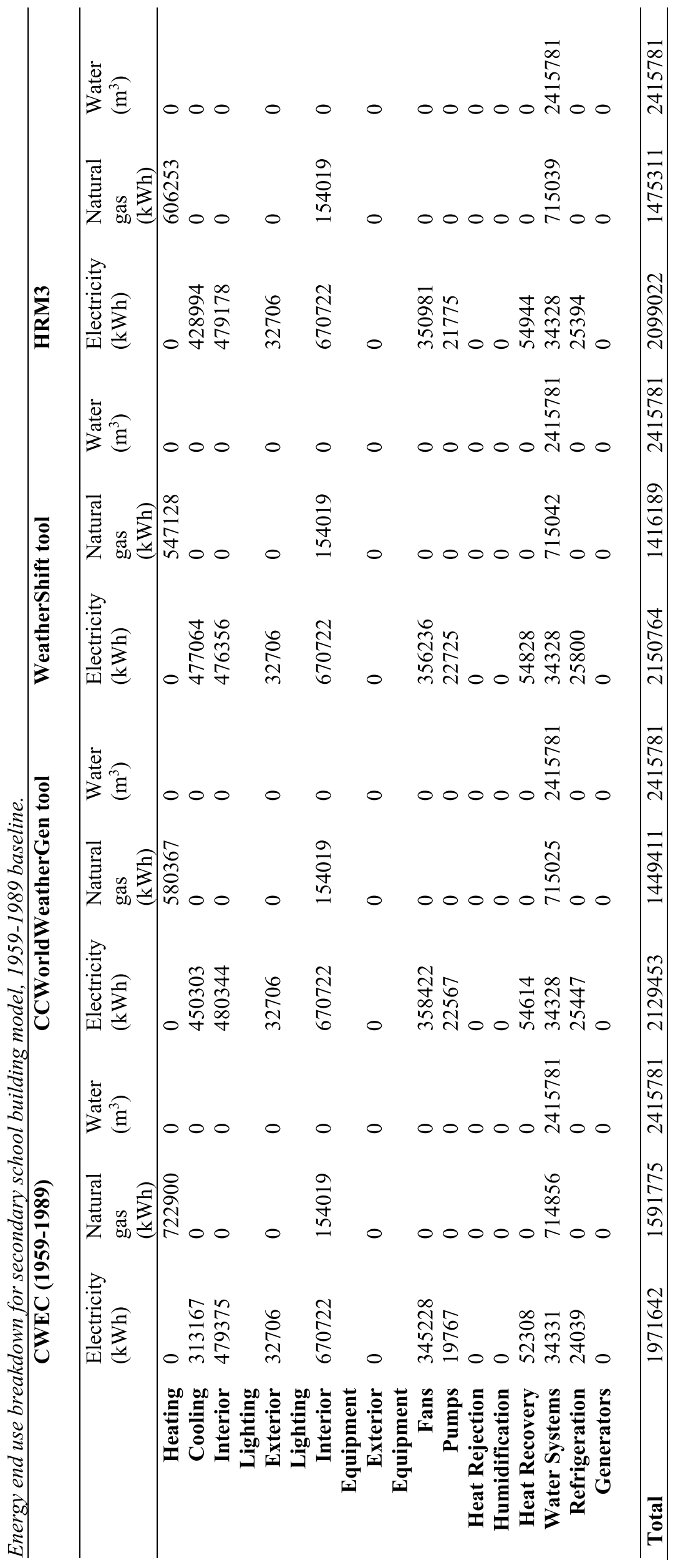


b) CWEC (1998-2014)

\begin{tabular}{|c|c|c|c|c|}
\hline & & $\begin{array}{l}\text { Total Energy } \\
\text { (kWh) }\end{array}$ & $\begin{array}{l}\text { Energy Per Total } \\
\text { Building Area } \\
\left(\mathbf{k W h} / \mathbf{m}^{2}\right)\end{array}$ & $\begin{array}{l}\text { Energy Per } \\
\text { Conditioned } \\
\text { Building Area } \\
\left(\mathbf{k W h} / \mathbf{m}^{2}\right)\end{array}$ \\
\hline \multirow{4}{*}{$\begin{array}{l}\text { Total Site } \\
\text { Energy }\end{array}$} & CWEC (1959-1989) & $3,544,953$ & 180.9 & 180.9 \\
\hline & CCWorldWeatherGen tool & $3,589,592$ & 183.2 & 183.2 \\
\hline & WeatherShift tool & $3,576,097$ & 182.5 & 182.5 \\
\hline & HRM3 & $3,580,908$ & 182.8 & 182.8 \\
\hline
\end{tabular}
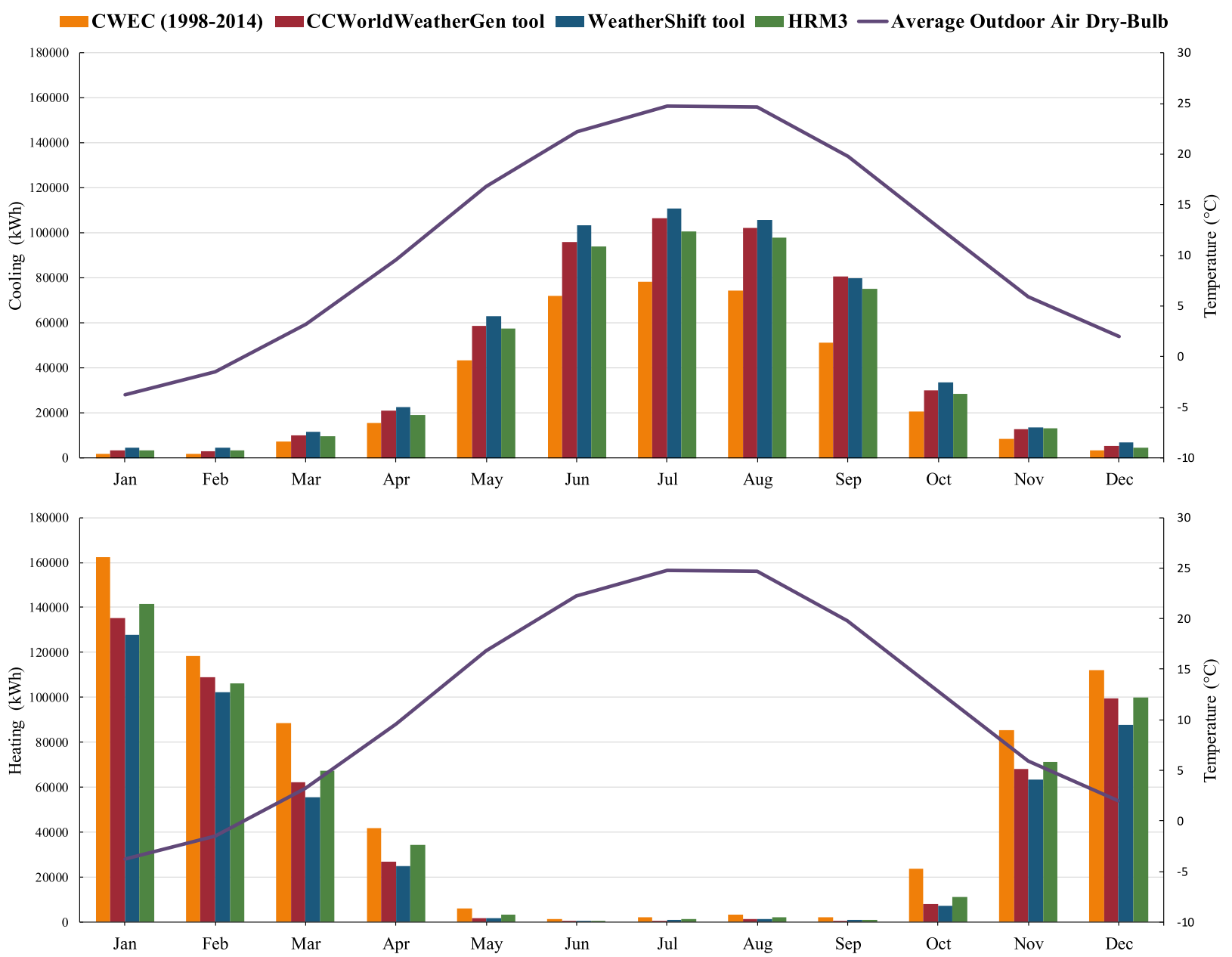


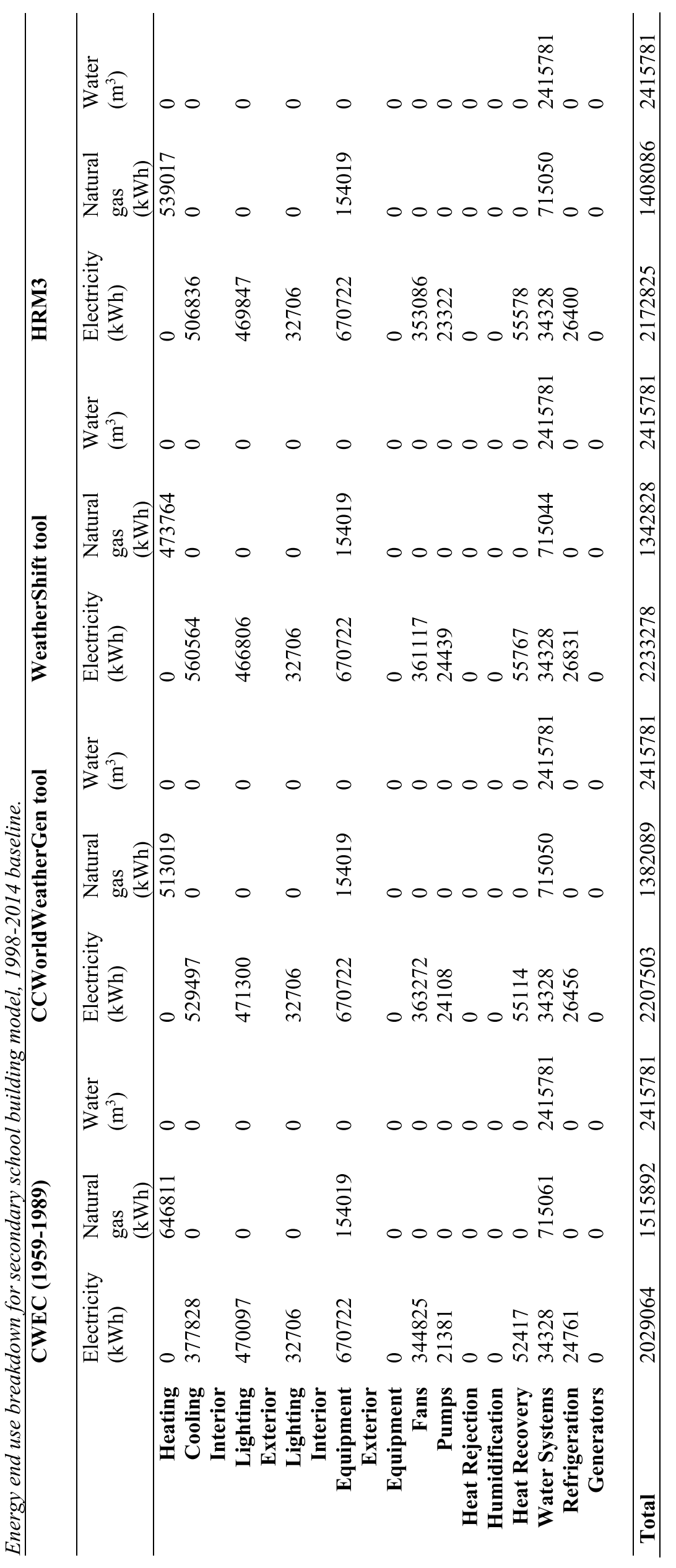




\section{Warehouse building model}

a) CWEC (1959-1989)

\begin{tabular}{|c|c|c|c|c|}
\hline & & $\begin{array}{l}\text { Total Energy } \\
(\mathbf{k W h})\end{array}$ & $\begin{array}{l}\text { Energy Per Total } \\
\text { Building Area } \\
\left(\mathbf{k W h} / \mathbf{m}^{2}\right)\end{array}$ & $\begin{array}{l}\text { Energy Per } \\
\text { Conditioned } \\
\text { Building Area } \\
\left(\mathbf{k W h} / \mathbf{m}^{2}\right)\end{array}$ \\
\hline \multirow{4}{*}{$\begin{array}{l}\text { Total Site } \\
\text { Energy }\end{array}$} & CWEC (1959-1989) & 393,975 & 81.5 & 81.5 \\
\hline & CCWorldWeatherGen tool & 343,383 & 71 & 71 \\
\hline & WeatherShift tool & 336,372 & 69.6 & 69.6 \\
\hline & HRM3 & 359,578 & 74.4 & 74.4 \\
\hline
\end{tabular}
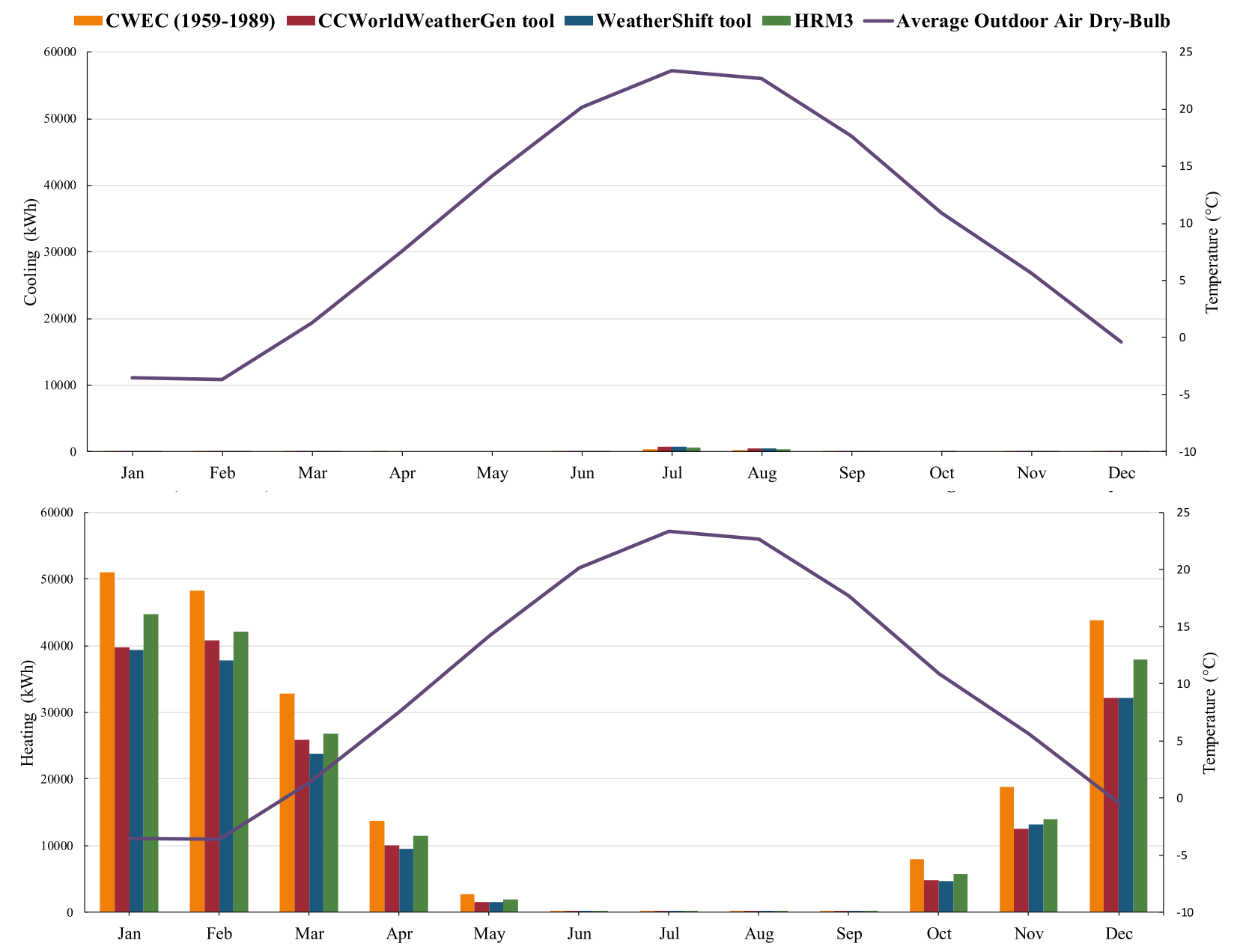


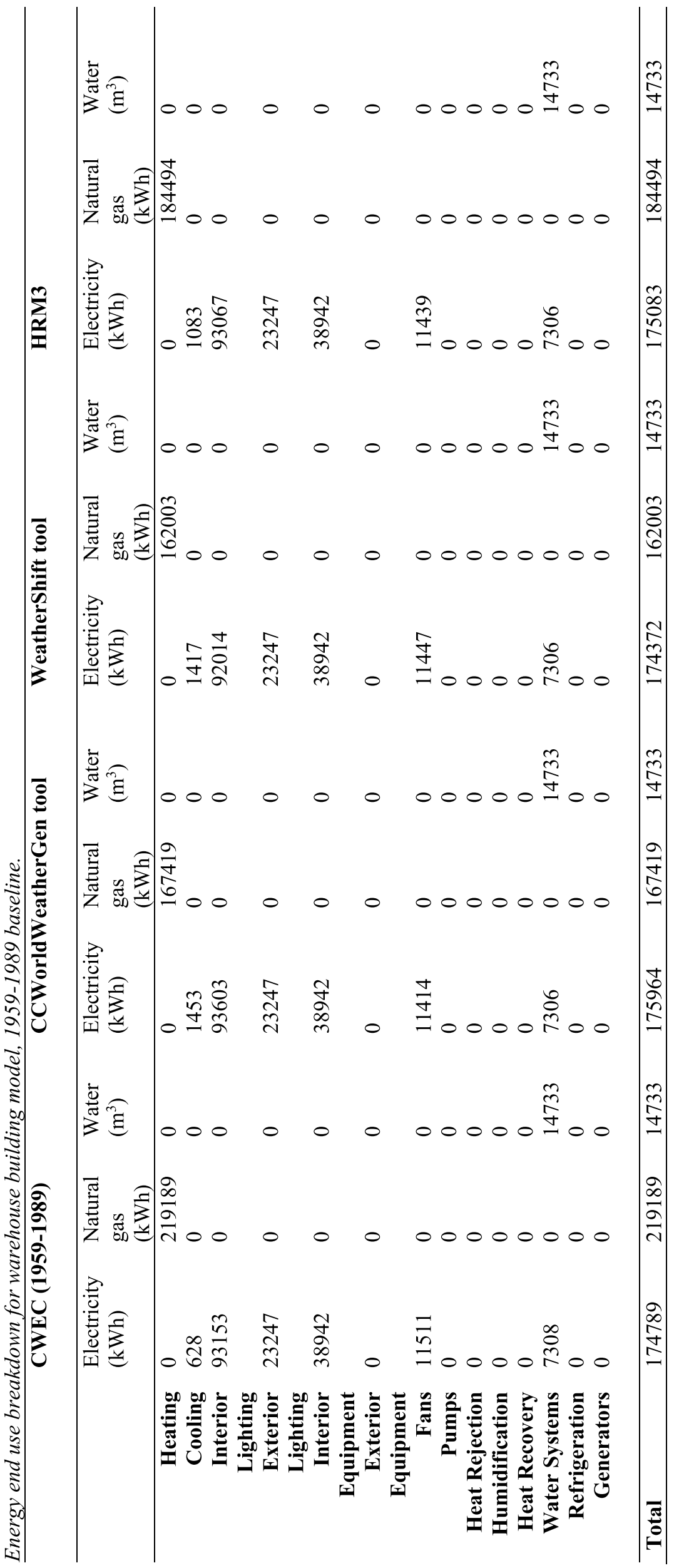


b) CWEC (1998-2014)

\begin{tabular}{|c|c|c|c|c|}
\hline & & $\begin{array}{l}\text { Total Energy } \\
\text { (kWh) }\end{array}$ & $\begin{array}{l}\text { Energy Per Total } \\
\text { Building Area } \\
\left(\mathbf{k W h} / \mathbf{m}^{2}\right)\end{array}$ & $\begin{array}{l}\text { Energy Per } \\
\text { Conditioned } \\
\text { Building Area } \\
\left(\mathbf{k W h} / \mathbf{m}^{2}\right)\end{array}$ \\
\hline \multirow{4}{*}{$\begin{array}{l}\text { Total Site } \\
\text { Energy }\end{array}$} & CWEC (1959-1989) & 357,828 & 74 & 74 \\
\hline & CCWorldWeatherGen tool & 313,197 & 64.8 & 64.8 \\
\hline & WeatherShift tool & 307,272 & 63.5 & 63.6 \\
\hline & HRM3 & 327,367 & 67.7 & 67.7 \\
\hline
\end{tabular}
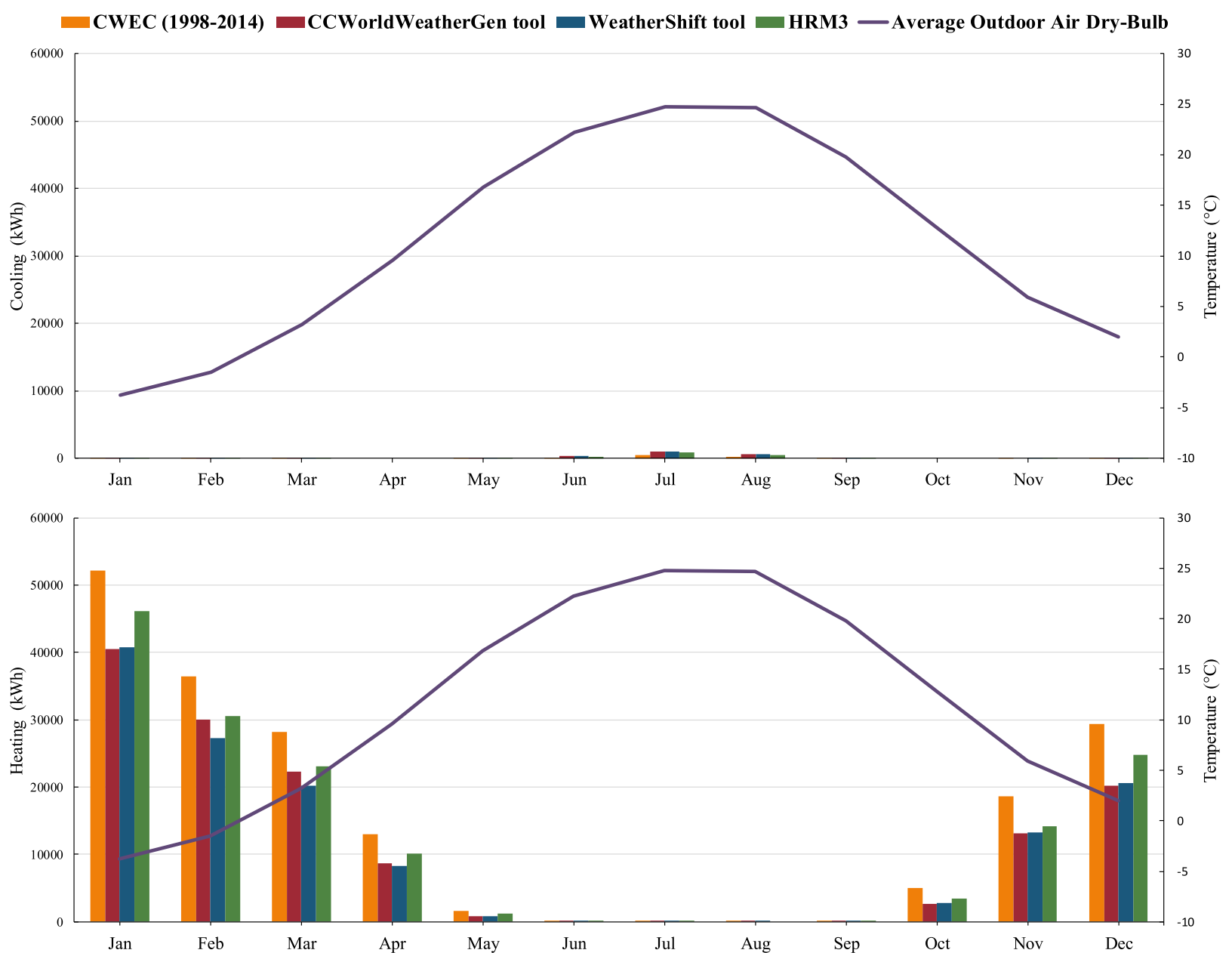


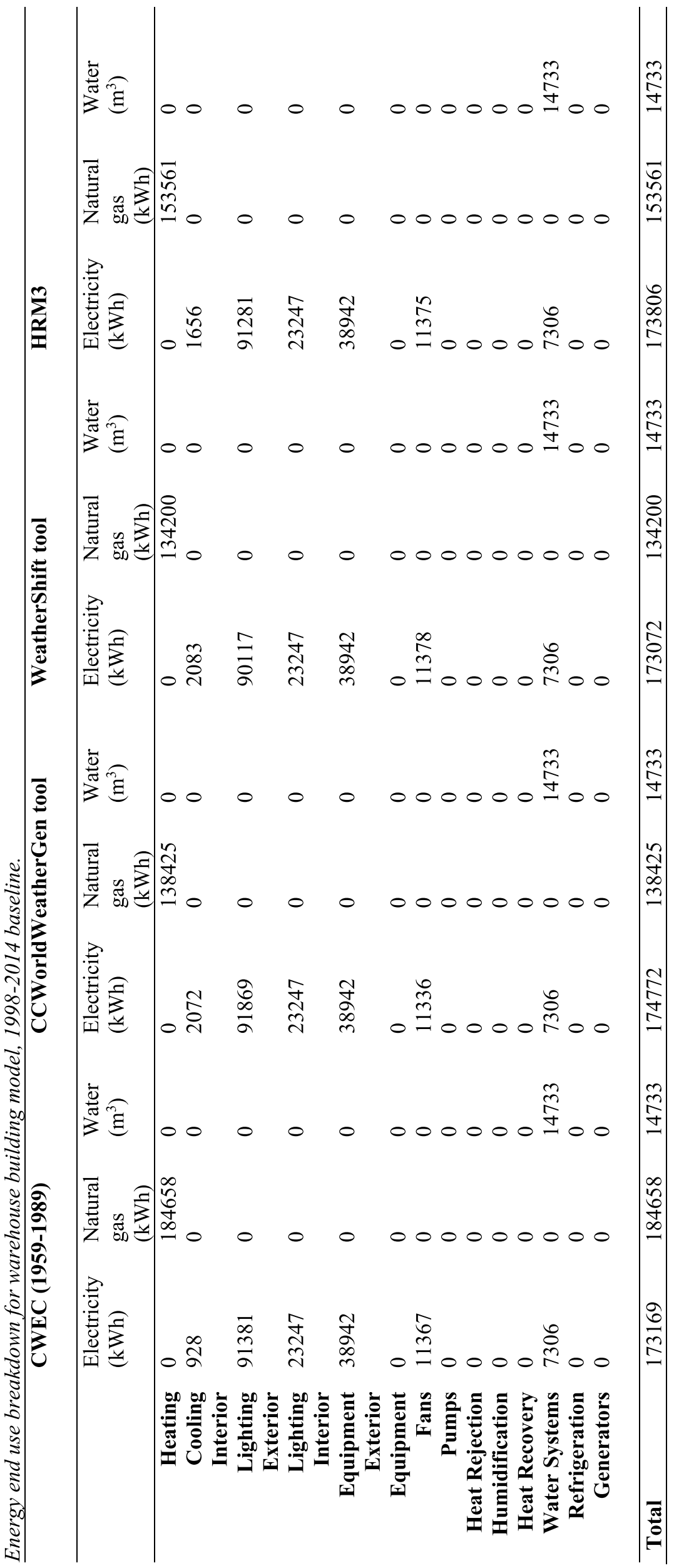




\section{References}

Adelard, L., Boyer, H., Garde, F., and Gatina, J. C. (2000). A detailed weather data generator for building simulations. Energy and Buildings, 31(1), 75-88. doi:10.1016/S0378-

7788(99)00009-2

American National Standards Institute, American Society of Heating, Refrigerating and AirConditioning Engineers (ASHRAE), and Illuminating Engineering Society of North America. (2013). Energy standard for buildings except low-rise residential buildings (I-P ed.) American Society of Heating, Refrigerating and Air-Conditioning Engineers.

Bahadori, M. N., and Chamberlain, M. J. (1986). A simplification of weather data to evaluate daily and monthly energy needs of residential buildings. Solar Energy, 36(6), 499-507.

doi:10.1016/0038-092X(86)90014-9

Belcher, S. E., Hacker, J. N., and Power, D. S. (2005). Constructing design weather data for future climates. Building Services Engineering Research and Technology, 26(1), 49-61.

doi:10.1191/0143624405bt112oa

Berardi, U. (2017). A cross-country comparison of the building energy consumptions and their trends. Resources, Conservation and Recycling, 123, 230-241.

doi:10.1016/j.resconrec.2016.03.014

Bilbao, J., Miguel, A., Franco, J. A., and Ayuso, A. (2004). Test reference year generation and evaluation methods in the continental Mediterranean area. Journal of Applied Meteorology, 43(2), 390-400. Accessed on September 11 ${ }^{\text {th }}, 2019$, http://ezproxy.lib.ryerson.ca/login?url=https://search-proquestcom.ezproxy.lib.ryerson.ca/docview/224579853?accountid $=13631$

Briggs, R. S., Taylor, Z. T., and Lucas, R. G. (2003). Climate classification for building energy codes and standards: Part 2-zone definitions, maps, and comparisons. ASHRAE Transactions, 109, 122.

Chan, A. L. S., Chow, T. T., Fong, S. K. F., and Lin, J. Z. (2006). Generation of a typical meteorological year for Hong Kong. Energy Conversion and Management, 47(1), 87-96. doi:10.1016/j.enconman.2005.02.010

Chan, A. L. S. (2011). Developing future hourly weather files for studying the impact of climate change on building energy performance in Hong Kong. Energy and Buildings, 43, 2860-2868. doi:10.1016/j.enbuild.2011.07.003

The Chartered Institution of Building Services Engineers (CIBSE). (2016). Degree-days: Theory and application. Technical Manual 41. Chartered Institution of Building Services Engineers: London, UK. ISBN-10: 1-903287-76-6. 
Christenson, M., Manz, H., and Gyalistras, D. (2006). Climate warming impact on degree-days and building energy demand in Switzerland. Energy Conversion and Management, 47(6), 671686. doi:10.1016/j.enconman.2005.06.009

Ciscar, J. C., and Dowling, P. (2014). Integrated assessment of climate impacts and adaptation in the energy sector. Energy Economics, 46, 531-538. doi:10.1016/j.eneco.2014.07.003

The City of Toronto. (2018). 2017 Annual Energy Consumption and Greenhouse Gas (GHG) Emissions. Accessed on July $31^{\text {st }}, 2019$, https://www.toronto.ca/legdocs/mmis/2018/pe/bgrd/backgroundfile-117753.pdf

The City of Toronto. (2019). Energy efficiency report submission and modelling guidelines for the Toronto Green Standard (TGS) Version 3. Accessed on July $31^{\text {st }}, 2019$, https://www.toronto.ca/wp-content/uploads/2019/02/93d5-CityPlanning V3-Energy-ModellingGuidelines-Feb-2019.pdf

Cox, R. A., Drews, M., Rode, C., and Nielsen, S. B. (2015). Simple future weather files for estimating heating and cooling demand. Building and Environment, 83, 104-114.

doi:10.1016/j.buildenv.2014.04.006

Crawley, D. B. (2008). Estimating the impacts of climate change and urbanization on building performance. Journal of Building Performance Simulation, 1(2), 91-115.

doi: $10.1080 / 19401490802182079$

Dear, R. D. (2006). Adapting buildings to a changing climate: But what about the occupants? Building Research and Information, 34(1), 78-81. doi:10.1080/09613210500336594

Dickinson, R., Brannon, B. Generating future weather files for resilience. In proceeding of PLEA 2016 Los Angeles - 36th International Conference on Passive and Low Energy Architecture. Accessed on July $31^{\text {st }}, 2019$, http://www.weathershift.com/Generating\%20Future $\% 20$ Weather\%20Files.pdf

Eames, M., Ramallo-Gonzalez, A., and Wood, M. (2016). An update of the UK's test reference year: The implications of a revised climate on building design. Building Services Engineering Research and Technology, 37(3), 316-333. doi:10.1177/0143624415605626

Ebrahimpour, A., and Maerefat, M. (2010). A method for generation of typical meteorological year. Energy Conversion and Management, 51(3), 410-417.

doi:10.1016/j.enconman.2009.10.002

Festa, R., and Ratto, C. F. (1993). Proposal of a numerical procedure to select reference years. Solar Energy, 50(1), 9-17. doi:10.1016/0038-092X(93)90003-7

Field, K., Deru, M., and Struder, D. (2010). Using Department of Energy (DOE) commercial reference buildings for simulation studies. In proceedings of the SimBuild, New York, New York. Accessed on July 31 ${ }^{\text {st }}$, 2019, https://www.nrel.gov/docs/fy10osti/48588.pdf 
Fuentes, U., and Heimann, D. (2000). An improved statistical-dynamical downscaling scheme and its application to the alpine precipitation climatology. Theoretical and Applied Climatology, 65(3), 119-135. doi:10.1007/s007040070038

The Government of Canada. (2016). Pan-Canadian Framework on Clean Growth and Climate Change: Canada's plan to address climate change and grow the economy. Accessed on July $31^{\text {st }}$, 2019, https://www.canada.ca/content/dam/themes/environment/documents/weather1/20161209_1-en.pdf

The Government of Canada. (2018). Canadian Weather Year for Energy Calculation (CWEC). Accessed on July $31^{\text {st }}, 2019$, http://climate.weather.gc.ca/prods servs/engineering e.html

The Government of Canada Statistics. (2019). Canadian Mortgage and Housing Corporation. Accessed on July $31^{\text {st }}$, 2019, https:/www150.statcan.gc.ca/t1/tbl1/en/tv.action?pid=3410013501\&pickMembers $\% 5 B 0 \% 5 \mathrm{D}=1$ $.8 \&$ pickMembers $\% 5 \mathrm{~B} 1 \% 5 \mathrm{D}=4.1$

The Government of Ontario. (2016) Climate Change Action Plan. Accessed on July $31^{\text {st }}, 2019$, http://www.applications.ene.gov.on.ca/ccap/products/CCAP ENGLISH.pdf

The Government of Ontario. (2018). Ontario's Climate Act from Plan to Progress: Annual greenhouse gas progress report 2017. Accessed on July $31^{\text {st }}, 2019$, http://docs.assets.eco.on.ca/reports/climate-change/2017/From-Plan-to-Progress.pdf

Guan, L. (2009) Preparation of future weather data to study the impacts of climate change on buildings. Building and Environment, 44, 793-800. doi:10.1016/j.buildenv.2008.05.021

Guan, L., Yang, J., Bell, J. M. (2007). Cross-correlation between weather variables in Australia. Building and Environment, 42(3), 1054-1070. doi:10.1016/j.buildenv.2006.01.010

Guyennon, N., Romano, E., Portoghese, I., Salerno, F., Calmanti, S., Perangeli, A. B., Tartari, G., and Copetti, D. (2013). Benefits from using combined dynamical-statistical downscaling approaches -- lessons from a case study in the Mediterranean region. Hydrology and Earth System Sciences, 17(2), 705-720. doi:10.5194/hess-17-705-2013

Hall, I. J., Prairie, R. R., Anderson, H. E., and Boes, E. C. (1978). Generation of a typical meteorological year. In proceedings of the 1978 Annual Meeting of American Section of ISES, Denver, CO.

Herrera, M., Natarajan, S., Coley, D. A., Kershaw, T., Ramallo-González, A. P., Eames, M., ... Wood, M. (2017). A review of current and future weather data for building simulation. Building Services Engineering Research and Technology, 38(5), 602-627.

doi:10.1177/0143624417705937 
Huang, J., and Gurney, K. R. (2016). The variation of climate change impact on building energy consumption to building type and spatiotemporal scale. Energy, 111, 137-153.

doi:10.1016/j.energy.2016.05.118

International Energy Agency1 (IEA). (2017). Tracking Clean Energy Progress 2017, pp.54-55. Accessed on July $31^{\text {st }}, 2019$, https://www.iea.org/publications/freepublications/publication/TrackingCleanEnergyProgress201 $\underline{7 . p d f}$

International Energy Agency and the United Nations Environmental Programme. (2018). Global Status Report: Towards a zero-emission, efficient and resilient buildings and construction sector. Accessed on July $31^{\text {st }}$, 2019, https://www.unenvironment.org/resources/report/globalstatus-report-2018

Intergovernmental Panel on Climate Change (IPCC). (2014). Climate Change 2014: Synthesis Report. Contribution of Working Groups I, II and III to the Fifth Assessment Report of the Intergovernmental Panel on Climate Change [Core Writing Team, R.K. Pachauri and L.A. Meyer (eds.)]. IPCC, Geneva, Switzerland, 151 pp. Accessed on July $31^{\text {st }}, 2019$, https://www.ipcc.ch/site/assets/uploads/2018/05/SYR_AR5 FINAL full wcover.pdf

Janjai, S., and Deeyai, P. (2009). Comparison of methods for generating typical meteorological year using meteorological data from a tropical environment. Applied Energy, 86(4), 528-537. doi:10.1016/j.apenergy.2008.08.008

Jenkins, D., Liu, Y., and Peacock, A. D. (2008). Climatic and internal factors affecting future UK office heating and cooling energy consumptions. Energy and Buildings, 40(5), 874-881. doi:10.1016/j.enbuild.2007.06.006

Jentsch, M. F., James, P. A. B., Bourikas, L., and Bahaj, A. S. (2013). Transforming existing weather data for worldwide locations to enable energy and building performance simulation under future climates. Renewable Energy. 55, 514-24. doi:10.1016/j.renene.2012.12.049

Kalamees, T., and Kurnitski, J. (2006). Estonian test reference year for energy calculations. Proceedings of the Estonian Academy of Sciences Engineering. 12, 40-58.

Lam, J. C., Hui, S. C. M., and Chan, A. L. S. (1996). A statistical approach to the development of a typical meteorological year for Hong Kong. Architectural Science Review, 39(4), 201-209. doi.org/10.1080/00038628.1996.9696818

Lee, K., Yoo, H., and Levermore, G. J. (2010). Generation of typical weather data using the ISO Test Reference Year (TRY) method for major cities of South Korea. Building and Environment, 45, 956-963. doi:10.1016/j.buildenv.2009.10.002

Liu, C., and Coley, D. (2015). Overheating risk of UK dwellings under a changing climate. Energy Procedia, 78, 2796-2801. doi:10.1016/j.egypro.2015.11.628 
Marion, W., and Urban, K. (1995). User's manual for TMY2s (Typical Meteorological Years). Accessed on July $31^{\text {st }}$, 2019, https://rredc.nrel.gov/solar/pubs/tmy2/PDFs/tmy2man.pdf

Mearns, L. O., Arritt, R., Biner, S., Bukovsky, M. S., McGinnis, S., Sain, S., Caya, D., ... Snyder, M. (2012). The North American Regional Climate Change Assessment Program: Overview of phase I results. Bulletin of the American Meteorological Society, 93, 1337-1362.

Meteorological Service of Canada [MSC] (2008). Updated User's Manual: Canadian Weather Energy and Engineering Data Sets (CWEEDS files) and Canadian Weather for Energy Calculation (CWEC files). Accessed on July $31^{\text {st }}, 2019$, $\underline{\mathrm{http}: / / \text { climate.weather.gc.ca/prods_servs/engineering_e.html }}$

Moazami, A., Carlucci, S., and Geving, S. (2017). Critical analysis of software tools aimed at generating future weather files with a view to their use in building performance simulation. Energy Procedia, 132, 640-645. doi.org/10.1016/j.egypro.2017.09.701

Nakicenovic, N. et al (2000). Special report on emissions scenarios: A special report of working group III of the Intergovernmental Panel on Climate Change, Cambridge University Press, Cambridge, U.K., 599 pp. Accessed on September 12 ${ }^{\text {th }}, 2019$, http://www.grida.no/climate/ipcc/emission/index.htm

Natural Resources Canada (NRCan). (2015). Comprehensive energy use database. Accessed on July $31^{\text {st }}$, 2019, http://oee.nrcan.gc.ca/corporate/statistics/neud/dpa/menus/trends/comprehensive tables/list.cfm

Natural Resources Canada (NRCan). (2019). Energy efficiency trends in Canada. Accessed on July $31^{\text {st }}, 2019$, http://oee.nrcan.gc.ca/publications/statistics/trends/2015/totalsectors.cfm

North American Regional Climate Change Assessment Program (NARCCAP). (2010). The NARCCAP output dataset. Accessed on July $31^{\text {st }}, 2019$, http://www.narccap.ucar.edu/data/datatables.html

Petrakis, M., Kambezidis, H. D., Lykoudis, S., Adamopoulos, A. D., Kassomenos, P., Michaelides, I. M., Kalogirou, S. A., ... Hadjigianni, A. (1998). Generation of a "typical meteorological year" for Nicosia, Cyprus. Renewable Energy, 13(3), 381-388. doi.org/10.1016/S0960-1481(98)00014-7

Pissimanis, D., Karras, G., Notaridou, V., and Gavra, K. (1988). The generation of a "typical meteorological year" for the city of Athens. Solar Energy, 40(5), 405-411. doi:10.1016/0038$\underline{092 X(88) 90095-3}$

Pusat, S., Ekmekçi, İ., and Akkoyunlu, M. T. (2015). Generation of typical meteorological year for different climates of Turkey. Renewable Energy, 75, 144-151. doi:10.1016/j.renene.2014.09.039 
Radhi, H. (2009). Evaluating the potential impact of global warming on the UAE residential buildings - A contribution to reduce the $\mathrm{CO}_{2}$ emissions. Building and Environment, 44(12), 2451-2462. doi.org/10.1016/j.buildenv.2009.04.006

Remund, J., and Kunz, S. (1997). Meteonorm: Global meteorological database for solar energy and applied climatology. Switzerland, Bern: Meteotest.

Remund, J., Müller, S., Studer, C., and Cattin, R. (2018). Meteonorm: Global meteorological database version 7 for software and data for engineers, planers and education. Bern, Switzerland: Meteotest.

Robert, A., and Kummert, M. (2012). Designing net-zero energy buildings for the future climate, not for the past. Building and Environment, 55, 150-158.

doi:10.1016/j.buildenv.2011.12.014

Sehizadeh, A., and Ge, H. (2016). Impact of future climates on the durability of typical residential wall assemblies retrofitted to the PassiveHaus for the Eastern Canada region. Building and Environment, 97, 111-125. doi.org/10.1016/j.buildenv.2015.11.032

Shen, P. (2017). Impacts of climate change on U.S. building energy use by using downscaled hourly future weather data. Energy and Buildings, 134, 61-70.

doi:10.1016/j.enbuild.2016.09.028

Siurna, D. L., D’Andrea, L. J., and Hollands, K.G.T. (1984). A Canadian Representative Meteorological Year for solar system simulation. In proceedings of the 10th Annual Conference of the Solar Energy Society of Canada (SESCI), Calgary, Alberta, Canada.

Straube, J. F., and Burnett, E. F. P. (2005). Building science for building enclosures Building Science Press.

Toronto Environment Office. (2012). Toronto's future weather and climate driver study.

Trzaska, S., and Schnarr, E. (2014). A review of downscaling methods for climate change projections. African and Latin American Resilience to Climate Change (ARCC) Project. Accessed on July $31^{\text {st }}, 2019$, http://www.ciesin.org/documents/Downscaling_CLEARED 000.pdf

University of Southampton. (2009). CCWorldWeatherGen tool. Accessed on September 12 ${ }^{\text {th }}$, 2019, http://www.energy.soton.ac.uk/ccworldweathergen/

The U.S. Department of Energy (DOE). (2018). Commercial building prototype models. Accessed on July $31^{\text {st }}, 2019$, https://www.energycodes.gov/development/commercial/prototype_models 
van Paassen, A. H. C., and Luo, Q. X. (2002). Weather data generator to study climate change on buildings. Building Services Engineering Research and Technology, 23(4), 251-258.

doi:10.1191/0143624402bt048oa

Wan, K. K. W., Li, D. H. W., Pan, W., and Lam, J. C. (2012). Impact of climate change on building energy use in different climate zones and mitigation and adaptation implications. Applied Energy, 97, 274-282. doi:10.1016/j.apenergy.2011.11.048

Wang, H., and Chen, Q. (2014). Impact of climate change heating and cooling energy use in buildings in the United States. Energy and Buildings, 82, 428-436.

doi:10.1016/j.enbuild.2014.07.034

Wang, L., Liu, X., and Brown, H. (2017). Prediction of the impacts of climate change on energy consumption for a medium-size office building with two climate models. Energy and Buildings, 157, 218-226. doi:10.1016/j.enbuild.2017.01.007

Wang, X., Chen, D., and Ren, Z. (2011). Global warming and its implication to emission reduction strategies for residential buildings. Building and Environment, 46(4), 871-883.

doi:10.1016/j.buildenv.2010.10.016

White Box Technologies. (2015). Announcement: 21st Century "typical year" weather files for 224 Canadian locations now available. Accessed on July $31^{\text {st }}, 2019$, http://weather.whiteboxtechnologies.com/CN2014-release

Wilcox, S., and Marion, W. (2008). Users manual for TMY3 data sets. Accessed on July $31^{\text {st }}$, 2019, https://permanent.access.gpo.gov/gpo23820/43156.pdf

Williams, M., and Harmer, J. (2017). White paper: Modelling weather futures. RWDI Consulting Engineers and Scientists. Accessed on July $31^{\text {st }}, 2019$, https://rwdi.com/assets/factsheets/Modelling-weather-futures.pdf

Xu, P., Huang, Y. J., Miller, N., Schlegel, N., and Shen, P. (2012). Impacts of climate change on building heating and cooling energy patterns in California. Energy, 44(1), 792-804. doi:10.1016/j.energy.2012.05.013

Zang, H., Xu, Q., Du, P., and Ichiyanagi, K. (2012). A modified method to generate typical meteorological years from the long-term weather database. International Journal of Photoenergy, 1-9. doi:10.1155/2012/538279

Zorita, E., and Storch, H. v. (1999). The analog method as a simple statistical downscaling technique: Comparison with more complicated methods. Journal of Climate, 12(8), 2474-2489. doi:10.1175/1520-0442(1999)012<2474:TAMAAS $>2.0$. CO;2 